University of Louisville

ThinkIR: The University of Louisville's Institutional Repository

\title{
The impact of using technology on student achievement : teaching functions with the TI-Nspire to 9th grade algebra students.
}

Barbara Renee Buckner 1973-

University of Louisville

Follow this and additional works at: https://ir.library.louisville.edu/etd

\section{Recommended Citation}

Buckner, Barbara Renee 1973-, "The impact of using technology on student achievement : teaching functions with the TI-Nspire to 9th grade algebra students." (2011). Electronic Theses and Dissertations. Paper 175.

https://doi.org/10.18297/etd/175

This Doctoral Dissertation is brought to you for free and open access by ThinkIR: The University of Louisville's Institutional Repository. It has been accepted for inclusion in Electronic Theses and Dissertations by an authorized administrator of ThinkIR: The University of Louisville's Institutional Repository. This title appears here courtesy of the author, who has retained all other copyrights. For more information, please contact thinkir@louisville.edu. 
THE IMPACT OF USING TECHNOLOGY ON STUDENT ACHIEVEMENT:

TEACHING FUNCTIONS WITH THE TI-NSPIRE TO $9{ }^{\text {TH }}$ GRADE ALGEBRA STUDENTS

By

Barbara Renee Buckner

B.S., Lee University, 1994

M.S., Tusculum College, 1996

\begin{abstract}
A Dissertation
Submitted to the Faculty of the Graduate School of the University of Louisville in Partial Fulfillment of the Requirements for the Degree of
\end{abstract}

Doctor of Philosophy

Department of Teaching and Learning

University of Louisville

Louisville, Kentucky

May 2011 
Copyright 2011 by Barbara Renee Buckner

All rights reserved 

THE IMPACT OF USING TECHNOLOGY ON STUDENT ACHIEVEMENT: TEACHING FUNCTIONS WITH THE TI-NSPIRE TO $9{ }^{\mathrm{TH}}$ GRADE ALGEBRA STUDENTS

\section{By}

Barbara Renee Buckner

B.S., Lee University, 1994

M.S., Tusculum College, 1996

A Dissertation Approved on

April 4, 2011

by the following Dissertation Committee:

Robert Ronau

Dissertation Director

William Bush

Susan A. Peters

Namok Choi

Carl W. Lee 


\section{DEDICATION}

This dissertation is dedicated:

- To my Great-grandmother, Barbara Bradshaw, who always said I would be a teacher.

- To my Papaw, Frank Bradshaw, who provided my earliest memories of mathematics trying to add up on paper what he calculated faster in his head.

- To my Mamaw, Elizabeth Bradshaw, you were my best friend and I still miss you so.

- To my Parents, James and Rita Buckner, for moving back to Virginia to give me my rural roots and the experience of a tight-knit family.

- To my Great Aunt Carol, for continual support and encouragement. I know your prayers made a difference.

- To my high school mathematics teacher, Mr. James Sink, you allowed me to advance through high school mathematics in a unique way that set me up for excellent educational opportunities.

- To my college professor, mentor, and friend, Dr. Cliff Schimmels, your influence on my life lives on in my classroom. 


\section{ACKNOWLEDGEMENTS}

While it may take a village to raise a child, there is no way I could have completed this dissertation without the help, support, and guidance of my family, friends, colleagues, cohort members, and committee. I am extremely grateful for the ACCLAIM Program, specifically Dr. Bill Bush and Dr. Vena Long, for the creation and support of this unique doctoral program. Special thanks to my cohort members who are more like family. I treasure the memories from the summers spent at the University of Tennessee, the University of Kentucky, and the University of Louisville. I would especially like to thank my committee chair, Dr. Robert Ronau for his assistance, guidance, and support throughout this entire process. I would also like to thank Dr. Bill Bush, Dr. Carl Lee, Dr. Sue Peters, and Dr. Namok Choi for serving on my committee and providing valuable feedback and support.

Special thanks for my colleagues at Bradley Central and Lee University. Thank you for grading papers, covering classes, and encouraging me. This process has taught me to be more understanding with assignments and to be more grateful for the opportunity to gain an education. Mr. Tom Losh, Mr. Johnny McDaniel, Mr. Bob Taylor, and Mr. Todd Shoemaker, as administrators, you have allowed me to pursue this degree. I am grateful for your trust and encouragement along the way. I pray that I can continue to make a difference in the lives of the students I teach and help them to see the complete potential within themselves. 
My deepest gratitude is to my family. To my mom and dad, thank you for raising me in a loving Christian home, always challenging me to do my best, and encouraging me to be and do all that God wants of me. Thank you for the many times you drove to Cleveland, cooked meals, folded clothes, took out the trash, and countless other ways you assisted me. To my sisters, Hope and Jenny, gone is my need to take the easy way out on family events and to arrange the calendar around my graduate school schedule. I am so ready for more family time. To my niece and nephew, Faith and Sam, you have both grown up into such wonderful young adults as I have completed this degree. Your encouragement, text messages, and emails have always brought a smile to my face. You are both so bright and intelligent; I look forward to being there to celebrate the many accomplishments that lie ahead for you both. Special thanks to Mrs. Mary Schimmels for being my personal editor. Your unending support and encouragement have been invaluable. You are such a gift from God.

I am often amazed at how God has ordered my steps and brought such leaders my life. At a student council retreat, Ken Brummett gave me a plaque with the following quote that has been a constant encouragement: "I have a dream that soars on eagle's wings, a dream of your accomplishments and other wondrous things. I know not when, or where you will challenge fate, I only know you will be great." Then on a mission trip traveling across Europe, Dr. Randall Parris challenged me with the statement that "Preparation always has a way of Crossing the path of Opportunity." These two quotes served as constant reminders of the unique voice that would fill my classroom when Doc would come back to check in on me and inquire about my going to start a doctoral program. The many conversations we had about students, teaching, strawberries, and life 
were a small part in how Dr. Cliff Schimmels communicated the future opportunities that he saw for me, more potential than I ever even saw in myself. My life is forever changed because of Dr. Cliff Schimmels. Hope I made you proud, Doc! 


\section{ABSTRACT \\ THE IMPACT OF USING TECHNOLOGY ON STUDENT ACHIEVEMENT: TEACHING FUNCTIONS WITH THE TI-NSPIRE TO $9^{\mathrm{TH}}$ GRADE ALGEBRA STUDENTS}

\section{Barbara Renee Buckner}

April 4, 2011

The purpose of this study was to determine the effect of TI-Nspire graphing calculator use on student achievement and on teacher behavior variables of planning, teaching, and assessing. This study investigated the teaching of functions by teachers using the TI-Nspire graphing calculator versus teachers using a non-graphing scientific calculator.

A review of the literature found that the emergence of calculators and computers has changed the way mathematics is both done and used (Ellington, 2006; Thorpe, 1989; \& Kieran, 1992). Research also showed that students can effectively use a graphing calculator as an instructional tool to make and understand different types of representations (Choi-Koh, 2003; Colgan, 1993; and Drijvers \& Doorman, 1996). Other studies have shown how graphing calculator use has engaged students in higher level thinking skills (Dessart, DeRidder, Charleen, \& Ellington, 1999; Ellington, 2006; Graham \& Thomas, 1998; Keller \& Hirsch, 1998; Huntley, Rasmussen, Villarubi, Sangtong, \& Fey, 2000; \& Ronau et al., 2008). Since it is a relatively new tool, there is a limited amount of research on the classroom use of the TI-Nspire. The TI-Nspire is 
designed to link together multiple-representations within a single problem, so the concept of functions is an ideal context within which to study the impact of the TI-Nspire.

This was a quasi-experimental study. The researcher gathered and analyzed pretest, post-test, and post post-test data on student performance on function concepts. The study included a 90 minute classroom observation of each class as well as document analysis of weekly questionnaires, daily lesson plans, and daily assessments. Vignettes employed classroom observations, document analysis, and thick description to triangulate the results of the qualitative analysis.

During the summer prior to this study, all teachers attended 12 hours of training over the course of two days with a National Texas Instruments Instructor in which they were trained to use the TI-Nspire graphing calculator. Teachers were then given a TINspire, TI-Nspire emulator and access to online Atomic learning video training (Atomic Learning, 2011), to continue their exploration of the TI-Nspire. The week prior to the study, the teachers attended another day of professional development activity taught by a Texas Instruments Trained Cadre member. This "Function Focused Session" was six hours long and provided review on the TI-Nspire, specific training about teaching the function concept with the TI-Nspire, and time to create lesson plans and activities for this study. During the two weeks of treatment and two weeks of follow up, teachers met once a week for "Weekly Touchdown Sessions," a 90 minute meeting held after school to complete a weekly questionnaire, turn in lesson plans, assessments, and receive further professional development on the TI-Nspire. Providing a trained Texas Instruments Instructor on a weekly basis to answer questions, assist in providing direction for the following week, and meeting weekly with the teachers to complete questionnaires were 
vital strategies necessary to support teachers with this new technology tool and to assure their fidelity in treatment implementation and control maintenance. All professional development sessions were taught by Texas Instruments trained Instructors.

The results from four teachers, each with one treatment class using the TI-Nspire and one control class using a non-graphing scientific calculator, were significant on the pre-test with the control group having a higher mean score than the treatment group and statistical significance on the post post-test with the treatment group having a higher mean score than the control group. While there was a statistically significant effect of Teacher Zeta on the post-post test in comparisons with the other teachers, most of the teacher effect was controlled for within the design of the study. To control for teacher effect, all teachers taught both a treatment and a control class. For each teacher, one of their two algebra classes was randomly assigned to treatment and the other was then assigned to control. There was not enough power in the data to properly analyze the effect of socioeconomic status and special education.

This study supports the use of TI-Nspire graphing calculators in Algebra classrooms while studying the concept of functions. This study shows that, while using the TI-Nspire graphing calculator, the use of multiple representations and higher Depth of Knowledge activities can be used to improve student achievement, and impact classroom teaching, and lesson planning. While this study shows the impact of the TI-Nspire graphing calculator for the concept of functions, further research is needed to continue evaluating the impact of the TI-Nspire across additional mathematics topics. 


\section{TABLE OF CONTENTS}

Acknowledgements



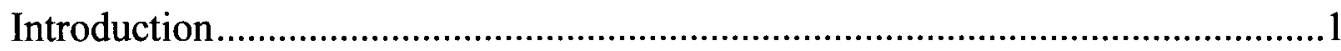

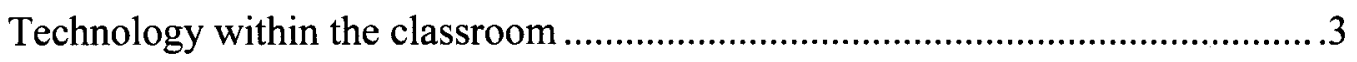

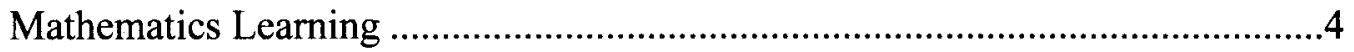

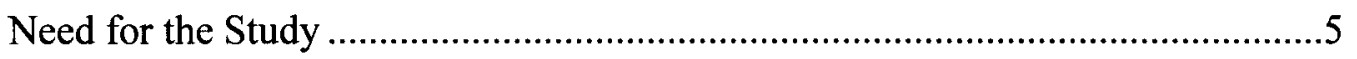

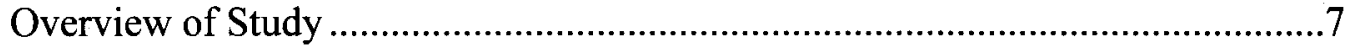

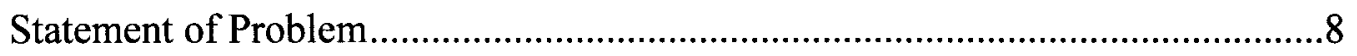



Research Questions and Hypotheses ........................................................

Research Questions .................................................................10

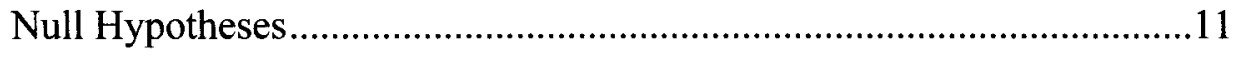

Definitions of Terms ............................................................................... 11

Significance of the Study …................................................................... 12

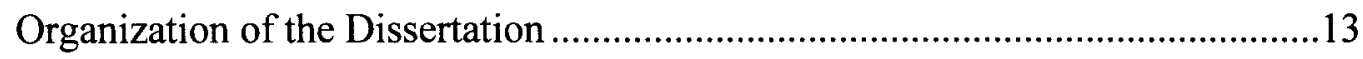

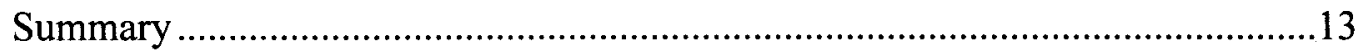

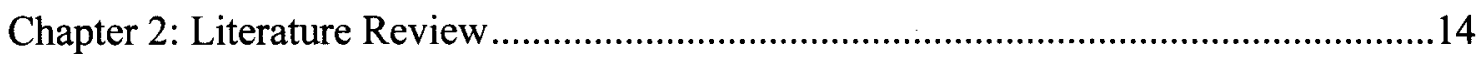






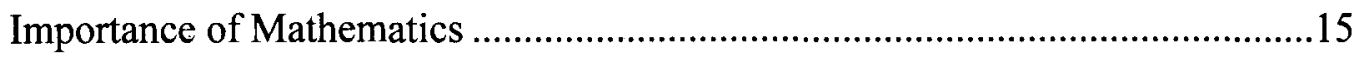

Historical Framework: School Mathematics ......................................................21

Historical Framework: Learning ....................................................................29

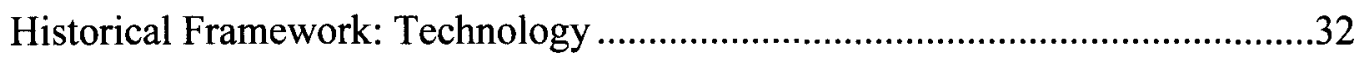

Historical Framework: Technology in Learning...................................................33

Calculators as Learning Tools .........................................................................38

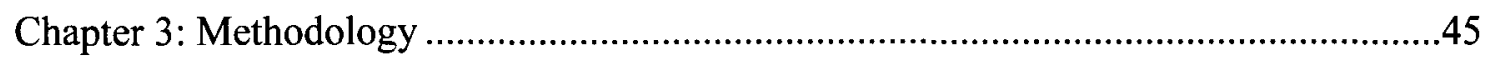



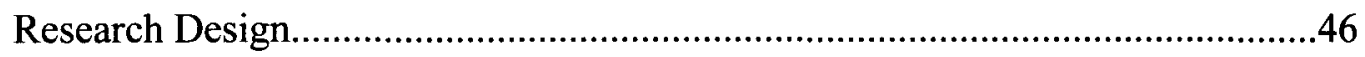

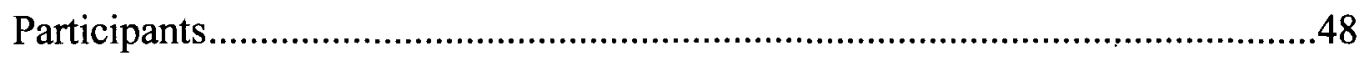

Population and Sampling ....................................................................48



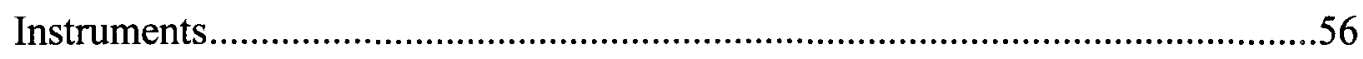

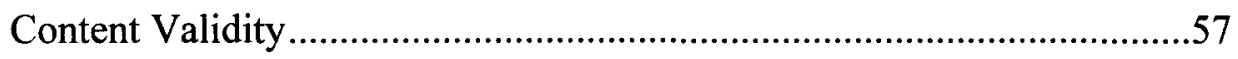

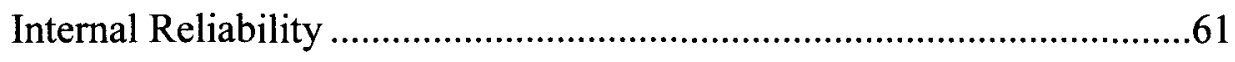

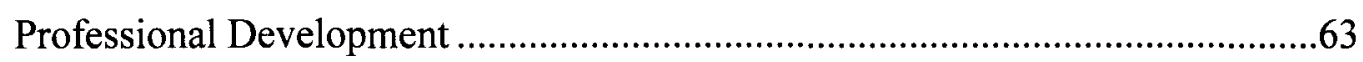

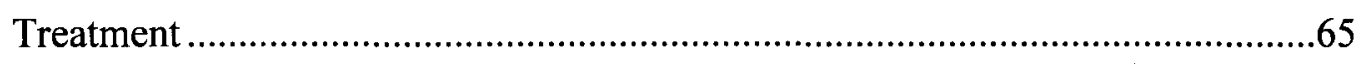

Data Collection Procedures...............................................................................

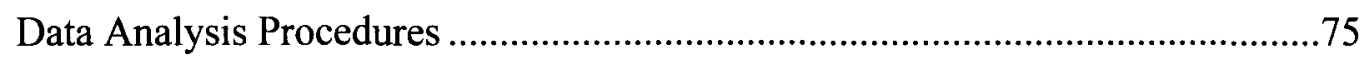

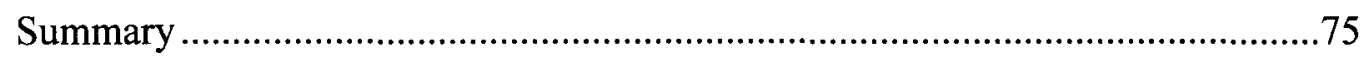

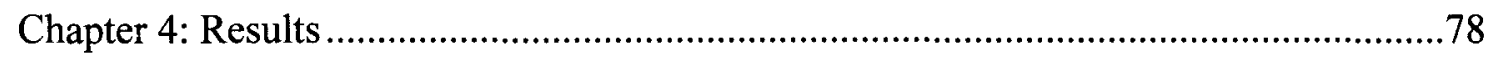

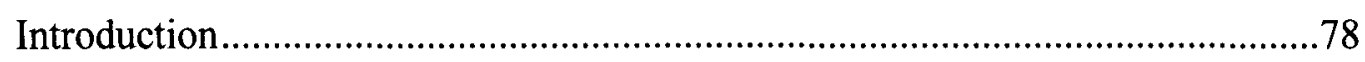




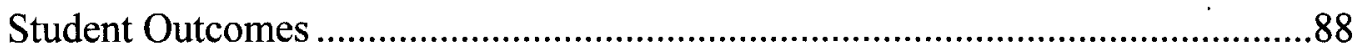



Teacher Alpha - Control Class ..............................................................103

Teacher Alpha - Treatment Class ..........................................................110

Across Teacher Alpha's Treatment and Control Classes .........................117

Teacher Epsilon - Control Class.......................................................121

Teacher Epsilon - Treatment Class ...................................................128

Across Teacher Epsilon's Treatment and Control Classes ......................135

Teacher Gamma - Control Class .........................................................139

Teacher Gamma - Treatment Class .........................................................147

Across Teacher Gamma's Treatment and Control Classes ......................154

Teacher Zeta - Control Class.............................................................158

Teacher Zeta - Treatment Class ............................................................ 165

Across Teacher Zeta's Treatment and Control Classes ............................171

Summary of Control Classes .................................................................174

Summary of Treatment Classes ............................................................176

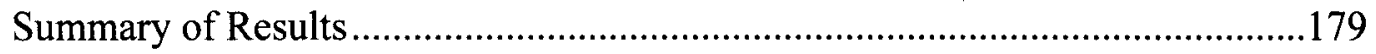

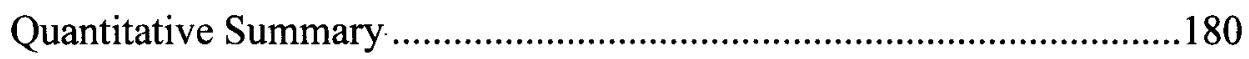

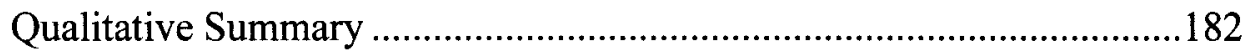

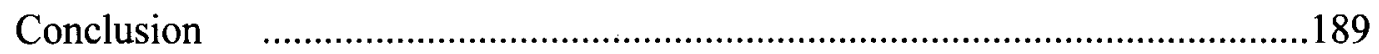

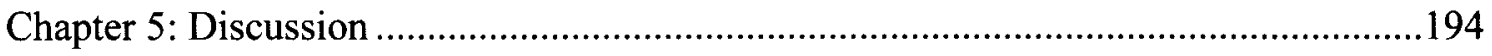

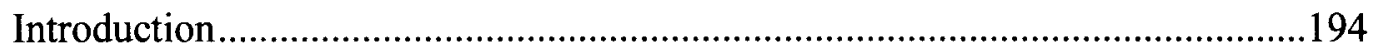






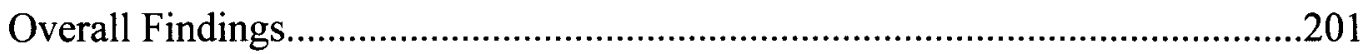

Limitations of the Study.....................................................................204

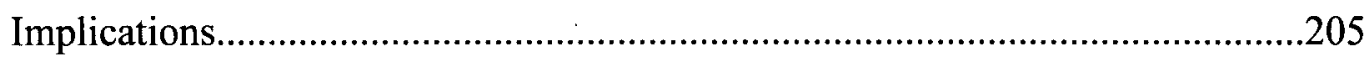

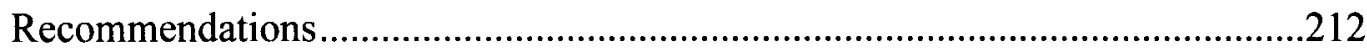

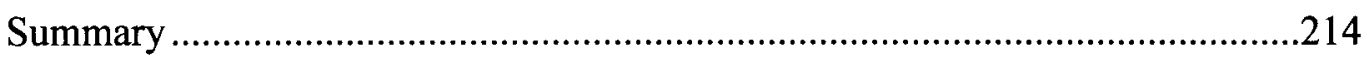

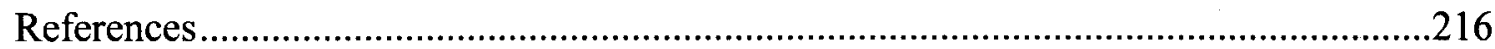

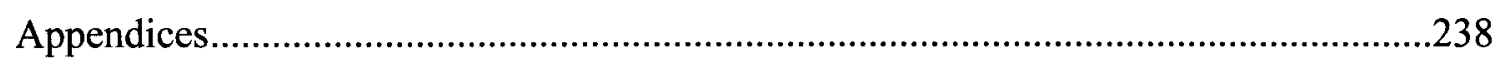






\section{LIST OF TABLES}

$\begin{array}{ll}\text { TABLE } & \text { PAGE }\end{array}$

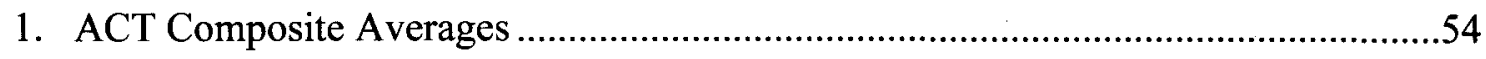

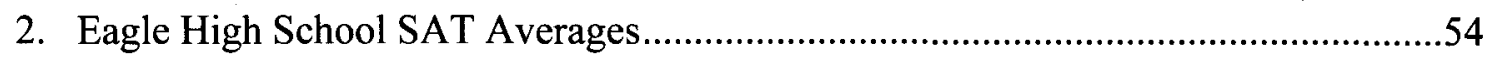

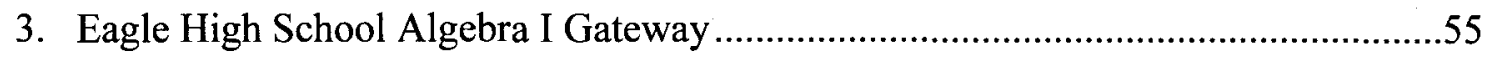

4. Eagle High School Dropout and Graduation Rates ...........................................55

5. Results of Content Validity Analysis..............................................................60

6. Internal Reliabilities for Algebra I Clusters and Complete Assessment..................62

7. Internal Reliabilities for Geometry Clusters and Complete Assessment..................62

8. Internal Reliabilities for Algebra II Clusters and Complete Assessment ..................63

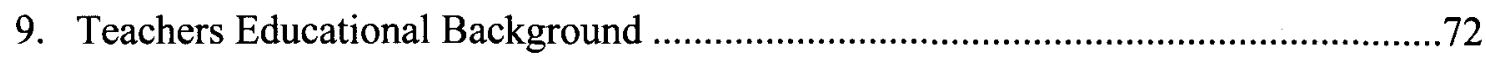

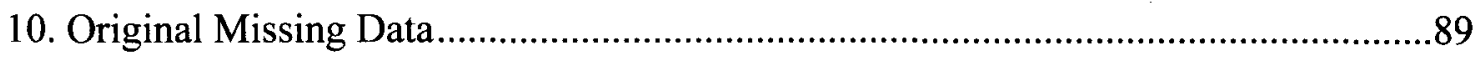



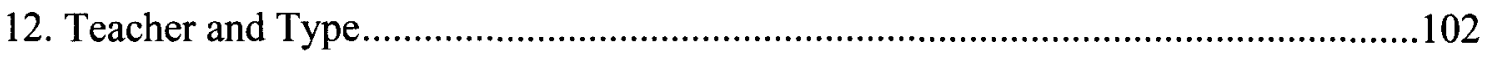

13. Depth of Knowledge Noted During Classroom Observations.................................186

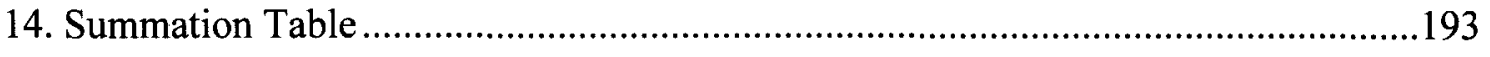




\section{LIST OF FIGURES}

$\begin{array}{lll}\text { FIGURE } & \text { PAGE }\end{array}$

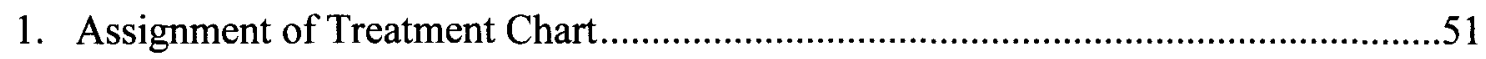

2. Final Treatment Assignment .........................................................................52

3. Treatment Class Questionnaire ...........................................................................

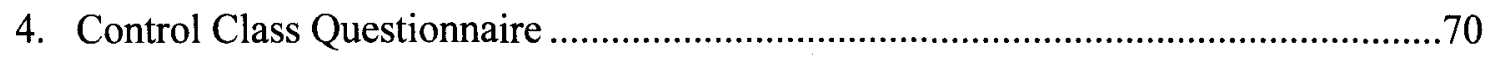

5. Quasi-experimental design................................................................................

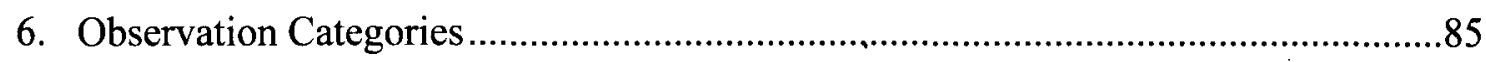

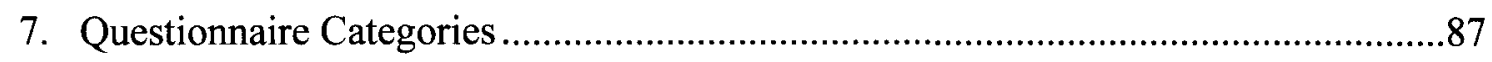

8. Original Scores by Type for Each Test ................................................................91

9. Pooled Imputed Scores by Type for Each Test..........................................................93

10. Original Scores for Each Teacher by Test ..............................................................94

11. Pooled Imputed Scores for Each Teacher by Test .......................................................95

12. Original Scores for Each Test by Teacher and Type .................................................97

13. Pooled Imputed Scores for Each Test by Teacher and Type ......................................98

14. Average Way of Representing an Activity During Observation ................................183

15. Average Way of Representing an Activity Within Lesson Plans ...............................184

16. Average Depth of Knowledge During Observations ................................................185

17. Average Depth of Knowledge from Lesson Plan Analysis ........................................187

18. Average Depth of Knowledge on State Competencies from Lesson Plans ................188 


\section{CHAPTER 1 INTRODUCTION}

\section{INTRODUCTION}

The technological world in which today's students are growing up is very different from the one in which their parents grew up. In the late 1960s, the launch of Sputnik spurred the United States into a race for space that incorporated, improved, and advanced mathematics that was used in science, engineering, and new technologies. After having been to the moon and helping create the International Space Station, the United States Space Program must again take a renewed look at where we stand in this key area. While mathematics is important to space and engineering, as a society we must also be aware of the current status of mathematics within our classrooms. The 1997 Third International Mathematics and Science Study (TIMMS) study (Tarr, Uekawa, Mittag, \& Lennex, 2000) showed that in the United States there was a gap between fourth grade students' performance and fourth graders from various other countries around the world. The study went on to show that this gap widens when comparing our eighth grade students' performance (Tarr et al., 2000).

The United States Department of Education (2000) documented how the level of mathematical thinking and problem solving in the workplace is increasing dramatically. Every aspect of our lives is inundated with technology. From fast food to nano-science, 
technology is an ever present part of our daily lives. Today's students have never known a time without cell phones, microwaves, or the internet. The National Council of Teachers of Mathematics (2000) recommends that the availability of technology supports the need for new ways to teach, while integrating this technology into the classroom.

History shows there have been many types of "tools," such as the abacus, that have been used to "do" mathematics computations (Maxfield \& Brown, 1997; Rostky, 1997). The slide rule of the $17^{\text {th }}$ century dominated and was the tool of choice for the next 300 years (Museum of HP Calculators, 2004). The need for accuracy brought about the Pascaline in 1643, which was the first mechanical adding device used for practical purposes (Redin, 2004a). In the late $17^{\text {th }}$ century, Gottfried Leibniz designed a machine that would add, subtract, multiply, and divide. William Burroughs is credited with the first practical calculator that was really an adding machine that included a full keyboard and had printing capabilities (Rostky, 1997). In 1963, Sumlock Comptometer of England introduced the first fully electronic calculator called the ANITA, meaning $\underline{A} \underline{N}$ ew Inspiration to Arithmetic (Redin, 2004b).

With the invention of the transistor, the electronic calculator exploded on the scene. In 1964, gas-discharged tubes were used to help create the first almost-alltransistor calculator (Rostky, 1997). Canon and Texas Instruments came on the scene and introduced the "Pocketronic" in 1970 to Japan and in 1971 to the United States (Redin, 2004c). In 1972, Hewlett-Packard introduced the HP-35, named 35 for the number of keys on its keypad, as the first pocket calculator with scientific functions selling for $\$ 395$ (Ball, 2004). The four-function calculator started the process of making 
the slide rule obsolete, but the scientific calculator completed the process. Casio introduced the first graphing calculator in 1986 (Waits \& Demana, 1998).

In 1998, handheld technology took an amazing leap when Texas Instruments started using flash technology for the purpose of updating a calculators' operating system. In time, this same flash technology has allowed programs to be written within an individual calculator and to share these applications between calculators, or to be downloaded from computers (Waits \& Demana, 1998). This flash technology created a time when "portable and affordable computers with pedagogical software designed to enhance the teaching and learning of mathematics" (Waits \& Demana, 1998, p. 2) were made readily available and practical for the classroom teacher.

\section{TECHNOLOGY WITHIN THE CLASSROOM}

What started with a chalkboard and slate has now progressed to computers and projectors. Along the way, there have been many other devices such as the slide rule, overhead projector, chalk dust graph grid, protractor, printer, and copier to name a few. Teachers used such items for instruction and allowed students to use them for computations. The handheld calculator came into the classroom and progressed from the basic four function device to scientific, to graphing, and, finally, to computer algebra systems. The use of such items varies from classroom to classroom, subject area, and school district.

With technology such as the ditto master, teachers were able to provide worksheets and handouts. Present day copiers and laser printers have made this process cleaner, neater, and much faster. Advanced use of websites allows for lectures online.

Web based homework systems are also available for students to gain repeated practice as 
well as immediate feedback to work. Today a student can take a mathematics class virtually and never step into the classroom or meet the teacher face to face.

The development of the overhead projector enabled teachers to have pre-made notes that allowed for easier lectures while teachers faced the students. This allowed teachers to have problems worked out step by step that they could show simply. A teacher could present a problem and, as students worked on the problem, circulate the classroom to check on progress and understanding. Then the instructor could then show the completed answer, which was prepared in advance, on the overhead for the students to see the entire process, thus saving time within the classroom. This also allowed for more teacher interaction among the students as they worked the problems.

As calculators have become increasingly more common, they have made their way into the classroom, soon followed by computers as well. Advances with calculators have produced devices that allow students to see the teacher's view screen to understand the process the teacher uses with the calculator. Graphing calculators allow the teacher to use graphs with extreme accuracy, precision, and repeatability in a short period of time. There are also projection devices available that show a dual screen. One screen shows the actual keystrokes that were input on the calculator, while the other shows what the calculator screen would actually be doing. The dual screen allows for students to easily follow along and to literally see where they are in the process.

\section{MATHEMATICS LEARNING}

Typically mathematics has been taught using the lecture format. The teacher presents the mathematics idea, provides an example or two, and then assigns the problems for the students to perform. This method of teaching is often referred to as 
"drill and kill" or traditional where student complete multiple problems over and over to help students master the concept (Waits \& Demana, 1998, pg 5).

Another theory about learning reform mathematics involves the Theory of Constructivism. In this approach students are engaged in activities where they actually construct or discover the mathematical knowledge by building relationships out of the material presented. This theory allows students to be the processor of knowledge by creating their own methods of learning and understanding mathematics.

The recent use of computers, projectors, and interactive white boards continue to make teaching more interactive and user friendly, allowing the teacher more time to circulate around the classroom and assist students, all the while continuing the lecture while standing away from the board. This new technology also allows for more student led discussion and activity within the class. The ability to do many problems in a short period of time allows topics to be looked at in-depth and students are allowed to “discover" how manipulating an equation affects a graph.

\section{NEED FOR THE STUDY}

As technology advances at lightning speed, mathematics performance and achievement in schools "shortchanges our students' future and endangers our prosperity and our nation's security" (United States Department of Education, 2004a, p. 1). In Principles and Standards, the National Council of Mathematics Teachers includes technology as one of "the six principles for school mathematics" (NCTM, 2000, p. 10). These principles are not specific content or process, but are critical issues within schools. NCTM espouses, "Technology is essential in teaching and learning mathematics; it influences the mathematics that is taught and enhances students' learning" (NCTM, 2000, 
p. 11). The interaction between the six principles and the standards will help to develop high quality school mathematics programs (NCTM, 2000).

The Principles and Standards state that technology "enhances mathematical learning" (NCTM, 2000, p. 24), "supports effective mathematics teaching” (NCTM, 2000, p. 25), and "influences what mathematics is taught" (NCTM, 2000, p. 25). The Principles and Standards (NCTM, 2000) goes on to say that students can make and test conjectures and work at higher levels of generalization or abstraction within a technologically-enhanced instructional environment.

A review of the literature on the impact of technology on mathematics teaching and learning found significant evidence that calculators, both scientific and graphing, are being used within the mathematics classroom. In particular, several studies focused on graphing calculators at the elementary level (Fleener, 1995a), middle school level (Fleener, 1995b; Merriweather \& Tharp, 1999), and high school level (Doerr \& Zangor, 2000; Farrell, 1996; Fleener, 1995a; Fleener, 1995b; Goos, Galbraith, Renshaw \& Geiger, 2000; Huntly, Rasmussen, Villaruni, Sangtong \& Fey, 2000; Kendal \& Stacey, 1999; Lauten, Graham, \& Ferrini-Mundy, 1994; Lloyd \& Wilson, 1998; Slavit; 1996, Thompson \& Senk, 2001). Research exists at the college level regarding the use of graphing calculators in college classes (Adams, 1997; Hollar \& Norwood, 1999; Keller \& Hirsch, 1998; Keller \& Russell, 1997; Keller, Russell, \& Thompson, 1999; Lauten, Graham, \& Ferrini-Mundy, 1994; Quesada \& Maxwell, 1994; Shoaf-Grubbs, 1994; Slavit, 1998; Zbiek, 1998). This review of the research revealed little, if any, research on the use of graphing calculators within the first year of algebra in high school. If technology is to take a leading role in the mathematics classrooms (American 
Mathematical Society, 1994), then research needs to be done to investigate what level of technology needs to be used as well as what technology is effective. This evidence-based research can then be disseminated to have teaching that works within the classroom.

\section{OVERVIEW OF STUDY}

In this southern state, all high school students are required to take four years of high school mathematics. Algebra I is the lowest level of mathematics a student can take to obtain a credit towards high school graduation. For most students, this is typically their first course in mathematics in high school.

This study took place at "Eagle High School," a comprehensive four-year high school, located in this southern state. Eagle High School has a current enrollment 1673 students and is on the block scheduling format. Block scheduling provides an extended period for a class and fewer classes each day. Different types of block scheduling allow for variations in student schedule such the classes attended each day were alternated, the classes could be completed within one semester, or were a combination or both block scheduling and traditional scheduling. At Eagle High School, the block scheduling format provided four classes each day that met for ninety minutes within each class period. Specifically, the teachers selected taught Algebra I, which is the first year of algebra for a high school student. Utilizing data and statistics from the southern state's Department of Education, the school was categorized by socio-economic status, racial demographics, and location within Chapter 3.

This study was a quasi-experimental study. For the quantitative portion the researcher gathered and analyzed teachers' class pre-test averages and compared them with the teachers' class post-test averages and the teachers' class post post-test averages. 
Teachers were selected to teach their classes either with or without the utilization of a TIInspire calculator. The study used the Kentucky High School Diagnostic Mathematics Assessment Tool for Algebra, which had been created and developed by the University of Louisville and was being used by the Kentucky Department of Education. There were three versions of this test. These three different versions were used for the pre-test, posttest, and post post-test. The test addressed the use of functions within algebra. For the qualitative portion of this study, the research completed a 90 minute classroom observation of each class as well as document analysis of a weekly questionnaire, daily lesson plans, and daily assessments. Document analysis, triangulation, and thick description were used to analyze the qualitative portion of the study.

\section{STATEMENT OF PROBLEM}

There has been a rapid change in technology that has occurred in the past thirty years. The launch of the calculator has changed the emphasis of mathematics in school classrooms. Rather than spending the majority of time on rote and procedural learning, teachers and students can now apply such answers to situations and problems in real life. A once difficult task of mathematical computation has been simplified to a combination of punching buttons. With the realization of the dreams of Babbage and Leibniz, the computing machine is available to the common man in many shapes and formats from desktop, pocket, watch, and hand held formats (Davis, 2000). With the advances in technology, there are increased opportunities for their employment within the mathematics classroom (Privateer, 1999).

As technology influences both the instructional practices and what concepts are taught (NCTM, 2000), educators need to be informed about which technologies used 
within the mathematics classroom environment lead to increased student understanding. Instructional technology used in the classroom needs to be thoughtfully selected, appropriately used, and pedagogically sound. Sang Sook Choi-Koh says that the "universal availability of technology is having a profound impact on what should be taught in mathematics curricula and how mathematics processes should be taught" (ChoiKoh 2003, p. 1).

The questions for educators today, regarding the TI-Nspire calculator, are the same questions that faced educators when the four function calculator and the scientific calculator were made available (Waits \& Demana, 1998). Does one allow students to use the TI-Nspire calculators? If so, when and how much does one allow them to use them? What effect does the calculator have on how the students learn and what the students learn? Under what circumstances should students be allowed to use them? What is the impact on assessment, testing, and on content that is taught?

\section{PURPOSE OF STUDY}

The purpose of this study was to determine the effect of the implementation of the TI-Nspire graphing calculators on student achievement and teacher behavior variables of teacher planning, teacher teaching, and assessments used. With the many variables that exist within the classroom, the design of this study sought to control for as many factors as possible while investigating the treatment of the use of a TI-Nspire graphing calculator by a trained teacher while teaching the concept of functions with respect to representations, Depth of Knowledge, and TPACK.

\section{RESEARCH QUESTIONS AND HYPOTHESES}

This study utilized the following research questions and null hypothesis. 


\section{Research Questions}

1) Was there a difference in student test scores on function concepts in Algebra I classrooms that used TI-Nspire graphing calculators versus those who did not use this device? The independent variable was treatment and the dependent variables were the pre-test, post-test, and post post-test.
a. Treatment Effect
b. Teacher Effect
c. Interaction of Teacher and Treatment
d. Factors: special education status and socioeconomic status

2) Did the use of TI-Nspire graphing calculators affect the way teachers taught function concepts in Algebra I classrooms with respect to representations, Depth of Knowledge, and TPACK? The independent variable was treatment and the dependent variables how teacher taught.

3) Did the use of TI-Nspire graphing calculators affect the way teachers planned lessons for function concepts in Algebra I classroom with respect to representations, Depth of Knowledge, and TPACK? The independent variable was treatment and the dependent variables how teacher planned.

4) Did the use of TI-Nspire graphing calculators affect the way teachers assessed students on functions concepts in Algebra I classrooms with respect to representations, Depth of Knowledge, and TPACK? The independent variable was treatment and the dependent variables how teacher assessed. 


\section{Null Hypothesis}

The above research questions were the basis for this study and lead to the following null hypothesis: There was no statistically significant difference in student test scores on function concepts in Algebra I classrooms that used TI-Nspire graphing calculators versus Algebra I classrooms that did not use this device. There was no difference in the way teachers taught function concepts in Algebra I classrooms that used TI-Nspire graphing calculators versus Algebra I classrooms that did not use this device with respect to representations, Depth of Knowledge, and TPACK. There was no difference in the way teachers planned lessons for function concepts in Algebra I classrooms that used TI-Nspire graphing calculators versus Algebra I classrooms that did not use this device with respect to representations, Depth of Knowledge, and TPACK.

There was no difference in the way teachers assessed students on functions concepts in Algebra I classrooms that used TI-Nspire graphing calculators versus Algebra I classrooms that did not use this device with respect to representations, Depth of Knowledge, and TPACK.

\section{DEFINITIONS OF TERMS}

Algebra I - the first year of algebra taken by a high school student. The following is a description taken from various southern states' Department of Education:

Algebra $I$ is a course that uses problem situations, physical models, and appropriate technology to extend algebraic thinking and engage student reasoning. Problem solving situations will provide all students an environment which promotes communication and fosters connections within mathematics, to other disciplines and to the real world. Students will use physical models to represent, explore, and develop abstract concepts. The use of appropriate technology will help students apply mathematics in an increasingly technological world. The concepts emphasized in the course include functions, solving equations, and slope as rates of change, and proportionality (Tennessee State Department of Education, 2004) 
Algebra I is a formal, in-depth study of algebraic concepts and the real number system. In this course students develop a greater understanding of and appreciation for algebraic properties and operations. Algebra I reinforces concepts presented in earlier courses and permits students to explore new, more challenging content which prepares them for further study in mathematics. The course focuses on the useful application of course content and on the development of student understanding of central concepts. Appropriate use of technology allows students opportunities to work to improve concept development. As a result, students are empowered to perform mathematically, both with and without the use of technological tools (Alabama State Department of Education, 2006).

In Algebra I, students build upon the mathematical understandings that are addressed in prekindergarten through the eighth grade. Students will use symbolic reasoning to represent mathematical situations, to express generalizations, and to study relationships among quantities; use functions to represent and model problem situations as well as to analyze and interpret relationships; set up equations in a wide range of situations and use a variety of methods to solve them; and use problem solving, representation, reasoning and proof, language and communication, and connections both within and outside mathematics. In Algebra I, hand-held graphing calculators are required as part of instruction and assessment. Students should use a variety of representations (concrete, numerical, algorithmic, graphical), tools (matrices, data), and technologies to model mathematical situations to solve meaningful problems. The technologies include, but are not limited to, powerful and accessible hand-held calculators as well as computers with graphing capabilities (South Carolina State Department of Education, 2009).

Ditto master - machine that used carbon paper for the purpose of making mass production of worksheets.

Mathematical knowledge - the relating and utilization of mathematics that is used to construct, develop, and relate analogies, illustrations, multiple ways of doing mathematic problems

\section{SIGNIFICANCE OF THE STUDY}

The results of this study could provide guidance for the utilization of TI-Nspire

calculators within the first year of algebra. The results could promote the idea of schools supporting and providing the integration, training, and access to TI-Nspire calculators 
within the mathematics classrooms. Significance would also promote more Algebra I teacher training and professional development with the use of TI-Nspire calculators.

\section{ORGANIZATION OF THE DISSERTATION}

This study is organized into five chapters. Chapter 1 is the introduction of the study and provides the background, history and development of technology. Chapter 2 contains the literature review regarding key research as related to the study. Chapter 3 consists of an explanation of the methodology that was used to test the hypotheses. Chapter 4 includes and describes the quantitative results of the study. Chapter 5, the final chapter, consists of conclusions, implications, and suggestions for needed further research.

\section{SUMMARY}

Before hand held calculators, mathematical knowledge and application were held by engineers, bankers, and tax collectors among others? Many advances in technology led to the creation of the hand held calculator that is so widely used today. The creation of the hand held calculator revolutionized the availability of mathematical knowledge, computation, and understanding that made it easier for the everyday common man to solve mathematical problems with the punch of a button. This study sought to show that the utilization of the TI-Nspire calculator within the first year of algebra is an effective tool to allow students to be successful in mathematics, specifically in the learning of functions. 


\section{CHAPTER 2}

\section{LITERATURE REVIEW}

\section{INTRODUCTION}

Long gone are the days of getting the news by only watching the evening news or reading the newspaper. As the world constantly changes, today's news can be accessed with daily updates sent to one's blackberry, watched on CNN around the clock or found instantly via the internet. Checking out from the local store is less about counting change and more about processing with a computer. If students are not prepared to be productive members in this ever changing global and technical society, is education really succeeding? In a society with ever increasing technology, it seems fitting to incorporate that technology into the classroom. Since technology has its base within mathematics, mathematics should be the starting place to the integration of technology into the classroom (Heid, 1997).

Advancement in technology through research and development is generally first seen within the business and industry or the government. The National Science Board (2010) reported in 2008 that $\$ 398$ billion was spent on research and development. Business and industry represented $67.4 \%$ of this spending. The federal government spent $26.1 \%$, while colleges and universities were at $3.5 \%$ and nonprofit organizations represented only $3 \%$. With the lack of investment into research and development into education it is easy why it takes so long for new technology to reach the classroom. The "time-lag" tends to 
separate the creation and induction of technology into practical education and use within the classroom (Privateer, 1999). Vogel and Klassen (2001) state that content changes so much that it can become outdated before a student even graduates.

\section{IMPORTANCE OF MATHEMATICS}

Mathematics has always held importance in society for the purpose of trade, industry, and business. In the early days of the United States, the main textbooks were imported from England, and mathematics was taught for the understanding of weights, measurements, navigation, and bookkeeping. However, over time, the importance of mathematics has greatly increased.

According to Jones and Coxford (1970), in 1726, arithmetic and surveying were the only mathematics taught at Yale. By 1776, algebra and trigonometry were added to the course selection available at Yale. By the end of the 18 th century, the rise of science created a new demand for increased need for mathematics which was reflected in new curricula in the early 19th century at such colleges as Princeton, West Point, and Virginia. In 1820, Harvard began requiring algebra for admission. This was soon followed by Yale in 1847 and Princeton in 1848 (Jones \& Coxford, 1970).

With the emergence of mathematics into the curriculum came organizations that helped to shape the role of mathematics. In 1888, the American Mathematical Society was created to unite mathematics teachers within already established teacher organizations. In 1892, the National Education Association formed the Committee of Ten (Osborne \& Crosswhite, 1970). In 1920, the National Council of Teachers of Mathematics was created to address the concern of mathematics in the school curriculum (Stanic, 1986). These organizations began to have an effect on what and when the 
mathematics was taught. With academic mathematics, students would complete algebra, geometry, trigonometry and another year of algebra. This led to the requirements of algebra, geometry and trigonometry being the basis within high school for college admission. (Osborne \& Crosswhite, 1970).

With the many changes occurring on the collegiate level, things had to change at the grammar school level as well. Part of this was accommodated with the creation of a new type of secondary school, which is now called high school, in 1821 . The mid-19 century saw a booming increase in these high schools. As colleges continued to push down requirements such as arithmetic, algebra, and then geometry, the secondary schools started doing the same. By the end of the 19th century, the teaching of arithmetic was pushed down from the secondary school to the elementary school (Jones \& Coxford, 1970). "A remarkable notion had emerged around 1900: that schooling could make the ordinary office clerk, shop-floor worker, and even the farmer more productive" (Goldin, 2003).

With the Great Depression, came an influx of students into the school system. Data from James and Tyack (1983) show that from 1890 to 1940, the number of students attending high school had increased nearly twenty fold. While there were more students attending elementary and high school, there were fewer students going on to college, which caused an increased focus of vocation and a trend towards general mathematics as an alternative to algebra. While the beginning of the 20th century showed $59 \%$ of students taking algebra, by the mid-20th century, that percentage had dropped to 24 (Jones \& Coxford, 1970). 
With the occurrence of the two world wars, there was a realization of the need for a greater knowledge of mathematics. The wars served to revitalize the need for mathematics to the public not only in war time, but also demonstrated the everyday benefits of communications and electronics for peace time. The post-war society was readily becoming a scientific society. Not only were people concerned with atomic energy, missiles, and radar, but other educational disciplines, such as psychology and sociology, were utilizing mathematics for the creation of models and in calculating statistics (Jones \& Coxford, 1970).

With the Cold War and the launch of Sputnik in 1957, public attention was quickly turned to the educational needs of the United States (United States Department of Education, 2009). The government realized the need to increase support, in particular, financially. In 1958, the passing of the National Defense Education Act by President Eisenhower provided much needed funding for mathematics and science. Parts of this act provided student loans, funding to strengthen science, mathematics and modern foreign language instruction, and the identification and encouragement of able students (Flattau, Bracken, Atta, Bandeh-Ahmadi, de la Cruz, \& Sullivan, 2006).

In the 1950s, several programs were created to research and improve mathematics education. The National Science Foundation, NSF, was created to develop national polices for the promotion of basic research and education in the sciences. Osborne and Crosswhite (1970) claimed that the unprecedented amount of money put into both curriculum development and teacher training allowed for several curriculum projects to be produced from the late 1950 s through the 1970s. One of the largest such projects was the School Mathematics Study Group, SMSG. Another program created by The Colleges 
of Education, Engineering, and Liberal Arts and Sciences of the University of Illinois was the University of Illinois Committee on School Mathematics, UICSM (Golden, 2006).

With the two large-scale projects of SMSG and UICSM came curricula and materials that expressed a more modern view and role of mathematics. In the mid-1960s, the Secondary School Mathematics Curriculum Improvement Study (SSMCIS) and the Comprehensive School Mathematics Program (CSMP) created additional curricula (Fey \& Graeber, 2003). The focus of these curricula was less about computation and more about conceptual understanding (Garrett \& Davis, 2003). Out of UICSM, a four-year high school curriculum was created that addressed the mathematical content and the aspect of teaching philosophy. This, in turn, led to an increased focus of the importance of teaching strategies (Osborne \& Crosswhite, 1970).

The 1970 s brought many changes including the emphasis on arithmetic and algebra and increased standardized testing. The new curriculum developed during this time included Individually Prescribed Instruction, IPI, and Developing Mathematical Processes, DMP, (Fey \& Graeber, 2003). The National Assessment of Educational Progress, NAEP, was created in 1969, for the purpose of assessing various subject areas within the educational curriculum across the nation. NAEP tests students in fourth grade, eighth grade, and twelfth grade. From these assessments came data for the Nation's Report Card as well as individual State's Report Cards (United States Department of Education, 2008).

The National Council of Teachers of Mathematics, with the support of the National Science Foundation, did a survey, known as Priorities in School Mathematics, 
PRISM, to collect the beliefs and reactions to potential curriculum (National Council of Teachers of Mathematics, 1981). The results of the PRISM project, as well as the first two NAEP results, were the driving forces that created the Agenda for Action: Recommendations for school mathematics of the 1980s (National Council of Teachers of Mathematics, 1980). There were eight recommendations from the Agenda for Action: problem solving as the focus of school mathematics, basic skills to include more than computation, use of calculators and computers and their full advantage at all grade levels, standards for teaching mathematics, evaluation of mathematics programs and student learning to include more than testing, flexible curriculum and more research, high level of professionalism for mathematics teachers, and public support for mathematics instruction (National Council of Teachers of Mathematics, 1980).

As newly elected President Ronald Reagan reduced funding for education, organizations sought out ways to increase educational awareness. In 1983, the National Science Board, NSB, commissioned a study on the nation's educational need. The National Council for Teachers of Mathematics also released a statement in 1981 stating that the federal government needed to take a role in teacher preparation and research, among other things. While these basically went unnoticed by the presidential administration, Secretary of Education, Terrel Bell, established the National Commission on Excellence in Education, NCEE, to create a report on the quality of education within the United States. This report became known as A Nation at Risk. While it received great media coverage by Reagan in his 1984 presidential campaign, once re-elected, Reagan continued to reduce the funding of the federal government for education (McLeod, 2003). 
While $A$ Nation at Risk did not bring increased federal support, it did stimulate concern about the quality of education in the United States. McLeod (2003) states that meetings held because of $A$ Nation at Risk were important to the development of the NCTM Standards Project. In 1989, NCTM produced the Curriculum and Evaluation Standards for School Mathematics. The Curriculum and Evaluation Standards was divided into three grade levels: $\mathrm{K}-4,5-8$, and 9-12 (NCTM, 1989). It was followed by the release of Professional Standards for Teaching Mathematics in 1991 and Assessment Standards for School Mathematics in 1995. The Professional Standards contained standards for teaching mathematics, evaluating the teaching of mathematics, the professional development of teachers and mathematics, and the support and development of mathematics teachers and teaching (NCTM, 1991).

While the 1989 Standards provided a foundation for both teachers and policymakers regarding mathematics education, NCTM felt the need to keep them viable through periodic examination and revisions as necessary. After a decade of discussions, NCTM (2000) released Principles and Standards for School Mathematics, PSSM. PSSM was built on the foundation of the 1989 Standards, but it also incorporated the classroom portion of both Professional Standards for Teaching Mathematics and Assessment Standards for School Mathematics (NCTM, 2000).

While the importance of mathematics has mushroomed over the years, the need for basic arithmetic is not the end to one's education, but merely the beginning of it. The advancement of technology within society has only demanded that there be an increase of mathematics within our classrooms. The requirements that were once necessary to obtain entrance into colleges and universities are now necessary to simply graduate from high 
school. The day of technology is here, and the need for higher mathematics learning came with it.

\section{HISTORICAL FRAMEWORK: SCHOOL MATHEMATICS}

Three "Rs" of education have long been reading, writing and arithmetic; however, there have been many changes in arithmetic. While in the early grades, dealing with arithmetic can be associated with working with numbers. Numbers are all around us. One of the first tasks children use relating numbers is displaying the number of fingers that corresponds with their age. Whether looking at a clock to tell time, reciting their phone number, learning an address or counting the number of chicken nuggets in a happy meal, children are constantly bombarded with numbers that can easily be formulated into the arithmetic content (Usiskin, 2002).

Arithmetic is now more commonly called mathematics as it has been expanded within the curriculum to include more topics. When dealing with fractions, decimals, percents, addition, and subtraction, people recognize this as the use of mathematics within their daily lives. Usiskin (2002) states that while arithmetic is more about numbers, people can see the direct need just by picking up a daily newspaper. Adults use fractions, decimals, and percents in many areas of life from recipes, bills, taxes or discounts while shopping. Russell, Geddes, and Grosset (1990) define mathematics as "the science dealing with quantities, forms, etc. and their relationships by the use of numbers and symbols" (Russell, Geddes \& Grosset, 1990, p. 336).

When the concepts within arithmetic or mathematics are generalized such that they include the use of unknowns, letters or variables, researchers refer to this as algebra (Kieran, 1992; MacLane \& Birkhoff, 1967; \& Usiskin 1988, 1997). Different people 
divide the algebra curriculum into different sections. Kieran (1989) suggests that algebra starts with variables, simplifying algebraic expressions, solving equations with one unknown and eventually solving multiple variable equations. Thorpe (1989) describes the main topics of algebra as the real number system, relations, functions, graphs, algebraic manipulations, word problems, quadratic formulas, complex numbers, tables, and interpolation, and systems of linear equations.

Within mathematics, there are many specific content areas across the curriculum from K-16. In particular, in elementary schools the curriculum focuses on arithmetic, while in middle school and high school, the curriculum transitions into the concepts of algebra, geometry, and some calculus. In the post-secondary setting, algebra, calculus, and beyond are explored. Recently, efforts have led to a model of algebra that spans grades K-12 (Carpenter, Franke, \& Levi, 2003; Kaput, Carraher, \& Blanton, 2007; \& RAND Mathematics Study Panel, 2003).

According to the United States Department of Education, there is a need for scientifically proven results on the best ways to teach mathematics (United States Department of Education, 2004b). The NCTM Standards have created a framework for raising mathematics achievement. According to Burrill (1998), more students, than ever before, are taking three or four years of mathematics in high school. In recent years, the focus has been on reading with the incorporation of scientifically proven programs. The focus is now shifting to mathematics, in particular algebra. Zalman Usiskin (1988) claims that algebra is the key area of study in secondary school mathematics and that it will continue to be for a long time to come. 
The NCTM's Agenda for Action (1980) called for problem solving to become an important activity within the mathematics classroom. Middleton, Dougherty, Heid, D'Ambrosio, Reys, de Loach-Johnson, Gutstein and Hala (2004) credit the Agenda for Action as being the "first step in perhaps the greatest and longest-lasting ferment of educational research and development ever (certainly since the early post-Sputnik days)" (p.76). Within the Assessment Standards for School Mathematics, NCTM created five general goals for all students: (1) that they learn to value mathematics, (2) that they become confident in their ability to do mathematics, (3) that they become mathematical problem solvers, (4) that they learn to communicate mathematically, and (5) that they learn to reason mathematically (NCTM, 1995).

In looking at state mathematics requirements, several states have required that every high school graduate must pass at least an entry level algebra course in order to graduate. Recently, Tennessee conducted a high school redesign to implement more stringent requirements in the field of science, technology, engineering and mathematics, STEM. This new redesign requires students to successfully take a mathematics class each of their four years in high school. Tennessee further strengthened their mathematical requirements by recognizing the first year of algebra as the lowest level of high school mathematics that will be honored as credit towards a high school diploma (Tennessee Department of Education, 2009). This is a huge shift from algebra being the gatekeeper (Hill, Griffiths, Bucy, et al., 1989; Stone, 1996; Atanda, 1999; Rech \& Harrington, 2000; Usiskin, 2004; Seeley, 2005; \& Norfolk Public Schools, 2006).

While there is a need to increase mathematics achievement, this study sought to specifically look at one topic within mathematics, namely functions. In thinking about 
the need for reaching students with mathematics and the need for raising mathematics achievement, it is important to take a deeper look at algebra. According to Jones and Coxford (1970) during colonial times, mathematics, even at the college level, focused very little on algebra. Osborne and Crosswhite (1970) go on to say that students mainly studied algebra for the purpose of getting into college. At the college level, in a typical mathematics textbook of 429 pages, only $8 \%$ or 33 pages were devoted to the study of algebra (Jones \& Coxford, 1970).

In 1981, NCTM released the results of the PRISM project which provided several insights into the way algebra was taught. "Strong support was given to four goals for teaching algebra: these concerned applying mathematics, building background for taking more mathematics, gaining vocational skills and preparing for college" (NCTM, 1981, p. 9). Strong support was also shown for the algebraic topics of signed numbers, evaluating formulas, linear equations, writing equations to solve word problems, and exponents in the curriculum for all students (NCTM, 1981). Furthermore, the PRISM project reported that teachers "totally rejected" the idea of dropping formal work with algebra from the curriculum (NCTM, 1981, p. 10). PRISM also reported that while the use of calculators was strongly supported for checking answers within an algebra class, the use of calculators during an algebra test were quite mixed as to agreement and rejection (NCTM, 1981).

Ten years later in the Principles \& Standards for School Mathematics, NCTM (2000) explained the need for more emphasis on relationships within algebra. PSSM described algebra as having its historical roots within the study of solving equations. PSSM clearly states that algebra should be embedded within the prekindergarten through 
twelfth grade curriculum in such a way that all students are able to "understand patterns, relations, and functions; represent and analyze mathematical situations and structures using algebraic symbols; use mathematical models to represent and understand quantitative relationships; and analyze change in various contexts" (NCTM, 2000, p. 36). PSSM goes on to say that within the Algebra Standard, the emphasis should be on the relationships between quantities, representing relationships, and the analysis of change. $P S S M$ specifically states that the "functional relationships can be expressed by using symbolic notation, which allows complex mathematical ideas to be expressed succinctly and change to be analyzed efficiently" (NCTM, 2000, p. 36).

Russell $(1990$, p. 28) defines algebra as "the branch of mathematics dealing with the properties and relations of numbers; the generalization and extension of arithmetic." Fey (1989) stated that algebra should be the core of the high school mathematics curriculum because of its contribution to problem solving, which is used in every scientific discipline. Kieran (1992) stated that the content of algebra has not changed significantly; however, "mathematics and its applications have changed dramatically" (Thorpe, 1989, p. 11). The need for algebra goes beyond the need to gain entrance into college, although colleges continue to use algebra as a gatekeeper and placement tool (Atanda, 1999; Usiskin, 2004; \& Norfolk Public Schools, 2006).

The National Council of Teachers of Mathematics (1989) states that most of mathematics is communicated through the language of algebra. NCTM went on to describe algebra as the vehicle through which the application of abstract concepts can cultivate generalizations and understanding beyond the original context. Algebra should 
be seen as a means of representation with an emphasis on conceptual understanding and problem solving (NCTM, 1989).

Recently, there has been a push to have algebra included across all levels of the mathematics curriculum. In a position statement from the National Council of Teachers of Mathematics, algebra was described as

“... a way of thinking and a set of concepts and skills that enable students to generalize, model, and analyze mathematical situations. Algebra provides a systematic way to investigate relationships, helping to describe, organize, and understand the world. Although learning to use algebra makes students powerful problem solvers, these important concepts and skills take time to develop. Its development begins early and should be a focus of mathematics instruction from pre-K through grade 12 . Knowing algebra opens doors and expands opportunities, instilling a broad range of mathematical ideas that are useful in many professions and careers. All students should have access to algebra and support for learning it. (NCTM 2008, p.1).

The Algebra Project, Equity 2000, and Algebra for All advocated for the inclusion of algebra beyond the high school level and into elementary and middle school levels (Silva, Moses, Rivers, \& Johnson, 1990; Choike, 2000; Pugalee, 2001; \& NCTM, 2008). The underlying conviction of The Algebra Project is summed up in their statement that "all children can learn algebra." (Silva, Moses, Rivers, \& Johnson, 1990, p.375). As algebra is pushed down to the lower grades, mathematics at the secondary level must continue to be strengthened as well. Seeley (2005) said that having students take four years of mathematics while in high school was a good idea and that starting with algebra was part of our moral and ethical responsibility. Various articles have been published to help implement algebra for all, including various strategies and activities (Blubaugh \& Emmons, 1999; Cox \& Bridges, 1999; Driscoll, Foster, \& Moyer, 1999; McConnell \& Bhattcharya, 1999; Philipp \& Schappelle, 1999; Leitze \& Kitt, 2000; \& Lesser, 2000). 
The inclusion of functions into the mathematics curriculum occurred at the end of the 19th century. With the addition of graphs to geometry, other aspects of analytical geometry and calculus into the curriculum, functions were beginning to find their natural place (Hamley, 1934; Osborne \& Crosswhite, 1970). Felix Klein is credited for pushing the concept of functional thinking as a part of mathematics in Germany. According to Hamley (1934), D. E. Smith and E. R. Hedrick were the first advocates of the function concept in the United States. The National Committee on Mathematical Requirements committed an entire chapter to the concept of functions at the high school level (American Association for the Advancement of Science, 1922; \& Osborne \& Crosswhite, 1970). According to Hamley (1934), this chapter was a comprehensive overview implying that functions were an integral part of formulas, equations, graphs, proportions, congruence, and similarity. In the 1930s, the concept of function "permeated" the algebra curriculum (Osborne \& Crosswhite, 1970).

The concept of function is both essential and fundamental to the algebra curriculum and is considered by many to be the most important concept in all of mathematics (Hamley, 1934; Froelich, Bartkovich, \& Foerester, 1991; \& O’Callaghan, 1998). Within algebra, functions are typically represented as equations, tables or graphs (Fey, 1984). Hamley (1934) compares the concept of function to the concept of the relation and claims that they are elementary to human thought. He further states that "the concept of relation is fundamental to human thought" (Hamley, 1934, p.3). Often the definition of a function is really the definition of a functional relation. Hamley (1934) believes it would make for clearer understanding if the term functional relation was used instead of function. 
The familiarity of relations and functions is common among mathematics teachers (May \& Van Engen, 1959; \& Herscovics, 1989). Herscovics (1989) brought light to the fact that most primary level teachers use the "function machines" with inputs and outputs (Herscovics, 1989, 7p. 5). When students solve problems such as $\square+3=10$ or even $x+$ 7 when $x$ is 2 , they may not realize that they are working with a function, but the underlying concept is still there. Furthermore, function tables, two variable equations, and graphs also expose students to the intuitive concept of functions (Herscovics, 1989; \& Blanton \& Kaput, 2005). Mathematics now uses the concept of sets to define the terms of function and relation. Various examples of sets used in daily life include the heightweight and time-temperature. Within the realm of science, there are uses of linear, quadratic, polynomial, exponential, and other classes of functions. With these connections, the concept of functions can provide a more efficient and deeper understanding of the concept (May \& Van Engen, 1959).

O'Callaghan (1998) created a framework for functions that had four conceptual areas: modeling, interpreting, translating, and reifying. Each conceptual area was associated with a set of procedural skills as well. The research of function was broken down into six themes in the Research in Colligate Mathematics Education (Dubinsky, Schoenfeld, \& Kaput, 1994, 23):

1. Concept image and concept definition

2. Function as action, as process, and as object

3. Function as co-variation of quantities and function as correspondence

4. Understanding phenomena and representing phenomena

5. Operations on numbers and operations on functions

6. Emergent Issues

These are just a few of the areas of functions still to be examined by research. 
With the call for more mathematics in the curriculum, the level of mathematics continues to be pushed down. While algebra, still a gatekeeper course, is now the beginning course for many high school students, algebra is also being included in the elementary mathematics curriculum as well. With an increased focus on algebra, the fundamental concept of functions can be seen throughout all grade levels, therefore, serving as an ideal topic to research.

\section{HISTORICAL FRAMEWORK：LEARNING}

Three theories addressing how students learn are the Behavior Theory, the Cognitive Theory, and the Constructivist Theory. For the first half of the 20th century, the psychological learning theory was behaviorism. "Behaviorists held that the scientific study of psychology must restrict itself to the study of observable behaviors and the stimulus conditions that control them" (Bransford, Brown, \& Cocking, 2000, p. 6). Pavlov, Thorndike, and Bloom are three of the noted psychologist that dealt with behaviorism. Pavlov's conditioning, or reflexology, trained a dog to salivate at the ringing of a bell (Sacknery \& Mergel, 2007). Thorndike's theory was known as connectionism, but it is best remembered as the stimulus-response explanation of learning (Lankford, 1959).

While Pavlov and Thorndike are best known for stimulus-response, Bloom was more focused on the thought process. Educators often use Bloom's Taxonomy for the purpose of classifying students' cognitive ability. There are six levels to Bloom's Taxonomy: Knowledge, Comprehension, Application, Analysis, Synthesis, and Evaluation (Krathwohl, 2002). With the progression to each level, students must have successfully completed the previous levels. Bloom's Taxonomy is one of the most 
widely accepted guides used to classifying cognitive ability (Granello, 2000). With an understanding of the different levels, teachers can design and ask specific questions that determine the level as well as compel students to achieve new levels. The Taxonomy of Educational Objectives expands on Bloom's Taxonomy in such a way that it can be used as a "scheme for classifying educational goals, objectives, and most recently, standards" (Krathwohl, 2002, p. 218).

Behaviorism was unable to explain why a child did not respond as stimulated or why the child responded when they had not been stimulated. These and other unanswered questions led to the development of the Cognitive Theory that viewed learning as involving the "acquisition or reorganization of the cognitive structures through which humans process and store information" (Good \& Brophy, 1990, p. 187). Tolman, Piaget, Bruner, and Gardner are some of the noted cognitive psychologists. Cognitive psychology focuses more on the intellectual development of a person, in particular how they acquire, process, and store information. For example, Tolman worked with rats and mazes. He discovered that the rats created a mental map of the maze. When a part of the maze was blocked off, the rats would take a different route that led to success (Sackney \& Mergel, 2007).

Piaget studied the mental development of children. From his study, Piaget identified "four stages of cognitive development: the sensorimotor, the preoperational, the concrete operational, and the formal operational" (Stiff, Johnson, \& Johnson, 1993, p. 6). Stiff, Johnson, \& Johnson (1993) go on to say that Piaget's theory centered on the processes of assimilation and accommodation. Piaget encouraged the discovery and interaction within the classroom, both with other people and with manipulatives. Piaget 
and other cognitive development theorists have provided the framework from which we have gained research on conceptual understanding (Wagner \& Parker, 1993).

According to Stiff, Johnson, \& Johnson (1993), Bruner created four theorems about learning mathematics: construction theorem, notation theorem, contrast and variation theorem, and the connectivity theorem. The first, construction, talks about how students are to create their own mathematical models. The second, notation, is that good use of notation can simplify the cognitive process when learning new materials. The third, contrast and variation, describes the process of going from concrete to abstract as one that varies based upon one's experiences. The fourth and last one, connectivity, describes how every mathematical concept, principle and skill are related to each other. These four theorems helped to support the constructivist view of cognition (Stiff, Johnson, \& Johnson, 1993).

Howard Gardner's theory of multiple-intelligences provides a different view of human learning than that of Piaget. Gardner posited that there were seven intelligences: logical-mathematical, linguistic, musical, spatial, bodily-kinesthetic, interpersonal and intrapersonal (Gardner \& Hatch, 1989). He stated that there are multiple ways to introduce concepts to students to take advantage of the variety of ways of knowing that students bring to the classroom (Gardner, 1995).

The writings of Dewey, Piaget, and Bruner helped to lay the ground work for constructivism (Mergel, 1998). The Constructivist Theory is based on the idea that students learn new information by scaffolding, which is building new knowledge upon previous knowledge (Long \& Barrett, 2007). Brooks and Brooks (1999) go on to describe the learning within constructivism as "ever-transforming mental schemes" that 
are necessary within a student's cognitive growth (Brooks \& Brooks, 1999, p. 18).

Within the classroom stetting, constructivist approaches to learning would have students using group work, discussions, and word problems to help create their new knowledge (Lee, 1999). Long and Barrett (2007) compare a behaviorist approach of teaching mathematics to a constructivist approach. While there is no one specific approach to either theory, those who espouse both theories attempt to guide instruction in such ways as to take advantage of their beliefs of how students learn. Because behaviorists believe that a student can be conditioned to learn the right answer, classroom instruction includes positive reinforcement. Since constructivists learning builds on previous knowledge, classroom instruction occurs through a participatory role where the student learns by discoveries that challenge previous held beliefs. It is important to note that this is not discovery learning, but learning where the teacher is constantly monitoring, guiding, and modifying the students' responses to the material (Long \& Barrett, 2007).

There are many theories on how students learn and how instruction within the classroom should occur. Many contributions by behavioral psychologists and cognitive psychologists have greatly impacted how mathematics is taught in the classroom today. Teachers strive to teach more than rote memorization and more application. Students are participatory learners and teachers create environments where they can build on previous knowledge and higher order thinking skills.

\section{HISTORICAL FRAMEWORK: TECHNOLOGY}

Skemp (1976) describes two different ways to teach for understanding, instrumental and relational. Instrumental understanding deals with the steps to the process, while relational understanding is more about the why behind the process. When 
teaching for instrumental understanding, the teacher drills the algorithm until the student is able to repeat the steps. Relational understanding is more about the application of the algorithm, which leads to true understanding (Skemp, 1976). Once a student has gained relational understanding, technology within the classroom can assist in quickly moving through cumbersome calculations to the deeper applications. The teacher must be aware of which algorithms to continue teaching and which procedures to explain with an algorithm, but carry out using technology (Burrill, 1998). National Council of Teachers of Mathematics (NCTM) has stated that instruments designed to assess students' mathematical understanding and application must acknowledge students' access to and use of calculators (National Council of Teachers of Mathematics, 1998).

\section{HISTORICAL FRAMEWORK: TECHNOLOGY IN LEARNING}

From the abacus to the calculator, instructional technology in the mathematics classroom has been around for a long time. One of the first technology tools for mathematics goes back to the abacus, which was used before the formal acceptance of a written number system. In the 17th century came the slide rule, the Pascaline, and Leibniz's calculating machine (Davis, 2000). The use of multi-media such as music, television, and movies created an interactive teaching environment. The development of the microchip for the computer truly started a revolution of using computers within education. Computer programs have been developed to effectively do mathematics on the computer such as Maple, Cabri, and Geometer's Sketchpad (Marrades \& Gutierrez, 2000; \& Mariotti, 2000). The same is true for calculators, in that calculators have progressed from a basic four function calculator to a graphing calculator with the ability 
to draw geometric images with Cabri Jr. or solve algebraic equations with CAS (Computer Algebra Systems) technology.

Sang Sook Choi-Koh says that the "universal availability of technology is having a profound impact on what should be taught in mathematics curricula and how mathematics processes should be taught" (Choi-Koh 2003, p. 1). The mathematics classroom envisioned by the Principles and Standards includes access to technology that facilitates a student's learning (National Council of Teachers of Mathematics, 2000). NCTM goes on to say that the effective use of technology within the mathematics classroom depends on the teacher (National Council of Teachers of Mathematics, 2000, p. 25). Klassen and Vogel suggest that the infusion of technology within the classroom does not remove the teacher from the educational equation; however, it changes the role of the teacher. The changes include a more interactive approach to teaching with the use of a multimedia environment (Klassen \& Vogel, 2001). Choi-Koh (2003) went on to say that the use of technology has assisted in moving students" "thinking process from intuitive to operative, and then on to application" (Choi-Koh, 2003, p. 368).

The use of music, movies, and television allow a teacher to address several different types of learners. Studies have shown that the use of various resources is effective in instruction and learning, while at the same time enhances the learning environment (Imig, 1981; \& Stein, 1983). The use of such media allows for deeper and more meaningful understanding according to Gardner's multiple intelligences (Gardner, 1995).

According to Privateer (1999), mathematics learning with technology is a new way of teaching and learning. Privateer states that "instructional technology can 
spearhead serious institutional reform because they create real change, especially in the area of course content and delivery (Privateer, 1999, p. 62)." Galbraith (2002, p. 15) states that technology may be "regarded as a mathematical tool or as a transforming tool. It may also be regarded as a cultural tool." In this, Galbraith describes the mathematical tool as one that amplifies capacity, the transforming tool as one that reorganizes thinking, and the cultural tool as one that changes the relationship between people and tasks. The process of using a calculator for deeper understanding ensures that students achieve higher levels within Bloom's Taxonomy and within the mathematics classroom.

Overall there is a prevailing policy of allowing calculators during classroom learning activities and testing (Dion, Harvey, Jackson, Klag, Liu, \& Wright, 2001). Although it is evident from Dion, Harvey, Jackson, Klag, Liu, and Wright (2001) that calculators are used on tests, their study did not determine whether the tests actually had questions that were designed for calculator usage when answering them. The TIMMS study indicated that one of the greatest characteristics of the calculator was its use with problem solving and discovery of mathematical relationships (Tarr, Uekawa, Mittag, \& Lennex, 2000).

Privateer (1999) suggests that learning outcomes be developed by teachers using technology to teach that would integrate the technology throughout the curriculum. With all of the available technologies today, one of the biggest challenges to teachers is determining the difference between what is trending and what is good for instruction (Podlesni, 1999). Sang Sook Choi-Koh also emphasizes that the type of questions asked when using technology will need to be adjusted so that students will be able to more readily see the relationships and not just get a quick answer by pushing a button (Choi- 
Koh, 2003). Burrill (1998) points out that a student needs to see the mathematical objective that needs to be learned and not focus on the particular tool that assists them in arriving at an answer. Burrill goes on to say that test questions should also focus on the mathematics and not the particular tool that is going to be used (Burrill, 1998).

Sang Sook Choi-Koh (2003, p. 1) states that "there is little research about how technology affects mathematical thinking processes and even less on the impact of the graphing calculator in the learning environment." Hembree and Dessart (1986) conducted a meta-analysis on the effects of hand-held calculators. Hembree and Dessart (1992) also produced a meta-analysis on the research on calculators in mathematics education. Both of these publications show an increase in the amount of research that has occurred during the decade, but also reinforce the need for additional research to be completed.

While there is still a need for more research, there are several studies that have demonstrated the value of calculators within the mathematics classroom. Ellington (2003) concluded that when calculators were an integral part of instruction, operational skills and problem solving skills improved. Research shows that students with the strongest mathematics skills perform best with handheld calculators at solving problems (Hembree \& Dessart, 1986). Research has also shown that students who used graphing calculators have a more positive attitude towards mathematics (Hennessy, Fung \& Scanlon, 2001; Ellington, 2003; Ellington, 2004, \& Ellington, 2006). Hollar and Norwood completed a mathematical study that focused on the student's understanding of a function. The study showed that while the students using graphing technology performed as well as those using traditional algebra, the students using the graphing 
technology improved their performance on visual and graphing tasks (Hollar \& Norwood, 1999). Hollar and Norwood went on to say that students with the graphing technology were allowed a greater ability to "create equations, tables, and graphs quickly and the facility to move among the representations rapidly" (Hollar \& Norwood 1999, p. 224).

Another recent piece of technology being used within the mathematics classroom is the interactive white board, often called a Smart Board. The interactive white board is a system that allows the teacher to network with a computer, projector and a white board. The teacher can use the white board as a standalone, or incorporate it with visual demonstrations, PowerPoint, etc. Ball $(2003$, p. 7$)$ stated that the use of interactive whiteboards can influence teaching and learning of mathematics because:

- one shared image encourages discussion

- the pace of the lesson is increased

- the teacher is encouraged to plan utilizing whole-class activities

- the teacher can face the students within the classroom

- the teacher can concentrate on student responses

- numbers, diagrams, and graphs can be quickly changed

- dynamic images are readily available and easily manipulated

- ease of switching between different modes of use and programs.

The introduction of Flash-ROM changed the look of hand-held technologies. In 1999, Texas Instruments released the TI-83, which came preloaded with various applications and upgradeable software. The TI-84 was released in 2004. The TI-84 had twice the speed and three times the memory of the TI-83. In addition to the speed and memory, the TI-84 came with a versatile USB plug allowing for easy computer connection. One of the newest technologies released by Texas Instruments in 2007 was the TI-Nspire. The TI-Nspire offers a dual keypad, allowing it to bridge the learning between the TI- 84 and the actual TI-Nspire. One of the newest features is the ability to 
simultaneously link multiple represents of a single problem, while also providing enhanced interactivity. In particular, the TI-Nspire allows one to take an algebraic equation written symbolically, to graph it geometrically, to create a table of values numerically, to show flow charts of it analytically and to take notes verbally. Because the TI-Nspire has been out since the fall of 2007, there has been very limited research done using it to see how it compares to the other technologies that are available.

The mathematics classroom has come a long way from drawing in the sand, using an abacus or even a slide rule. Teachers have many options when wanting to diversify the tools with which they teach. While the computer and the internet hold many opportunities, the cost of computers and even the space to place them within a school can be a challenge. Fortunately for mathematics, advances have been made so that programs originally designed for computers, such as Cabri and Maple, can now be held in your hand with similar programs like Cabri, Jr. and Computer Algebra Systems or CAS. Time will only tell how the impact of new technologies, such as the interactive whiteboard and the TI-Nspire, will influence the way students learn.

\section{CALCULATORS AS LEARNING TOOLS}

According to Reys and Arbaugh, a four dollar calculator has the ability to do computations in a matter of seconds that in the past would require students to have years of instruction and practice to learn (Reys \& Arbaugh, 2001). Although the calculator can be very efficient and accurate at computing, it has also raised several questions for both teachers and parents (Thompson \& Sproule, 2000). The calculator cannot think for itself; it cannot decide on which buttons to push, or what to think of the outcome. The quality of the output of any calculator is wholly dependent on the input (Reys \& Arbaugh. 2001). 
The Third International Mathematics and Science Study (TIMMS) indicated that the United States and Portugal tend to have relatively high levels of calculator use, while Japan has practically no calculator usage (Tarr, Uekawa, Mittag, \& Lennex, 2000).

Podlesni (1999) states that he believes that students should use graphing calculators. According to Dion, Harvey, Jackson, Klag, Liu, and Wright (2001), the use of scientific calculators in United States schools is greater than the use of graphing calculators within Algebra I classrooms and geometry classrooms. However, graphing calculators are more frequently used within Algebra II classrooms and pre-calculus or trigonometry classrooms.

A study among United States schools by Dion, Harvey, Jackson, Klag, Liu, and Wright (2001) indicates that as the mathematics class level increases, so does the fact of the graphing calculator becoming an integral part of the classroom. Their study showed that graphing calculators were required as a part of eighteen percent of the Algebra I classrooms, twelve percent of the geometry classrooms, forty-two percent of the Algebra II classrooms, and seventy percent of pre-calculus/trigonometry classrooms. Graphing calculators were not allowed in thirteen percent of the Algebra I classrooms, eight percent of the geometry classrooms, five percent of the Algebra II classrooms, and only one percent of pre-calculus/trigonometry classrooms (Dion, Harvey, Jackson, Klag, Liu, \& Wright, 2001). Within the TIMMS study, only $10 \%$ of United States students said that they had "never" used a calculator during a mathematics lessons (Tarr, Uekawa, Mittag, \& Lennex, 2000).

The technology that is available should not be used as a replacement but rather as a tool that complements, deepens, and expands the understanding and exploration of 
mathematics. The use of technology while teaching concepts that have massive computations allows the teacher to focus on the concept being taught and further allows the student to see the big picture of the concept instead of becoming confused with the computation details (Hudnutt \& Panoff, 2002). According to Hudnutt and Panoff, the teacher should be able to discern in what capacity technology should be used. Choi-Koh (2003) states that there is a great importance in asking appropriate questions for students to process through the mathematics with technology. Although the calculator can help process through lower levels of mathematics with a simple push of a button, the teacher has the responsibility to ask the higher order of thinking skills questions such as "how" and "why" to stimulate students to think "mathematically and meaningfully" (Choi-Koh, 2003, p. 367). Teachers have gone from being the sage on the stage to the facilitator of discovery (Burrill, 1998).

The emergence of calculators and computers has changed the way mathematics is both done and used (Ellington, 2006; Thorpe, 1989; \& Kieran, 1992). Thorpe (1989, p. 11) says that "it is time for algebra instruction in the schools to begin to reflect these changes." Research shows that students can effectively use a graphing calculator as an instructional tool to make and understand the connections between graphical and algebraic concepts (Drijvers \& Doorman, 1996; \& Choi-Koh, 2003). Graphing, functions included, is taken to a new level by technique, instrument and process. Research has shown that in using computers to graph functions, students are capable of using one algebraic system to extend and acquire an understanding of another (Colgan, 1993, p. 57). With the use of technology and such handheld devices, students can become competent problem solvers (Ronau et al., 2008). 
By allowing students to explore with the calculator, students can also learn new ways to think about solving mathematics problems. This has been reflected within the College Board Scholastic Achievement Test (SAT) Program that has allowed students to use calculators since 1994. The allowance of calculators on the SAT is reflective of what is occurring within the classroom. Other research has shown how the use of graphing calculators has led to students using higher level thinking skills (Graham \& Thomas, 1998; Keller \& Hirsch, 1998; Dessart, DeRidder, Charleen, \& Ellington, 1999; Huntley, Rasmussen, Villarubi, Sangtong, \& Fey, 2000; \& Ronau et al., 2008), relating mathematical problems to real life (Drijvers \& Doorman, 1996; Zbiek, 1998; Schwarz \& Hershkowitz, 1999; \& Forster, 2000), and collaboration on problem solving. (Goos, Galbraith, Renshaw \& Geiger, 2000; \& Hennessy, Fung, \& Scanlon, 2001).

Research has been gathered regarding the perceptions of graphing calculator use within the mathematics classroom. The major trends for advantages of using the graphing calculator were less distraction with computational detail, availability of immediate feedback and enhancement of visualization (Simonsen \& Dick, 1997; \& Hennessy, Fung, \& Scanlon, 2001). Disadvantages of using the graphing calculator include logistical difficulties, lack of access, and problems with security (Simonsen \& Dick, 1997; Hong, Toham, \& Kiernan, 2000; \& Mitchelmore \& Cavanagh, 2000). Additional disadvantages were the time spent learning the calculator and the fear of calculator dependency (Quesada \& Maxwell, 1994; Simonsen \& Dick, 1997; \& Hennessy, Fung, \& Scanlon, 2001).

In looking at the classroom dynamics and trends from teacher responses, the mathematics classroom is less teacher-centered, allowing for more open-ended questions, 
fostering a discovery approach, and allowing more of a cooperative learning environment (Rochowicz, 1996; Simmt, 1997; \& Simonsen \& Dick, 1997). Minor trends also show increased student discussion of mathematical ideas, increased student involvement, and increased student enthusiasm (Simonsen \& Dick, 1997). In respect to curriculum and evaluation, there is both increased preparation time and increased mathematical depth (Simonsen \& Dick, 1997). In respect to professional support and development, the major trends are the need for technology-sensitive materials and handouts, the need for additional in-service, and the need for teacher networking (Simonsen \& Dick, 1997).

Mathematics educators appear to support the use of calculators within the classroom (Fleener, 1995; Dessart, DeRidder, Charleen, \& Ellington, 1999; Merriweather \& Tharp, 1999; \& Dion, Harvey, Jackson, Klag, Liu, \& Wright, 2001). According to Tarr, Uekawa, Mittag, and Lennex (2000), teachers can use technology to improve their mathematics instruction which would, in turn, improve student learning. Some of the biggest questions still before educators are when to use the calculators, what topics need to be covered before using calculators, and how much the calculators should be used within the classroom (Fleener, 1995; \& Thompson \& Sproule, 2000). The Technological Pedagogical Content Knowledge (TPACK) model for professional development provides a five-stage developmental process (from Recognizing to Accepting to Adapting to Exploring to Advancing) to assist teachers when integrating technology on different levels (Niess et al., 2009).

There is very little research that has been done on calculators in the past 20 years. Hembree's (1986) meta-analysis showed only 96 studies done on the calculator in general. Ellington's (2003) meta-analysis looked at only 54 studies. Choi-Koh (2003, 
p. 369) states that "if students use tools early in the learning environment to acquire a broader picture of the ways in which concepts may be realized, they might progress cognitively. The experience also helps students to operate mathematical proprieties and apply them to more complicated problems." A study by Vendlinski, Morris, \& Michels (2008) compared the order of instruction, conceptual or procedural, within an algebra class while students used the TI-Nspire. Results showed that teaching conceptually first had greater benefits (Vendlinski, Morris, \& Michels, 2008).

Whether using a four-function calculator to check calculations or a scientific calculator to find the value of sine for an angle, calculators have become helpful learning tools (Hembree \& Dessart, 1986; \& Ellington, 2003). While some research has been done regarding the graphing calculator, Ellington's (2003) meta-analysis had only 22 of the 54 studies dealing with graphing calculators. Most of the problem solving research has been dealing with non-graphing calculators (Ellington, 2003). There is very little research on the TI-Nspire since it was released in the fall of 2007 . One study showed the use of the TI-Nspire with pre-service teachers developed both a favorable attitude towards the technology and created inquiry based and open-ended lesson plans (Meagher, Ozgun-Koca, \& Edwards, 2008).

While there are many different applications with the TI-Nspire, there is an extremely limited amount of research on the TI-Nspire. With the ability of the TI-Nspire to link together multiple-representations within a single problem, it is imperative that research investigate the effect that this new tool will have within the classroom. With the wide variety of methodologies, evidence supports the use of quasi-experimental design (Keller \& Hirsch, 1998; Hollar \& Norwood, 1999; Harskamp, Suhre, \& Van Streun, 
2000; \& Huntley, Rasmussen, Villarubi, Sangtong, \& Fey, 2000), treatment/control groups (Roberts, 1980; Ruthven, 1990a; Quesada \& Maxwell, 1994; Shoaf-Grubbs, 1994; Adams, 1997; Keller \& Russell, 1997; Keller \& Hirsch, 1998; O’Callaghan, 1998; Keller, Russell, \& Thompson, 1999; Merriweather \& Tharp, 1999; Schwarz \& Hershkowitz, 1999; Harskamp, Suhre, \& Van Streun, 2000; Huntley, Rasmussen, Villarubi, Sangtong, \& Fey, 2000; Connors \& Snook, 2001; \& Thompson \& Senk, 2001), pre/posttest (Roberts, 1980; Ruthven, 1990a; Adams, 1997; Slavit, 1997; Tharp, Fitzsimmons, \& Ayers, 1997; Keller \& Hirsch, 1998; O'Callaghan, 1998; Hollar \& Norwood, 1999; Merriweather \& Tharp, 1999; Drijvers, 2000; Drijvers \& Van Herwaarden, 2000; Harskamp, Suhre, \& Van Streun, 2000; \& Thompson \& Senk, 2001), and the use of educational data for comparative analysis (Quesada \& Maxwell, 1994; Keller \& Russell, 1997; Hollar \& Norwood, 1999; Keller, Russell, \& Thompson, 1999; Doerr \& Zangor 2000; Drijvers \& Van Herwaarden, 2000; Huntley, Rasmussen, Villarubi, Sangtong, \& Fey, 2000; Connors \& Snook, 2001; Dimock \& Sherron, 2005). Since the concept of functions within algebra can be looked at as equations, ordered pairs, and as graphs, functions in algebra are an ideal context to explore the new technology. This makes a logical connection to research how effective the new technology of the TI-Nspire is at linking ordered pairs within a table, the graph on a coordinate plane, and the symbolical writing of an equation. The concept of functions within algebra is an ideal context in which to study hand held instructional technology. 


\section{CHAPTER 3}

\section{METHODOLOGY}

\section{INTRODUCTION}

The focus of this study was to explore the effect of a teaching strategy using the TI-Nspire on student achievement measured by a pre-test, a post-test, and a post post-test using the Kentucky High School Diagnostic Mathematics Assessment. This study also examined the effect of the teaching strategy on teacher behavior variables including teacher planning, teacher teaching, and assessments used. The teaching strategy was employed within the first year of algebra with "trained teachers" using the TI-Nspire graphing calculator as an instructional tool to teach function concepts. The effect on student achievement was determined by measuring students' understanding of functions through comparisons of pre-test and post-test results. Student achievement was measured using a pre-test, a post-test, and a post post-test using Repeated Measures with ANOVA. The effect of how teachers taught, planned, and assessed students while teaching function concepts was measured by observations and document analyses. The following research questions guided the investigation:

1) Was there a difference in student test scores on function concepts in Algebra I classrooms that used TI-Nspire graphing calculators versus those who did not use this device? The independent variable was treatment and the dependent variables were the pre-test, post-test, and post post-test. 

a. Treatment Effect
b. Teacher Effect
c. Interaction of Teacher and Treatment
d. Factors: special education status and socioeconomic status

2) Did the use of TI-Nspire graphing calculators affect the way teachers taught function concepts in Algebra I classrooms with respect to representations, Depth of Knowledge, and TPACK? The independent variable was treatment and the dependent variables how teacher taught.

3) Did the use of TI-Nspire graphing calculators affect the way teachers planned lessons for function concepts in Algebra I classroom with respect to representations, Depth of Knowledge, and TPACK? The independent variable was treatment and the dependent variables how teacher planned.

4) Did the use of TI-Nspire graphing calculators affect the way teachers assessed students on functions concepts in Algebra I classrooms with respect to representations, Depth of Knowledge, and TPACK? The independent variable was treatment and the dependent variables how teacher assessed.

This chapter is divided into the following sections: (1) research design; (2) participants; (3) instrumentation; (4) treatment; (5) data collection procedures; (6) data analysis procedures; and (7) summary.

\section{RESEARCH DESIGN}

The researcher used a quasi-experimental pre-test, post-test, post post-test controlgroup research design to answer the research questions of the study. Gall, Gall, and Borg (2003) indicate that, when establishing cause and effect relationships between two or 
more variables, an experimental study is the most powerful research method. Shadish, Cook, \& Campbell (2002) indicate that experiments are well-suited for studying causal relationships when three conditions are met:

1. Manipulate the presumed cause and observe an outcome afterward.

2. See whether variation in the cause is related to variation in the effect.

3. Use various methods during the experiment to reduce the plausibility of other explanations for the effect (Shadish, Cook, \& Campbell, 2002, 6).

In this study, first-year algebra teachers were taught to the use of a TI-Nspire graphing calculator. These "trained teachers" were provided with examples to supplement their textbooks and training specifically for the use of the TI-Nspire when teaching the concepts of functions. The independent variable was the use or non-use of a TI-Nspire graphing calculator by the trained teachers while teaching functions in a firstyear algebra course. For student achievement, the effect of the independent variable on the dependent variable of student understanding of functions was determined by differences in test scores on the post post-test, the post-test, and the pre-test. The use of pre-tests provided baseline comparisons. The post-test was used to examine if there was a statistically significant difference in these scores from the pre-test scores. The post post-test strengthened the design by adding another data point, thereby increasing the stability of the post-treatment measure and showing whether the information had been retained over a longer period of time.

According to Patton (2002), the researcher was an insider in that she was a colleague and knew the teachers. The researcher was an outsider in that the she worked in a different building and in a different department. While both an insider and an 
outsider, the researcher guarded against both positive and negative bias by giving full disclosure, using multiple data collection types, and using triangulation to support all results found.

The effect of the independent variable on the dependent variable was established through teacher observations and weekly teacher questionnaires. A document review was used to determine the effect of the teaching strategy of how teachers planned lessons and assessed students on function concepts. A vignette was completed for each teacher specifically looking at both the treatment class and the control class and then comparing them.

\section{PARTICIPANTS}

\section{Population and sampling}

This research was conducted in the ninth grade of a high school located within a school district in the southern part of the United States. The high school is referred to as "Eagle High School," and the school district is referred to as the "Aerie District." The population for this study is defined as any ninth grade first year Algebra class. The sample for this study was is defined as the 301 ninth graders at Eagle High School and taking the first year of Algebra.

Eagle High School is a comprehensive high school with both college and technical/career track programs. The school is accredited by the Southern Association of Colleges and Schools and is recognized as a National School of Excellence. Eagle High School has honors, advanced placement, dual enrollment, and independent study courses. Students may also take any course listed in the catalogs of the nearby postsecondary institutions. Eagle High School offers 16 mathematics classes ranging from Foundations 
to Calculus II Honors. The Foundations class is designed for students not ready for Algebra I. In Foundations, students are prepared for algebra by building content knowledge in number and operations, algebra, geometry, measurement, data analysis and probability. Students use the processes of problem solving, reasoning, communication, connections, and representation. Calculus II Honors is an Advanced Placement class in which students earn college credit by taking the Calculus AB Advanced Placement test at the end of the course. Students may also take College Algebra and Statistics on campus at Eagle High School to earn dual enrollment credit for both high school and college credit.

All students within this southern state must take a mathematics class each year of high school in order to graduate. The lowest level mathematics to count toward graduation is Algebra I. While students may be enrolled in more than one mathematics class, all students must take Algebra I as their first mathematics credit. To meet the "No Child Left Behind" requirements, this southern state requires an exit examination for all Algebra I students.

Because all students are required to take Algebra I in high school, this study included a representative cross-section of all students at Eagle High School. Students in the Algebra I classes were required to take a pre-test, a post-test, and a post post-test focusing on the topic of functions. During the 2008-2009 school year, Eagle High School started school-wide-testing of English, mathematics, and science content areas, which produced a database of student test scores in these subjects. Teachers were provided reports to be used as feedback to identify areas of need for classes as well as for individual students. 
In the spring of 2009 , students met with their guidance counselors to discuss class schedules for the fall of 2009. A statewide database program to build school master schedules to create student schedules also was used to manage attendance, create transcripts, and more. The guidance department determined the number of classes for each subject and created the master schedule. Computer generated class schedules and rosters assigned students to classes. In the fall of 2009 , these generated classes were assigned a specific teacher by the school's academic assistant principal. Since this assignment was not totally random, a table was created and included to show student and teacher demographics within each classroom to demonstrate the equivalent groups. Since all teachers within the ninth grade were teaching Algebra I, no teacher input into which teacher received each class was available.

Once the classes for the fall of 2009 had been established, the classes were designated randomly as either treatment or control. The state database system assigned each Algebra I class a number. The random assignment was accomplished by listing the teachers alphabetically by last name and then using a random number generator to assign a number to each teacher. The teachers were then sorted by their assigned number from least to greatest. The teacher with the lowest random number generated was known as Teacher Alpha, the second was be Teacher Beta, the third was Teacher Gamma, the fourth was Teacher Delta, the fifth was Teacher Epsilon and the sixth teacher was Zeta. While an equal number of both male and female teachers were included, all teachers were identified with the prefix "Teacher" to provide additional anonymity.

Six teachers at Eagle High School taught Algebra I in the ninth grade. Four of the Eagle High teachers taught two Algebra I classes and two taught only one class, as shown 
in Figure 1. To decrease teacher effect, a teacher with two Algebra I classes had one class assigned as a treatment class and one as a control class. For the two teachers who had only one class, one teacher taught a treatment class and the other taught a control class. Some classes at Eagle High School were period specific, such as Band and was only taught fourth period. To decrease the effect of which period Algebra I was taught, classes were selected so that there was at least one treatment class and one control class each period.

\begin{tabular}{|c|c|c|c|c|}
\hline period & Control & Treatment & & Options \\
\hline 1 & & & & Beta*, Epsilon, Zeta \\
\hline 2 & & & & Alpha, Epsilon, Gamma \\
\hline 3 & & & & Alpha, Gamma \\
\hline 4 & & & & Delta*, Zeta \\
\hline
\end{tabular}

*indicates a teacher with only one class

Figure 1. Assignment of treatment chart. This chart was used to assign treatment with the use of a coin flip.

Teacher Delta taught only one class during fourth block. Since only two teachers taught in the fourth period block, Teacher Delta's assignment was determined based upon Teacher Zeta. So if Teacher Zeta had treatment, then teacher Delta had control and vice versa. Accordingly, since Teacher Delta and Teacher Beta were the only two teachers teaching one class, one was assigned as treatment and the other was control. A coin was flipped to determine which class was treatment and which class was control.

The first flip was for Teacher Alpha's first class of the day, which was second period. Teacher Alpha's second period class was control. This then made Teacher Alpha's other class, third period, a treatment class. Since Teacher Alpha's third period class was a treatment class; then Teacher Gamma's third period class became a control class. The second flip of the coin was for Teacher Beta's only class. Flip two was heads; 
therefore Beta's only class was a control class. Since Teacher Beta's only class was a control class, to keep the classes balanced, Teacher Delta's only class was a treatment class. Because Delta's class was a treatment class, this forced Teacher Zeta's second class to be a control class and Zeta's first class to be a treatment class. The third flip of the coin was for Teacher Epsilon's first period class. Flip three was heads; therefore, Teacher Epsilon's first period class was control. This made Teacher Epsilon's second period class a treatment class. Final assignment of treatment based upon the three coin flips can be seen within Figure 2 .

\begin{tabular}{|c|c|c|c|c|}
\hline period & Control & Treatment & options \\
\hline 1 & Epsilon, Beta & Zeta & & Beta*, Epsilon, Zeta \\
\hline 2 & Alpha & Epsilon, Gamma & & Alpha, Epsilon, Gamma \\
\hline 3 & Gamma & Alpha & & Alpha, Gamma \\
\hline 4 & Zeta & Delta & Delta*, Zeta \\
\hline \multicolumn{4}{|c|}{ *indicates a teacher with only one class }
\end{tabular}

Figure 2. Final treatment assignment. Displays each teacher by period and their assignment to either treatment or control.

This design not only established control and treatment classes for each teacher, but also for each period. This balanced random assignment design provided an equal number (five) of control classes and treatment classes. This selection also allowed half of the teachers to teach their treatment class first, while the other half of the teachers taught their control class first. While Teacher Beta and Teacher Zeta did not have a second class of Algebra I, their inclusion in this study provided balance to the schedule, class selection, and treatment/control selection.

\section{Demographics}

Eagle High School is located in Eagle County, which has a population of around 90,000 and a mean age in the middle $30 \mathrm{~s}$, and is located within a southern state. There 
are over 10,000 households in Eagle County with children under 18 years of age. The population of Eagle County is $93 \%$ Caucasian, $4 \%$ African-American, and 3\% other minorities. Approximately $16 \%$ of the population age 25 and over hold a bachelor's degree or higher. The median family income is around $\$ 45,000$. Approximately $14 \%$ of families in Eagle County are living below poverty level.

Eagle High School serves approximately 1,607 students. There are currently 339 seniors, 409 juniors, 408 sophomores, and 451 freshmen. The school population is $53 \%$ male, $47 \%$ female, $95 \%$ white, and $5 \%$ minority. Approximately $10 \%$ of the students receive special services. Roughly $1 \%$ of students are considered English language learners. Approximately $46 \%$ of the students at Eagle High School receive free and reduced lunch and fee waivers through the Federal Lunch Program and local funds. Most of the parents/guardians are rural blue collar workers. The current unemployment rate for Eagle County is approximately $12.7 \%$.

Eagle High School has a staff that includes 126 teachers, 5 secretaries, 18 cafeteria workers, 8 custodians, 10 teacher assistants, 2 bookkeepers, a school nurse, a school guard, a school resource officer, 1 principal, 3 assistant principals, and 4 counselors. The faculty is approximately $55 \%$ female, $45 \%$ male; $96 \%$ white, $3 \%$ African-American, and 1\% Hispanic. Approximately $47 \%$ of the faculty members have attained a master's degree or higher. Faculty members at Eagle High School have an average of nine years of teaching experience.

All students at Eagle High School are required to take the ACT exam. Results are shown in Table 1. While not all students at Eagle High School are required to take the SAT exam, those that do still have the scores reported back as shown in Table 2. In 
2006-2007, Eagle High School implemented a requirement of their 10th graders. All $10^{\text {th }}$ graders were required to take the PLAN test which was to be given at the school on a set testing date. The PLAN test is an indicator of the score students may expect to make on the ACT test. At Eagle High School, 364 out of 408 (or $89 \%$ ) $10^{\text {th }}$ graders took the PLAN test, which resulted in an average composite score of 15.7. The national average for the composite score is 17.5 on the PLAN test

Table 1

ACT Composite Averages

\begin{tabular}{cccccc}
\hline & $2003-2004$ & $2004-2005$ & $2005-2006$ & $2006-2007$ & $2007-2008$ \\
\hline Eagle High & 19.7 & 18.8 & 19.9 & 19.9 & 20.0 \\
State & 20.5 & 20.5 & 20.7 & 20.7 & 20.7 \\
National & 20.9 & 20.9 & 21.1 & 21.2 & 21.1 \\
\hline
\end{tabular}

Table 2

Eagle High School SAT Averages

\begin{tabular}{ccccc}
\hline & $2004-2005$ & $2005-2006$ & $2006-2007$ & $2007-2008$ \\
\hline Verbal & 544 & 583 & 560 & 597 \\
Mathematics & 520 & 571 & 608 & 607 \\
Composite & 1064 & 1154 & 1168 & 1204 \\
\hline
\end{tabular}

Since the passing of No Child Left Behind (NCLB), each state created statewide test in mathematics, English and science. Eagle High School has always been at or above 
target for its mathematics scores. The passing rates for Eagle High School are listed in Table 3 .

Table 3

Eagle High School Algebra I Gateway

\begin{tabular}{cc}
\hline Year & Passing \\
\hline $2005-2006$ & $83 \%$ \\
$2006-2007$ & $92 \%$ \\
$2007-2008$ & $86 \%$ \\
\hline
\end{tabular}

Thurlow, Sinclair, and Johnson (2002) defined the event dropout rate as the number of students who drops out in a single school year without completing high school. The state goal for the event dropout rate is $5 \%$ or less. Thurlow, Sinclair, and Johnson (2002) defined the cohort dropout rate as the number of students who drops out from a set group or cohort over a period of time. The state goal for the cohort dropout rate is $10 \%$ or less. The state goal for the graduation rate is $90 \%$. Dropout and graduation rates for Eagle High School are noted in Table 4.

Table 4

Eagle High School Dropout and Graduation Rates

\begin{tabular}{cccc}
\hline Year & Event Dropout Rate & Cohort Dropout Rate & Graduation Rate \\
\hline $2005-2006$ & $1.4 \%$ & 9.7 & $69.8 \%$ \\
$2006-2007$ & $0.36 \%$ & 6.7 & $79.2 \%$ \\
$2007-2008$ & $.4 \%$ & 4.6 & $79.2 \%$ \\
\hline
\end{tabular}




\section{INSTRUMENTS}

The instruments used to measure instructional effects on student achievement were the Kentucky High School Diagnostic Mathematics Assessment Tool for Algebra I and two questions from the textbook's standardized test from the specific chapter that dealt with function concepts Chapter 4. Kentucky developed diagnostic Mathematics Assessment Tools for Algebra I, Geometry, and Algebra II. The Kentucky High School Diagnostic Mathematics Assessment for each course is divided into content clusters. These content clusters represent the key mathematics standards within a given course. In Algebra I, cluster 3 addressed specifically function concepts and was used for this study.

The Kentucky High School Diagnostic Mathematics Assessments were developed for students in Algebra I, Geometry, and Algebra II courses. The development of these assessments began in the fall of 2004 by middle and high school teachers and university faculty members from both mathematics and mathematics education. The purpose of the assessments was (1) to inform teachers at important intervals as to whether students were ready for the next level of mathematics, (2) to inform teachers whether or not they were preparing students for the next level, and (3) to inform the students of how well they had learned the mathematics needed for the next level. Overall, the assessments allowed teachers to determine if high school students had mastered the necessary content within each course.

The Kentucky High School Diagnostic Mathematics Assessment for each course is divided into content clusters. These content clusters represent the key mathematics standards within the particular course. Specifically, the Kentucky High School Diagnostic Mathematics Assessment Tool for Algebra I is divided into five content 
clusters: One-Variable Expressions, Equations, and Inequalities; Properties of Lines and Graphing Lines; Linear Functions; Polynomial Expressions; and Systems of Equations. Three versions of each cluster are available allowing for a pre-test, post-test and a post post-test at Eagle High School.

The first cluster focused on a students' ability to solve and or graph on a number line one-variable equations and inequalities. This cluster also assessed absolute value, ratios, proportions, real number properties and equivalence relations to reason mathematically and solve real-world and mathematical problems. The second cluster focused on students' ability to graph on a coordinate plane and to use lines to solve realworld and mathematical problems. The third cluster focused on the students' ability to identify, model and use linear functions and arithmetic sequences to reason mathematically and to solve real-world problems. The fourth cluster focused on the students' ability to simplify, add, subtract, multiply, and factor polynomial expressions. This cluster also focused on the law of exponents when used to reason mathematically and solve real-world mathematical problems. The fifth cluster focused on students' ability to solve systems of equations by graphing, substitution or elimination while solving real-world and mathematical problems (Bush 2006).

\section{Content Validity}

Three strategies were used to establish the content validity for the Kentucky High School Diagnostic Mathematics Assessments. The first strategy involved development teams that created "power standards" that were aligned with the Kentucky Mathematics Core Content 4.1 (2006) and with the American Diploma Project Mathematics Benchmarks (2004). The development teams found or developed assessments that 
focused on the mathematics standards within the Core Content and Mathematics

Benchmarks. The second strategy was to have teams comprised of classroom teachers, mathematics educators, and mathematicians review the standards and the items developed. The teams would gather, create or revise items and assessments, while members from other teams validated their work through constant internal reviews (Bush 2006).

Finally, during the fall of 2005,45 postsecondary mathematicians, mathematics educators, high school teachers, and middle school teachers participated in an all-day external review session. These 45 reviewers were divided into three equal groups to work on Algebra I, Geometry, or Algebra II. Each group was provided with large sets of items for review. For each item, reviewers were asked to determine the (1) mathematics content area in which the item belonged, (2) depth-of-knowledge level that the item measured, and (3) appropriateness and clarity of each item (Bush, 2006).

After the morning group had assessed the items and discussed their ratings, individual reviewers then analyzed the items independently. Items in which $80 \%$ of the reviewers agreed with regard to mathematics content, depth-of-knowledge level, and appropriateness were preserved for subsequent field testing of the assessments. Items that did not meet these criteria were either eliminated or revised. Any item that was revised then went through another review process by smaller groups of educators. Of the revised items, those that met the $80 \%$ criteria were retained (Bush, 2006).

Using power strands, the Kentucky High School Diagnostic Mathematics Assessment directly aligned with both Core Content and Mathematics Benchmarks. Utilizing constant review, the standards and items contained within the Kentucky High 
School Diagnostic Mathematics Assessment have repeatedly been validated. In addition, individual reviewers were used, allowing for each item to be individually tested in regard to content, Depth of Knowledge, and appropriateness. Through the rigorous process of creating and developing the Kentucky High School Diagnostic Mathematics Assessment, the assessment has been deemed to have both internal and external validity.

To ensure that the Kentucky High School Diagnostic Mathematics Assessment covered the same material that was covered during the treatment, a content validity analysis of the test was completed (Bush, 2006). The content validity analysis compared the items on the Kentucky High School Diagnostic Mathematics Assessment, Cluster 3, the topics covered in the chapter dealing with function concepts, Chapter 4 , in the Algebra I textbook, and the standardized test produced by the Algebra I textbook
publisher for the chapter dealing with function concepts, Chapter 4. In addition to
comparing concepts, the Depth of Knowledge (Webb, 2006) was also examined. Below
are the results of the content validity analysis. 
Table 5

Results of Content Validity Analysis

\begin{tabular}{|c|c|c|c|c|c|c|}
\hline \multirow[b]{2}{*}{ Item \# } & \multicolumn{2}{|l|}{ KY Cluster 3} & \multicolumn{2}{|c|}{ Ch 4 in book } & \multicolumn{2}{|c|}{$\begin{array}{c}\text { End of } \\
\text { Chapter } 4 \text { Exam }\end{array}$} \\
\hline & Content & DOK & Content & DOK & Content & DOK \\
\hline $\begin{array}{c}\mathrm{Ky} \# \\
1\end{array}$ & $\begin{array}{l}\text { Determining which is a } \\
\text { function with mapping, table, } \\
\text { ordered pairs, \& graph }\end{array}$ & 2 & $100 \%$ & $1,2, \& 3$ & $100 \%$ & $2 \& 3$ \\
\hline $\begin{array}{c}\text { Ky \# } \\
2\end{array}$ & Evaluating a function & 2 & $100 \%$ & $2 \& 3$ & $100 \%$ & $2 \& 3$ \\
\hline $\begin{array}{c}\text { Ky \# } \\
3\end{array}$ & $\begin{array}{c}\text { Domain / range of a function } \\
\text { given a graph }\end{array}$ & 2 & $100 \%$ & $1,2, \& 3$ & $0 \%$ & $\mathrm{n} / \mathrm{a}$ \\
\hline $\begin{array}{c}\text { Ky \# } \\
4\end{array}$ & $\begin{array}{c}\text { Evaluating a function using a } \\
\text { table }\end{array}$ & 3 & $100 \%$ & 2 & $0 \%$ & $\mathrm{n} / \mathrm{a}$ \\
\hline $\begin{array}{c}\text { Ky \# } \\
5\end{array}$ & Arithmetic sequence & 2 & $100 \%$ & $1,2, \& 3$ & $100 \%$ & 2 \\
\hline $\begin{array}{c}\text { Ky \# } \\
6\end{array}$ & Definition of a function & 2 & $100 \%$ & $1,2, \& 3$ & $100 \%$ & 1 \\
\hline $\begin{array}{c}\text { Ky \# } \\
7\end{array}$ & $\begin{array}{c}\text { Domain / range of a function } \\
\text { using an equation }\end{array}$ & $2-3$ & $100 \%$ & $1,2, \& 3$ & $50 \%$ & $1 \& 2$ \\
\hline $\begin{array}{c}\text { Ky \# } \\
8\end{array}$ & $\begin{array}{l}\text { Choosing function of best fit to } \\
\text { a real life problem using a table }\end{array}$ & 3 & $100 \%$ & $2 \& 3$ & $100 \%$ & $1 \& 2$ \\
\hline $\begin{array}{c}\text { Ky \# } \\
9\end{array}$ & $\begin{array}{l}\text { Develop a table, write a } \\
\text { function, \& solve a real life } \\
\text { problem using functions }\end{array}$ & $3-4$ & $100 \%$ & $2,3, \& 4$ & $50 \%$ & $1 \& 2$ \\
\hline $\begin{array}{c}\mathrm{Ky} \# \\
10\end{array}$ & $\begin{array}{l}\text { Apply concept of functions to } \\
\text { solve real life problem using a } \\
\text { table, creating an equation, and } \\
\text { predictions }\end{array}$ & $3-4$ & $100 \%$ & $2,3 \& 4$ & $30 \%$ & $1 \& 2$ \\
\hline $\mathrm{n} / \mathrm{a}$ & $\begin{array}{c}\text { Coordinate plane, quadrants } \& \\
\text { ordered pair }\end{array}$ & 0 & $100 \%$ & $1,2, \& 3$ & $100 \%$ & $1,2, \& 3$ \\
\hline $\mathrm{n} / \mathrm{a}$ & $\begin{array}{l}\text { Geometric transformations on } \\
\text { the coordinate plane }\end{array}$ & 0 & $100 \%$ & $1,2 \& 3$ & $100 \%$ & $1,2, \& 3$ \\
\hline $\mathrm{n} / \mathrm{a}$ & Graphing linear equations & 0 & $100 \%$ & $1 \& 2$ & 0 & $\mathrm{n} / \mathrm{a}$ \\
\hline
\end{tabular}


The content validity assessment found the items on the Kentucky High School Diagnostic Mathematics Assessment to be fully covered within Chapter 4, and the standardized Chapter 4 textbook exam. To adjust for the test items that were covered within the Algebra 1 textbook addressing function concepts, Chapter 4, but were not on the Kentucky High School Diagnostic Mathematics Assessment, three items from the Chapter 4 standardized test were also included on the pre-test, post-test, and the post post-test. Content validity and reliability (Cronbach Alpha) for the tests, including the additional three questions was unavailable student by item data were not provided to the researcher.

\section{Internal Reliability}

During the spring of 2006, the Kentucky High School Diagnostic Mathematics Assessment developed three versions of clusters within Algebra I, Geometry, and Algebra II that were field-tested in middle and high schools in the five participating school districts (Bush, 2006). In all, 2,255 students completed two versions of mathematics clusters in the Algebra I assessments. These field test results were used to determine the internal reliability of clusters and the assessments overall. Table 6 reports the internal consistency reliability coefficients for the three versions of each cluster for the Algebra I assessment, as well as the overall internal reliability of each individual version of the assessments. The internal consistency reliability coefficient for the Algebra I assessment ranged from 0.48 to 0.78 . For comparison purposes, the reliability results for the Kentucky High School Diagnostic Mathematics Assessment for Algebra II are shown in Table 7, and for the Kentucky High School Diagnostic Mathematics Assessment for Geometry are shown in Table 8. The internal consistency reliability 
coefficient for the Algebra II assessment ranged from 0.33 to 0.75 . The internal consistency reliability coefficient for the geometry assessment ranged from 0.05 to 0.59 (Bush, 2006).

The internal reliability coefficients for the whole assessments were computed using the Spearman-Brown formula for determining the overall reliability of assessments based on the reliabilities of subtests. Specifically, Cluster 3, which dealt with functions and was used for this study, had an average reliability of 0.51 . The reliabilities for the three complete versions of the Algebra I assessment were quite high, with an average of 0.90 (Bush, 2006).

Table 6

Internal Reliabilities for Algebra I Clusters and Complete Assessment

\begin{tabular}{ccccccc}
\hline Version & Cluster 1 & Cluster 2 & Cluster 3 & Cluster 4 & Cluster 5 & Total \\
\hline 1 & 0.78 & 0.61 & 0.48 & 0.52 & 0.65 & 0.89 \\
2 & 0.73 & 0.65 & 0.50 & 0.60 & 0.73 & 0.90 \\
3 & 0.69 & 0.70 & 0.55 & 0.62 & 0.64 & 0.90 \\
\hline
\end{tabular}

Table 7

Internal Reliabilities for Geometry Clusters and Complete Assessment

\begin{tabular}{ccccccccc}
\hline \multirow{2}{*}{ Version } & Cluster & Cluster & Cluster & Cluster & Cluster & Cluster & Cluster & \multirow{2}{*}{ Total } \\
& 1 & 2 & 3 & 4 & 5 & 6 & 7 & \\
\hline 1 & 0.65 & 0.52 & 0.75 & 0.50 & 0.77 & 0.61 & 0.44 & 0.91 \\
2 & 0.62 & 0.59 & 0.63 & 0.49 & 0.76 & 0.64 & 0.58 & 0.92 \\
3 & 0.60 & 0.52 & 0.72 & 0.33 & 0.58 & 0.66 & 0.36 & 0.89 \\
\hline
\end{tabular}


Table 8

Internal Reliabilities for Algebra II Clusters and Complete Assessment

\begin{tabular}{cccccccc}
\hline Version & Cluster & Cluster & Cluster & Cluster & Cluster & Cluster & Total \\
& 1 & 2 & 3 & 4 & 5 & 6 & \\
\hline 1 & 0.58 & 0.43 & 0.14 & 0.40 & 0.28 & 0.22 & 0.76 \\
2 & 0.58 & 0.55 & 0.40 & 0.49 & 0.59 & 0.05 & 0.83 \\
3 & 0.58 & 0.21 & 0.18 & 0.59 & 0.20 & 0.04 & 0.72 \\
\hline
\end{tabular}

Through student testing, the Kentucky High School Diagnostic Mathematics Assessment had been tested for internal reliability. Within each test and each cluster, the internal consistency reliability coefficients obtained suggested that the students were fairly consistent in their responses. Cluster 3 was used for this study because it dealt specifically with functions. In this cluster, students determined the domain and range of linear functions, identified linear functions from graphs, equations and tables, and modeled functions using coordinate pairs, graphs, mapping and algebraic functions. Although Cluster 3 had the lowest overall internal reliability within the Kentucky High School Diagnostic Mathematics Assessment for Algebra I, the overall average for every cluster within the three tests was 0.52 . Furthermore, the internal consistency reliability coefficients of each individual version of the Kentucky High School Diagnostic Mathematics Assessment for Algebra I was more consistent than the Assessments for Algebra II and Geometry. The Kentucky High School Diagnostic Mathematics Assessment for Algebra I had an overall internal reliability rating of 0.90 .

\section{PROFESSIONAL DEVELOPMENT}

Because the TI-Nspire was new technology, all teachers needed professional development to be able to use and teach with it. There were three opportunities for teachers to receive professional development training on the use of the TI-Nspire. The 
first opportunity was a summer session led by a National Texas Instruments (TI) Instructor who was assisted by six Texas Instruments Trained Cadre members from around the region. A Texas Instrument Trained Cadre member is an active classroom mathematics teacher who has received training on the TI-Nspire, has a class set of TINspire calculators, and regularly provides professional development training to other mathematics teachers. The other two professional development opportunities were the "Function Focused Session" and the "Weekly Touchdown Session," which was led by a Texas Instruments Trained Cadre member from an adjacent county.

During the summer prior to this study, all teachers attended the 12 hours of training over the course of two days in which they were trained to use the TI-Nspire graphing calculator. Teachers were then given a TI-Nspire, TI-Nspire emulator, and access to online Atomic Learning video training (Atomic Learning, 2011) to continue their exploration of the TI-Nspire. The week prior to the study, the teachers attended the Function Focused Session, which was six hours long and provided review on the TINspire, specific training about teaching the function concept with the TI-Nspire, and time to create lesson plans and activities for this study. During the two weeks of treatment and the two weeks of follow up, teachers met once a week for the Weekly Touchdown Session, a 90 minute meeting after school, to complete a weekly questionnaire, turn in lesson plans, assessments, and receive further professional development on the TI-Nspire.

Sustained professional development was central to training the teachers on how to use the TI-Nspire and for providing continual support as teachers implemented the new technology while teaching function concepts. All professional development sessions were taught by Texas Instruments Trained Instructors providing fidelity in treatment 
implementation. At every professional development session, Texas Instruments Trained Instructors gave instruction and review on the TI-Nspire, answered questions, and provided direction for the teachers' next steps. During the Weekly Touchdown Sessions, the Texas Instruments Trained Cadre member worked with teacher issues with the TINspire as well as provided specific function content activities and examples to prepare teachers for the next week of instruction. This set of professional development opportunities provided vital strategies necessary for teachers to use this new technology tool and to assure fidelity implementation of the treatment and to maintain the consistency of the control group instruction..

\section{TREATMENT}

In the fall of 2009, the first-year algebra classes (Algebra I) for ninth grade at Eagle High School was selected to be either treatment or control. Treatment was defined as the use of the TI-Nspire graphing calculator by a trained teacher while teaching the concept of functions with respect to representations, Depth of Knowledge, and TPACK. Prior to this study at Eagle High School, the only classroom set of calculators that teachers and students used in Algebra I classrooms were non-graphing scientific calculators.

Teachers in the treatment group taught the concept of functions using a TI-Nspire graphing calculator, and those in the control group taught the concept of functions without using the TI-Nspire at Eagle High School. While students in the control group were allowed to use any calculator, their teacher did not use the TI-Nspire graphing calculator as part of instruction. The control teachers taught using non-graphing scientific calculators. Neither the treatment group of students nor the control group of 
students were allowed to use a TI-Nspire graphing calculator on the pre-test, the post-test, or the post post-test. This requirement provided a more accurate picture of the students' true understanding of the function concept. All students were allowed to use a nongraphing scientific calculator on the pre-test, the post-test, or the post post-test as was normal protocol for typical Eagle High School Algebra I classes.

The topics covered within Algebra I were the same for both the treatment and control groups. In 2005, the Eagle High School mathematics department completed curriculum mapping which outlined the state standards to be taught within each of their classes, including the Algebra I curriculum. To ensure treatment fidelity, the researcher required teachers to complete a weekly questionnaire showing how often and to what extent they integrated representations and teaching tools into the classroom. Since all students in the ninth grade was taking Algebra I, every Algebra I class in the ninth grade was asked to participate in this study. Teachers assigned to teach Algebra I classes were contacted and asked to participate in this study.

Participating teachers all received the professional development described above and were asked to provide documents and scores from their class. The teachers participated in both the Function Focused Sessions and the Touchdown Sessions as described above. The class information collected included the current grade averages for each student, the number of absences of each student, and the pre-test, post-tests and post post-tests scores for the function cluster of the Kentucky High School Diagnostic Mathematics Assessment for Algebra I. The documents collected included daily lesson plans, handouts, quizzes, and tests. 
During the summer of 2009, mathematics teachers in the Aerie School District were provided the opportunity to receive professional development from Texas Instruments staff on the use of the TI-Nspire in the mathematics classroom. Teachers received this training in the month before school started. While all mathematics teachers at Eagle High School have had the opportunity to be trained on the use of the TI-Nspire, teachers in this study were provided also with further professional development and training about the specific topic of functions.

A "trained teacher" was defined as a mathematics teacher who had attended both the two-day training offered by Texas Instruments and Eagle High School as well as the Function Focused Sessions designed specifically for teachers teaching the first course of algebra to ninth grade students. The Function Focused Sessions took place one school week prior to the introduction of functions with the first-year of algebra. The sessions were taught by a Texas Instruments trained presenter.

Three Function Focused Sessions were provided. The first session reinforced the initial concepts and training learned at the initial two-day professional development offered in the summer by the high school and Texas Instruments. Teachers also were reminded also of how to use the five different types of representations (numeric, geometric, symbolic, writing and analytical) with the TI-Nspire. During this session, teachers also were able to ask other questions concerning the basic operations of the TINspire.

The second session of the Function Focused Sessions integrated the TI-Nspire with the classroom textbook. Teachers were trained on the specific topics within their current algebra textbook which was already designed for graphing calculator integration. 
Teachers using the same textbook worked in small groups, which allowed for collaboration among teachers. Each teacher took a turn directing a technology activity within the book. While one teacher taught, the other teachers took the role of student/observer. This strategy provided teachers an experience in answering questions while teaching an example. Selected examples of topics included the following:

- Coordinate plane

- Ordered pairs

- Defining a function

- Domain/range with a table

- Domain/range with a graph

- Domain/range with a equation

- Using tables to evaluate functions

- Graphing relation

- Graphing linear equations

After the second session, teachers engaged in group discussions which allowed them to process the information, collaborate about the inclusion of TI-Nspire, and reflect on teaching functions. Teachers discussed how their classroom would change with the use of the TI-Nspire. Teachers also collaborated concerning the use of TI-Nspire within their classrooms.

The third session provided training using extended applications and other resources. Teachers were given a copy of Getting Started: Calculator Software Apps and the TI Classroom Activities CD. Teachers then explored specific exercises from these resources that addressed with functions. Again, teachers collaborated on these activities. 
Teachers again took turns directing a technology activity. While one teacher was teaching, the other teachers served as students. This strategy provided teachers with experience in answering questions while teaching.

The concluding session was to expose teachers to the Texas Instruments website: http://education.ti.com. Teachers explored within the teacher exchange (http://education.ti.com/exchange) so that they could access activities, worksheets, and programs developed by Texas Instruments, as well as activities by other book companies, researchers, and teachers. This session concluded with instructions on how to sign up for weekly emails from Texas Instruments that include course relevant activities.

After completing the Function Focused Sessions, teachers had a portfolio of examples, worksheets, programs and activities specifically when dealing with functions to integrate within their classrooms. They also could independently continue to tap into these resources for the purpose of obtaining additional material for other topics. These materials may be used for many different purposes such as class starters, lectures, examples, reinforcement, or re-teaching.

In the four-week period (two weeks from pre-test to post-test and then an additional two weeks until the post post-test) the trained teachers had weekly review sessions in which they engaged in reflection, refreshing, and reviewing. At the beginning of each session, the teachers completed a reflection task by answering a questionnaire. The open-ended questionnaires were different for control and treatment classes. The treatment class questionnaire (Figure 3) asked questions specific to the TI-Nspire, while the control class questionnaire (Figure 4) asked about teaching tools in general. Teachers were provided a daily data (Appendix A) sheet to help them keep track of this weekly 
questionnaire information. Teachers also were advised that the daily data sheet should be

filled out either during or immediately after class to insure better accuracy.

\section{Treatment Class Questionnaire}

1. In what ways have you used representations to teach functions this week?

2. In what ways have you linked those representations while teaching functions this week?

3. Have you used the TI-Nspire this week to teach functions?

4. How often have you used the TI-Nspire this week?

5. What issues have you had with the TI-Nspire while teaching functions?

6. What goals do you have for students with respect to learning functions with the TI-Nspire?

7. What are some examples of what you have done teaching functions using the TINspire this week?

8. What have you been able to teach (better/more easily) using the TI-Nspire than using other tools?

Figure 3. Treatment Class Questionnaire. A list of open-ended questions given to treatment class teachers to fill out weekly.

\section{Control Class Questionnaire}

1. In what ways have you used representations to teach functions this week?

2. In what ways have you linked those representations while teaching functions this week?

3. What teaching tools have you used this week to teach functions?

4. How often have you used these tools to teach functions this week?

Name of tool

Name of tool

How often

Name of tool How often How often

5. What issues have you had with using these teaching tools while teaching functions?

6. What goals do you have for students with respect to learning functions?

7. What are some examples of what you have done teaching functions using the teaching tools described above this week?

8. What have you been able to teach (better/more easily) using the above mentioned teaching tools than using other tools?

Figure 4. Control Class Questionnaire. A list of open-ended questions given to control class teachers to fill out weekly.

After the reflections were completed, any questions the teachers had regarding the

TI-Nspire were answered by the TI Cadre Member. The TI Cadre Member then 
reviewed the TI-Nspire for the topics that were to be covered in the coming week. The goal of the Touchdown session was to gather data regarding the implementation of the TI-Nspire within the classroom as well as to provide teachers with additional support. During the two-week period there was also a classroom observation where the researcher observed the teacher to provide triangulation and validity to the weekly questionnaires.

Teachers received professional development or in-service credit for attending both the Function Focused Sessions and the Touchdown Sessions. All teachers at Eagle High School must participate in at least 12 hours of professional development or inservice training each year. Permission had been given by Eagle High School administration to allow this training to count towards this required professional development and in-service training.

Teachers in control classes at Eagle High School were expected to follow their normal course of teaching, which included the use of non-graphing scientific calculators, but not the TI-Nspire graphing calculators. Students within a normal course of Algebra I at Eagle High School are allowed to use any calculator that they choose; which may include a TI-Nspire graphing calculator.

Teachers who had the treatment classes at Eagle High School were provided with additional activities during the professional development activities by the TI Cadre Members to use in conjunction with the TI-Nspire. These activities were used with students as homework, reinforcement, or re-teaching. Teachers also used the sections within the Algebra I textbook that made use of graphing calculators. The current textbook that is being used at Eagle High school is Algebra I (Holliday et al., 2005). Within this textbook were examples and lessons that were designed to be used with the TI-Nspire 
graphing calculator. Glencoe/McGraw-Hill also provided online links for additional assistance with graphing calculators.

All six teachers who were teaching Algebra I to ninth graders in the fall of 2009 participated in this study. Teacher educational background information is explained within Table 9. Eagle High School requires that all students in Algebra I take pre-tests, post-tests, and post post-test throughout the semester. For the purpose of this study, the scores from all ninth graders taking the pre-test before studying functions, as well as a post-test two weeks after the pre-test, and a post post-test four weeks after taking the pretest were analyzed.

Table 9

Teachers Educational Background

\begin{tabular}{|c|c|c|c|c|}
\hline Name & Education & Certification & $\begin{array}{c}\text { Years } \\
\text { Teaching }\end{array}$ & $\begin{array}{l}\text { Years at } \\
\text { Eagle }\end{array}$ \\
\hline Alpha & $\begin{array}{l}\text { Bachelor - Mathematics } \\
\text { Masters - Secondary Ed }\end{array}$ & Mathematics 7-12 & 4 years & 4 years \\
\hline Beta & Bachelor - Mathematics & Mathematics 7-12 & 4 years & 4 years \\
\hline Delta & Bachelor - Mathematics Ed & Mathematics 7-12 & 1 year & 1 year \\
\hline Gamma & Bachelor - Education & $\begin{array}{c}\text { Elementary K-8 } \\
\text { Mathematics 7-12 } \\
\text { Science 5-8 }\end{array}$ & 7 years & 4 years \\
\hline Epsilon & $\begin{array}{l}\text { Bachelor - Elementary Ed } \\
\text { Bachelor - Mathematics Ed } \\
\text { Masters - Mathematics Ed }\end{array}$ & Mathematics 7-12 & 4 years & 4 years \\
\hline Zeta & $\begin{array}{l}\text { Bachelor - Business Management } \\
\text { Masters - Business Administration }\end{array}$ & $\begin{array}{c}\text { Mathematics 7-12 } \\
\text { Business }\end{array}$ & 2 years & 1 year \\
\hline
\end{tabular}




\section{DATA COLLECTION PROCEDURES}

Following the approval of the IRB Committee at the University of Louisville, the researcher collected data from the teachers. These teachers taught the first year of algebra course at the high school level. Each class was assigned a two letter prefix. The first letter was $\mathrm{T}$ for treatment or $\mathrm{N}$ for control. Teacher Alpha had a second letter prefix of A. Teacher Beta had a second letter prefix of B. Teacher Gamma had a second letter prefix of G. Teacher Delta had a second letter prefix of D. Teacher Epsilon had a second letter prefix of E. Teacher Zeta had a second letter prefix of O. Each teacher then arranged the class rosters alphabetically and assigned the students a number. Sample identifiers included TD05, which stood for the fifth student on the alphabetical roll who was in Teacher Delta's treatment class.

Within this southern state, students take a state mathematics test in the eighth grade. Within the Aerie District, students in the eighth grade also take the Explore Exam, which is a precursor to the PLAN test and the ACT. The researcher secured each student's eighth grade state mathematics score and Explorer Exam from the guidance department at Eagle High School. The student's current grade in the Algebra I class also was obtained from the Algebra I teacher.

Teachers at Eagle High School also used the Kentucky High School Diagnostic Mathematics Assessment for Algebra I, Algebra II, and Geometry. For the purpose of this study, the researcher obtained the Algebra I, Cluster 3 exam scores from each class. Since three versions of each test existed, a different version was used for the pre-test, post-test, and post post-test and recorded by the teacher. A Microsoft Office Excel spreadsheet was utilized to track each student by their pre-assigned identifier. The 
spreadsheet included the identifier, pre-test scores, post-test scores, post post-test scores, and whether or not they were in the treatment or control group. Included within this spreadsheet was the information gathered from the guidance department regarding the eighth-grade state mathematics test, the Explore test, gender, and socioeconomic status, as well as GPA, and current class averages as gathered from the classroom teacher. This spreadsheet was on a secure computer and was password protected.

Teachers were asked to keep a manila folder for each class in the study. Inside each folder, teachers placed copies of daily lesson plans, handouts, starters, worksheets, quizzes, and tests for each individual class. Teachers with two classes were given two folders; each folder was labeled with the appropriate class period to ensure that treatment and control class materials were correctly identified. Each teacher was asked to turn the folders in at the Weekly Touchdown Sessions with their Weekly Questionnaire.

The researcher also conducted classroom observations of each teacher once during the two-week treatment period. For teachers who taught both a treatment and a control class, the researcher observed both classes on the same day, so that the same lesson could be compared. The researcher used a classroom observation form, Appendix B, which included teacher name, class type (treatment/control), the class period, date, observation start time, observation end time, and a place to record activity information. For each activity, the time, content area, type of representations, Depth of Knowledge, Technological Pedagogical Content Knowledge (TPACK) level, and how the activity was completed was all recorded within the classroom observation form. 


\section{DATA ANALYSIS PROCEDURES}

Data collected were analyzed using the Concurrent Mixed Analysis:

Simultaneous Analysis of Qualitative and Quantitative data (Tashakkori \& Teddlie, 1998). For the quantitative portion, Repeated Measures with ANOVA was used to analyze the effect of the independent variable on mathematic achievement based on pretest, post-test, and post post-test scores. Additional analyses were done to see if gender, socioeconomic status, eighth grade Explorer Exam scores, class absences or class averages made a statistically significant difference on pre-test scores or on post-test scores. A confidence level of $95 \%(p<0.05)$ was used to determine if statistical significance existed. Gigerenzer (2004) stated that a $p$-level of $p<0.05, p<0.01$, or $p<0.001$ be used depending on which is the next in reference to the obtained $p$-level.

While teachers reported through the Weekly Touchdown Questionnaire, the classroom observation of the teacher served as a way to triangulate the actual implementation of the representations and teaching tools used while teaching function concepts. Document analyses of daily lesson plans and handouts of treatment and control classes were analyzed to determine the effect of the independent variable on the dependent variable on teacher planning. Document analyses of bell ringers, quizzes, and tests of treatment and control classes were analyzed to determine the effect of the independent variable on the dependent variable of student assessment.

\section{SUMMARY}

This study sought to examine the effects of student achievement, teacher planning, teacher teaching and assessments used within the first year of algebra when trained teachers use a TI-Nspire graphing calculator as an instructional tool to teach 
function concepts. With the weekly Touchdown Sessions, teachers reported how often and to what extent they integrated representations and teaching tools into the classroom. Using the three versions of Kentucky High School Diagnostic Mathematics Assessment for Algebra I, Cluster 3, the students' understanding of and application of functions were measured by comparing pre-test results with post-test and post post-test results.

In seeking to discover the statistically significant difference in students' test scores in Algebra I classes that integrated TI-Nspire graphing calculators versus those that did not, teachers were trained on how to use the TI-Nspire graphing calculator, were shown examples of problems dealing with functions, and were given sample worksheets and handouts for their classes. To determine the effect of the independent variable on the dependent variable of how teachers taught, the researcher administered questionnaires and conducted observations. To determine the effect of the independent variable on the dependent variable of how teachers planned their lessons, document analysis were used. Document analysis was also used to determine the effect of the independent variable on the dependent variable of how teachers assessed students.

Treatment classes were taught specifically with the TI-Inspire graphing calculators. Control classes were not taught with the TI-Nspire graphing calculator. Control classes continued with the current school method of instruction using only a nongraphing scientific calculator to teach Algebra I.

This study specifically looked at the third of five clusters within the Kentucky High School Diagnostic Mathematics Assessment for Algebra I. The Kentucky High School Diagnostic Mathematics Assessment for Algebra I came with three versions, perfect for a pre-test, post-test, post post-test study. A pre-test (version 1) provided a 
baseline for all students. A post-test (version 2) was given two weeks after the pre-test. A post post-test (version 3) was given two weeks after the post-test. This study was completed in four weeks.

The Repeated Measures with AVOVA was used with the pre-test, post-test and post post-test scores to determine if a statistically significant difference in students' understanding of functions in Algebra I classes that integrate the TI-Nspire graphing calculators versus those that do not integrate the TI-Nspire graphing calculators existed. Other factors such as attendance, previous state mathematics test scores, and current class average were used also to determine if they had any statistical significance as well.

This chapter provided a description of the methods that were used to describe the effect of the independent variable on the dependent variable of student understanding, teacher planning, teacher teaching, and assessments used within the first year of algebra when teachers used the TI-Nspire graphing calculator as an instructional tool while studying functions. The next chapter details the results and describes the major findings in the study. 


\section{CHAPTER 4}

\section{RESULTS}

\section{INTRODUCTION}

The purpose of this study was to investigate the effect of the independent variable (a teaching strategy using the TI-Nspire) on the dependent variable of student achievement measured by pre-, post- and post post-tests using the Kentucky High School Diagnostic Mathematics Assessment. This study also examined the effect of the independent variable on teacher planning, teacher teaching, and assessments that teachers used.

The independent variable, teaching strategy, was implemented in the first year of algebra with teachers using the TI-Nspire graphing calculator as an instructional tool to teach function concepts. The effects on student achievement were determined by measuring students' understanding of functions through comparisons of pre-test and posttest results as displayed in Figure 5. $R$ is the random assignment of classes, $O_{1}$ is the pretest, $\mathrm{X}$ is the treatment, $\mathrm{O}_{2}$ is the post-test and $\mathrm{O}_{3}$ is the post post-test. Student achievement was measured using a pre-test, post-test, and a post post-test using Repeated Measures with ANOVA. The effects of how teachers teach, plan, and assess students while teaching function concepts were measured by document analysis. 


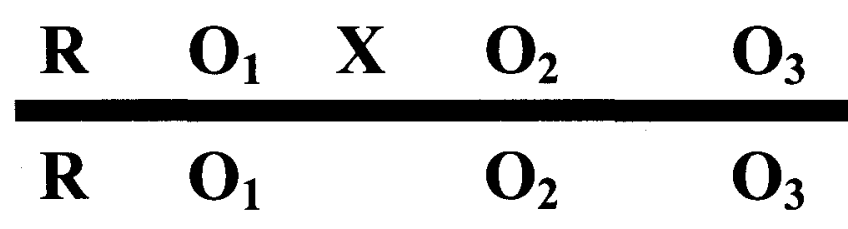

Figure 5: Quasi-experimental design. Quasi-experimental design using control groups with a pre-test, post-test, and post post-test.

All algebra teachers at Eagle High school attended a two-day workshop taught by a $\mathrm{T}^{3}$ National Instructor (Texas Instruments). The $\mathrm{T}^{3}$ instructor was assisted by five TI Cadre members providing one-on-one assistance when needed. The workshop taught the teachers how to use the TI-Nspire. All teachers were provided with a copy of the TINspire emulator to load onto their computers as well as a TI-Nspire calculator. Teachers were asked to become familiar with the calculator, emulator and to complete the online tutorials offered by Atomic Learning for TI-Nspire Handhelds and Atomic Learning for TI-Nspire Computer Software (Atomic Learning, 2011).

Two weeks prior to the implementation of the study, all teachers attended a six hour Function Focused Session, which was taught by a Texas Instruments Cadre member (a Texas Instruments representative). The Function Focused Session began with a review of how to use the TI-Nspire and allowed for any questions that teachers had regarding the calculator or the emulator. The Cadre member then provided the teachers with resources, activities, and instruction on ways to use the TI-Nspire to teach the function concept. For example, the Cadre member provided the teachers with the "Intro to Functions" Activity and demonstrated how to use the Texas Instruments website to access additional materials. "Intro to Functions" is a beginner level activity designed to teach students how to identify graphs of functions while using equations, tables and graphs. The session ended with the teachers working on their first week of lesson plans using the TI-Nspire. 
This four-week data collection period began one week after the Function Focused Session. During the four-week period of this study (two weeks from pre-test to post-test and then an additional two weeks until the post post-test), the teachers had weekly review sessions in which they engaged in reflection, refreshing, and reviewing. These weekly review sessions began with the teachers completing a questionnaire. While completing the questionnaire, the same Texas Instruments Cadre member who had led the Function Focused Session, answered any questions or concerns that the teachers had from that week of instruction. The Cadre member then provided more resources and activities to assist the teachers in the next week's lesson.

The two algebra classes for each of the four teachers in the study were randomly assigned to treatment and control groups in a way that every teacher and every school period had a treatment and control class. This design not only allowed for control and treatment classes for each teacher, but also for each class period. This balanced random assignment design provided an equal number of control classes and treatment classes and this selection process resulted in half of the teachers teaching their treatment class first, while the other half of the teachers were teaching their control class first.

For the qualitative portion of the study, the researcher was an insider in that the researcher was a fellow staff member and knew the teachers (Patton, 2002). The researcher was an outsider in that the researcher worked within a different building and in a different department. While both an insider and an outsider, the researcher guarded against both positive and negative bias by giving full disclosure, using multiple data collection types and triangulation to support all results found. 
The students in these Algebra classes had not used graphing calculators before this treatment. All teachers taught Algebra I with a classroom set of Casio non-graphing scientific calculators. A scientific calculator can be used to perform mathematical calculators for scientific notation, logarithms, trigonometric functions, exponential functions. Some scientific calculators also have the capabilities to calculate complex numbers, fractions, statistics and unit conversions.

While some teachers had taught with a Casio graphing calculator before, none of the teachers had ever used a TI-Nspire calculator, much less taught with one. While graphing calculators allow students to use graphs, tables, and equations to represent functions, the TI-Nspire calculator has the ability to connect the different representations together within a single document. For example, when a table, equation, and a graph àre connected within the same TI-Nspire document, changing one aspect of the equation immediately changes the data within the table and on the graph.

During the first two weeks of the treatment, teachers used the TI-Nspire graphing calculator to teach function concepts in Chapter 4 of the Algebra I textbook (Holliday et al., 2005). During the final two-weeks of the treatment, teachers continued using the TINspire graphing calculator in their treatment classes, but the mathematics content was linear equations. Teachers in their control classes taught the same concepts as they did in their treatment classes, but did not use the TI-Nspire or any graphing calculator. The control classes used non-graphing scientific calculators that could perform basic math functions, trig calculations, and fractions.

The role of the researcher was to facilitate teacher training by Texas Instruments $\mathrm{T}^{3}$ National Presenter and Cadre Members. The researcher provided copies of all pre- 
tests, post-tests, post post-tests that were distributed to the students by the teachers, and the weekly questionnaires filled out by the teachers. The researcher set up the meeting room for the weekly touchdown meetings making sure that technology was available. While the teachers met with the Cadre Member for the weekly touchdown meeting, the researcher attended to some of the teacher's after school duties so that all participating teachers could attend. At the conclusion of the weekly touchdown meeting, the researcher would then gather questionnaires, lesson plans, assessments, and test scores provided by the teachers from the meeting room.

In addition to gathering weekly documents, the researcher also observed each class once during the first two weeks of the study. The role of the researcher was as a complete observer in that the researcher was not a participant but simply an observer (Creswell, 2009). She completed one observation session of 90 minutes during the second week of the study within each class using a classroom observation sheet (Appendix B) developed by the researcher.

Data were stored in a locked closet. The researcher categorized the data by tool, by teacher, and by treatment and control, analyzed the documents, and summarized the findings. The researcher then used different color highlighters to code the data based upon the key constructs developed from the literature. The researcher then cut out different highlighted data and placed them together for further analysis. Each construct was then sorted according to teacher and treatment so that comparisons could be made between each teacher's treatment and control class, among each teacher, among each type, and among all teachers and types. For example, all lesson plans were collected, sorted by teacher, and analyzed by key construct. The constructs of standards, objectives, 
instructional strategies, technology and assessments were each highlighted in a different color and then separated. The constructs were then analyzed comparing Teacher Alpha's treatment class to Teacher Alpha's control class. The constructs were then reorganized and analyzed comparing all treatment classes to all control classes. These findings were summarized for each tool according to treatment type within the individual teacher, among all treatment teachers, among all control teachers, and finally among all treatment and all control teachers. Each construct that was identified in one set of documents, such as lesson plans, was verified by analyzing other documents, such as assessments. The triangulation of constructs across documents contributed to the validity of these findings. The constructs were further verified by observations in the classrooms.

This study began when the first-year Algebra classes started chapter 4 in their textbooks which was on the study of functions. Treatment was defined as the use of the TI-Nspire by a trained teacher while teaching the function concept during a two-week period. Teachers had access to a classroom set of TI-Nspire calculators, the TI-Nspire emulator, and the Texas Instruments website. During the four weeks of this study, teachers kept a daily log about included notes about the use of technology, assessments, and lesson plans for both their treatment and control classes.

Each student was given a pre-test at the beginning of the treatment, a post-test two weeks later at the end of the treatment, and a post post-test two weeks after the end of the treatment. The tests were derived from the three versions of Kentucky High School Diagnostic Mathematics Assessment for Algebra I, Cluster 3, and three additional questions from the textbooks standardized test in the chapter on functions. These tests were used to measure the students' understanding and application of functions. Version 1 
was used as the pre-test, Version 2 was used as the post-test, and Version 3 was used as the post post-test. The reliability and validity of the tests were described in chapter 3 .

All test scores were entered into SPSS as well as students socioeconomic and special education status. Within SPSS, four different aspects of the first research question were analyzed to explain differences in student data. Research question la analyzed the mean scores for the pre-test, post-test, and post post-tests with type (treatment and control) as the categorical factors. Research question $1 \mathrm{~b}$, a one-way ANOVA, was conducted with the mean scores for the pre-test, post-test, and post posttest as dependent variables and teacher $($ Teacher $=$ Alpha, Epsilon, Gamma or Zeta) as the categorical factor. Research question 1c employed MANOVA with the three test scores as the dependent variables and both teacher and type as fixed factors. Research question $1 \mathrm{~d}$ added socioeconomic status and special education as fixed factors.

All classroom observations occurred during the first two weeks of the study. The researcher observed each teacher teaching their treatment and control classes the same day. During the classroom observations, the researcher used a classroom observation sheet (Appendix B) to document class activities. Figure 6 displays the design of the classroom observation. The categories included within the classroom observation sheet combined various aspects of the teaching process to triangulate the teachers' lesson plans, weekly teacher questionnaires, and concepts tested. The content category referred to the topics covered by the teacher as related to the thirteen items on the pre-test, post-test, and post post-test to verify that the content covered in class was also the content on the test. The types of representations category in figure 6 captured the various ways function representations were taught such as numeric, geometric, analytic, symbolic, written or 
other. The Depth of Knowledge category was used to code the use of higher order thinking as described by Webb (2006). The Technological Pedagogical Content Knowledge (TPACK) ranking category was used to describe levels at which each teacher integrated the technology in their instruction (Niess et al., 2009).



Figure 6: Observation Categories. Categories for analysis of activities observed during classroom observations.

For each activity, the observer noted the start time and charted the categories: content area, type(s) of representations, Depth of Knowledge, TPACK level, and how the activity was completed. The content area listed which items from the pre-test, post-test, and post post-test were addressed. Item 1 through Item 10 on the tests focused on functions. Item 11 through Item 13 focused on graphing. Different types of representations used were categorized as either numeric, geometric, symbolic, analytic, writing or other. The Depth of Knowledge level was recorded as 1 for recall, 2 for 
skill/concept, 3 for strategic thinking and 4 for extended thinking (Webb, 2006). TPACK ranking recorded a 1 for Recognizing, a 2 for Accepting, a 3 for Adapting, a 4 for Exploring, and a 5 for Advancing (Niess et al., 2009).

The observer coded each activity including class starters, sample exercises, worksheets, and textbook assignments. Each activity was treated as a different entry into the classroom observation sheet. Sample exercises were worked by the teacher for the entire class. Worksheets were handouts given by the teacher that contained additional exercises from the textbook for students to work independently. Textbook assignments were specific exercises assigned to students directly from the book. The researcher recorded the Depth of Knowledge for each activity as well as the number of representations used within each activity. An activity might have involved a combination of numeric, geometric, symbolic, analytic, and writing or other representation, each of these would have been coded as they occurred. Some activities received multiple codes.

Each teacher completed a weekly questionnaire for their treatment and their control classes. The questionnaire contained eight questions designed to triangulate both the classroom observations and lesson plans. Since each teacher had both a treatment and a control class, the questionnaire allowed each teacher the opportunity to examine and express the similarities and differences between each of the two classes. All questions on the questionnaire were open response, but teachers were allowed to make additional comments regarding the experiment.

The questions on the treatment questionnaire (Appendix C) addressed the use of the TI-Nspire, while the control questionnaire (Appendix D) addressed the use of other teaching tools. Both questionnaires contained similar components as shown in Figure 7. 
Items on the questionnaire inquired about representations, teaching tools, goals, issues, and benefits. When asking about the use of representations, teachers were asked to specify ways that the representations were used and how they were linked to teaching functions. When asking about the teaching tools, teachers identified which tools were used and how often the tools were used. Teachers were asked about specific goals with respect to how students were learning functions. Issues and benefits provided information regarding the teaching tools, goals, and treatment in general.

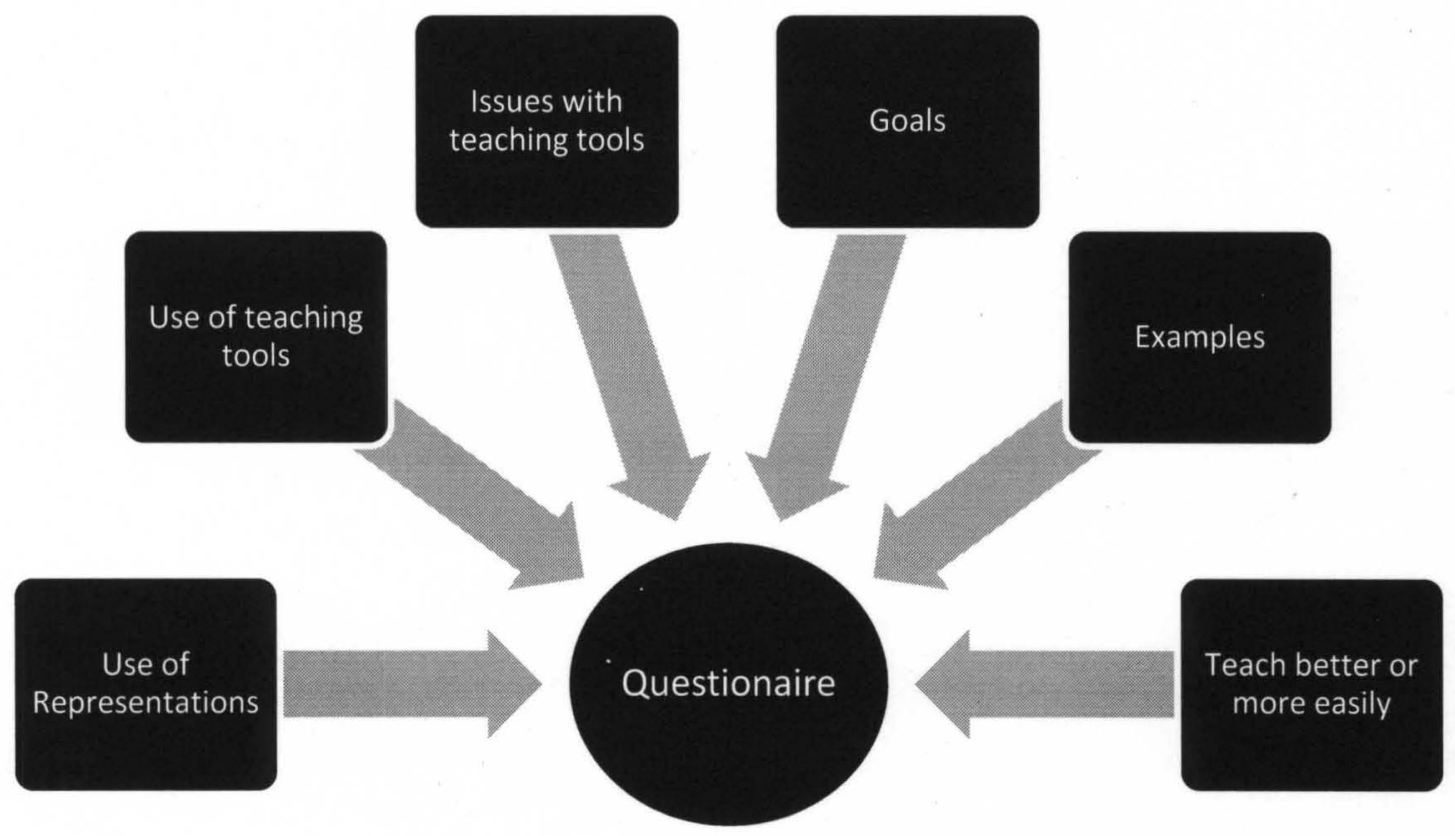

Figure 7: Questionnaire categories. Categories of the weekly teacher questionnaire.

Each teacher submitted all lesson plans and assessments for their control class and treatment class. The teacher lesson plans for each class included a list of state competencies, objectives, methods of instruction, materials used, technology used, learning style, instructional strategies and assessments for a given day. Teachers submitted copies of all assessments used during treatment and control classes. In 
comparing assessments, the researcher looked at starters, classroom work, homework, worksheets, quizzes, and tests.

\section{STUDENT OUTCOMES}

Research question 1 was addressed in this section. Is there a statistically significant difference in students test scores on function concepts in Algebra I classrooms that use the TI-Nspire graphing calculators versus those that do not use this device? In addressing the research question, the following null hypothesis was offered: No statistically significant difference in student test scores on function concepts in Algebra I classrooms that used TI-Nspire graphing calculators versus Algebra I classrooms that did not use this device was evident.

In each class, students were given a pre-test the day before the class began their study of functions, which was the beginning of Chapter 4 in their textbooks. All students were given a post-test two weeks after the date of the pre-test, which was approximately at the end of the first chapter on functions within their textbooks. Finally students were administered the post post-test two weeks after the post-test or four weeks after the pretest.

The results were gathered and put into a password protected Excel spreadsheet which already contained demographics, socioeconomic status, gender, age, and special education status. The data were coded, and no personal and identifiable information was included. The spreadsheet was then entered into SPSS. Data was analyzed and missing data was discovered as reported in Table 10. Missing data comes from a student who does not complete all three tests. SPSS uses listwise deletion for missing data; that is if data is missing in a record that is needed for a specific analysis, that record is deleted. 
Table 11 shows the amount of missing data that would occur when comparing multiple tests.

Table 10

Original Missing Data

\begin{tabular}{ccccccc} 
& $\begin{array}{c}\text { Teacher } \\
\text { Alpha }\end{array}$ & $\begin{array}{c}\text { Teacher } \\
\text { Epsilon }\end{array}$ & $\begin{array}{c}\text { Teacher } \\
\text { Gamma }\end{array}$ & $\begin{array}{c}\text { Teacher } \\
\text { Zeta }\end{array}$ & $\begin{array}{c}\text { All } \\
\text { Teachers }\end{array}$ & $\mathrm{N}=$ \\
\cline { 2 - 7 } Pre-Test & $10.3 \%$ & $5.4 \%$ & $7.4 \%$ & $1.7 \%$ & $6.2 \%$ & 212 \\
Post-Test & $19.0 \%$ & $3.6 \%$ & $3.7 \%$ & $5.2 \%$ & $8.0 \%$ & 208 \\
Post Post-Test & $6.9 \%$ & $3.6 \%$ & $22.2 \%$ & $8.6 \%$ & $10.2 \%$ & 203
\end{tabular}

Table 11

Missing Data when Comparing Tests

\begin{tabular}{cccc} 
& Total missing & Percent missing & $\mathrm{N}=$ \\
\cline { 2 - 4 } Pre - Post & 30 & $13.3 \%$ & 196 \\
Pre - Post Post & 34 & $15.0 \%$ & 192 \\
Post - Post Post & 37 & $16.4 \%$ & 189 \\
Pre, Post, Post Post & 47 & $20.8 \%$ & 179
\end{tabular}

Four different analyses were conducted using SPSS. The analysis for research Question 1a was a one-way ANOVA with pre-, post-, and post-post test score means as the dependent variables and the type (treatment or control) as the categorical factors. The analysis for research question $1 \mathrm{~b}$ was a one-way ANOVA with pre-, post-, and post-post test score means as the dependent variables and the teacher $($ Teacher $=$ Alpha, Epsilon, Gamma or Zeta) as the categorical factor. The analysis for research question 1c employed MANOVA with pre-, post-, and post post-test as the dependent variables and 
both teacher and type as fixed factors. The analysis for research question 1d added socioeconomic status and special education as fixed factors.

Horton and Lipsitz (2001) stated that missing data is a common occurrence within scientific research. To account for missing data noted in Tables 10 and 11, multiple imputations were used within the SPSS program. The imputations were repeated five times to decrease the error introduced by imputations (Allison, 2000). The average of those five complete imputation sets were then pooled and subsequently used to increase the confidence of the data set.

Analyzing research question 1aa one-way analysis of variance was conducted to assess if differences between the type of class (treatment and control) on the pre-test, post-test, and post post-test existed as shown in Figure 8. All four control class scores were combined to calculate the control mean score. All four treatment class scores were combined to calculate the treatment mean score. An analysis between the pre-test mean scores of the control group and the treatment group revealed a statistical significance $(p=.028$, Cohen's $d=0.51)$ in favor of the control class meaning that the control group started at a significantly higher level of mathematical achievement over the treatment group. On the post-test, the slope treatment group and the control group improved on their mean pre-test scores, but not at a statistically significant level. The level of significance $(p=.754)$ between the control group's mean scores and the treatment group's mean scores revealed no statistical significance indicating that any differences between the two groups were eliminated during the treatment period (or that the treatment group was able to catch up with the control group with respect to test scores). The control group's post post-test mean score of 6.31 was a decrease from their post-test mean score, 
implying the control group did not retain all of the knowledge. The treatment groups post post-test mean score of 7.45 was an increase from their post-test mean score, implying the sustained learning of the treatment group continued to improve. The treatment group scored statistically significantly higher $(\mathrm{p}=.031$, Cohen's $\mathrm{d}=0.66$ ) than the control group on the post post-test, revealing the effectiveness of the treatment.

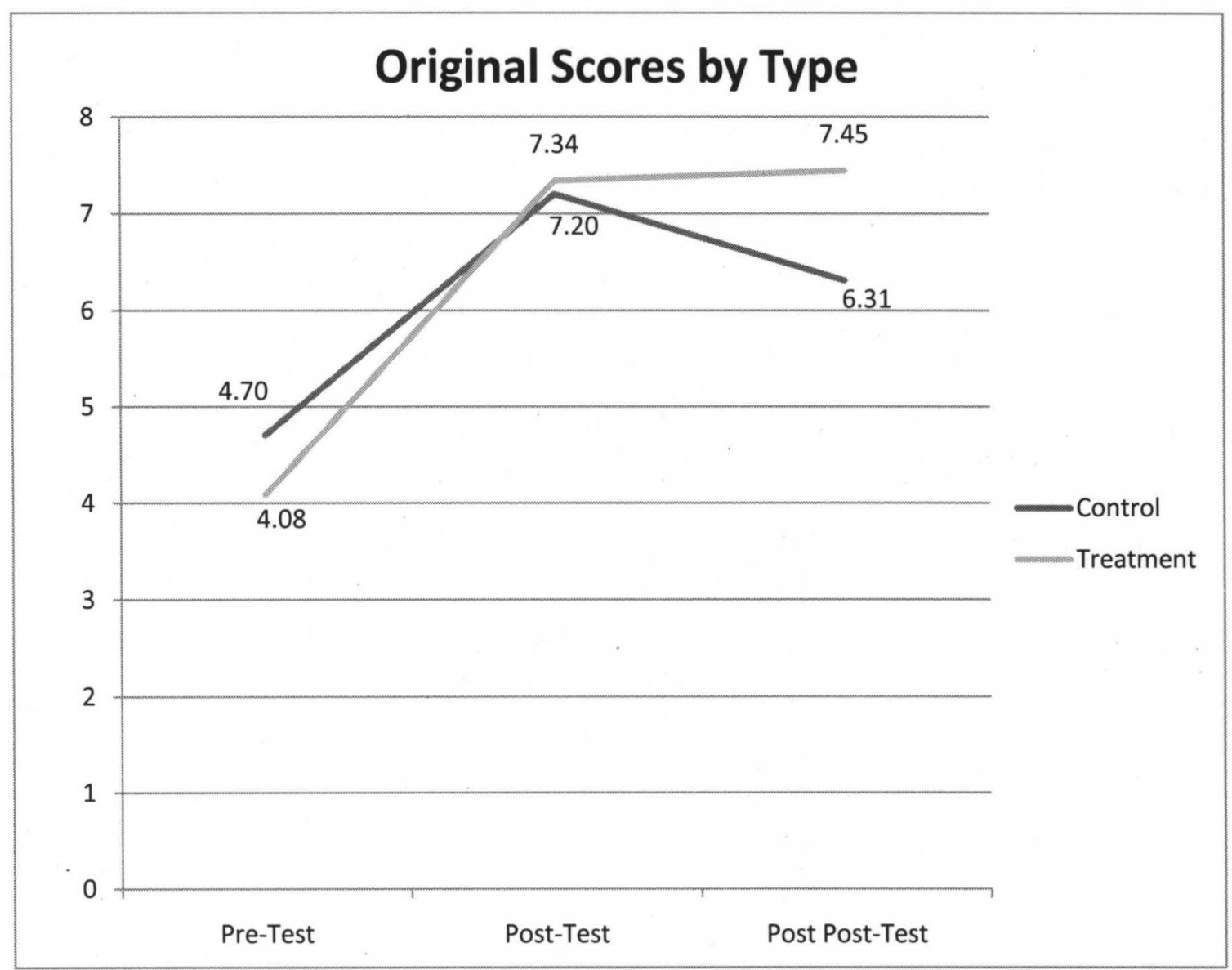

Figure 8: Original scores by type for each test. This figure illustrates the mean score out of a possible 13 point score for control group and treatment group on the pre-test, post-test and post post-test using the original data.

An additional analysis was conducted to determine if the slope from pre-test to post-test, pre-test to post post-test, and post-test to post post-test was significant for treatment and control groups. A regression analysis of post-test when controlled by pre- 
test for a standardized beta coefficient that was statistically significant for the control group for original means $(\mathrm{p}=.000)$, which was also supported by the pooled imputed means $(\mathrm{p}=.000)$. A regression analysis of post post-test when controlled by pre-test for a standardized beta coefficient that was statistically significant for the control group for original means $(\mathrm{p}=.001)$, which was also supported by the pooled imputed means $(\mathrm{p}=.001)$. A regression analysis of post post-test when controlled by post-test for a standardized beta coefficient that was statistically significant for the control group for original means $(\mathrm{p}=.001)$, which was also supported by the pooled imputed means $(\mathrm{p}=.001)$.

A regression analysis of post-test when controlled by pre-test for a standardized beta coefficient that was statistically significant for the treatment group for original means $(\mathrm{p}=.000)$, which was also supported by the pooled imputed means $(\mathrm{p}=.000)$. A regression analysis of post post-test when controlled by pre-test for a standardized beta coefficient that was statistically significant for the treatment group for original means $(\mathrm{p}=.001)$, which was also supported by the pooled imputed means $(\mathrm{p}=.001)$. A regression analysis of post post-test when controlled by post-test for a standardized beta coefficient that was statistically significant for the treatment group for original means $(p=.001)$, which was also supported by the pooled imputed means $(\mathrm{p}=.001)$.

After pooling the imputed values, the level of significance $(p=029)$ between the control group's mean scores and the treatment group's mean scores showed statistical significance as shown in figure 9. On the post-test, both treatment and control groups improved on their mean pre-test scores. The level of significance $(p=.440)$ between the control group's mean scores and the treatment group's mean scores showed no statistical 
significance. The treatment group scored statistically significantly higher $(\mathrm{p}=.044)$ than the control group on the post post-test. The information of the imputed pooled data confirmed the results from the original data.



Figure 9: Pooled imputed scores by type for each test. This figure illustrates the mean score out of a possible 13 point score for control group and treatment group on the pretest, post-test and post post-test after imputing values for missing data.

Research question $1 \mathrm{~b}$ investigated possible variance due to teacher effect. A General Line Model using MANOVA was ran with the pre-test, post-test, and post-post test controlled for while looking at teacher, type and teacher by type. The original scores for each teacher by test are displayed in Figure 10. Each teacher had both their treatment and control class scores combined to analyze teacher effect on each test. No effect on the original pre-test scores or post-test scores was found, meaning there was no teacher effect on the pre-test or post-test scores. The effect on the original post post-test scores ( $p=.000$, Cohen's $d=0.27$ ) was found to be statistically significant, meaning that there 
was significant teacher effect on the post post-test. The imputed scores each teacher by test are displayed in Figure 11. The effect on the imputed post post-test scores $(p=.001)$ was also found to be statistically significant. The information of the imputed pooled data confirmed the results from the original data.

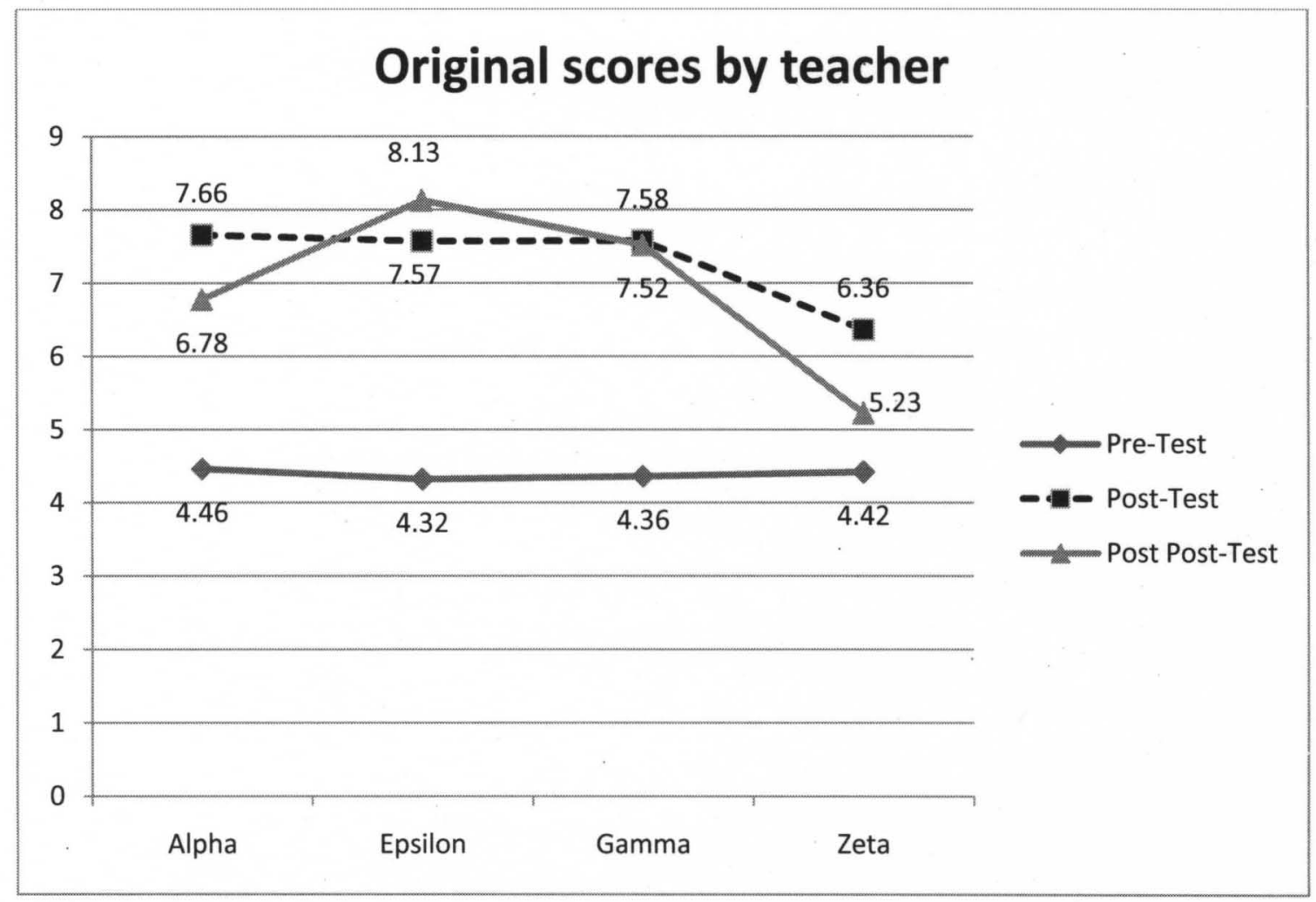

Figure 10: Original Scores for each teacher by test. This figure illustrates the mean score out of a possible 13 point score for each teacher on the pre-test, post-test and post post-test. 


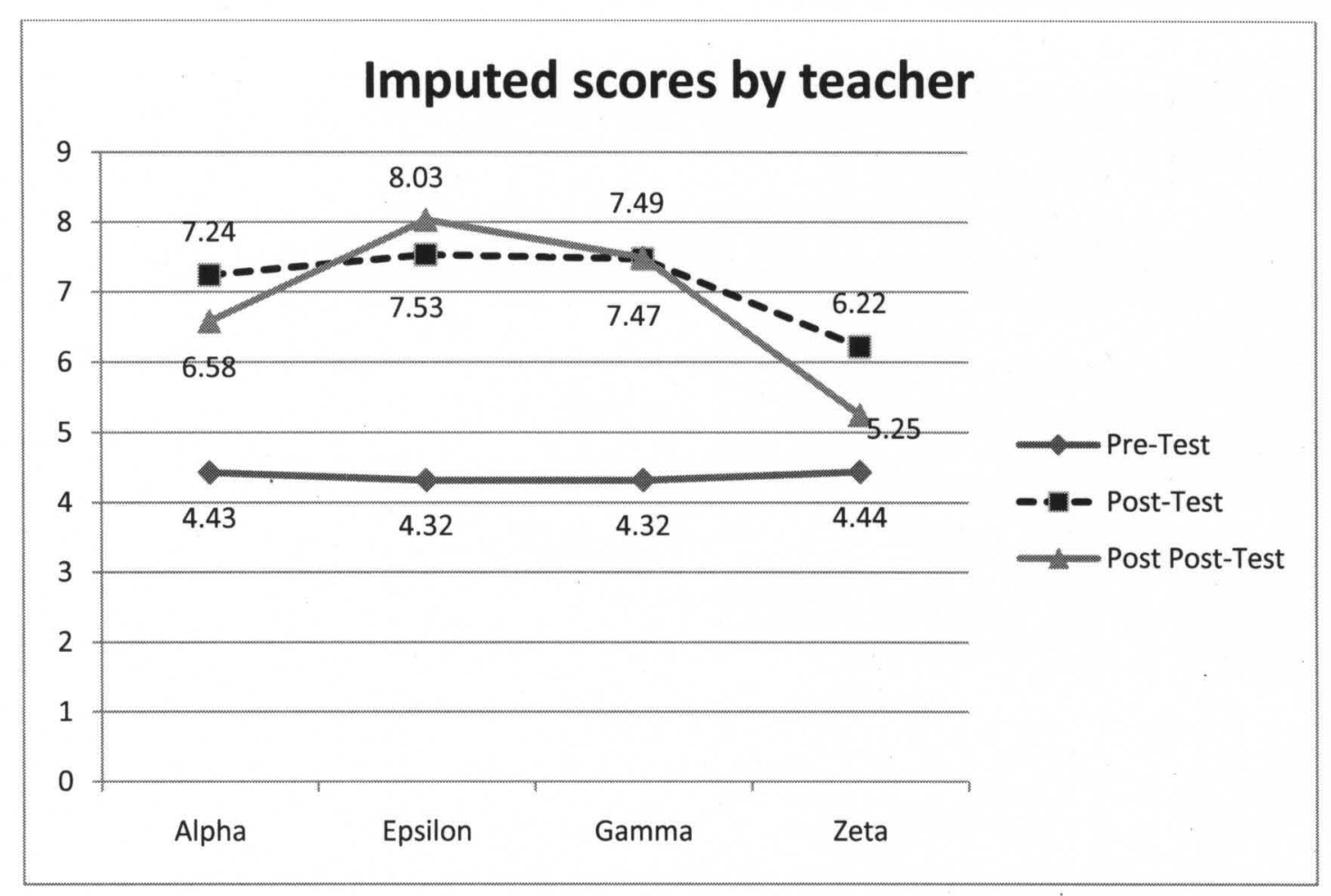

Figure 11: Pooled imputed scores for each teacher by test. This figure illustrates the mean score out of a possible 13 point score for each teacher on the pre-test, post-test and post post-test after imputing values for missing data.

A multiple comparison test was run to further investigate the significant difference within the post post-test among teachers. The statistical significance focused around Teacher Zeta's classes. When comparing Teacher Zeta's classes post post-test scores with Teacher Epsilon's classes and Teacher Gamma classes, statistical significance was found. The original data revealed a difference (higher) between the post post-test scores for Teacher Epsilon's classes $2.903(\mathrm{p}=.000)$ higher than Teacher Zeta's classes. The original data revealed a difference between the post post-test score for Teacher Gamma's classes $2.297(\mathrm{p}=.013)$ higher than Teacher Zeta's classes. The pooled imputed mean difference showed Teacher Epsilon's classes post post-test $2.783(p=.001)$ higher than Teacher Zeta's classes mean score. The pooled imputed mean difference 
showed Teacher Gamma's classes post post-test $2.245(\mathrm{p}=.012)$ higher than Teacher Zeta's classes mean score. The information of the imputed pooled data confirmed the results from the original data

Research question 1c used a multivariate test with the teacher as fixed variable, the pre-test mean as covariate and centered at the class level. Figure 12 shows a comparison of the original mean scores for the pre-test, post-test, and post post-test by teacher for the control class and treatment class. Each of the eight lines represents the eight individual classes within this study and their mean scores on each test. The original data for the classes by teacher on the post-test ( $p=.042$, Cohen's $d=0.07)$ and the post post-test $(p=.000$, Cohen's $d=0.27)$ were statistically significant, indicating teacher effect on the post-test and the post post-test. The original data for the interaction of teacher by type on the post-test ( $p=.007$, Cohen's $d=0.52)$ and the post post-test $(p=.036$, Cohen's $d=0.44$ ) were also statistically significant, indicating an effect of the interaction of teacher and type on the post-test and the post post-test. Wilks' Lambda showed a significant level for teacher $(\mathrm{p}=.001)$, type $(\mathrm{p}=.027)$ and the interaction of teacher and type $(\mathrm{p}=.004)$ which indicates that the assumptions of variance for teacher, type and the interaction of teacher and type were verified. Additional post hoc tests were run for teacher, type, and teacher by type. 




Figure 12: Original Scores for each test by teacher and type. This figure illustrates the mean score out of a possible 13 point score for each teacher on the pre-test, post-test and post post-test after imputing values for missing data.

Figure 13 shows a comparison of the pooled imputed mean scores for the pre-test, post-test, and post post-test by teacher for the control class and treatment class. The pooled imputed class scores by teacher on the post-test $(\mathrm{p}=.121)$ revealed no statistical significance, while the post post-test $(p=.001)$ showed statistically significant. The pooled imputed data for the interaction of type on the post post-test $(\mathrm{p}=.057)$ were not significant. The pooled imputed data for the interaction of teacher by type on the posttest $(\mathrm{p}=.003)$ and the post post-test $(\mathrm{p}=.016)$ were both statistically significant. Wilks' Lambda showed a significant level for teacher $(\mathrm{p}=.010)$, type $(\mathrm{p}=.005)$ and the interaction 
of teacher and type $(\mathrm{p}=.005)$. The assumptions of variance for teacher, type and the interaction of teacher and type on the Wilks' Lambda test were verified. Additional post hoc tests were run for teacher, type, and teacher by type. The results for the pooled imputed means analysis for teacher on post-test were different from that of the original means analysis. The results for the pooled imputed means analysis for the interaction of teacher and type on both the post-test and the post post-test were supported by the original means analysis.

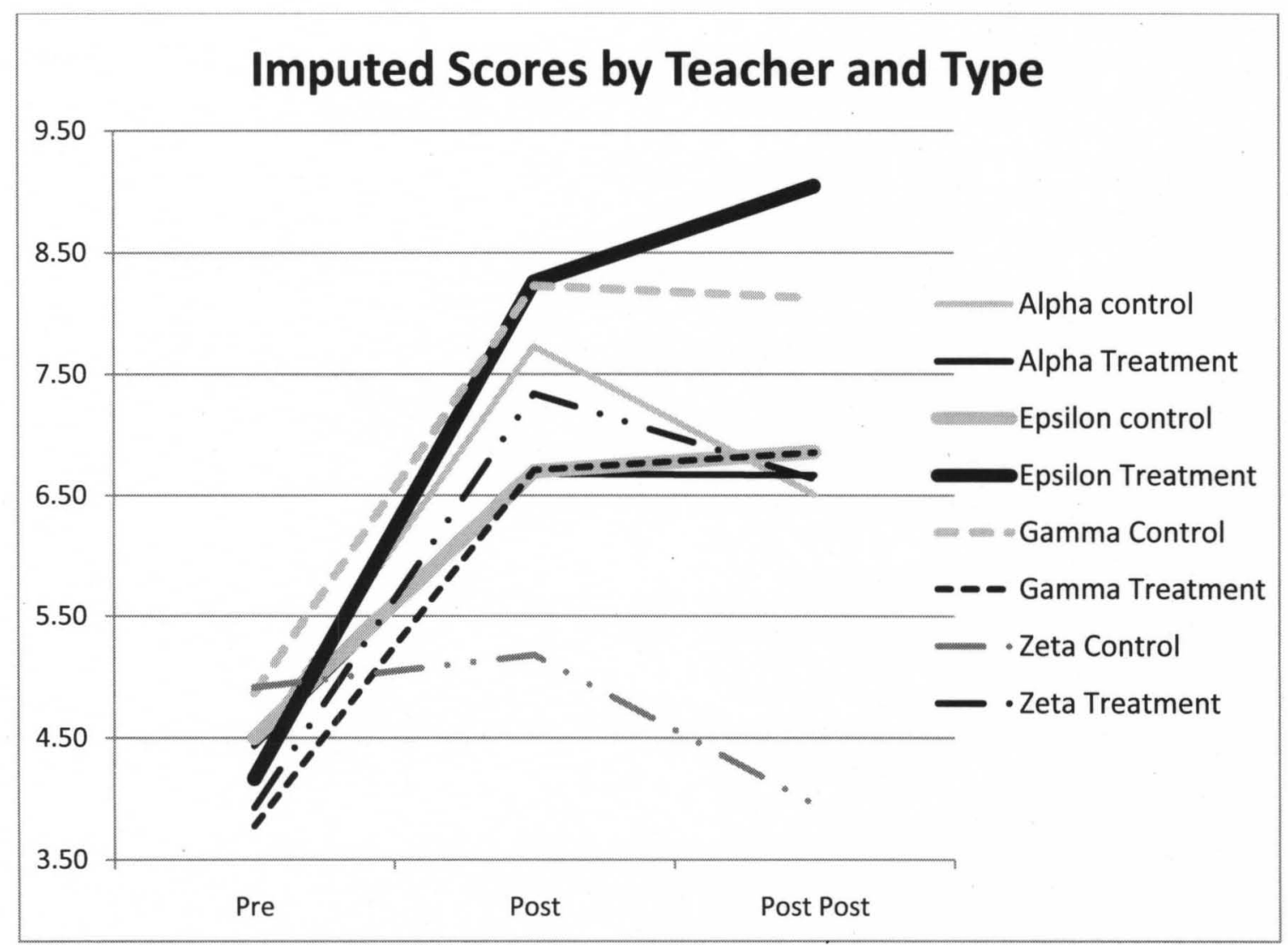

Figure 13: Pooled imputed scores for each test by teacher and type. This figure illustrates the mean score out of a possible 13 point score for each teacher on the pre-test, post-test and post post-test after imputing values for missing data.

A pairwise comparison test was then run for teacher, type, and the interaction between teacher and type using the original means. For the pairwise comparison by 
teacher, statistically significant interactions were found on the post-test and the post posttest for the results for the classes of Teacher Zeta. On the post-test, the data for Teacher Zeta's classes had an original mean difference of $-1.720(p=.009$, Cohen's $d=1.10)$ when compared with the data for Teacher Alpha's classes, $-1.115(p=.071$, Cohen's $d=.84)$ compared with Teacher Epsilon's classes and $-1.389(p=.035$, Cohen's $d=.32)$ compared with Teacher Gamma's classes. On the post post-test, Teacher Zeta's classes original mean difference of $-1.936(p=.010$, Cohen's $d=1.13)$ compared with Teacher Alpha's classes $-2.839(p=.000$, Cohen's $d=1.46)$ compared with Teacher Epsilon's classes and 2.735 ( $\mathrm{p}=.000$, Cohen's $\mathrm{d}=1.37$ ) compared with Teacher Gamma's classes. This revealed that a student within Teacher Zeta's class, whether treatment or control, would have a significantly lower post post-test score than a student in another Teacher's class. Wilks' Lambda was significant for this multivariate test $(\mathrm{p}=.001)$ with the original means.

A pairwise comparison test was then run for teacher, type, and the interaction between teacher and type using the pooled imputed means. For the pairwise comparison by teacher, statistically significant interactions were found on the post-test and the post post-test when for Teacher Zeta's classes. On the post-test, Teacher Zeta's classes pooled mean scores showed a difference of $-.944(p=.123)$ compared with Teacher Alpha's classes, a pooled mean difference of $-1.217(\mathrm{p}=.040)$ compared with Teacher Epsilon's classes and a pooled mean difference of $-1.209(p=.043)$ compared with Teacher Gamma's classes. On the post post-test, Teacher Zeta's classes pooled mean difference scores showed difference of -1.294 ( $\mathrm{p}=.068)$ compared with Teacher Alpha classes, of $-2.658(\mathrm{p}=.000)$ compared with Teacher Epsilon classes and a pooled mean difference of $-2.198(p=.002)$ compared with Teacher Gamma's classes. The results for 
the pooled imputed means analysis for the interaction of teacher and type on both the post-test and the post post-test were partially supported by the original means analysis. Wilks' Lambda showed a significant level for this multivariate test $(\mathrm{p}=.010)$ with the pooled imputed means for the interaction of teacher and type on both the post-test and the post post-test

The analysis for research question 1d investigated the interaction of socioeconomic status and special education students. A multivariate analysis of variance was conducted to assess if there were differences between the teacher and socioeconomic status, special education status, or the interaction of socioeconomic status and special education status on the post-test, and the post post-test. The pre-test was a dependent variable so that variance due to the pre-test was controlled. When analyzing with the original means, the socioeconomic status had a statistically significant impact on the post-test $(\mathrm{p}=.003)$ and on the post post-test $(\mathrm{p}=.016)$. When analyzing with the pooled imputed means, only the socioeconomic status post-test $(\mathrm{p}=.014)$ was confirmed to be statistically significant. When analyzing with the original means, the interaction between teacher and socioeconomic status, a significant impact on the post post-test $(p=.014)$ was found, but this same interaction was not confirmed to be significant with the pooled imputed means $(\mathrm{p}=.097)$. When analyzing with the original means, the interaction between type and socioeconomic status, a significant impact on the pre-test $(p=.040)$ was found, but this same interaction was not confirmed to be significant with the pooled imputed means $(p=.076)$. When analyzing with the original means, no statistically significant results were found with special education; however on the pooled imputed means, a statistically significant interaction between teacher and special education was 
found on the post post-test $(\mathrm{p}=.005)$. Wilks' Lambda showed a statistically significant level for the original means of the socioeconomic status $(\mathrm{p}=.017)$ while the pooled imputed means was not significant $(\mathrm{p}=.204)$. Wilks' Lambda did not show a significant level for the original means for the interaction of teacher and special education $(\mathrm{p}=.170)$ nor did the pooled imputed means $(\mathrm{p}=.276)$. An attempt to investigate further was futile due to the lack of data. There was not enough statistical power to continue with further analysis.

Analysis of the quantitative data revealed statistically significance. Analyzing for treatment effect revealed statistical significance on the pre-test and the post post-test for original and imputed data. Analyzing for teacher effect revealed statistical significance on the post post-test for original and imputed data. Analyzing for the effect of teacher, type and the interaction between teacher and type using the pre-test as a control value and centering by pre-test at the class level revealed statistical significance on the post posttest for teacher effect with the original and imputed data. The original data also showed a statistically significant teacher effect on the post-test. Analysis of the interaction of teacher by type revealed statistical significance on the post-test and the post post-test for both the original and imputed data. Further pairwise comparison revealed a statistical significance of Teacher Zeta's classes on both the post-test and the post post-test. Analysis of the interaction of teacher and type with socioeconomic status and special education students produced conflicting results. It appeared that the lack of data caused different interactions and further analysis was not possible due to lack of power. 


\section{VIGNETTES}

The ten Algebra I classes in the study included six teachers at Eagle High School in the fall of 2009. The four teachers, who had two Algebra I classes, taught one treatment class and one control class. One of the remaining teachers, Teachers Delta taught a treatment class and Teacher Beta, taught a control class. To control the effect of the time of.day that Algebra I was taught, classes were selected so that at least one treatment and one control was taught for each school class period.

Teacher Delta did not follow the treatment protocol. In fact, Teacher Delta only used the calculators in class three times over the entire four week period. Since this was not consistent with the treatment, the data generated by Teacher Delta's classes would have no construct validity. Therefore, Teacher Delta was removed from the study. Teacher Beta was the control for Teacher Delta, and therefore not necessary with the removal of Teacher Delta, therefore Teacher Beta was also removed from the study. Table 12 below lists the final sample of teachers, the number of students in each class, and the assignment of either treatment or control.

Table 12

Teacher and type

\begin{tabular}{cccc} 
Period & Teacher & Type & $\mathrm{N}=$ \\
\cline { 2 - 4 } $2^{\text {nd }}$ & Alpha & Control & 30 \\
$3^{\text {rd }}$ & Alpha & Treatment & 30 \\
$1^{\text {st }}$ & Epsilon & Control & 29 \\
$2^{\text {nd }}$ & Epsilon & Treatment & 32 \\
$2^{\text {nd }}$ & Gamma & Treatment & 29 \\
$3^{\text {rd }}$ & Gamma & Control & 29 \\
$1^{\text {st }}$ & Zeta & Treatment & 30 \\
$4^{\text {th }}$ & Zeta & Control & 29
\end{tabular}


Observations and document analyses were used to identify the predetermined constructs for analysis across teachers and classes. Analyses of the classroom observations, questionnaires, lesson plans, and assessments were organized around the constructs of representations, Depth of Knowledge and TPACK. The researcher coded each activity within the treatment and control classes. For coding representations, the activities included starters, example problems, goals, worksheets, textbook assignments, and homework. The coding for Depth of Knowledge was based upon Webb (2006). In the observation and document analysis for Depth of Knowledge, all objectives, goals, and activities were coded with a Level 1 for recall, Level 2 for skill or concept, Level 3 for strategic thinking and Level 4 for extended thinking. The coding for TPACK was based upon Niess and others (2009). Within the observation and document analysis for TPACK, a 1 was assigned to Recognizing, a 2 to Accepting, a 3 to Adapting, a 4 to Exploring and a 5 to Advancing.

\section{Teacher Alpha - Control Class}

Teacher Alpha's control class was observed on the sixth day of treatment. During the observation, the activities within Teacher Alpha's control classroom included a starter, homework review, and lecture with demonstrations, guided practice, and homework. The lesson began with a class starter. Teacher Alpha had the starter written on the board. Students turned to page 191 in their books and completed exercises 15-20. While students worked these exercises by substituting values into an equations and solving for $\mathrm{x}$, Teacher Alpha called roll and passed back homework papers.

Teacher Alpha reviewed the starter exercises and then had the control class students take notes that were displayed using a multimedia projector. Teacher Alpha then 
reviewed mapping, domain, range, and the vertical line test. Teacher Alpha demonstrated the relationship between mapping and tables. Teacher Alpha then had students work exercises using the vertical line test on a graph in which they were to determine which set of mappings were functions. Teacher Alpha then gave students the equation $2 x-y=6$ and instructed them to create a table and graph it on their notebook paper. As students worked through these exercises, Teacher Alpha provided guidance by also working through them on the classroom dry erase board. Teacher Alpha then lectured about nonlinear functions. At the end of the lecture and guided practice, Teacher Alpha assigned a set of exercises from the book to be completed for homework. Students then worked on their homework in the remaining time in class.

The exercises within Teacher Alpha's control classes contained an average of about 2 representations per activity. For example, when Teacher Alpha's control class was instructed to complete the starter exercise, students used symbolic representation and analytical representations. For taking notes, the only representation used was writing. When given the equation $2 x-y=6$, students were instructed to make a table and then drawing the corresponding graph. Students completed numeric representations within the table, geometric representations within the graph and symbolic representations within the equation. Teacher Alpha's homework review used numeric, geometric, and symbolic representations. The notes, lecture, in class examples, guided work, and homework all used numeric, geometric, symbolic and writing representations.

Teacher Alpha's starter exercise had cognitive complexity of Level 2 (skill/concept). Taking notes off the board and practicing the vertical line test are examples of Level 1 (recall) activities that the control class completed. When students 
were instructed to make a table and then draw the corresponding graph to exercises like $2 x-y=6$, students were working at a Level 2 (skill/concept). Teacher Alpha's control class experienced an average level of about 2 Depth of Knowledge.

Within Teacher Alpha's control class, Teacher Alpha functioned at a TPACK Accepting level. For example, Teacher Alpha demonstrated an Accepting level with the technology by using PowerPoint and a projector to teach function concepts. By allowing students to use the Casio non-graphing scientific calculators to perform calculations while working on mathematics problems, Teacher Alpha continued to demonstrate an Accepting level of TPACK. Teacher Alpha also demonstrated the Recognizing level with the technology by using the projector to have the starter up on screen at the beginning of class and in using it to refer back electronically to materials within the book.

Over the course of this study, Teacher Alpha reported in the questionnaires for the control class that tables, graphs, mappings, coordinate plane, order pairs, linear equations, word problems, and PowerPoint presentations were used as representations to teach functions. Teacher Alpha provided weekly examples of how the representations had been linked together while teaching. For example, Teacher Alpha stated that "Tables were used to get the ordered pairs to graph on graphs. Mappings were used to help show domain and range." Teacher Alpha also stated that "The students learned how to use the slope intercept formula ' $y=m x+b$ ' to graph linear equations."

Teacher Alpha responded within the questionnaire that Casio non-graphing scientific calculators were used every day of the study for the control class. Teacher Alpha also responded that the computer and projector were used most days for instruction 
within the control class. Teacher Alpha reported no issues with any of the teaching tools that were used during the study for the control class.

When asked about the goals for the control class with respect to learning functions, Teacher Alpha responded with goals about graphing points on the Cartesian plane, determining domain and range, and identifying independent and dependent variables. Teacher Alpha also stated that another goal was that students would master the concepts of graphing linear equations. Specifically, Teacher Alpha stated that "The students were to learn the concepts of linear equations and how to relate the formula to actual graphing of the equation."

Within the questionnaire, Teacher Alpha was asked to provide examples of how the tools were used within the control class to teach functions. Teacher Alpha shared that PowerPoint introduced and illustrated concepts. Teacher Alpha also said that the coordinate plane was used as a visual guide, the Casio non-graphing scientific calculators were used to make computations, and the homework assignments provided practice to reinforce what was taught with the control class. Teacher Alpha also stated that the "PowerPoint presentations were used to show examples of functions, mappings, tables, and functions."

When asked about what Teacher Alpha was able to teach better or more easily using the tools with the control class, Teacher Alpha stated that "The PowerPoint presentations seemed to get their attention a lot better than using examples out of their textbook." Teacher Alpha added that the "PowerPoint presentations were helpful showing examples of transition word problems to data that can be used to graph using linear equations." 
When asked for additional comments concerning the control class, Teacher Alpha indicated that the students seemed to like taking notes from the PowerPoint instead of out of the book. Teacher Alpha claimed that the PowerPoint presentations were useful tools to show the transition from formula to graph for the control classes. Teacher Alpha also commented that the control class students "had trouble interpreting the data from the graphs to being able to understand their answers." Teacher Alpha also pointed out that the concept of slope had to be repeatedly reviewed for the control class, as well as how to use the data to get the answer.

In the lesson plan analysis, Teacher Alpha recorded various state competencies, which are listed in Appendix E, for the control class during the course of this study. Teacher Alpha also had objectives that were aligned with the competencies. For example, state competency Checks for Understanding 3102.3.15 stated that students were to "Determine domain and range of a relation and articulate restrictions imposed either by the operations or by real life situation that the function represents." Teacher Alpha stated that the objective was that the "Student will be able to identify domain and range of relations."

The methods of instructions used by Teacher Alpha with the control class varied each day. The starter activities included note taking, working exercises from the board, and reviewing textbook assignments. Examples of Teacher Alpha's control class starters included graphing coordinate points listed on the board, doing exercises 1-20 on page 255 in the textbook, and writing formulas down multiple times in their notes. Teacher Alpha used lecture, PowerPoint, and the dry erase board to teach the control class. Teacher Alpha used a variety of instructional strategies including cooperative learning, small 
group activities, large group activities, independent practice, and guided practice. Independent practice was used every day. Large group activities and guided practices were used every day except on test or quiz days.

Teacher Alpha stated that within the lesson plans, the technology used for the control class included multi-media PowerPoint presentations, which were used on most days, and the Casio non-graphing scientific calculator. Teacher Alpha remarked that within the control class lesson plans, learning styles included auditory and visual examples daily. Beyond the use of test and quizzes for assessment, Teacher Alpha noted that observations were used on a daily basis to assess students within the control class.

Lesson plans were collected on the third, sixth and eleventh days to examine content, Depth of Knowledge (Webb, 2006) and the types of representations used for the Teacher Alpha's control class. The content covered in these lessons was compared to the content areas that was on the pre-test, post-test and post post-test as listed in Appendix F. On the third day, Teacher Alpha's control class starter covered functions (item 1, item 3, and item 4) at a Level 2 (skill/concept) and used numeric, geometric, and analytic representations. Teacher Alpha listed three state competencies which covered the content area of functions (item 1 , item 2 , item 3 , item 4 , item 6 , and item 7 ). These competencies had a range of Depth of Knowledge from Level 1 (recall) to Level 3 (strategic thinking). For example, the state competency Checks for Understanding 3102.1.12 (Create and work flexibly among representations of relations including verbal, equations, tables, mappings, graphs)was from the function content area (item 1 and item 4) and had a Level 2 Depth of Knowledge. Three goals were stated for the third day; the content area was functions (item 1, item 2, item 3, item 4, and item 7) and was at either a Level 1 or Level 
2 Depth of Knowledge. All goals included numeric representations. Two goals also included geometric representations, two included symbolic representations, and two included analytic representations. For example, the goal of identifying the domain and range focused on functions (item 3 and item 7), was at a Level 1 Depth of Knowledge, and used numeric, geometric and analytic representations. In looking at the textbook exercises assigned for homework, the concepts covered were within the content area of functions (item 1, item 2, and item 4) at a Level 2 Depth of Knowledge and used numeric, geometric, symbolic, and analytical representations.

On the sixth day, Teacher Alpha's control class starter covered content area 2 at a Level 2 on Webb's Depth of Knowledge and used both numeric and analytic representations. Teacher Alpha listed two state competencies which covered the function content area (item 1, item 3, item 4, and item 7). These competencies had a range of Depth of Knowledge at Level 2 and Level 3. Four stated goals of the class for the sixth day included both functions and graphing (item 1, item 2 , item 3 , item 4 , item 8 , item 9 , item 10, item 11, and item 13) and were Level 1 and Level 2. All goals included geometric representations. One goal included numeric representations, two goals included symbolic representations, and two included analytic representations. In looking at the textbook exercises assigned for homework, the concepts covered were in the graphing content area (item 11 and item 13) at a Level 2 Depth of Knowledge and used geometric, symbolic, and analytical representations.

On the eleventh day, Teacher Alpha's control class starter covered content area 11, was at a Level 1, and used numeric, geometric and analytic representations. Teacher Alpha listed four state competencies that focused on function and graphing content areas 
(item 9, item 12, and item 13). These competencies had a range of Depth of Knowledge from Level 1 to Level 3. Four goals of the class for the eleventh day were identified; the content areas of both functions and graphing (item 10 and item 13) ranged from a Level 1 to Level 3 Depth of Knowledge. All goals included symbolic representations. One goal focused on numeric representations, three included geometric representations, and three included analytic representations. The textbook exercises assigned for homework included the concepts not listed within the content areas covered on the pre-test, post-test or post post-test. The homework assignment was at a Level 2 and required both symbolic and analytical representations.

When analyzing the assessments used within Teacher Alpha's control class, the starter activities focused on note taking, review of homework exercises, or similar review activities. Teacher Alpha's control class was assigned all the homework directly from the textbook or textbook worksheets. Teacher Alpha's control classes had both quizzes and tests. One quiz was a vocabulary quiz, and the other quizzes and chapter tests were from the textbook publishers.

\section{Teacher Alpha - Treatment Class}

Teacher Alpha's treatment class was observed on the sixth day of the treatment, the same day as the control class. During the observation, the types of activities within Teacher Alpha's treatment classroom were the same for Teacher Alpha's control class. These activities included a starter, homework review, a lecture with demonstrations, guided practice, and homework. Unlike the control class, Teacher Alpha took time during the starter activity to pass out the TI-Nspire calculators to the students. 
Teacher Alpha reviewed the starter exercises and allowed discussions to lead directly into homework review within the treatment class. The homework included graphing different sets of equations such as $y=-1$. Teacher Alpha then gave a lecture using PowerPoint about the relationships, tables, and graphs. Teacher Alpha demonstrated how to graph $y=2 x$ by using a table and then drawing the line on a graph using the dry erase board. Students were then given a set of exercises, including $y=3 x$. As students worked through these exercises using the TI-Nspire calculator, Teacher Alpha provided guidance by also working through them on the dry erase board. At the end of the lecture and guided practice, Teacher Alpha assigned a set of exercises from the book to be completed for homework. Students then worked on their homework in the remaining time in class.

The exercises within Teacher Alpha's treatment classes contained an average of 2.86 representations per activity. For example, when Teacher Alpha's treatment class was asked to complete the starter exercise, students used symbolic representation and analytical representations. For the exercise set including $y=3 x$, students were instructed to make a table and then to draw the corresponding graph. Students completed numeric representations within the table and geometric representations within the graph and symbolic representations within the equation. Teacher Alpha's homework review used both geometric representation and symbolic representations. The lecture, in-class examples, guided work, and homework included numeric representations, geometric representations, and symbolic representations.

Teacher Alpha's starter exercise had the same cognitive complexity (Level 2) as the control class. In graphing such equations às $y=-1$, students were also working at a 
Level 2. When students were instructed to make a table and then to draw the corresponding graph to exercises like $y=2 x$, students worked at a Level 2 . Teacher Alpha's treatment class experienced an average level of 2.14 Depth of Knowledge. Within Teacher Alpha's treatment class, Teacher Alpha functioned at a TPACK level of Accepting. For example, Teacher Alpha was willing to participate in TI-Nspire professional development activities and to teach using the TI-Nspire within the treatment classes. In addition, Teacher Alpha also used both the computer projector and TI-Nspire emulator within the treatment class while demonstrating how to complete exercises. Teacher Alpha also demonstrated the Recognizing level with the technology by using the projector to have the starter on screen at the beginning of class and in also using it to refer back electronically to materials within the book.

Over the course of this study, Teacher Alpha reported on the questionnaires that tables, graphs, mappings, order pairs, linear equations, word problems, and PowerPoint presentations were used as representations to teach functions within the treatment class. Teacher Alpha provided weekly examples of how the representations had been linked together while teaching. For example, Teacher Alpha stated that "Tables used to find ' $y$ ' given the ' $x$ ' coordinate graphs were used to show lines and to show if they were linear. Mappings used to help show range and domain." Teacher Alpha also stated that "The students learned how to use the slope intercept formula ' $y=m x+b$ ' to graph linear equations."

Teacher Alpha responded within the questionnaire that the TI-Nspire was not used on the first day of this study within the treatment class. However for every remaining day, the TI-Nspire was used. Teacher Alpha reported issues within the 
treatment class regarding the TI-Nspire. Those issues included low batteries, lack of students understanding on how to use them, and the time spent checking the calculators out to the students each day. Teacher Alpha remarked that "The students have been so preoccupied with the $\mathrm{N}$-spire calculators that the material covered in the lesson had to go at a slower pace. After the students got more familiar with the calculators, both classes were able to go at the same pace." By the end of the second week of the study, Teacher Alpha's treatment class was able to catch up to Teacher Alpha's control class.

When asked about the goals for the treatment class with respect to learning functions with the TI-Nspire, Teacher Alpha responded with goals about making "functions easier and more fun for them." Teacher Alpha also included goals such as to graphing points on the Cartesian plane, determining domain and range, identifying independent and dependent variable using real-life examples and mastering the concept of graphing linear equations using the TI-Nspire. Teacher Alpha stated another goal "to show how much time the TI-Nspire can save them making tables and graphing functions." Additional goals included relating the formulas within the TI-Nspire to the graphs and interpreting what those graphs meant.

Teacher Alpha provided examples of how the TI-Nspire was used within the treatment classroom. For example, Teacher Alpha noted that, in using tables and graphs for linear equations and plotting points, the program "What's the Point" from the Texas Instruments website was used. Teacher Alpha said that "several examples of word problems and showing how to use linear equations and functions to solve these problems" were demonstrated for the students. Teacher Alpha also pointed out that the 
TI-Nspire was used throughout the study to complete calculations, graph linear equations, and check answers.

When asked about what Teacher Alpha was able to teach better or more easily using the TI-Nspire than other tools with the treatment class, Teacher Alpha stated that using and creating tables was much better with the TI-Nspire. Teacher Alpha also said that answering student's questions with the emulator to demonstrate what was being said was beneficial. When asked for additional comments, Teacher Alpha stated that "the (treatment) class has to repeatedly go over formulas and where to plug in numbers from problems into the formulas." Teacher Alpha pointed out that there was a 50 percent failure rate within the treatment class and that several students struggled to pass any math class in middle school. Teacher Alpha also remarked that there were several behavior issues within the treatment class.

In the lesson plan analysis, Teacher Alpha recorded the same state competencies as the treatment class during this study, with the exception that the treatment class also had Course Level Expectation 3102.1.7. This Course Level Expectation states that students will "Use technologies appropriately to develop understanding of abstract mathematical ideas, to facilitate problem solving, and to produce accurate and reliable models." Teacher Alpha had the same objectives as the control class except that Teacher Alpha's treatment class included the use and application of the TI-Nspire as an objective.

The methods of instructions used by Teacher Alpha with the treatment class varied each day. The starter activities for the treatment class mainly involved distributing calculators. Teacher Alpha used lecture, Texas Instruments website activities, the TINspire emulator, PowerPoint and the dry erase board to teach the treatment class. 
Teacher Alpha used the same instructional strategies as the control class. Independent practice was used everyday just like the control classes. Also, large group activities and guided practices were used on all non-test or non-quiz days just like the control class.

Teacher Alpha noted on the lesson plans that the technology used for the treatment class included the TI-Nspire graphing calculator on a daily basis and that most days a PowerPoint presentation was also used. Teacher Alpha remarked that within the treatment class lesson plans that the learning styles daily included auditory and visual examples. Teacher Alpha also noted that when using the Texas Instruments website activities in the treatment class that kinesthetic activities were used as well. Beyond the use of tests and quizzes for assessment, Teacher Alpha noted within the lesson plans that observations were used on a daily basis to assess students within the treatment class, which was the same as the control class.

A lesson plan analysis was also used on the third, sixth and eleventh day to examine content, Depth of Knowledge (Webb, 2006), and the types of representations used for the Teacher Alpha's treatment class. On the third day, Teacher Alpha's treatment class starter covered the graphing content area (item 11) which was different from Teacher Alpha's control class. However, the content area and types of representations used were the same as Teacher Alpha's control class. Teacher Alpha listed the same state competencies and goals for the treatment class as the control class; therefore the content areas covered, Depth of Knowledge, and types of representations were all the same. Teacher Alpha's treatment class homework was different from Teacher Alpha's control class. Teacher Alpha's treatment class completed worksheets 
over the function content area (item 1, item 3, and item 4) at a Level 2 (skill/concept) Depth of Knowledge and used numeric, geometric, and analytical representations.

On the sixth day of the study, Teacher Alpha's treatment class lesson plan was totally different from Teacher Alpha's control class. The treatment class did not include a starter. Teacher Alpha listed three state competencies for the treatment class which covered the function content area (item 2 , item 3 , item 4 , item 6 , item 7 , item 8 , item 9 , and item 10). These competencies had either a Level 2 or Level 3 (strategic thinking) Depth of Knowledge. There were three stated goals that included the function content area (item 1, item 2, item 3, item 4, and item 7) and were either a Level 1 or Level 2 Depth of Knowledge. Two goals included numeric, geometric and symbolic representations and the other goal included numeric and analytical representations. The homework assigned to Teacher Alpha's treatment class was from the textbook. The concepts covered were function content area (item 1, item 2, and item 4) at a Level 2 Depth of Knowledge and used numeric, geometric, symbolic, and analytical representations.

On the eleventh day of the student, Teacher Alpha's treatment class lesson plan was exactly the same as Teacher Alpha's control class lesson plan. The classes had the same starter, same state competencies, same goals, and the same homework. This also made all of the content areas, Depth of Knowledge, and types of representations used the same as well.

When analyzing the assessments used within Teacher Alpha's treatment class, the starter activities were less about exercises or activities and more about passing out the calculators. Teacher Alpha's treatment class used the Scavenger Hunt, What's the Point 
and Intro to Functions Program activities from the Texas Instruments website. While these activities took place in the treatment classroom setting, homework assignments were always textbook assignments or textbook worksheets. Teacher Alpha's treatment classes had the same quizzes and tests as the control class.

\section{Across Teacher Alpha's Treatment and Control Classes}

Teacher Alpha's treatment class and Teacher Alpha's control class were both observed on the sixth day of the study. While both classes had the same starter, the remainder of the lesson was different. Teacher Alpha's control class reviewed mapping, domain, range, and the vertical line test. Teacher Alpha's treatment class appeared to be just starting the function material about relationships, tables, and graphs.

Since the starter activity was the same for treatment and control, both classes used the same three representations, on the starter exercise during the classroom observation. Teacher Alpha's control class completed an average of 2.18 representations during the twelve different activities whereas; the treatment class completed an average of 2.86 representations during the seven different activities. The Depth of Knowledge (Webb 2006) was the same, Level 2 (skill/concept), for Alpha's treatment and control class on the starter. Teacher Alpha's control class experienced an average Depth of Knowledge level of 1.81 during the twelve different activities. Teacher Alpha's treatment class experienced an average Depth of Knowledge level of 2.14 during the seven different activities. Teacher Alpha functioned at the same TPACK levels for both classes.

Teacher Alpha functioned at both Recognizing and Accepting levels of TPACK.

Teacher Alpha reported within the questionnaire that tables, graphs, mappings, coordinate planes, order pairs, linear equations, word problems and PowerPoint 
presentations were used as representations to teach functions in both the treatment class and control class. Teacher Alpha noted that prior to the study; both classes were using the Casio non-graphing scientific calculator. When this study began, Teacher Alpha's treatment class started using the TI-Nspire. Teacher Alpha noted some difficulties for both the teacher and the student in learning the new technology tool.

Teacher Alpha reported basically the same goals for both classes. Teacher Alpha provided some TI-Nspire specific goals for the treatment class. For example, Teacher Alpha stated that one goal for the treatment class was "to show how much time the TINspire can save them making tables and graphing functions." Other goals which were similar for both classes, but Teacher Alpha added a TI-Nspire component to the goal for the treatment class. For example, Teacher Alpha's control class had a goal that included relating formulas to the graphs and to be able to interpret what those graphs. Teacher Alpha's treatment class had this same goal except it was stated that students would be relating the formulas within the TI-Nspire to the graphs and then be able to interpret the meaning of those graphs.

In comparing the issues and benefits with the TI-Nspire, Teacher Alpha mentioned some of both for the treatment class. In addition to the learning curve issues that were previously stated, Teacher Alpha said that the time spent distributing the calculators and replacing batteries was an issue. Teacher Alpha stated that using and creating tables were much better with the TI-Nspire. Teacher Alpha said that "The emulator for the $\mathrm{N}$-spire was a great tool to be able to show the students how to do things on the calculators." Teacher Alpha also stated that the emulator was beneficial in answering student questions and working through questions as a class. Teacher Alpha 
also pointed out that students within the treatment class were better at interpreting data from graphs and in understanding their answers than were students in the control class.

Teacher Alpha noted fourteen state competencies for the control class and fifteen for the treatment class. The treatment class had the same competencies as the control with the addition of Course Level Expectation 3102.1.7. The objectives for Teacher Alpha's treatment class were the same as Teacher Alpha's control class with the addition of using the TI-Nspire to achieve the objectives.

The method of instruction differed in that the treatment class completed activities designed specifically for the TI-Nspire. Teacher Alpha noted that activities from the Texas Instruments website were used for the treatment class. These activities included the use of the TI-Nspire emulator, programs for the TI-Nspire, as well as, worksheets for the treatment class.

The same instructional strategies were used for both classes. The same types of assessments were used for both classes. Teacher Alpha also noted that the Casio calculator was used within the control class, while the treatment class used the TI-Nspire. Teacher Alpha noted within the lesson plans that both classes used auditory and visual learning styles, but only the treatment class used the kinesthetic learning style during this study.

To get a representative sample from the lesson plans, three days were chosen to compare lesson plans. The third day was chosen, because it was the first day teachers were teaching without giving a test or introducing the TI-Nspire, a new technology tool. The sixth day was chosen because it was halfway through the treatment. The eleventh day was chosen because it was the first day after the treatment had ended. 
The specific lesson plans on the third, sixth, and eleventh day were compared with regard to content, representations, and Depth of Knowledge. When comparing content on the third day, Teacher Alpha's treatment class used a TI-Nspire activity to cover the same objectives and goals as the control class. No difference in the type of representation of the Depth of Knowledge for Teacher Alpha's treatment class or control class was noted.

On the sixth day of the study, Teacher Alpha's lesson plans were different in comparing the treatment class to the control class. The state competencies, objectives, and homework assignments were all different. It was evident that the control class was further ahead of the treatment class in their study of function concepts. For example the control class covered section three of chapter 5 in the textbook, while the treatment class still reviewed chapter 4. Both of Teacher Alpha's classes had state competencies that were Level 2 (skill/concept) or Level 3 (strategic thinking). Both of Teacher Alpha's class had goals that were only Level 1 (recall) or Level 2. Teacher Alpha's control class objectives were more focused on geometric representations, while Teacher Alpha's treatment class objectives were more focused on numeric representations.

By the eleventh day of the study, Teacher Alpha's treatment class caught up with Teacher Alpha's control class. Both of Teacher Alpha's classes were at the same point within the textbook and with regard to the concepts covered within the class. The starter, state competencies, objectives and homework were the same for both classes.

The difference in assessments for Teacher Alpha's class focused on the TI-Nspire. While the control class did not participate in any Texas Instrument activities, the Teacher Alpha's control class used several. To compensate for the additional work for the 
treatment class, Teacher Alpha did not assign as much book work to the treatment class. All quizzes and test were the same for both the treatment class and control class. All quizzes and tests came from the textbook and were at either a Level 1 (recall) or Level 2 (skill/concept) Depth of Knowledge. In looking at the representations used, all quizzes and test used numeric, geometric, symbolic, analytic and written representations.

\section{Teacher Epsilon - Control Class}

Teacher Epsilon's control class was observed on the eighth day of treatment. During the observation, the activities within Teacher Epsilon's control classroom included a starter, review of the starter, a review lecture with demonstrations, guided practice with worksheet assignments, and homework. Teacher Epsilon began class with a set of equations on the board, and students were instructed to create input/output tables for each equation.

Teacher Epsilon completed the review of the starter exercises with a kinesthetic activity. Teacher Epsilon had the students stand and complete a cheer about slope using their arms to make an airplane. Students would "tilt their wings" to demonstrate positive, negative, zero and undefined slope. Teacher Epsilon then instructed students to write definitions of vocabulary words. Teacher Epsilon then used PowerPoint to review patterns, functions, and sequences. Students were given a review worksheet from the textbook. Teacher Epsilon then provided guided instruction as students worked through the worksheet activities. Toward the end of class, Teacher Epsilon reminded students of the procedure to use y-intercepts to graph and write equations. At the end of class, Teacher Epsilon instructed students that the remaining exercises on the worksheet were to be completed for homework. 
The activities within Teacher Epsilon's control classes contained an average of 1.93 representations per problem. For example, when Teacher Epsilon's control class was instructed to complete the starter exercise, students used both numeric and symbolic representations. When writing definitions, students were only using writing as a representation. When working worksheet exercises on patterns and sequences, students only used symbolic representations. When Teacher Epsilon's control class students worked worksheet exercises that had them create a table of coordinates from a graph to then form an equation, students used numeric, geometric, and symbolic representations.

In looking at the Depth of Knowledge for Teacher Epsilon's control class, the starter was a Level 2 (skill/concept) activity. The kinetic cheer and writing of definitions were both Level 1 (recall) activities. The exercise of writing the equation of a graph after choosing coordinates within a table was a Level 2 activity. Teacher Epsilon's control class experienced an average Depth of Knowledge level of 1.43 .

Teacher Epsilon appeared to be at the TPACK Recognizing level and somewhat into the Accepting level. While Teacher Epsilon had access to an emulator and projector in the classroom, neither technology tool was used during the observation. Teacher Epsilon used the non-graphing scientific calculators to instruct the control class students on completing calculations and to reinforce the concepts taught. Teacher Epsilon's participation in professional development workshops that were about integrating technology into the mathematics classroom would continue to be at an Accepting level. By allowing students to use the Casio non-graphing scientific calculators to perform calculations while working on mathematics problems, Teacher Epsilon continued to demonstrate an Accepting level of TPACK. 
Over the course of this study, Teacher Epsilon reported in the questionnaire that tables, graphs, mappings, coordinate plane, order pairs, function notation, linear equations, graphic organizers and real world problems were used as representations to teach functions to the control class. Teacher Epsilon provided weekly examples of how the representations had been linked together while teaching. For example, Teacher Epsilon stated that "Students determined whether an equation was linear by examination of the equation." Teacher Epsilon noted that "tables, ordered pairs, and the coordinate plane were used in graphing linear equations," "various representations were used to solve contextual problems," and "scatter plots were used to determine correlations" in the control class.

Teacher Epsilon responded in the questionnaire that Casio non-graphing scientific calculators were used every day of the study for the control class. Teacher Epsilon also reported that the computer and projector were used most days for instruction within the control class. Teacher Epsilon also used individual-sized dry erase boards on which the students in the control class students drew graphs. The only issue reported by Teacher Epsilon within the control class was that students seemed to get off task when working with the individual dry erase boards.

When asked about the goals for the control class with respect to learning functions, Teacher Epsilon responded with goals that included mastering vocabulary, graphing points on the Cartesian plane, determining domain and range, and finding slope when using the slope formula. Teacher Epsilon also listed the goals of identifying independent and dependent variables using real-life examples, writing equations from patterns, and using function notation. Specifically Teacher Epsilon stated that students 
were to "determine if a relation is a function from its graph, from ordered pairs, from a mapping, and from a table."

Within the questionnaire, Teacher Epsilon was asked to provide examples of how the tools were used within the control class to teach functions. Teacher Epsilon indicated that a PowerPoint was used to introduce concepts and produce model examples and that the Casio non-graphing scientific calculators were used to compute and reinforce concepts. Teacher Epsilon explained that the coordinate plane dry erase board was used by the teacher to plot points and draw lines while the students used individual dry erase boards. Teacher Epsilon also indicated that various mappings such as concept maps or thinking maps, such as the Frayer Model, were used to map selected words, attributes, and representations.

When asked about what Teacher Epsilon was able to teach better or more easily using the tools with the control class, Teacher Epsilon remarked that within the control class, the same tools that were used all year were still used, and, as such, nothing really was better or easier to teach. Teacher Epsilon stated that individual-sized dry erase boards helped "create more involvement for some students." Teacher Epsilon added that "students had rather watch a PowerPoint than constantly see and listen to the teacher."

When asked for additional comments concerning the control class within the questionnaire, Teacher Epsilon stated that "The individual graphing (dry erase) boards and physically modeling slope helped create interest and involvement in the lessons." Teacher Epsilon surmised that within the control class, "Many students are having difficulty with these (function) concepts and having to complete multiple steps.” Teacher 
Epsilon added that "determining the desired outcome seems to be a problem" for the control class students.

In looking at the lesson plans, the methods of instruction used by Teacher Epsilon with the control classes varied each day. The starter activities included copying notes, reviewing homework, studying for the upcoming quiz, textbook exercises, and working exercises written on the dry erase board. Examples of Teacher Epsilon's control class starters included review vocabulary, copying outlines from the dry erase board, reviewing ordered pairs, and doing exercises $37-42$ on page 245. Teacher Epsilon used lecture, PowerPoint, thinking maps, Frayer model, and the dry erase board. Teacher Epsilon used a variety of instructional strategies including cooperative learning, small group activities, large group activities, guided practice and independent practice. The main instructional strategies used were large group activities, guided practice and independent practice.

Teacher Epsilon noted within the lesson plans that the technology used for the control class was PowerPoint presentations, which was used on most days, a website with the computer and projector, and the Casio non-graphing scientific calculator. Teacher Epsilon remarked that, within the control class lesson plans, the learning styles included auditory, visual, and kinesthetic examples. Examples of kinesthetic learning involved Teacher Epsilon's control class use of painter's tape and index cards to create a coordinate graph on the classroom floor. Beyond the use of test and quizzes for assessment, Teacher Epsilon noted in her the lesson plans that observations were used daily and active votes were used on most days to assess students within the control class.

A lesson plan analyses were done on the third, sixth and eleventh day to examine content, Depth of Knowledge (Webb, 2006) and the types of representations used for 
Teacher Epsilon's control class. The content covered was compared to the content areas that were used with the pre-test, post-test and post post-test as listed in Appendix F. On the third day, Teacher Epsilon's control class starter was copying notes from the board which is a Level 1 (recall) activity using written representations. Teacher Epsilon listed three state competencies which covered the function content area (item 1, item 2, item 3 , item 4, item 6, item 7, and item 10). These competencies had a range of Depth of Knowledge from Level 1 to Level 3 (strategic thinking). For example, the state competency Check for Understanding 3102.3.15 (Determine domain and range of a relation and articulate restrictions imposed either by the operations or by the real-life situation that the function represents) was over the function concept (item 3 and item 7) at a Depth of Knowledge Level 3. Two stated goals of the class for the third day were the function content area (item 1, item 2, and item 4) and were at either a Level 1 or Level 2 (skill/content) Depth of Knowledge. For example, one stated goal was for students to find function values. This goal covered the function concept (item 2 and item 4) at a Level 1 Depth of Knowledge using both numeric and analytic representations. All goals included numeric representations. One goal included geometric and symbolic representations, while the other goal included analytic representations only. In looking at the textbook exercises assigned for homework, the concepts covered were within the function content area (item 1, item 2, item 4, item 9, and item 10) at Level 1, Level 2 or Level 3 Depth of Knowledge and used numeric, geometric, symbolic, and analytical representations.

On the sixth day, Teacher Epsilon's control class starter was returning a quiz the students had taken during the previous class period. For the lesson that day, Teacher 
Epsilon listed one state competency which covered the function content area (item 1 and item 8). This competency had a Depth of Knowledge of Level 2. Two stated goals for the class on the sixth day of the study were in; the graphing content area (item 13) had a Depth of Knowledge of either Level 1 or Level 2. The first goal included geometric and analytic representations. The second goal included geometric, symbolic and analytic representations. In looking at the worksheet assigned for homework, the graphing concept area (item 13) was covered at a Level 2 Depth of Knowledge and used geometric, symbolic, and analytical representations.

On the eleventh day, Teacher Epsilon's control class starter was returning a test the students had taken during the previous class period. Teacher Epsilon listed two state competencies which covered the graphing content (item 12). These competencies had a Depth of Knowledge of Level 1 and Level 2. Two goals of the class were stated for the eleventh day; neither goal covered a content area that was represented on the pre-test, post-test, or post post-test. The stated goals were at either a Level 1 or Level 2 Depth of Knowledge. One goal included geometric and symbolic representations, while the other included symbolic and analytic representations. The worksheet assigned for homework, revealed that the concepts again were not listed within the content areas covered on the pre-test, post-test or post post-test. The homework assignment was at a Level 2 and used both symbolic and analytical representations.

When analyzing the assessments used within Teacher Epsilon's control class, the starter activities focused on note taking, review of homework exercises, or similar review activities. Teacher Epsilon used both real-life examples and technology by using problems from "USA Today." Teacher Epsilon also had the students use individual dry 
erase boards to work examples and exercises. Teacher Epsilon's control class had all the homework assignments directly from the textbook or textbook worksheets. Teacher Epsilon's control classes had both quizzes and tests. While vocabulary was reviewed during the starters, the assessments do not indicate that there was a quiz on it. The quizzes were given as starters and represented exercises from the book. The chapter tests were from the textbook publishers.

Teacher Epsilon - Treatment Class

Teacher Epsilon's treatment class was observed on the eighth day of treatment, the same day as the control class. During the observation, the types of activities within Teacher Epsilon's treatment class included a starter, TI-Nspire emulator use, vocabulary review, Texas Instrument website activity, guided practice, independent practice, and textbook work. Teacher Epsilon's treatment class starter was different from Teacher Epsilon's control class starter. Treatment class students were instructed to find the domain and range when given an equation such as $y=2 x-1$. As students completed this activity, Teacher Epsilon passed out the TI-Nspire calculators.

Teachers Epsilon reviewed the starter problems and allowed the discussion to lead directly into the vocabulary review. Teacher Epsilon then used the TI-Nspire Emulator to demonstrate how to solve the starter problem step-by-step with the TI-Nspire graphing calculator. Teacher Epsilon then introduced an activity called "Graphing Linear Equations" from the Texas Instruments website. Students were given a handout from the website and instructed to "Use the TI-Nspire calculator spreadsheet tool and graphing functions to solve problems by making tables of $\mathrm{x}$ values, give the function, come up with the ordered pairs, and graph the function." As the students worked through the 
worksheet, Teacher Epsilon provided individual guidance and instruction both on how to use the TI-Nspire and how to complete the worksheet. Upon completion of the worksheet, students were instructed by Teacher Epsilon to complete a textbook assignment.

The exercises within Teacher Epsilon's treatment class contained an average of 3.08 representations per activity. Teacher Epsilon's treatment class starter included both numeric and symbolic representations. For the Graphing Linear Equations activity, students worked with tables, plotted ordered pairs, made graphs, and wrote equations. In completing this exercise, students used numeric representations within the table, geometric representations within the graph, symbolic representations within the equations, and analytical representations in choosing ordered pairs. Teacher Epsilon's textbook assignment was a word problem requiring them to analyze and write with representations.

Teacher Epsilon's treatment class's starter exercise had the same cognitive complexity (Level 2) as the control class. In reviewing vocabulary, Teacher Epsilon's treatment class was doing a Level 1 (recall) activity. When students were completing the Graphing Linear Equation activity as explained above, the treatment class was working Level 2 (skill/concept) exercises. Teacher Epsilon's treatment class experienced an average level of 2.00 Depth of Knowledge.

Within Teacher Epsilon's treatment class, Teacher Epsilon demonstrated TPACK level of Accepting. Teacher Epsilon was willing to participate in TI-Nspire professional development activities and to teach using the TI-Nspire in the treatment classes. Teacher Epsilon used both the projector and emulator within the treatment classes to illustrate 
concepts. For example, Teacher Epsilon demonstrated an Accepting level with the emulator technology by using it as an extension of review for the starter exercise.

Within the treatment class, Teacher Epsilon reported using the same types of representations as the control class. Teacher Epsilon provided weekly examples of how the representations had been linked together while teaching. The examples for the treatment class were the same as the control class with the addition of one example. Teacher Epsilon indicated that "Graphing was used to investigate how changing the yintercept modified the linear equation."

Teacher Epsilon responded within the treatment class questionnaire that the TINspire graphing calculator was used 80 percent of the time. Teacher Epsilon shared the personal difficulties of learning how to load programs onto TI-Nspire emulator and learning how to use it. Teacher Epsilon also said that it was time consuming to load all of the programs on the individual calculators, having to daily pass them out, and in dealing with low batteries. Teacher Epsilon expressed the difficulties of "students having problems finding the correct commands on the calculator." Teacher Epsilon felt like the concepts were not learned because students were "playing or typing notes to each other, instead of doing their work."

When asked about the goals for the treatment class with respect to learning functions with the TI-Nspire, Teacher Epsilon responded that one goal was "to web more concepts together using the TI-Nspire." Teacher Epsilon also included goals such as mastering vocabulary, determining domain and range, identifying a relation as a function, using function notation, and writing equations symbolically to express a contextual problem. Teacher Epsilon listed the goal for students to be able to "understand that a 
linear equation has a constant rate of change called slope" and to be able to "represent slope in various forms." Teacher Epsilon added that another goal was for students to be able to "identify independent and dependent variable using real-life examples and be able to write tables, equation rules, and graph to represent the problem."

Teacher Epsilon provided examples of how the TI-Nspire was used within the treatment classroom. Teacher Epsilon listed programs designed for the TI-Nspire such as Scavenger Hunt, What's the Point, and Introduction to Functions, which were downloaded from the Texas Instruments website. Teacher Epsilon stated that students would "graph equations from tables, ordered pairs, and equation rules." Teacher Epsilon said that students would move a line up and down the y-axis and then see the effects on the equation or the student would input multiple equations with different slopes to see the effect on the graphs.

When asked about what Teacher Epsilon was able to teach better or more easily using the TI-Nspire than other tools in the treatment class, Teacher Epsilon stated that "The TI-Nspire allows you to web concepts together such as incorporating dependent and independent variables while graphing real-life situations and determining if there is a positive correlation, no correlation or a negative correlation between the variables." Teacher Epsilon remarked that the TI-Nspire simplified finding slope using the control/divide feature. Teacher Epsilon went on to say that "The TI-Nspire allows you to model different representations of functions using the split screen or easily move between tables, equations and graphs." Teacher Epsilon also said, "Using the TI-Nspire allows students to discover important concepts rather than the teacher having to constantly lecture and model." 
When asked for additional comments, Teacher Epsilon stated that treatment class was a large class and the students were very social. Teacher Epsilon went on to say that "The students are still more interested in the TI-Nspire as a new toy than as a learning tool." Teacher Epsilon summarized the study by saying, "I like the TI-Nspire, but have had some difficulty with using it and getting students to follow directions using it." Teacher Epsilon also expressed concern about the cost to purchase the TI-Nspire due to other computer and infrastructure needs within the school.

In the lesson plan analysis, Teacher Epsilon listed seven fewer state competencies for the treatment class than Teacher Epsilon had listed on the lesson plans for the control class. While Teacher Epsilon's treatment class objectives appeared different from Teacher Epsilon's control class, the objectives were simply worded differently by including the use of the TI-Nspire or other technology within the objective. Teacher Epsilon's treatment class had different objectives than the control class when using the Texas Instruments website activities. For example, while Teacher Epsilon's control class included objectives on the use of the dry erase board and coordinate plane, Teacher Epsilon's control class would use the emulator and the TI-Nspire to complete those same objectives.

The methods of instructions used by Teacher Epsilon's treatment class varied each day. The types of starter activities were the same for both classes. In Teacher Epsilon's treatment class, the same methods of instruction were used as in Teacher Epsilon's control class. The only difference was the use of the emulator and the TINspire. Teacher Epsilon's treatment class had fewer thinking map activities than the control class, but had additional small group activities. For example, one small group 
activity in Teacher Epsilon's treatment class was an experiment using baggies with washers and rubber bands. The main instructional strategies were the same for both classes.

Within the lesson plans, Teacher Epsilon noted that the technology used in the treatment class was the same as that of the control class with the addition of the emulator and the TI-Nspire calculator. Teacher Epsilon noted that the treatment class used the TINspire every day. The learning styles within Teacher Epsilon's treatment class were the same as Teacher Epsilon's control class. The types of assessments listed on the lesson plan by Teacher Epsilon for the treatment class were the same as those for the control class.

A lesson plan analysis was conducted on the third, sixth and eleventh day to examine content, Depth of Knowledge (Webb, 2006), and the types of representations used for the Teacher Epsilon's treatment class. On the third day, Teacher Epsilon's treatment class lesson plan was exactly like Teacher Epsilon's control class. The only exception was that the treatment class did not include one state competency (Course Level Expectation 3102.3.25). While the content area for Teacher Epsilon's treatment class was the same as the control class, the treatment class did not cover item 4 or item 10. Teacher Epsilon listed the same goals and homework for the treatment class as the control class; therefore the content areas, Depth of Knowledge, and types of representations were all the same.

On the sixth day of the study, Teacher Epsilon's treatment class lesson plan was totally different from that of the control class. The control class did not include a starter; however, the treatment class starter covered content area 1 with a Level 2 (skill/concept) 
Depth of Knowledge while using numeric, geometric and symbolic representations. Teacher Epsilon listed two different state competencies for the treatment class which covered the same function content area as the control class. While the control class covered item 1 and item 8 , the treatment class covered item 1 , item 2 , item 3 , item 6 , and item 7. The competencies for the treatment class had either a Level 1 (recall) or Level 3 (strategic thinking) Depth of Knowledge. The two stated goals included the function content areas (item 1, item 2, and item 4) at a Level 1 and Level 2 Depth of Knowledge. While one goal included numeric, geometric, and symbolic representations, as the other goal included numeric, symbolic, and analytical representations. The homework assigned to Teacher Epsilon's treatment class was a textbook worksheet covering the function concept (item 2 and item 4) at a Level 2 Depth of Knowledge and used numeric, geometric, symbolic, and analytical representations. The homework for Teacher Epsilon's treatment class was different from the control class.

On the eleventh day of the study, Teacher Epsilon's treatment class lesson plan was exactly the same as Teacher Epsilon's control class lesson plan. The classes had the same starter, same state competencies, same goals, and the same homework. The classes also covered all of the content areas, Depth of Knowledge, and types of representations used the same as well.

When analyzing the assessments, Teacher Epsilon's treatment class had the same types of starter activities as Teacher Epsilon's control class. When it came to classroom activities, Teacher Epsilon's treatment class did not do the coordinate plane activity with tape and index cards, but they completed the USA Today website and Texas Instruments website activities. While both classes used textbook worksheets and textbook 
assignments, Teacher Epsilon's treatment class was only assigned the odd exercises. Teacher Epsilon's treatment class had the same type of homework as the control classes, most of which were textbook worksheets. Both classes used the same outlines, notes, quizzes and tests.

\section{Across Teacher Epsilon's Treatment and Control Classes}

Both of Teacher Epsilon's classes had the same starter, but the remainder of the lesson was different. Teacher Epsilon's control class reviewed slope and then covered the concepts of patterns, functions, and sequences. Teacher Epsilon's treatment class completed the Texas Instruments activity called "Graphing Linear Equations."

Since the starter activity was the same for treatment and control, both classes used the same number of representations, on the starter exercise during the classroom observation. Teacher Epsilon's control class completed an average of 1.93 representations during the fourteen different activities. Teacher Epsilon's treatment class completed an average of 3.08 representations during the thirteen different activities. The Depth of Knowledge (Webb 2006) was also the same, Level 2 (skill/concept), for Teacher Epsilon's treatment and control class on the starter. Teacher Epsilon's control class had an average Depth of Knowledge level of 1.43 during the fourteen different activities. Teacher Epsilon's treatment class experienced an average Depth of Knowledge of 2.00 during the thirteen different activities. Teacher Epsilon functioned at the Recognizing and Accepting TPACK levels for the control class; however, Teacher Epsilon was closer to the Accepting TPACK level for the treatment class.

Teacher Epsilon reported within the questionnaire that tables, graphs, mappings, coordinate planes, order pairs, function notation, linear equations, graphic organizers, and 
word problems were used as representations to teach functions within both the treatment class and control class. Teacher Epsilon noted that prior to the study, both classes used the Casio non-graphing scientific calculator. When this study began, Teacher Epsilon's treatment class started using the TI-Nspire. Teacher Epsilon noted some difficulties for both the teacher and the student in learning the new technology tool in particular for the teacher when loading new programs on the emulator and calculators.

Teacher Epsilon reported generally the same goals for both classes. Teacher Epsilon provided some TI-Nspire specific goals for the treatment class. For example, Teacher Epsilon stated that one goal for the treatment class was "web more concepts together using the TI-Nspire." Most goals were similar for both classes, but Teacher Epsilon added additional goals for the treatment class. For example, one focused on slope and represented it in various forms while another specifically indicated that students would be able to "identify independent and dependent variable using real-life examples and be able to write tables, equation rules, and graphs to represent the problem."

In comparing issues with and benefits of the TI-Nspire, Teacher Epsilon mentioned the initial process of learning to use the TI-Nspire. In addition to the learning curve issues that were previously stated, Teacher Epsilon said that the time spent distributing calculators, replacing batteries, and loading programs on each calculator was an issue. Teacher Epsilon also expressed issues in learning to use the emulator. Teacher Epsilon also pointed out issues for the treatment class students in that they would not follow specific directions in using the calculator and had trouble learning the correct commands. Teacher Epsilon also shared that the control classes had difficulty 
assimilating all of the information in order to do all the steps to complete some of the more difficult problems.

While examining Teacher Epsilon's lesson plans, Teacher Epsilon noted eleven state competencies for the control class and eighteen for the treatment class. The treatment class had seven more state competencies than the control class. The objectives for Teacher Epsilon's treatment class were the same as Teacher Epsilon's control class with the addition of using the TI-Nspire to achieve the objective.

The method of instruction differed in that the treatment class completed activities designed specifically for the TI-Nspire. Teacher Epsilon noted that activities from the Texas Instruments website were used for the treatment class. These activities included the use of the TI-Nspire emulator, programs for the TI-Nspire, and worksheets for the treatment class. While Teacher Epsiion's treatment class would use TI-Nspire emulator, Teacher Epsilon's control class would use the individual dry erase boards. Teacher Epsilon also noted that the treatment class also had fewer thinking map activities.

The same instructional strategies and learning styles were used for both of classes. The same types of assessments were used for both classes. Teacher Epsilon also noted that the control class used the Casio calculator and the treatment class used the TI-Nspire.

Specific lesson plans on the third, sixth, and eleventh day were compared for content, representations, and Depth of Knowledge. When comparing content on the third day, Teacher Epsilon's treatment class covered one less state competency as the control class. However, the goals and homework were the same for both classes. The type of representation of the Depth of Knowledge for Teacher Epsilon's treatment class and control class was not different. 
By the sixth day of the study, Teacher Epsilon's lesson plans were very different when comparing the treatment class and control classes. The state competencies, objectives, and homework assignments were all completely different. The control class was further ahead of the treatment class in their study the function concepts. For example the control class covered section five of chapter 4 in the textbook, while the treatment class covered section three of chapter 4. Teacher Epsilon's treatment class stated competencies were at a Level 1 (recall) and a Level 3 (strategic thinking) Depth of Knowledge, but the control class had a state competency with a Level 2 (skill/concept) Depth of Knowledge. The treatment class goals were Level 2, while the control class goals were Level 1 and Level 2. Teacher Epsilon's treatment class objectives were more focused on numeric and symbolic representations, while Teacher Epsilon's control class objectives were focused more on geometric and analytic representations. The homework assignments in both were worksheets that covered different content areas, but had the same Level 2 Depth of Knowledge. Both covered geometric, symbolic, and analytic representations, however, the treatment class homework worksheet also included numeric representations.

By the eleventh day of the study, Teacher Epsilon's treatment class had caught up with Teacher Epsilon's control class. Both of Teacher Epsilon's classes were at the same point within the textbook and in the concepts covered within the class. The starter, state competencies, objectives and homework were the same for both classes.

The difference in assessments for Teacher Epsilon's class focused on the TINspire. While the control class did not participate in any Texas Instrument activities, the Teacher Epsilon's control class used several. To compensate for the additional work for 
the treatment class, Teacher Epsilon did not assign as many worksheets to the treatment class. All quizzes and tests were the same for both of Teacher Epsilon's treatment class and control class. All quizzes and tests came from the textbook and were at either a Level 1 (recall) or Level 2 (skill/concept) Depth of Knowledge. In looking at the representations used, all quizzes and test used numeric, geometric, symbolic, analytic and written representations.

\section{Teacher Gamma - Control Class}

Teacher Gamma's control class was observed on the fourth day of treatment. The activities within Teacher Gamma's control classroom included a starter, review of the starter, a review lecture with demonstrations, guided practice with worksheet assignments, and homework. Teacher Gamma began class with the equation $y=3 x+1$ on the board, and students were instructed to determine whether or not it was a function.

Teacher Gamma completed the review of the starter exercise by graphing the equation on the starter equation on the board and then reviewing the concepts of coordinate plane, quadrants, and ordered pairs. Teacher Gamma then reviewed how to use tables and mappings to explain about domain and range and how to determine which mappings are functions. Teacher Gamma continued to refer back to the starter equation to continue building on the exercise. Teacher Gamma then reviewed scatter plots and correlations. Teacher Gamma then had the control class students stand and do a relaxation activity. At the completion of the relaxation activity, Teacher Gamma distributed a quiz, which was a textbook worksheet.

The activities within Teacher Gamma's control classes contained an average of 2.08 representations per problem. For example, when Teacher Gamma's control class 
was instructed to complete the starter exercise, students used only symbolic representations. When Teacher Gamma demonstrated the mapping of points from an equation, students used numeric and symbolic representations. When completing the quiz, students used different combinations of numeric, geometric, and symbolic representations.

In looking at the Depth of Knowledge for Teacher Gamma's control class, the starter was a Level 1 (recall) activity. When finding points from an equation and then mapping them, students completed a Level 2 (skill/concept) activity. Teacher Gamma's control class completed Level 1 and Level 2 Depth of Knowledge exercises while working on the quiz. Teacher Gamma's control class experienced an average Depth of Knowledge level of 1.82 .

Teacher Gamma appeared to be at the Accepting TPACK level. While teaching the control class, Teacher Gamma used the overhead projector to teach students the function concepts. Teacher Gamma also used non-graphing scientific calculators to assist control class students in completing calculations and reinforcing concepts. Teacher Gamma also allowed students to use calculators to perform calculations while working on various mathematics exercises. Teacher Gamma's participation in professional development workshops about technology was at a Accepting TPACK level.

Over the course of this study, Teacher Gamma reported within the questionnaire that tables, graphs, mappings, coordinate plane, order pairs, function notation, linear equations, patterns and sequences were used as representations to teach functions to the control class. Teacher Gamma provided weekly examples of how the representations had been linked together while teaching. Teacher Gamma stated that the students completed 
various exercises translating among graphs, mappings, tables, and ordered pairs. For example, Teacher Gamma also noted that "Tables were used to created equations. Equations were used to find a $\mathrm{y}$-value for a particular $\mathrm{x}$, and an $\mathrm{x}$-value for a particular y."

Teacher Gamma responded in the questionnaire that Casio non-graphing scientific calculators were used every day of the study for the control class. Teacher Gamma also responded that the computer and projector were used half of the time for instruction within the control class. Teacher Gamma also recorded the use of both a classroom dry erase board and individual sized dry erase boards on which the control class students drew graphs.

In regard to issues, Teacher Gamma stated on the control class questionnaire that "Students had trouble with the worksheets until they used the whiteboards to see the representation of functions." Teacher Gamma also stated that when teaching linear equations to the control class, the students were "having difficulty grasping slope as rise over run." During the last week of this study, Teacher Gamma said,

"The tasks for this week required the students to put together what they had learned over a couple of weeks, such as slope, y-intercepts, different forms of linear equations and what information each form gives, etc., in order to find the linear equations from various starting points. They (control class students) had a great deal of difficulty with this. I had to re-teach almost all the building concepts. They did not even seem to remember how to graph an equation when given the y-intercept and slope." 
When asked about the goals for the control class with respect to learning functions, Teacher Gamma responded with goals including mastering vocabulary, graphing points on the Cartesian plane, determining domain and range, and identifying independent and dependent variables using real-life examples. Teacher Gamma also listed the goals of writing equations in function notation, mastering the vertical line test, and graphing equations using the slope-intercept form. Specifically, Teacher Gamma stated that students were to "determine if a relation is a function from its graph, from ordered pairs, from a mapping and from a table."

Within the questionnaire, Teacher Gamma was asked to provide examples of how the tools were used within the control class to teacher functions. Teacher Gamma shared that PowerPoint was used to illustrate vocabulary as well as introduce and model all goals. Teacher Gamma explained that the "students used their whiteboards to practice graphing a y-intercept and an additional point, finding the slope as rise over run, and writing the resulting equation." Teacher Gamma commented further, "students used the whiteboard to plot an $\mathrm{x}, \mathrm{y}$ table of values and see how a straight line connected the values."

When asked about what Teacher Gamma was able to teach better or more easily using the tools with the control class, Teacher Gamma remarked that within the control class, the same tools that were used all year were still used and, as such, there was nothing really that was better or easier to teach. Teacher Gamma did state that "graphing on the individual whiteboards seemed to help the students grasp the concept of slope as rise over run." 
When asked for additional comments concerning the control class within the questionnaire, Teacher Gamma stated that "My students really enjoyed this PowerPoint presentation. The animation seemed to excite the students. It made the students almost as interested as the students in the treatment class." Teacher Gamma also remarked that the control class students were "easily able to find the linear equation for ordered pairs. However, their understanding does not appear to be complete. When going from an equation to a graph, they struggle to know how to start at the y-intercept, how to use the slope to determine the next point." Teacher Gamma added that "I felt that they (control class students) are not comprehending the concepts as well as my treatment class."

Teacher Gamma also provided some additional comments regarding the entire study within the final control questionnaire. Teacher Gamma stated that "This study reinforced for me the necessity for developing interesting, engaging lessons. In addition, I saw how much better the students comprehend the lesson when various methods are used in conjunction with each other to reinforce the concepts." Teacher Gamma added that while the lessons and tasks were basically identical for both classes, "The control class typically picks up the concepts better, but they seem to also need more re-teaching than the Nspire (treatment) class."

Within the lesson plan analysis, the methods of instructions used by Teacher Gamma with the control classes varied each day. While Teacher Gamma only had starters listed on the control class lesson plans for half of the days, those starter activities included textbook worksheet exercises, textbook "Chalkboard 5-minute checks", reviewing homework, textbook exercises, and working exercises written on the dry erase board. Examples of Teacher Gamma's control class starters including having the control 
class students "compute slope for several sets of ordered pairs using the slope formula." Teacher Gamma used lecture, PowerPoint, projector, and the dry erase board to teach the control class. Teacher Gamma used a variety of instructional strategies including cooperative learning, small group activities, large group activities, guided practice and independent practice. The main instructional strategies used were large group activities, guided practice and independent practice. Independent practice was used every day, while guided practice was used on all days except test days.

Teacher Gamma noted within the lesson plans that technology used for the control class included PowerPoint, computer with projector, and the Casio non-graphing scientific calculator. Teacher Gamma remarked that, within the control class lesson plans, the learning styles included auditory, visual, and kinesthetic examples. Examples of the kinesthetic learning involved Teacher Gamma's control class using the individual dry erase boards. Beyond the use of tests and quizzes for assessment, Teacher Gamma noted within the lesson plans that observations were used daily to assess students within the control class.

A lesson plan analysis was conducted on the third, sixth and eleventh day to examine content, Depth of Knowledge (Webb, 2006) and the types of representations used for the Teacher Gamma's control class. The content covered was compared to the content areas that were used with the pre-test, post-test and post post-test as listed in Appendix F. On the third day, Teacher Gamma's control class starter covered graphing content (item 11) at a Level 1 (recall) Depth of Knowledge while using geometric representations. Teacher Gamma listed two state competencies which covered function content (item 1, item 3, item 4, and item 7). These competencies had a Depth of 
Knowledge at either Level 2 (skill/concept) or Level 3 (strategic thinking). For example, the competency State Performance Indicator 3102.3.6 (Interpret various relations in multiple representations) covered the function concept (item 1 and item 4) at a Level 2 Depth of Knowledge. Four stated goals were included in the class for the third day, the content included functions and graphing (items 1 , item 2 , item 3 , item 4 , item 7 , item 9 , item 10, item 11, and item 13) and was at a Level 1, Level 2, or Level 3 Depth of Knowledge. For example, the goal of having student graph coordinate points using rise and run covered the graphing concept (item 11 and item 13) at a Level 1 Depth of Knowledge while using geometric and symbolic representations. All goals included geometric representations. Two goals also included numeric representations; two included symbolic representations; and two included analytic representations. No homework was assigned according to Teacher Gamma's control class lesson plan. On the sixth day, Teacher Gamma's control class starter covered the function content area (item 1, item 2, and item 4) at a Level 2 on Webb's Depth of Knowledge, and used both numeric and geometric representations. Teacher Gamma listed two state competencies which covered the function content area (item 1 , item 3 , and item 7). These competencies had a range of Depth of Knowledge going from Level 2 to Level 3. Two stated goals of the class for the sixth day covered the function content area (item 1, item 2, and item 4) at a Level 1 or Level 2 Depth of Knowledge. One goal included geometric representations, while the other goal included numeric, symbolic, and analytic representations. The worksheet exercises assigned for homework focused on the concepts covered within the function content area (item 1, item 3 , and item 4) at a Level 2 Depth of Knowledge while using geometric and analytical representations. 
On the eleventh day, Teacher Gamma's control class starter covered graphing content (item 13) at a Level 2 Depth of Knowledge using geometric, symbolic, and analytic representations. Teacher Gamma listed three state competencies which covered function and graphing content (item 9 and item 12). These competencies had a Depth of Knowledge of Level 1 to Level 3. Three stated goals of the class for the eleventh day were not listed within the content areas covered on the pre-test, post-test or post post-test. The goals were at a Level 1, Level 2, or Level 3 Depth of Knowledge. All goals included both geometric and symbolic representations. One goal also included analytic representations. No homework assignments were listed within Teacher Gamma's lesson plan for the eleventh day of this study.

When analyzing the assessments used within Teacher Gamma's control class, the starter activities were typical textbook exercises which were presented in the form of "Chalkboard 5-minute checks," worksheets and other textbook exercises written on the board for students to work. Teacher Gamma also had the students use individual dry erase boards to work examples and exercises. Teacher Gamma did not list any homework assignments on the control class lesson plans; however, Teacher Gamma submitted copies of classroom assessments that were used for this study. The assignments that Teacher Gamma submitted for the control class had both classwork and homework from the textbook or textbook worksheets. Teacher Gamma's control classes had both quizzes and tests. While vocabulary was reviewed during the starters, the assessments did not indicate that there was a quiz on it. The quizzes were given as starters and included exercises from within the book. The chapter tests were from the textbook publishers. 


\section{Teacher Gamma - Treatment Class}

Teacher Gamma's treatment class was observed on the fourth day of treatment, the same day as the control class. During the observation, the types of activities within Teacher Gamma's treatment class included TI-Nspire emulator use, vocabulary review, guided practice, independent practice, and a quiz. Teacher Gamma's treatment class started differently from Teacher Gamma's control class starter. The treatment class started with distribution of the TI-Nspire calculators to the students and collection of homework papers.

Teachers Gamma reviewed coordinate planes, points, domain and range. Teacher Gamma then used the TI-Nspire Emulator to provide guided review and had students create a table from the equation $y=x+5$. Teacher Gamma then instructed her treatment class to create a mapping from the same equation. Teacher Gamma then reviewed inverses and instructed the students to make a table on the TI-Nspire calculator. Students were then instructed to create graph from $y=2 x-1$ by finding points, creating tables, creating a mapping, and inverses. Teacher Gamma then reviewed that problem and distributed a worksheet for the control class to complete as a quiz. The quiz was the same one given to the control class earlier.

The exercises within Teacher Gamma's treatment class contained an average of 2.22 representations per activity. Teacher Gamma's treatment class activity having students create a table from the equation $y=x+5$ included numeric, symbolic, and analytic representations. For the inverse activity, students worked with tables, plotting ordered pairs, making graphs, writing equations, and mapping. In completing this exercise, students used numeric representations within the table, geometric 
representations within the graph, symbolic representations within the equations, and analytical representations to choose the ordered pairs and mapping. Teacher Gamma's quiz required students to use geometric, symbolic and analytical representations.

Teacher Gamma's treatment class' first exercise had the same Depth of Knowledge (Level 1) as the control class's starter activity. In reviewing vocabulary, Teacher Gamma's treatment class did a Level 1 (recall) activity. When completing the inverse activity as explained above, the treatment class worked with both Level 2 (skill/concept) and Level 3 (strategic thinking) exercises. Teacher Gamma's treatment class experienced an average level of 1.89 Depth of Knowledge.

Within Teacher Gamma's treatment class, Teacher Gamma demonstrated the same TPACK Accepting level as the within the Teacher Gamma's control class. All teachers were willing to participate in TI-Nspire professional development activities and to teach using the TI-Nspire within their treatment classes. Teacher Gamma used both the projector and emulator within the treatment classes to illustrate concepts. For example, Teacher Gamma demonstrated an Accepting level with the emulator technology by using it as an extension for reviewing inverse relations.

Within the treatment class, Teacher Gamma reported on the questionnaire using the same types of representations as the control class. Teacher Gamma provided weekly examples of how the representations had been linked together during teaching. The examples for the treatment class were much like the control class with the addition of examples using the TI-Nspire graphing calculator. Teacher Gamma indicated that "Students used the list function on the Nspire to enter $f(x)$ and $x$ values to determine values for $\mathrm{f}(\mathrm{x})$." Teacher Gamma also noted that "Using the Nspire, students practiced 
finding the rise over the run. They graphed 2 coordinate points, determined rise over run, identified the y-intercept, and displayed the equation using the menu action/coordinates and equations options." Teacher Gamma added "The students also found the slope using algebraic methods and verified their results $n$ the Nspire."

Teacher Gamma responded within the treatment class questionnaire that the TINspire graphing calculator was used daily. Teacher Gamma shared the personal difficulties during the first week of this study stating that "This week, I have not been confident in my presentation, and the lesson suffers as a result." Teacher Gamma explained another issue with students during the first week of the study within the treatment class by saying,

The students have been so preoccupied with learning the new calculator that the material covered in the lesson has not been fully absorbed. I will need to review next week all the material covered this week. However I expect it to go faster because the students have more involvement (visual, manipulation) than would normally be the case.

During the second week of treatment, Teacher Gamma remarked, "This week both the students and I were more confident in using the Nspire...I have noticed that the majority of the students are more engaged in the lessons." By the end of the second week of the study, Teacher Gamma's treatment class caught up to Teacher Gamma's control class on the material being taught.

When asked about the goals for the treatment class with respect to learning functions, Teacher Gamma responded with the same goals as the control class. In addition to these goals, Teacher Gamma had one additional goal for the treatment class 
that students were to "master the concept of the vertical line test for functions using the Nspire."

Teacher Gamma provided examples of how the TI-Nspire was used within the treatment classroom. Teacher Gamma listed programs designed for the TI-Nspire, such as What's the Point and Introduction to Functions, which were taken from the Texas Instruments website. Teacher Gamma added that "I used the Nspire independently from downloaded lessons to teach creating a table from a function, graphing it, tracing points on the line to obtain additional ordered pairs." Teacher Gamma also said that "students manipulated the lines created on the Nspire by dragging them and changing the slope and the y-intercept and observing how that changed the equations."

Teacher Gamma identified different ways that the TI-Nspire had made teaching to the treatment class better and more easily. In particular, "The TI-Nspire calculator shows the steps of putting points, tables, and graphs all together." Teacher Gamma then compared that with previous use of the Casio graphing calculator and said "In previously teaching the Casio graphing calculator would simply show the end result, the process was missing."

When asked for additional comments, Teacher Gamma stated that the treatment class was the lower of the two classes. Teacher Gamma expressed concerned that the treatment class was going to struggle with learning both the new technology and the lessons concept. Teacher Gamma stated that the "Treatment students have been so excited about the capabilities of the TI-Nspire that they are doing their work much more eagerly than ever before. The involvement of the class has improved more than $100 \%$." In reflecting on the entire study, Teacher Gamma said, 
I perceived that the TI-Nspire engaged more complex thought patterns in the treatment students, relating different concepts in a cohesive manner. The treatment students, on the whole, performed better on class work and on tests than they had all semester. The treatment class was my lower class. Until this study, their ability to learn and perform well on tests was lower than my control class. During this study, the treatment students' performance in class and on tests increased significantly.

In the lesson plan analysis, Teacher Gamma recorded the same state competencies for treatment class as the control class during this study, with the exception that the treatment class had two additional competencies (Course Level Expectation 3102.1.7 and State Performance Indicator 3102.3.7). The Course Level Expectation states that students will "Use technologies appropriately to develop understanding of abstract mathematical ideas, to facilitate problem solving, and to produce accurate and reliable models." The State Performance Indicator states that students will "Determine domain and range of a relation, determine whether a relation is a function and/or evaluate a function at a specified rational value." Teacher Gamma had the same objectives as the control class. The only difference was that within Teacher Gamma's treatment class the objectives also included the use and application of the TI-Nspire.

The methods of instruction used by Teacher Gamma's treatment class varied each day. The types of starter activities were the same for both classes. In Teacher Gamma's treatment class, the same methods of instruction were used as the control class. The only difference was the use of the emulator and the TI-Nspire. Teacher Gamma's treatment class engaged in additional small group activities than the control class. For example, 
one small group activity of Teacher Gamma's treatment class was an experiment using baggies with washers and rubber bands. The main instructional strategies were the same for both classes.

Within the lesson plans, Teacher Gamma noted that the technology used by the teacher for the treatment class was the same as the control class with the addition of the emulator and the TI-Nspire calculator. Teacher Gamma noted that the treatment class used the TI-Nspire every day. Within Teacher Gamma's treatment class lesson plans, the learning styles daily included auditory and visual examples. Teacher Gamma also noted that, when using the Texas Instruments website activities in the treatment class, kinesthetic activities were used as well. Beyond the use of tests and quizzes for assessment, Teacher Gamma noted within the lesson plans that observations were used on a daily basis to assess students within the treatment class, which was the same as the control class. The types of assessments listed on the lesson plan by Teacher Gamma for the treatment class were the same as the control class.

A lesson plan analysis was conducted on the third, sixth and eleventh day to examine content, Depth of Knowledge (Webb, 2006), and the types of representations used for the Teacher Gamma's treatment class. On the third day, Teacher Gamma's treatment class starter covered the same graphing content area (item 11) as Teacher Gamma's control class. However, the Depth of Knowledge was at a Level 2 (skill/concept) for the treatment class as opposed to Level 1 (recall) for the control class. The types of representations used for the treatment class included numeric, geometric, and analytic, whereas the control class included only geometric representations. Teacher Gamma listed one of the same state competencies for the treatment class as the control 
class; however, an additional state competency was listed as well. The content areas covered and the Depth of Knowledge addressed was the same for the treatment class and the control class. One goal was the same for both classes. The treatment class goals covered function content (item 1, item 2 , item 3 , item 4 , and item 7) while using Level 1 and Level 2 (skill/concept) Depth of Knowledge. All goals contained numeric representations. Two goals also contained geometric representations, two contained symbolic representations, and two contained analytic representations. Teacher Gamma's treatment class was assigned homework, unlike Teacher Gamma's control class. Teacher Gamma's treatment class completed worksheets over functions (item 1, item 3, and item 4) at a Level 2 Depth of Knowledge and used numeric, geometric, and analytical representations.

On the sixth day of the study, Teacher Gamma's treatment class lesson plan was similar to Teacher Gamma's control class lesson plan. The starters and state competencies were the same, meaning same content, same Depth of Knowledge, and same representations. The goals Teacher Gamma listed for the treatment class were different from those listed for the control class. Three stated goals included only the function content (item.1, item 2, item 3, item 4, and item 7) and were either a Level 1 or Level 2 Depth of Knowledge. Two goals included numeric, geometric and symbolic representations. The other goal included numeric and analytical representations. The homework assigned to Teacher Gamma's treatment class was to finish a Texas Instruments activity worksheet. The homework covered the function concept (item 1, item 2, and item 4) at a Level 2 Depth of Knowledge and used numeric, geometric, symbolic, and analytical representations. 
On the eleventh day of the study, Teacher Gamma's treatment class lesson plan was exactly the same as the control class lesson plan. The classes had the same starter, state competencies, goals, and homework. Therefore all of the content areas, Depth of Knowledge, and types of representations used the same as well.

When analyzing the assessments, Teacher Gamma's treatment class had the same types of starter activities as the control class. Teacher Gamma noted that during the beginning of class, time was taken to pass out the TI-Nspire calculators. During the first week Teacher Gamma's treatment class used the Scavenger Hunt, What's the Point, and Intro to Functions Program activities from the Texas Instruments website unlike Teacher Gamma's control class. Teacher Gamma's treatment class had the same type of homework as the control classes, most of which were textbook assignments and textbook worksheets. Both classes used the same quizzes and tests.

\section{Across Teacher Gamma's Treatment and Control Classes}

Teacher Gamma's treatment class and Teacher Gamma's control class were both observed on the fourth day of the study. Teacher Gamma's treatment class did not have a starter, but papers and calculators were distributed during that time. Teacher Gamma's control class reviewed the concepts of the coordinate plane, quadrants, ordered pairs, domain, range, mappings, and the vertical line test. Teacher Gamma's treatment class appeared to be just starting the function material on tables, mappings, graphs, and inverses.

Teacher Gamma's control class starter had students graphing an equation to determine if it was a function using the vertical line test with geometric representations. Teacher Gamma's control class completed an average of 2.08 representations during the 
twelve different activities. Teacher Gamma's treatment class completed an average of 2.22 representations during the ten different activities. The Depth of Knowledge (Webb 2006) used on Teacher Gamma's control class starter was a Level 1 (recall). Teacher Gamma's control class experienced an average Depth of Knowledge level of 1.82 during twelve different activities. Teacher Gamma's treatment class experienced an average Depth of Knowledge level of 1.89 during the ten different activities of the observation. Teacher Gamma functioned at the same TPACK Accepting level for both classes.

Teacher Gamma reported in the questionnaire that tables, graphs, mappings, coordinate planes, order pairs, function notation, patterns and sequences were used as representations to teach functions within both the treatment class and control class. Teacher Gamma noted that, prior to the study, both classes were using the Casio nongraphing scientific calculator. When this study began, Teacher Gamma's treatment class started using the TI-Nspire. Teacher Gamma noted beginning difficulties for both the teacher and the students in learning the new technology tool.

Teacher Gamma stated that one benefit for the treatment class was in "Using TINspire to click and drag the point, seeing slope, intercepts, and points change, really helped the concepts to gel in the treatment students' minds." Teacher Gamma also remarked that the treatment class "seemed to really grasp the concept of the $(\mathrm{x}, \mathrm{y})$ ordered pair in a much deeper way," and that "They also had a deeper understanding of functional notation as a replacement for $y$ better than the other class, since the Nspire uses function notation." Teacher Gamma also said that "Students seemed to really benefit from the three ways of doing the same task. They seemed to grasp the relationship of the concepts when they determined their own examples and performed the tasks." Teacher Gamma 
stated that the TI-Nspire "engaged more complex thought patterns in the treatment students, relating different concepts in a cohesive manner."

Teacher Gamma reported the same goals for both classes. Teacher Gamma provided one additional TI-Nspire specific goals for the treatment class. That goal indicated that students should master the concept of the vertical line test while using the TI-Nspire. While examining lesson plans, Teacher Gamma noted sixteen state competencies for the control class and eighteen state competencies for the treatment class. The treatment class had the two additional competencies Course Level Expectation 3102.1.7 and State Performance Indicator 3102.1.7. The objectives for Teacher Gamma's treatment class were the same as Teacher Gamma's control class with the addition of using the TI-Nspire.

The methods of instruction were the same for both Teacher Gamma's treatment and control class. The only difference was the use of the emulator and the TI-Nspire in the treatment class. Teacher Gamma used the individual dry erase board for the control class to perform some of the same exercises that the treatment class completed on the TINspire.

The instructional strategies were the same for both of Teacher Gamma's classes. Teacher Gamma also noted that the Casio calculator was used within the control class, while the treatment class used the TI-Nspire. Teacher Gamma noted within the lesson plans that both classes used the auditory, visual, and kinesthetic learning style during this study.

The specific lesson plans on the third, sixth, and eleventh day were compared for content, representations, and Depth of Knowledge (Webb, 2006). On the third day, 
Teacher Gamma's lesson plans were totally different when comparing the treatment class to the control class. While the starters, state competencies, objectives, and homework assignments were completely different, no difference in Depth of Knowledge for Teacher Gamma's treatment class or control class were noted when comparing the state competencies or the goals. Teacher Gamma's treatment class had a Level 2 (skill/concept) Depth of Knowledge whereas the control class only completed a Level 1 (recall) activity. A difference was noted in the types of representations. Teacher Gamma's treatment class had a started that used numeric, geometric, and analytic representations while Teacher Gamma's control class only used the geometric representation. Within the goals, the treatment class was more focused on numeric representations, while the control class used more geometric representations.

By the sixth day of the study, Teacher Gamma's lesson plans were closer for the treatment class and the control class. The starter and the state competencies were the same. The goals were different for the Teacher Gamma's treatment and control classes. While the goals for each class included both Level 1 and Level 2 Depth of Knowledge, the treatment class included twice as many representations as the control class. For the homework assignment, Teacher Gamma's treatment class was asked to finish a Texas Instruments activity worksheet while Teacher Gamma's control class completed a textbook worksheet. Although both worksheets were a Level 2 Depth of Knowledge, the TI Activity for the treatment class had twice as many representations when compared to the textbook worksheet of the control class.

By the eleventh day of the study, Teacher Gamma's treatment class had caught up with Teacher Gamma's control class. Both of Teacher Gamma's classes were at the 
same point within the textbook and in the concepts covered within the class. The starter, state competencies, objectives and homework were the same for both classes.

The difference in assessments for Teacher Gamma's class focused on the TINspire. While the control class did not participate in any Texas Instrument activities, the Teacher Gamma's treatment class engaged in several. All quizzes and tests were the same for both of Teacher Gamma's treatment class and control class. All quizzes and tests came from the text book and were at either a Level 1 (recall) or Level 2 (skill/concept) Depth of Knowledge. In looking at the representations used, all quizzes and tests used numeric, geometric, symbolic, analytic and written representations.

\section{Teacher Zeta - Control Class}

Teacher Zeta's control class was observed on the fourth day of treatment. During the observation, the activities within Teacher Zeta's control classroom included a starter, guided practice, lecture, worksheet and homework. The control classroom starter instructed students to state ordered pairs when given a table of data or an ordered pair on a graph. Teacher Zeta completed a review of the starter via PowerPoint for the control class to lead the class into the lecture, which was also taught via PowerPoint with interactive examples. Teacher Zeta then passed out a textbook worksheet for the students to complete. Teacher Zeta guided the students through the first exercise where they were instructed to create a graph and a table using substitution for the equation $y=4$. Teacher Zeta then provided guided examples of completing the table via PowerPoint for the control class. Students then worked independently on the worksheet while Teacher Zeta walked about the room helping students as needed. Toward the end of class, Teacher Zeta refocused the class on another equation, $y=4-x$, and had the class students create a 
graph, complete a table, and use substitution to find ordered pairs. After completing this exercise with the students, Teacher Zeta instructed the students to work until the bell on the given worksheet and finish the worksheet for homework.

The exercises within Teacher Zeta's control classes contained an average of 3.00 representations per activity. For example, when Teacher Zeta's control class was instructed to complete the starter exercise, students used numeric representations and geometric representations. For the equation $y=4$, when students were instructed to create a graph and table by using substitution, students completed geometric representations within the graph, numeric representations in the table, symbolic representations in the equation, and analytic representations in choosing the points. Teacher Zeta's worksheet review included numeric, geometric, and symbolic representations. The notes, lecture, in-class examples, guided work, and homework all included numeric representations, geometric representations, and symbolic representations.

Teacher Zeta's starter exercise had a cognitive complexity of Level 2 (skill/concept) for the students. When the control class students were instructed to use the equation $y=4-x$ to create a graph, complete a table, and use substitution to find ordered pairs, they worked at a Level 3 (strategic thinking). Teacher Zeta's control class experienced an average level of 2.11 Depth of Knowledge.

Teacher Zeta continually infused the control classroom with technology and appeared to be at the Accepting TPACK level and, at times, the Adapting TPACK level. By exploring the many ways to use PowerPoint and creating interactive slides, Teacher Zeta provided the control class with instruction that modeled what the treatment class 
received with the TI-Nspire. This allowed Teacher Zeta to become a guide while the students explored and applied the technology concepts. The graphs, problems, and stepby-step solutions that Teacher Zeta adapted the technology and explored additional ways to use the technology while challenging the students to think at higher levels. Teacher Zeta's participation in professional development workshops that integrated technology into the mathematics classroom would continue to be at an Accepting level. By allowing students to use the Casio non-graphing scientific calculators to perform calculations while working on mathematics problems, Teacher Zeta demonstrated an Accepting level of TPACK.

Teacher Zeta reported in the questionnaires for the control class that tables, graphs, mappings, order pairs, and PowerPoint presentations were used as representations to teach functions. Teacher Zeta provided weekly examples of how the representations had been linked together while teaching. For example, Teacher Zeta stated that "I've used tables to solve and form ordered pairs. I then used those ordered pairs to graph the corresponding line onto a graph." Teacher Zeta also gave the example that "Problems were first written out and then solved for algebraically by substitution variables, and then the equation was graphed to visualize the line."

Teacher Zeta responded on the questionnaire that Casio non-graphing scientific calculators were used on every day of the study for the control class. Teacher Zeta also responded that computer and projector were used with PowerPoint most of the days for instruction within the control class. Teacher Zeta reported no issues with any of the teaching tools that were used during the study for the control class. 
When asked about the goals for the control class with respect to learning functions, Teacher Zeta responded with goals concerning finding ordered pairs, graphing functions, determining if a relation is a function, calculating slope, and writing an equation in slope-intercept form. Teacher Zeta also stated that another goal for the students was "to be able to calculate an equation of a line when given one point." Teacher Zeta added that an extension to that goal was for students to be given one point and a line parallel or perpendicular to that line.

On the questionnaire, Teacher Zeta was asked to provide examples of how the tools were used within the control class to teach functions. Teacher Zeta indicated that PowerPoint was used to introduced and illustrated concepts. Teacher Zeta provided an example of how motion and animation within PowerPoint was used to demonstrate the vertical line test as well as how to solve problems when given only a point and slope. Teacher Zeta added that "I showed students how to make a table by substituting $\mathrm{x}$ values into the equation then solving for y." Teacher Zeta also commented that students used individual dry erase boards to practice graphing.

When asked about what Teacher Zeta was able to teach better or more easily using the tools with the control class, Teacher Zeta stated that "The dry erase boards seem to excite the students more than typical pencil and paper does." Teacher Zeta added that "PowerPoint allowed for a great visual demonstration." When asked for additional comments concerning the control class, Teacher Zeta did not have a response.

In the lesson plan analysis, Teacher Zeta recorded various state competencies (listed in Appendix E) for the control class during the course of this study. Teacher Zeta also identified objectives that accompanied the competencies. For example, state 
competency Checks for Understanding 3102.3.15 stated that students were to "Determine domain and range of a relation and articulate restrictions imposed either by the operations or by real life situation that the function represents" and Teacher Zeta stated that the student was "to be able to graph a function to real-world situations, and be able to interpret the results and determine what type of a relationship the two variables have."

The methods of instructions used by Teacher Zeta with the control class varied each day. The starter activities included note taking, working exercises from the board, and textbook assignments. Teacher Zeta's control class starters were all real life applications that emphasized mathematics. For example, Teacher Zeta showed a house, then used animated lines to form a triangle, and talked about slope as well as the effect of rain drainage creating the need for gutters. Teacher Zeta also used a graph to plot the relationship between the percent of blood flow after a concussion to the number of days since the concussion. Teacher Zeta used lecture, interactive PowerPoint, and the dry erase board to teach the control class. Teacher Zeta used a variety of instructional strategies including cooperative learning, small group activities, large group activities, independent practice and guided practice. Every day independent practice was used. Large group activities and guided practice were used every day except on test or quiz days.

Teacher Zeta stated within the lesson plans that the technology used for the control class was the use of multi-media PowerPoint presentation, which was used on most days, and the Casio non-graphing scientific calculator. Teacher Zeta added that within the control class lesson plans that the learning styles daily included auditory and 
visual examples. Beyond the use of test and quizzes for assessment, Teacher Zeta noted that observations were used daily to assess students in the control class.

A lesson plan analysis was done on the third, sixth and eleventh day to examine content, Depth of Knowledge (Webb, 2006) and the types of representations used for the Teacher Zeta's control class. The content was compared to the content areas that were used with the pre-test, post-test and post post-test as listed in Appendix F. On the third day, Teacher Zeta's control class starter covered the graphing content area (item 11) at a Level 2 (skill/concept) Depth of Knowledge while using numeric and geometric representations. Teacher Zeta listed two state competencies, which covered the function content area (item 1, item 2, item 3, item 6, and item 7) at a Depth of Knowledge at either Level 1 (recall) or Level 3 (strategic thinking). For example, the state competency Checks for Understanding 3102.3.16 (Determine if a relation is a function from its graph or from a set of ordered pairs) covered the function content area at a Level 1 Depth of Knowledge. Three goals of the class for the third day included the function concept (item 1, item 2, item 4, and item 10) and was at either a Level 2 or Level 3 Depth of Knowledge. All goals included both geometric and symbolic representations. One goal also included numeric representations, while the other two included analytic representations. For example, the goal to create a graph of a function using a real world situation covered the function content area (item 2) while at a Level 3 Depth of Knowledge using geometric, symbolic, and analytic representations. The textbook worksheet assigned for homework revealed that the concepts covered were within the function content area (item 2 and item 4) at a Level 2 Depth of Knowledge and used numeric, geometric, symbolic, and analytical representations. 
On the sixth day, Teacher Zeta's control class starter focused on the function content (item 9), at a Level 2 Depth of Knowledge, and used numeric, geometric, and analytic representations. Teacher Zeta listed two state competencies that covered the function content (item 2, item 3, item 4, item 6, item 7, and item 10) with a Depth of Knowledge of either Level 2 or Level 3. Three stated goals of the class for the sixth day covered the function content area (item 1, item 2, item 4, and item 10) at a Depth of Knowledge of Level 1, Level 2, or Level 3. One goal included numeric, geometric and symbolic representations; one goal included numeric and analytic representations; and one goal included geometric, symbolic, and analytic representations. The worksheet assigned for homework covered the function concepts (item 1, item 2 and item 4 ) at a Level 2 Depth of Knowledge and used numeric, geometric, symbolic, and analytical representations.

On the eleventh day, Teacher Zeta's control class starter was not listed within the content areas covered on the pre-test, post-test or post post-test. The Depth of Knowledge for the starter was Level 2 and used both geometric and analytic representations. Teacher Zeta listed four state competencies that covered the function and graphing content areas (item 9 , item 12 , and item 13). These competencies had a range of Depth of Knowledge going from Level 2 to Level 3. Four stated goals of the class for the eleventh day covered the function and graphing content areas (item 10 and item 13) at either a Level 1 or Level 2. All goals included symbolic representations. One goal included numeric representations, three included geometric representations, and three included analytic representations. The worksheet assigned for homework focused 
on the graphing content area (item 13) at a Level 2 Depth of Knowledge, and used geometric, symbolic and analytical representations.

When analyzing the assessments used within Teacher Zeta's control class, the starter activities were real-life applications of mathematics. Class activities for Teacher Zeta's control class were typically from the textbook or from textbook worksheets. However, once during the study, Teacher Zeta gave the control class a worksheet from the Texas Instruments website. While the control class did not use the TI-Nspire to complete the worksheet, Teacher Zeta asked the control class to use the individual white boards to answer the exercises on the worksheet. Teacher Zeta's control class had all the homework assignments directly from the textbook or textbook worksheets. Teacher Zeta's control classes had both textbook quizzes and textbook tests.

\section{Teacher Zeta - Treatment Class}

Teacher Zeta's treatment class was observed on the fourth day of the treatment, same day as the control class. During the observation, the activities within Teacher Zeta's treatment classroom were the same for Teacher Zeta's control class. These activities included a starter, homework review, a lecture with demonstrations, guided practice, and homework. Teacher Zeta's control class starter required students to create a table, graph and find multiple points for a given equation. Unlike the control class, Teacher Zeta passed out the TI-Nspire calculators to the students during the starter activity.

Teachers Zeta reviewed the starter exercises by using the Nspire emulator and allowed the discussion to lead directly into the lesson. Teacher Zeta's lesson focused on graphing lines when given points on a graph. Teacher Zeta gave the lecture using both 
PowerPoint and the Nspire emulator and included discussion connecting points, tables, graphs, and lines. For example, Teacher Zeta demonstrated how to take an equation such as $y=2 x+5$, use a table to create a set of order pairs, plot points on a coordinate system, draw a line on a graph, and determine if the relation is a function. Teacher Zeta used a combination of PowerPoint, the dry erase board, and the emulator to complete these tasks. Students were then given a worksheet with similar exercises. As students worked through these exercises using the TI-Nspire calculator, Teacher Zeta provided guidance to individual students. Teacher Zeta provided examples throughout the rest of the class on different exercises in the worksheet. At the end of class students were assigned the remainder of the worksheet for homework.

The exercises within Teacher Zeta's treatment classes contained an average of 2.55 representations per activity. For example, when Teacher Zeta's treatment class was asked to complete the starter exercise, students used numeric, geometric, symbolic, and analytical representations. When students were asked to simply graph via the TI-Nspire emulator, students only used geometric representations. When asked to put the equation $3 x+2 y=6$ into slope intercept form, students only used symbolic representations. The lecture, in class examples, guided work, and homework used numeric, geometric, symbolic, analytic, and writing representations.

Teacher Zeta's treatment class starter was at a higher Depth of Knowledge (Level 3) than that of the control class. When students were instructed to create a table, draw the corresponding graph, and find four points on the graph, they worked at a Level 3 (strategic thinking). When manipulating an equation into slope-intercept form, the 
treatment class worked at a Level 2 (skill/concept) Depth of Knowledge. Teacher Zeta's treatment class experienced an average level of 2.18 Depth of Knowledge.

Teacher Zeta's treatment class functioned at the same TPACK level (Accepting and Adapting) as the control class. For example, Teacher Zeta worked at an Adapting level when using combination of the computer projector, PowerPoint, and TI-Nspire emulator within the treatment class while demonstrating how to complete exercises. Teacher Zeta also worked at the Adapting level with the technology by using the interactive features within PowerPoint to provide a visual example of the vertical line test. Teacher Zeta's participation in professional development workshops that were integrating technology into the mathematics classroom was at the Accepting level. By allowing students to use the TI-Nspire calculators to perform calculations while working on mathematics problems, Teacher Zeta continued to demonstrate the Accepting level of TPACK.

Teacher Zeta reported on the questionnaires that the same representations used to teach functions to the treatment class were also used with the control class. Teacher Zeta provided weekly examples of how the representations had been linked together while teaching. For example, Teacher Zeta stated that "Equations were solved algebraically by substituting $x, y$ and $m$ and then solving for $b$. They were then linked graphically using the N-spire to visualize the equation."

Teacher Zeta responded on the questionnaire that the TI-Nspire was used for all but two days of this study. Teacher Zeta reported issues within the treatment class regarding the TI-Nspire. During the first week, Teacher Zeta indicated that "The lessons were considerably slower just to allow students time to become familiarized with the 
calculators." However, Teacher Zeta had the treatment class cover the same material as the control class. Teacher Zeta also stated that some pre-installed programs were different using the calculators. Teacher Zeta went on to say that "The students struggled a little bit while graphing two points then finding the equations. There seemed to be too many steps in order to find the equation." Teacher Zeta also reported that "Students found it a little difficult switching over to calculator mode, to do a calculation to help with their graph."

When asked about the goals for the treatment class with respect to learning functions with the TI-Nspire, Teacher Zeta responded that they were the same as the control class. Teacher Zeta provided examples of how the TI-Nspire was used within the treatment classroom. For example, Teacher Zeta noted that in using tables and graphs for linear equations and plotting points that the program "What's the Point" from the Texas Instruments website was used. Teacher Zeta stated, "I showed students how to use a table and the formula bar to have the calculator automatically calculate $y$ values to their $\mathrm{x}$ value inputs, then transfer those ordered pairs to a graph." Teacher Zeta also said, "I would help students plot both points on a graph, then use the equation button to show the $y=m x+b$ equation for the line."

When asked what content was more easily or better taught using the TI-Nspire, Teacher Zeta stated that it was so much quicker and easier to substitute and solve. Teacher Zeta also stated, "The Nspire makes a much better visual demonstration for the vertical line test." Teacher Zeta remarked about how the TI-Nspire allowed students to solve slope without using parentheses as well as demonstrate perpendicular slope as the negative reciprocal. 
In the lesson plan analysis, Teacher Zeta's treatment class lesson plan recorded the same state competencies as the control class during this study. Teacher Zeta used the same objectives as the control class. The only difference was that, within Teacher Zeta's treatment class, the objectives also included the use and application of the TI-Nspire. Teacher Zeta's treatment class also was expected to check their work using the TI-Nspire.

The methods of instruction used by Teacher Zeta with the treatment class varied somewhat each day. The starter activities for the treatment class were the same as the control class. In addition to the control class activities, Teacher Zeta also used activities from the Texas Instruments website. These activities included TI Scavenger Hunt, What's the Point, Function Junction, Exploring Linear Equations, and TI-Parallel and Perpendicular Lines Program. The TI Scavenger Hunt activity teaches students about the features that are commonly used with the TI-Nspire. The What's the Point activity has students drag a point around on the coordinate plane using the TI-Nspire. The TI-Parallel and Perpendicular Lines activity has students exploring lines, calculating slope, and dragging lines to be either parallel or perpendicular while watching the slope of the equation change. Teacher Zeta used the same instructional strategies as the control class. Independent practice was used everyday just like in the control classes.

Teacher Zeta noted in the lesson plans that the technology used for the treatment class included the TI-Nspire graphing calculator on a daily basis and that most days a multi-media PowerPoint presentation and the TI-Nspire emulator was used. Teacher Zeta remarked that, within the treatment class lesson plans, the learning styles daily included auditory and visual examples. Teacher Zeta also noted that, when using the Texas Instruments website activities in the treatment class, kinesthetic activities were used as 
well. Beyond the use of test and quizzes for assessment, Teacher Zeta noted that observations were used on a daily basis to assess students within the treatment class, which was the same as the control class.

A lesson plan analysis was also done on the third, sixth and eleventh day to examine content, Depth of Knowledge (Webb, 2006) and the types of representations used for the Teacher Zeta's treatment class. On the third day of the study Teacher Zeta's treatment class lesson plan was exactly the same as that of the control class. The classes had the same starter, same state competencies, and the same goals. The content areas, Depth of Knowledge, and types of representations used the same as well. Teacher Zeta's treatment class had the same homework worksheet as the control class with the addition of a Texas Instruments activity called "Intro to Functions." This Texas Instruments activity covered the function content (item 1, item 2 , and item 4 ) at a Level 2 (skill/concept) Depth of Knowledge while using numeric, geometric, symbolic, and analytical representations.

On the sixth day of the study, Teacher Zeta's treatment class lesson plan was exactly the same as that of the control class. The classes had the same starter, state competencies, goals, and homework. Therefore all the content areas, Depth of Knowledge, and types of representations were the same as well.

On the eleventh day of the study, Teacher Zeta's treatment class lesson plan was exactly the same as the control class lesson plan. The classes had the same starter, state competencies, goals, and homework. Therefore all of the content areas, Depth of Knowledge, and types of representations were the same as well. 
When analyzing the assessments used in Teacher Zeta's treatment class, the starter activities were the same as the control class. While Teacher Zeta's treatment class used activities from the Texas Instruments website, the treatment class only used part of the worksheets and homework that the control classes completed. While these TI activities took place in the treatment classroom setting, homework assignments were always textbook assignments or worksheets. Teacher Zeta's assessments in the treatment class focused on finding more points on a line than the treatment class. Also, Teacher Zeta asked the treatment class to not only graph lines, but also to find both parallel and perpendicular lines as opposed to finding one or the other with the control class. Teacher Zeta's treatment classes took the same quizzes and tests as the control class.

\section{Across Teacher Zeta's Treatment and Control Classes}

Teacher Zeta's treatment class and Teacher Zeta's control class were both observed on the fourth day of the study. During the observation, the types of activities within these classes were the same. These activities included a starter, homework review, a lecture with demonstrations, guided practice, and homework. Teacher Zeta's control class starter instructed the students to create a table, graph, and find multiple points for a given equation.

Since the starter activity was the same for treatment and control, both classes used the same number of representations (three) on the starter exercise during the classroom observation. Teacher Zeta's control class completed an average of 3.00 representations during the nine different activities. Teacher Zeta's treatment class completed an average of 2.67 representations during the twelve different activities. The Depth of Knowledge was also at Level 2 (skill/concept) for Teacher Zeta's treatment and control class on the 
starter. Teacher Zeta's control class experienced an average Depth of Knowledge level of 2.11 for nine activities. Teacher Zeta's treatment class experienced an average Depth of Knowledge level of 2.18 for the twelve activities. Teacher Zeta functioned at the same Accepting and Adapting TPACK levels in both classes.

Teacher Zeta reported within the questionnaire that tables, graphs, mappings, order pairs, and PowerPoint presentations were used as representations to teach functions in both the treatment and control classes. Teacher Zeta noted that prior to the study; both classes were using the Casio non-graphing scientific calculator. When this study began, Teacher Zeta's treatment class started using the TI-Nspire. Teacher Zeta noted some difficulties for the student in learning the new technology tool. Teacher Zeta reported the same goals for both classes. Teacher Zeta added the goal for the treatment class to check their work using the TI-Nspire.

In comparing issues and benefits with regard to the TI-Nspire, Teacher Zeta mentioned both for the treatment class. Teacher Zeta indicated that the treatment class moved at a slower pace while the students were learning with the new TI-Nspire. Teacher Zeta also said that students struggled with the multiple steps and in switching between graphing and calculators. When discussing the benefits of the TI-Nspire in the treatment class, Teacher Zeta stated that it was quicker and easier to "substitute $\mathrm{x}$ values into and equation and solve for y." Teacher Zeta also stated, "The Nspire showed a better visual demonstration of graphing a line by connecting two points." Teacher Zeta remarked how "using the function button allowed students to solve slope without using parentheses like other calculators." Teacher Zeta also remarked, "I have been able to 
show students visually perpendicular slope and why it is a negative reciprocal to the other line by grabbing the line and flipping it over using the calculator."

Teacher Zeta's lesson plans revealed the same eleven state competencies for both the control class and the treatment class. The objectives for Teacher Zeta's treatment class were also the same as the control class, with the addition of having students check their work using the TI-Nspire. The methods of instruction were the same for both classes. While Teacher Zeta used activities designed specifically for the TI-Nspire within the treatment class, Teacher Zeta used some of those same activities without the use of a calculator. While Teacher Zeta used the TI-Nspire emulator within the treatment class, Teacher Zeta created interactive PowerPoint presentations to help compensate for the control class not having the TI-Nspire. The same instructional strategies and assessments were used for both of Teacher Zeta's classes. Teacher Zeta also noted that the Casio calculator was used within the control class, while the treatment class used the TI-Nspire.

The specific lesson plans on the third, sixth, and eleventh day were compared with regard to content, representations, and Depth of Knowledge. When comparing content on the third day, Teacher Zeta's treatment class used a TI-Nspire activity to cover the same objectives and goals as the control class. No difference in the type of representation of the Depth of Knowledge Teacher Zeta's treatment class or control class was noted.

On the sixth day of the study, Teacher Zeta's treatment class and control class were at the same point in the textbook and focused on the same concepts. The starter, state competencies, objectives and homework were the same for both classes. The same 
was still on the eleventh day of the study. Both the treatment class and the control class seemed to cover the material at the same pace.

The difference in assessments for Teacher Zeta's class focused on the TI-Nspire. While the control class used some of the Texas Instrument activity worksheets, the treatment class used several. To compensate for the additional work in the treatment class, Teacher Zeta gave the control class additional textbook worksheets. All quizzes and tests were the same for both of Teacher Zeta's treatment class and control class. All quizzes and tests came from the textbook and were at either a Level 1 (recall) or Level 2 (skill/concept) Depth of Knowledge. All quizzes and tests used numeric, geometric, symbolic, analytic and written representations.

\section{Summary of Control Classes}

All control classes were observed within the first two weeks of the study. They all included a starter, guided practice, lecture and homework. All teachers covered the function content and the graphing content during the control class observation, on the questionnaire, within their lesson plans, and in the assessments.

All teachers used multiple representations during the control class observation and included numeric, geometric, symbolic, and analytic representations. Teacher Alpha and Teacher Gamma also used writing as a representation during the control class observation. On the questionnaire, all teachers reported using tables, graphs, mappings, and ordered pairs as a means to represent the function concept to the control class. Within the lesson plan analysis of the third, sixth, and eleventh day of the study, all teachers included using some form of numeric, geometric, symbolic, and analytic representations for their control class goals. Teacher Alpha, Teacher Epsilon, and 
Teacher Zeta included assessments in their lesson plans, and they used numeric, geometric, symbolic, and analytic representations. However Teacher Gamma assigned homework on only one of the three days and, on that day, only geometric and analytic representations were used. The analysis of the control class assessments revealed that each teacher used numeric, geometric, symbolic, analytic and writing representations.

Although all control classes had starters, Teacher Gamma's starter was at Level 1 (recall), while Teacher's Alpha, Epsilon, and Zeta starters were at Level 2 (skill/concept). All teachers used Level 1 and Level 2 Depth of Knowledge activities. Teacher Epsilon and Teacher Zeta were the only teachers who used a Level 3 (strategic thinking) activity. On the lesson plans of the third, sixth and eighth day of the study, all teachers stated state competencies at a Level 1, Level 2 or Level 3 Depth of Knowledge. Teacher Alpha, Teacher Gamma, and Teacher Zeta included goals at a Level 1, Level 2 or Level 3 Depth of Knowledge. Teacher Epsilon only included competencies at Level 1 or Level 2. The homework for these same lesson plans revealed a Level 2 Depth of Knowledge. When analyzing the assessments of all teachers, a Level 1 or Level 2 Depth of Knowledge of was used on quizzes and tests within all control classes.

All teachers demonstrated an Accepting level for TPACK. By allowing their control classes to use the Casio non-graphing scientific calculator, all teachers demonstrated the Accepting level for TPACK. All teachers had access to the projector and PowerPoint within the control classroom. Teacher Epsilon was the only teacher who did not use them; therefore, the Recognizing level for TPACK would be more appropriate. Teacher Alpha and Teacher Gamma used technology at an Accepting TPACK level. Teacher Zeta displayed the most extensive use of PowerPoint within the 
control classroom at an Adapting TPACK level. Teacher Zeta used the PowerPoint technology to create graphs and solve problems in a step-by-step manner, and used animation to demonstrate the vertical line test.

\section{Summary of Treatment Classes}

All treatment classes were observed during the first two weeks of the study. During the observations, Teacher Alpha, Teacher Epsilon, and Teacher Zeta included a starter to begin their lesson. Teacher Gamma did not included a starter, but used that class time to distribute the TI-Nspire calculators. All teachers also covered the function and graphing content during the treatment class observation, on the questionnaire, within their lesson plans and in the assessments.

All teachers used multiple representations during the observation, and they included numeric, geometric, symbolic, and analytic representations. On the questionnaire, all teachers reported using tables, graphs, mappings, and ordered pairs as a means to represent the functions. During the lesson plan analysis of the third, sixth, and eleventh day of the study, all teachers included some form of numeric, geometric, symbolic, and analytic representations. All teachers included assessments on their lesson plans that used numeric, geometric, symbolic, and analytic representations. All teachers used numeric, geometric, symbolic, analytic and writing representations.

All teachers reported issues in the treatment class with regard to the TI-Nspire and the emulator during the course of this study. Because the TI-Nspire was a new tool, both teachers and students revealed a learning curve, as with any new technology tool. During the course of this study, the teachers resolved the issue of needing time to distribute the TI-Nspire calculators by using the starter time at the beginning of each treatment class. 
Teachers had to learn how to download the programs form the internet and then how to upload them to the emulator and the calculators. Over the course of this study, the teachers and students in treatment class became more familiar with the calculator and had fewer issues in how it worked.

Treatment teachers stated that they enjoyed using the Texas Instruments website and the readymade programs that they were accessible on the TI website. With the addition of a new technology tool, Teacher Gamma reported that the students were "more eager to investigate with the TI-Nspire" and that the students were excited about the capabilities of the TI-Nspire. Teacher Zeta commented that the TI-Nspire allowed students to "quickly show how to substitute ' $x$ ' values into an equation and solve for ' $y$ '." The teachers felt they were much better at teaching students how to create tables in the treatment class.

Teachers also mentioned that the ability to connect the multiple aspects (graph, equation, table, etc.) of a problem on the TI-Nspire allowed them to teach from the big picture of how concepts relate to each other. While certain aspects of a lesson focused specifically on equations, graphs, tables, or functions, students did not always see how they all fit together. Teacher Zeta commented how the multiple representations with the TI-Nspire allowed the bigger picture to be discussed and then allowed the individual aspects to be specifically explored.

The teachers stated that the effects of changing constants and coefficients of an equation were much easier to recognize in the treatment classes as the students moved the lines up and down the y-axis or by simply changing the slope. Teachers liked the immediate support from the calculators to reinforce what the students in the treatment 
classes had graphed on their individual white boards. Teachers remarked how it helped students verify their work on slope, intercepts, and relating a graph to the value of $y=m x$ + b. Teacher Gamma said,

This was the first time in years that my students aren't totally lost in the concepts of slope and equations. In teaching slope, my treatment students are, for the first time, having to relate multiple concepts to obtain their results. In the past, this had taken weeks to accomplish. This time, they are moving much faster. I believe it is the visual representations and their own manipulation of the graphed line on the calculator.

The teachers also mentioned the benefits of using the emulator, the readymade programs, and the TI website. The emulator enhanced teachers' ability to visually communicate with students about the operation of their individual calculator and provide a quick and easy visual demonstration of the specific buttons to be pushed. The teachers felt that students in the treatment classes learned at a deeper level because of its ability to show multiple representations webbed together within the TI-Nspire. In particular the teachers mentioned that topics, such as functional notation, order pairs, slope, intercepts, and tables, were easier to teach with the TI-Nspire. They also mentioned that they were more effective in teaching such topics.

During the observations, Teacher Gamma's treatment class did not have a starter. Teacher Alpha, Teacher Epsilon and Teacher Zeta all had starters with a Level 2 (skill/concept) Depth of Knowledge. During the observation, all teachers had Level 2 and Level 3 (strategic thinking) Depth of Knowledge activities. Teacher Gamma and Teacher Epsilon also had Level 1 (recall) activities during the treatment class. During the 
lesson plan analysis of the third, sixth and eighth day of the study, all teachers included state competencies that were at a Level 1, Level 2 or Level 3 Depth of Knowledge. Teacher Alpha, Teacher Gamma, and Teacher Zeta included goals at a Level 1, Level 2 or Level 3 Depth of Knowledge; however, Teacher Epsilon only included goals at Level 1 or Level 2. The homework for all teachers in treatment class lesson plans revealed a Level 2 Depth of Knowledge. When analyzing all teachers' treatment class assessments, both Level 1 and Level 2 Depth of Knowledge exercises were used on quizzes and tests in all control classes. At no point in this study were any Level 4 Depth of Knowledge activities used.

As previously stated, by participating in the professional development activities, all teachers demonstrated an Accepting level for TPACK. All treatment teachers also allowed treatment students to use the TI-Nspire graphing calculator, demonstrating the Accepting level for TPACK. This Accepting level continued as all treatment teachers also used the emulator to teach the function concept using the TI-Nspire. Teacher Alpha, Teacher Epsilon, and Teacher Gamma used technology within the treatment class at an Accepting TPACK level. Teacher Zeta displayed the most extensive use of PowerPoint within the treatment classroom especially when applying mathematics to real life problems. While Teacher Zeta was at the Accepting TPACK level, Teacher Zeta was, at times, at the Adapting TPACK level for the treatment class.

\section{SUMMARY OF RESULTS}

Quantitative and qualitative analyses were conducted to examine the impact of using technology in teaching functions with the TI-Nspire in first year algebra classes. 


\section{Quantitative Summary}

Statistically significance was found in the quantitative data. Within the analysis for research question 1a, the control group's mean scores were statistically higher on the pre-test than those of the treatment group. While no statistical difference was evident in the post-test mean scores, the treatment group's mean scores were statistically higher on the post post-test. For both treatment and control groups, post-test mean scores were statistically higher than their respective pre-test mean scores. This finding was also true for both groups on the post post-test. The post post-test mean scores of both groups were statistically higher than their pre-test mean scores. No statistical difference between either groups' post-test mean scores or post post-test mean scores were found. When analyzing the slopes from pre-test to post test, pre-test to post post-test, and from post-test to post post-test a standardized beta coefficient revealed a statistically significant difference for treatment scores and for control scores.

The analysis for research question $1 \mathrm{~b}$ investigated the mean scores by teacher. A statistically significant effect on the post post-test was found between teachers. An additional post hoc test using multiple comparisons revealed statistically significant differences in the mean scores on the post post-test between Teacher Epsilon's classes and Teacher Zeta's classes and between Teacher Gamma's classes and Teacher Zeta's classes.

The analysis for research question $1 \mathrm{c}$ used a multivariate test with teachers as fixed variables, pre-test as a control value, and centered by pre-test at the class level. The teacher was found to have a statistically significant effect on the post-test and on the post post-test for the original means. The pooled imputed means found the teacher effect to be 
statistically significant on the post post-test. The interaction of teacher by type was also found to have a statistically significant effect on the post-test and the post post-test for both the original means and the pooled imputed means. Wilks' Lambda was statistically significant on the teacher effect, the type effect, and the interaction of teacher by type for both the original means and the pooled imputed means.

Further pairwise comparison analyses were made on the interactions among teachers. For the pairwise comparison by teacher, statistically significant interactions were revealed on the post-test and the post post-test for Teacher Zeta's classes. The original means revealed a statistically significant difference with Teacher Zeta's classes and Teacher Alpha's classes as well as with Teacher Zeta's classes and Teacher Gamma's classes on the post-test, while the pooled imputed means, revealed a statistically significant difference between Teacher Zeta's classes and Teacher Epsilon's classes as well as between Teacher Zeta's classes and Teacher Gamma's classes. The original means revealed a statistically significant difference between Teacher Zeta's classes and all other teachers' classes on the post post-test, while the pooled imputed means revealed a statistically significant difference between Teacher Zeta's classes and Teacher Epsilon's classes and between Teacher Zeta's classes and Teacher Gamma's classes.

The analysis for research question $1 \mathrm{~d}$ used a multivariate analysis to test the interaction of teacher and type with socioeconomic status and special education students. The multivariate analysis of variance was conducted to assess if differences between the teacher and socioeconomic status, special education status, or the interaction of socioeconomic status and special education status on the post-test and the post post-test 
existed. To control for the pre-test variance, pre-test was a dependent variable. The analysis revealed statistical significance with socioeconomic status and the post-test and the post post-test; however the pooled imputed data found only statistical significance with the socioeconomic status and the post-test. The original data revealed statistical significance with the interaction between teacher and the socioeconomic status on the post post-test; however the pooled imputed data did not reveal statistical significance with the interaction between teacher and socioeconomic status. The original data revealed statistical significance with the interaction between type and the socioeconomic status on the pre-test; however the pooled imputed data did not reveal statistical significance in the interaction between type and socioeconomic status. While the original data did not reveal statistical significance with the interaction between teacher and special education students, the pooled imputed data had statistical significance on the post posttest. The lack of data caused different interactions and further analysis was not possible due to lack of power.

\section{Qualitative Summary}

Observations and document analysis were used to investigate differences across the teachers and their classes. An analysis of the classroom observations, questionnaires, lesson plans, and assessments focused with respect to representations, Depth of Knowledge and TPACK.

The main representations used within activities across all analysis were numeric, geometric, symbolic, analytic, and written. Activities might have involved combinations of numeric, geometric, symbolic, analytic, writing or other representations. Although all teachers in all classes used all representations, the number of activities covered in each 
class varied among treatment and control classes. As noted in Figure 14, Teachers Alpha, Epsilon, and Gamma used more activities in their control classes. On the other hand, Teacher Zeta taught the treatment class using more activities than the control class. During the lesson plan analysis, all treatment classes used more representations on average for each activity as noted in Figure 15.

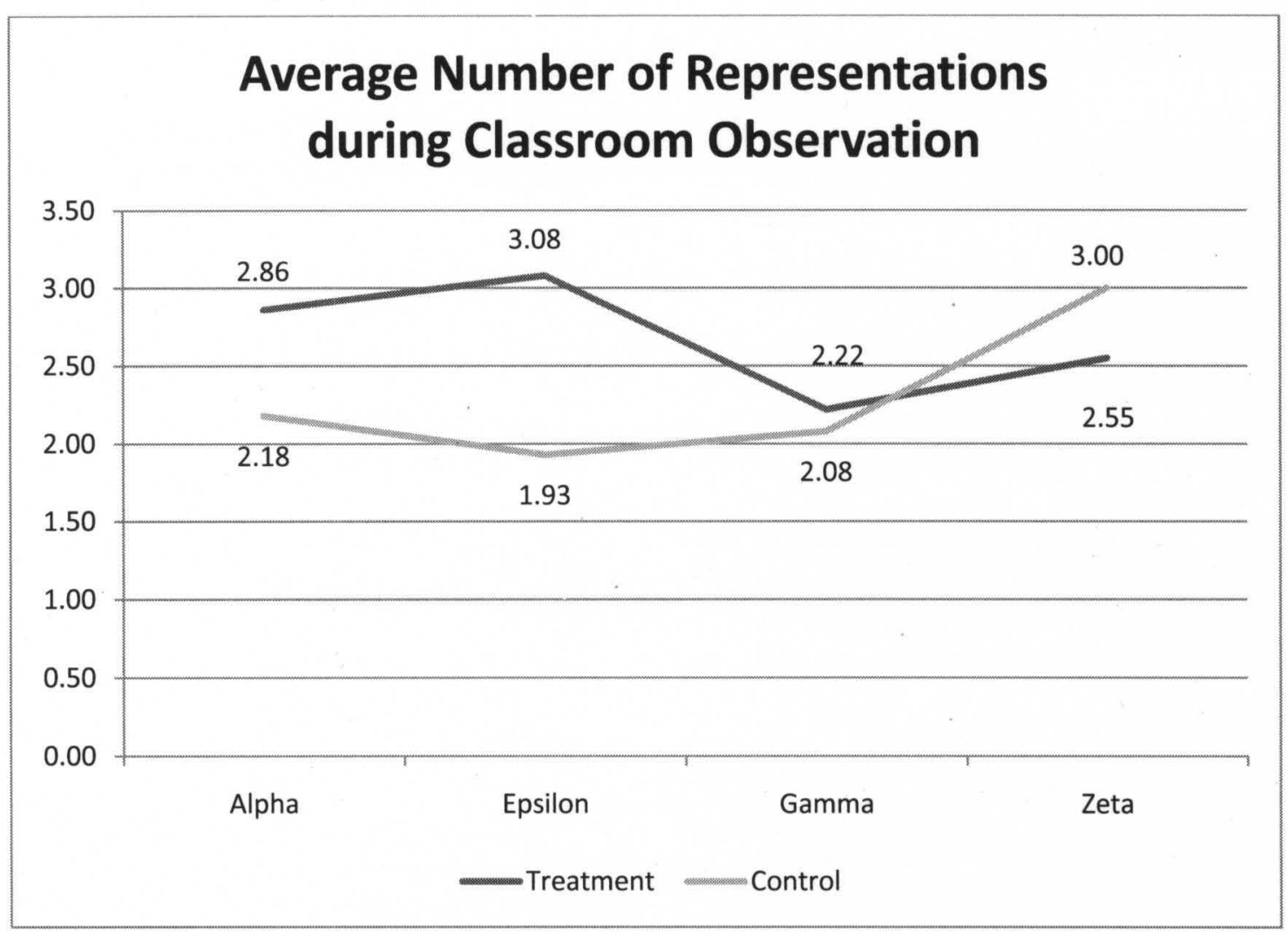

Figure 14: Average ways of representing an activity during observation. This figure illustrates the average number of representations for each activity during a classroom observation. 


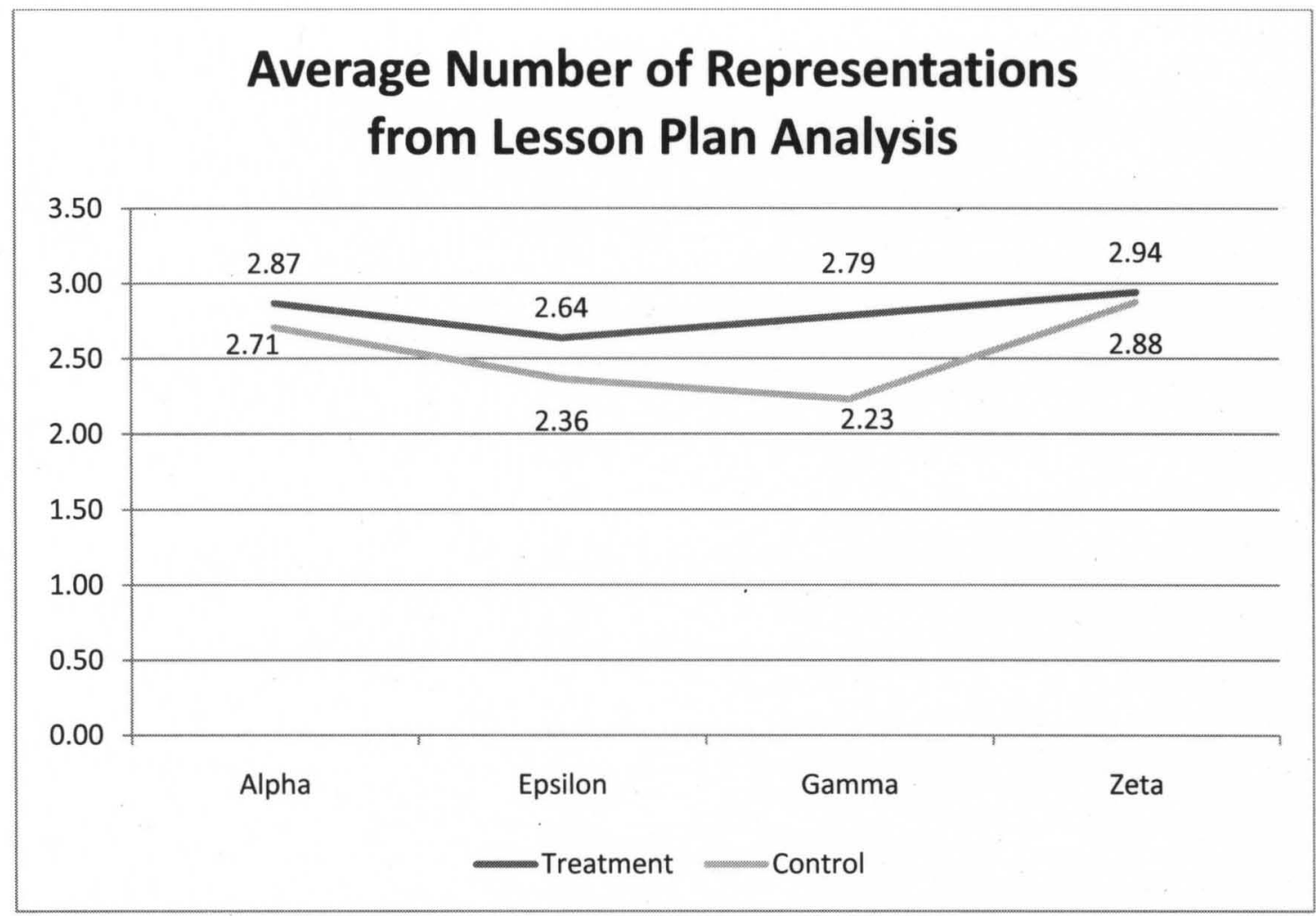

Figure 15: Average ways of representing an activity within lesson plans. This figure illustrates the average number of representations for each activity within the lesson plan analysis.

Four Levels to Webb's Depth of Knowledge (2006) were explored. Level 1 is recall activities, Level 2 is skill and concept activities, Level 3 is Strategic thinking, and Level 4 is extended thinking. Each activity was labeled according to the complexity as outlined by Webb. Most activities were at Level 1 (skill) and Level 2 (skill/concept), but some Level 3 (strategic thinking) activities were noted. No Level 4 (extended thinking activities) activities were found. As noted in Figure 16, each teacher's treatment class experienced on average a greater Depth of Knowledge than the corresponding control class. 


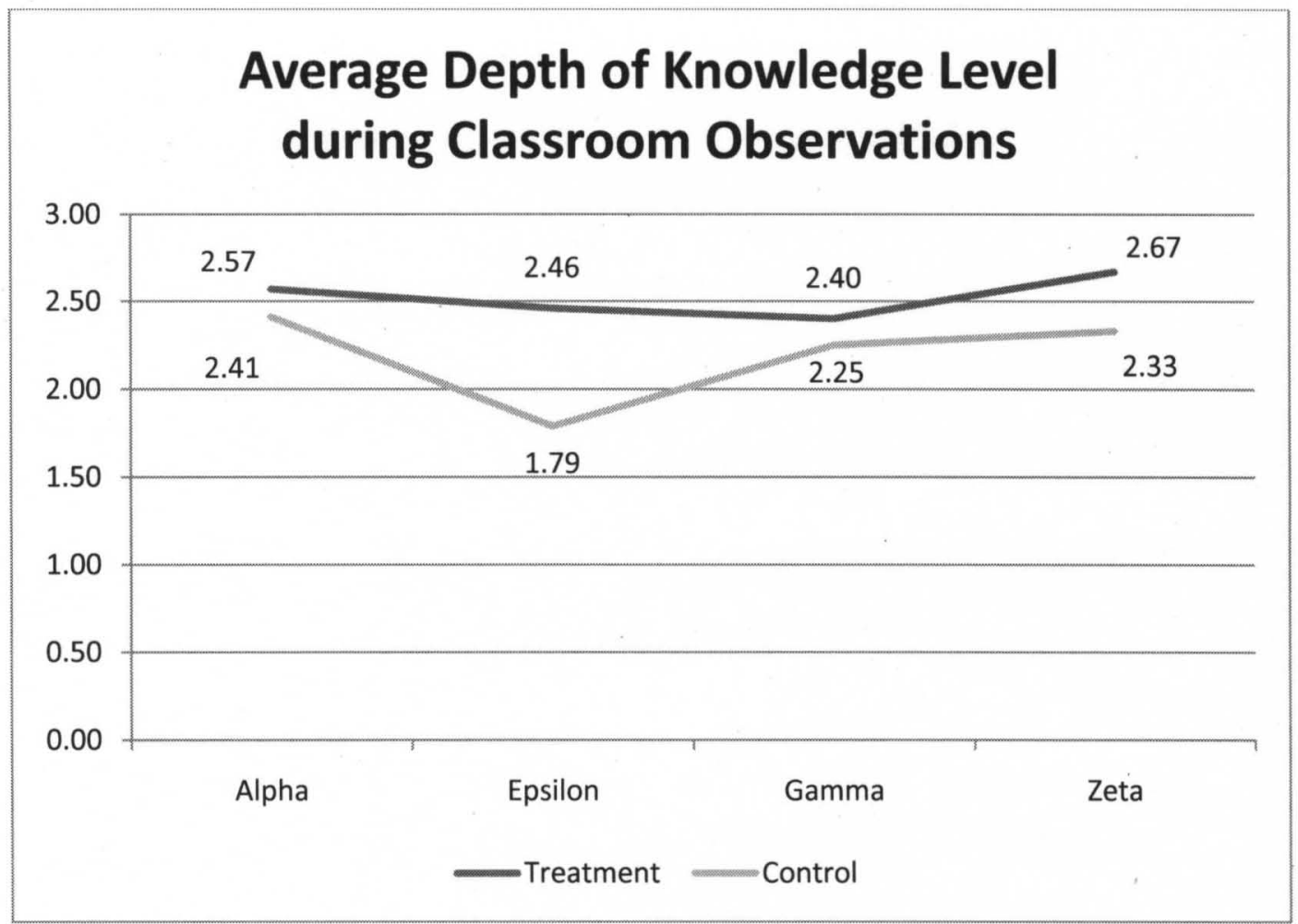

Figure 16: Average Depth of Knowledge during observations. This figure illustrates the average Depth of Knowledge that problems were asked within a classroom observation.

While the average Depth of Knowledge is displayed above, Table 13 reveals the maximum, minimum, and total number of activities. The control classes had more Level 1 (recall) activities. For example, both of Teacher Gamma's classes completed a Level 1 (recall) vocabulary review activity. Teacher Alpha's control class also completed a Level 1 (recall) activity where students were writing the definitions to vocabulary words. 
Table 13

Depth of knowledge noted during classroom observations

\begin{tabular}{cccccc} 
Teacher and Class & Max & Min & Avg. & St Dev & $\mathrm{n}=$ \\
\cline { 2 - 6 } Alpha Control & 3 & 1 & 2.41 & 0.59 & 12 \\
Alpha Treatment & 3 & 1 & 2.57 & 0.61 & 7 \\
Epsilon Control & 2 & 1 & 1.79 & 0.50 & 14 \\
Epsilon Treatment & 2 & 1 & 2.46 & 0.51 & 13 \\
Gamma Control & 3 & 1 & 2.25 & 0.66 & 12 \\
Gamma Treatment & 3 & 1 & 2.40 & 0.58 & 10 \\
Zeta Control & 3 & 1 & 2.33 & 0.52 & 9 \\
Zeta Treatment & 3 & 1 & 2.67 & 0.50 & 12
\end{tabular}

As indicated above, Teacher Epsilon's control class completed multiple activities focusing on different topics, due in part to the fact that Teacher Epsilon reviewed her control class for an upcoming quiz. For example, Teacher Epsilon's control class engaged in multiple Level 1 (recall) activities as students were asked to identify quadrants, state the coordinates of a point on a graph, and answer vocabulary questions. Conversely, Teacher Epsilon's treatment class combined several topics into one activity, requiring students to use a greater Depth of Knowledge to complete the problem. For example Level 2 (skill/concept) activities had students find the domain and range when given a table and finding ordered pairs from a graph on the calculator. Examples of Level 3 (strategic thinking) activities completed by Teacher Epsilon's treatment class included students using a given equation to create a graph and make a table of coordinates from that graph. In another example, students were shown a graph and asked to find the equation of the graph and to create a table of coordinates for that graph.

Teacher Zeta's treatment class appeared to use tasks with the greatest Depth of Knowledge. For example, Teacher Zeta began the treatment class with a level 2 activity by assigning the students a task to make a table, a graph, and find four ordered pairs that 
would satisfy the equation $y=10 x-2 / 3$. Teacher Zeta's use of PowerPoint and the TINspire Emulator assisted in webbing the problems together and allowing the students to see the connections.

During the document analysis of the lesson plans, the Depth of Knowledge was recorded for the starter, goals, class work, and homework. Figure 17 below shows that Teacher Alpha's control class had a higher average Depth of Knowledge for the control class more so than the treatment class. Teacher Epsilon and Teacher Gamma had slightly higher average Depth of Knowledge for the treatment class, and Teacher Zeta had the same level for both treatment and control.

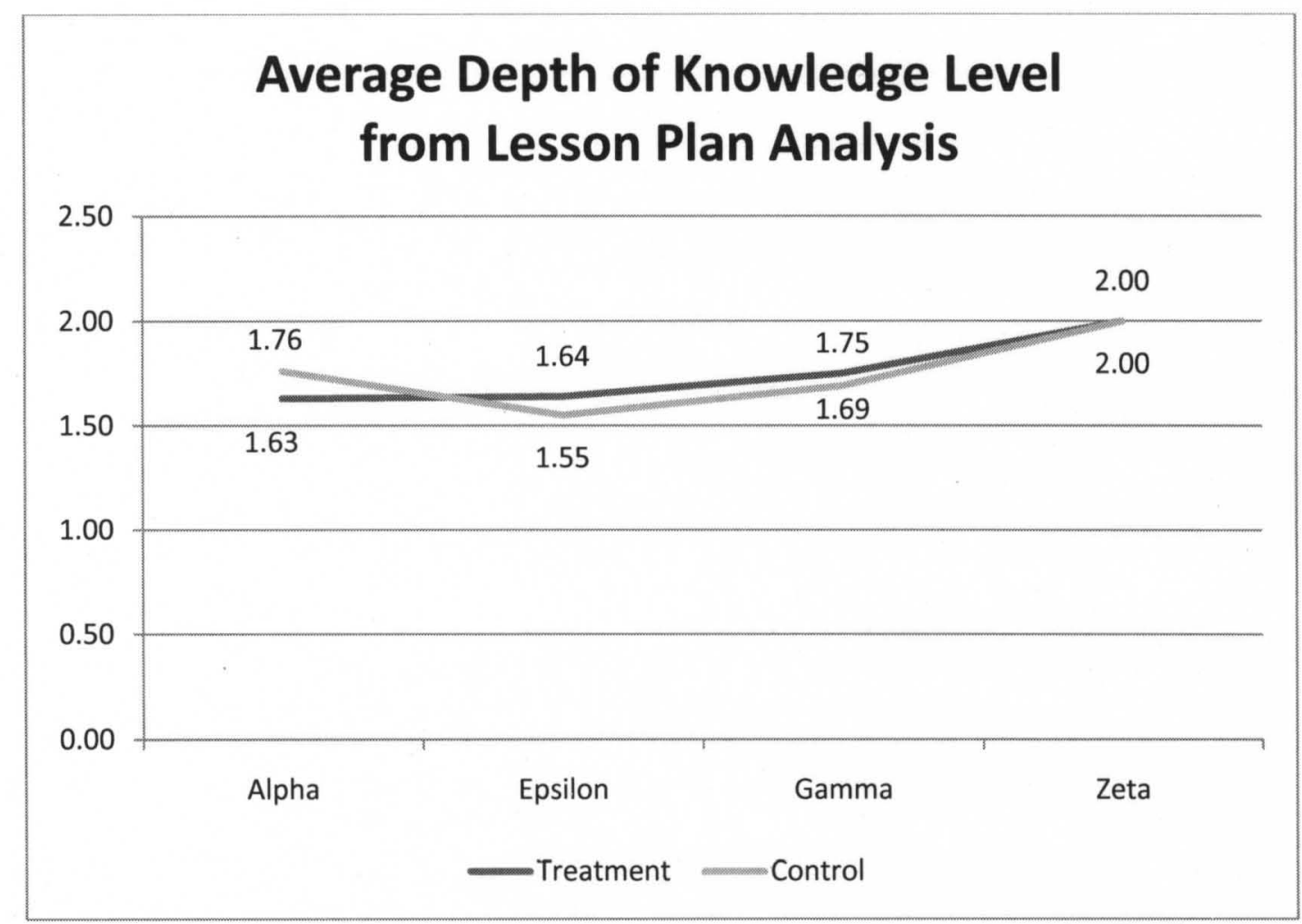

Figure 17: Average Depth of Knowledge Level from Lesson Plan Analysis. This figure illustrates the average Depth of Knowledge that problems were planned for a classroom lesson. 
The state competencies for all classes were listed within Appendix E. Figure 18 below provides an average of the Depth of Knowledge for the state competencies that were listed on the lesson plans by each teacher. Teacher Alpha and Teacher Epsilon used state competencies during the course of this study that had a higher average Depth of Knowledge for the treatment class. Teacher Gamma used state competencies during the course of this study that has a higher average Depth of Knowledge for the control class. Teacher Zeta had the same average Depth of Knowledge for both class because as the same state competencies were used for Teacher Zeta's treatment and Teacher Zeta's control class.

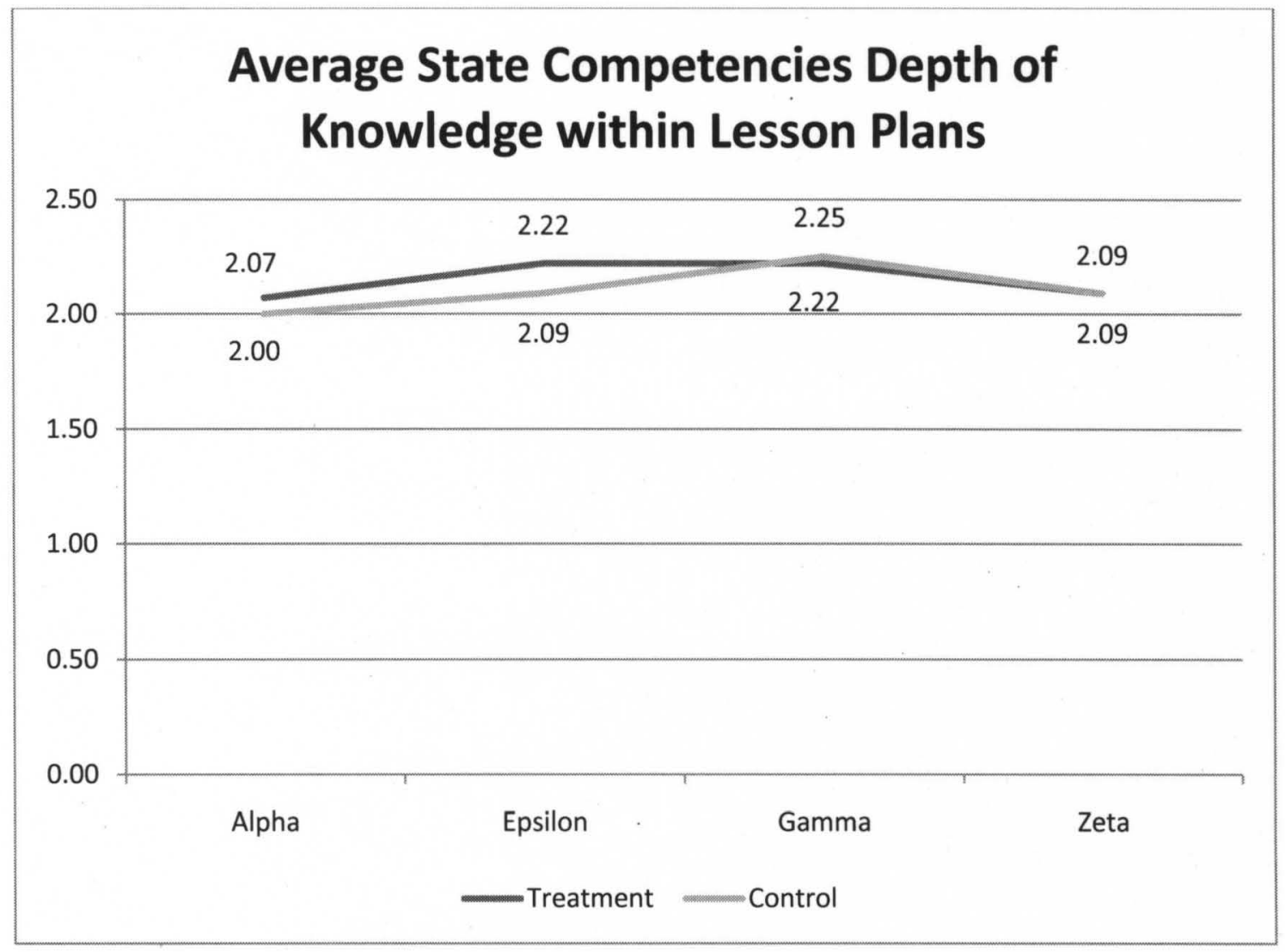

Figure 18: Average Depth of Knowledge on State Competencies from Lesson Plan Analysis. This figure illustrates the average Depth of Knowledge of the state competencies used as teachers planned for a classroom lesson. 
During the classroom observation, teachers demonstrated TPACK levels ranging from Recognizing to Adapting. Teacher Epsilon demonstrated a Recognizing level in the control class, but an Accepting level in the treatment class. Teacher Alpha and Teacher Gamma both demonstrated Accepting levels in both their treatment classes and control classes. Teacher Zeta demonstrated mainly an Accepting level, but at times an Adapting level, in both treatment and control classes.

The same TPACK levels were supported in the lesson plan analysis. In listing objectives and goals, teachers included the use of technology, such as the graphing calculator and PowerPoint within the control class and the TI-Nspire, emulator, and PowerPoint within the control class. All students were allowed and encouraged to use their calculators in completing assignments, quizzes, and tests. This practice demonstrated the Accepting TPACK level. Treatment teachers demonstrated the TPACK level in their assessments by using the Texas Instrument website activities that were specifically designed for the TI-Nspire.

\section{CONCLUSION}

This study investigated the effects of using the TI-Nspire on student achievement, using statistical analyses revealed statistically significant interactions. It also investigated teacher planning, teaching, and assessments using observations and document analysis.

Vignettes were then developed around the framework and key constructs of representations, Depth of Knowledge, and TPACK.

Statistical significance was found between treatment and control groups on pretests and on post post-tests. For the pre-test, the control group means were significantly higher than those of the treatment group. For the post post-test, the treatment group 
means were significantly higher than those of the control group. Post hoc analysis revealed statistically significant differences in the mean scores of the post post-test of Teacher Zeta's classes, Teacher Epsilon's classes and Teacher Gamma's classes. Teacher effect on the post post-test and an interaction effect between teacher and type on the post-test and the post post-test revealed statistical significance. Further pairwise comparisons among teachers revealed additional statistical significance between Teacher Zeta's classes and both Teacher Epsilon's and Gamma's classes on the post-test and the post post-test.

Using the original means, statistical significance for socioeconomic status was found on the post-test and on the post post-test; however, when using the pooled imputed means only the post-test showed statistical significance. The original means revealed a statistically significant interaction between teacher and socioeconomic status on the post post-test, but the pooled imputed means revealed no statistical significance. The original means revealed a statistically significant interaction between type and socioeconomic status on the pre-test, but the pooled imputed means revealed no statistical significance. The pooled imputed means revealed a statistical interaction between teacher and special education on the post post-test, but the original means did not find that interaction to be statistically significant. The lack of data caused different interactions and further analyses were not possible due to lack of power.

Qualitative analyses used vignettes of each teacher within the study. The key constructs included: types of representations, Depth of Knowledge, and TPACK. During classroom observations, Teacher Alpha, Teacher Epsilon, and Teacher Gamma used, on average, more representations within the treatment class than the control class. Teacher 
Zeta used, on average, more representations within the control class than the treatment class. In the document analysis of the lesson plan, all teachers used, on average, more representations in the treatment class than in the control class.

All teachers used, on average, higher Depth of Knowledge activities within the treatment class than the control class. During the analysis of the lesson plan, Teacher Alpha used higher Depth of Knowledge activities with the control class than with the treatment class while Teacher Epsilon, Teacher Gamma, and Teacher Zeta used higher Depth of Knowledge activities with their treatment classes than with their control classes. During the analysis of state competencies, Teacher Alpha, Teacher Epsilon, and Teacher Gamma used competences that were on average at a higher Depth of Knowledge for the treatment class than for the control class. Teacher Zeta used the same state competencies for both treatment and control classes; therefore, the average Depth of Knowledge was the same for both classes.

Teacher Epsilon was on the Recognizing TPACK level within the control class observation and Teacher Zeta was on the Adapting TPACK level. All teachers exemplified the Accepting TPACK level for the treatment classes during the observations. All teachers were at the Accepting TPACK level for both the treatment class and the control class on their lesson plans. When analyzing the assessments, all teachers were at the Accepting TPACK level in that they allowed and encouraged students to use calculators on starters, class work, homework, quizzes and tests.

A summation table (table 14) compared the quantitative data and qualitative data to provide an overall picture of the study. Teacher Alpha planned to have a higher depth of knowledge activities in the control class than the treatment, but during the observation 
had higher depth of knowledge activities in the treatment class. Teacher. Epsilon was the only teacher who had considerable more state standards depicted in the lessons for the treatment class over those for the the control class. Teacher Gamma's control class consistently scored higher than the treatment class meaning there could be some student effect. Teacher Epsilon's treatment class and Teacher Alpha's control class were the counter balance to Teacher Gamma's control class in that they were taught during the same class period. Upon investigation of their scores, Teacher Epsilon's treatment students excelled at the post-test and the post post-test while Teacher Alpha's control class did better on the post-test than the treatment, but not on the post post-test. The summation table reveals that there were many differences between the types and the teachers. While these differences could have accounted for some effect, the design of the study accounted for most of the effect. The random assignment of treatment and control, multiple measures on the tests, multiple teacher observations, and document analysis to control for construct validity all helped to strengthen the study and reinforce that the findings within the data were from the treatment of using a TI-Nspire graphing calculator to teacher the function concept in a first year Algebra class. 
Table 14

Summation Table

\begin{tabular}{|c|c|c|c|c|c|c|c|c|c|}
\hline & \multicolumn{2}{|c|}{$\begin{array}{c}\text { Number of } \\
\text { Representations }\end{array}$} & \multicolumn{3}{|c|}{ Depth of Knowledge } & \multirow{2}{*}{$\begin{array}{c}\text { Number } \\
\text { of } \\
\text { State } \\
\text { Comps }\end{array}$} & \multicolumn{3}{|c|}{ Original Means } \\
\hline & Observe $^{a}$ & $\begin{array}{c}\text { Lesson } \\
\text { Plans }\end{array}$ & Observe $^{a}$ & $\begin{array}{c}\text { Lesson } \\
\text { Plans }\end{array}$ & $\begin{array}{c}\text { State } \\
\text { Comps }^{b}\end{array}$ & & $\operatorname{Pre}^{c}$ & Post $^{d}$ & $\begin{array}{l}\text { Post } \\
\text { Post }^{\mathrm{e}}\end{array}$ \\
\hline $\begin{array}{l}\text { Alpha } \\
\text { control }\end{array}$ & $\begin{array}{c}2.18 \\
(0.98)\end{array}$ & $\begin{array}{l}2.71 \\
(.69)\end{array}$ & $\begin{array}{l}2.41 \\
(.59)\end{array}$ & $\begin{array}{l}1.76 \\
(.59)\end{array}$ & $\begin{array}{l}2.00 \\
(.76)\end{array}$ & 14 & 4.82 & 8.91 & 7.23 \\
\hline $\begin{array}{l}\text { Alpha } \\
\text { Treatment }\end{array}$ & $\begin{array}{c}2.86 \\
(0.38)\end{array}$ & $\begin{array}{l}2.87 \\
(.64)\end{array}$ & $\begin{array}{l}2.57 \\
(.61)\end{array}$ & $\begin{array}{l}1.63 \\
(.61)\end{array}$ & $\begin{array}{l}2.07 \\
(.76)\end{array}$ & 15 & 4.78 & 7.11 & 7.28 \\
\hline $\begin{array}{l}\text { Epsilon } \\
\text { control }\end{array}$ & $\begin{array}{c}1.93 \\
(0.92)\end{array}$ & $\begin{array}{l}2.36 \\
(.81)\end{array}$ & $\begin{array}{l}2.25 \\
(.66)\end{array}$ & $\begin{array}{l}1.55 \\
(.50)\end{array}$ & $\begin{array}{l}2.09 \\
(.67)\end{array}$ & 11 & 4.62 & 6.38 & 6.81 \\
\hline $\begin{array}{l}\text { Epsilon } \\
\text { Treatment }\end{array}$ & $\begin{array}{c}3.08 \\
(1.49)\end{array}$ & $\begin{array}{l}2.64 \\
(.92)\end{array}$ & $\begin{array}{l}2.40 \\
(.58)\end{array}$ & $\begin{array}{l}1.64 \\
(.66)\end{array}$ & $\begin{array}{l}2.22 \\
(.71)\end{array}$ & 18 & 4.18 & 8.43 & 9.50 \\
\hline $\begin{array}{l}\text { Gamma } \\
\text { Control }\end{array}$ & $\begin{array}{c}2.08 \\
(1.17)\end{array}$ & $\begin{array}{l}2.23 \\
(.73)\end{array}$ & $\begin{array}{l}1.79 \\
(.50)\end{array}$ & $\begin{array}{l}1.69 \\
(.66)\end{array}$ & $\begin{array}{l}2.25 \\
(.75)\end{array}$ & 16 & 4.41 & 8.18 & 8.65 \\
\hline $\begin{array}{l}\text { Gamma } \\
\text { Treatment }\end{array}$ & $\begin{array}{c}2.22 \\
(0.83)\end{array}$ & $\begin{array}{l}2.79 \\
(.58)\end{array}$ & $\begin{array}{l}2.46 \\
(.51)\end{array}$ & $\begin{array}{l}1.75 \\
(.58)\end{array}$ & $\begin{array}{l}2.22 \\
(.79)\end{array}$ & 18 & 4.05 & 7.18 & 7.45 \\
\hline $\begin{array}{c}\text { Zeta } \\
\text { Control }\end{array}$ & $\begin{array}{c}3.00 \\
(0.50)\end{array}$ & $\begin{array}{l}2.88 \\
(.72)\end{array}$ & $\begin{array}{l}2.33 \\
(.52)\end{array}$ & $\begin{array}{l}2.00 \\
(.52)\end{array}$ & $\begin{array}{l}2.09 \\
(.79)\end{array}$ & 11 & 5.00 & 5.50 & 4.19 \\
\hline $\begin{array}{c}\text { Zeta } \\
\text { Treatment }\end{array}$ & $\begin{array}{c}2.55 \\
(1.57)\end{array}$ & $\begin{array}{l}2.94 \\
(.75)\end{array}$ & $\begin{array}{l}2.67 \\
(.50)\end{array}$ & $\begin{array}{l}2.00 \\
(.50)\end{array}$ & $\begin{array}{l}2.09 \\
(.79)\end{array}$ & 11 & 3.80 & 7.08 & 6.44 \\
\hline $\begin{array}{l}\text { a Observati } \\
{ }^{b} \text { Competer } \\
{ }^{b} \text { Pre-test N } \\
{ }^{d} \text { Post-test } \\
{ }^{\text {Post Post }} \text { Post }\end{array}$ & $\begin{array}{l}\text { ion } \\
\text { ncies } \\
\text { Mean } \\
\text { mean }\end{array}$ & & & & & & & & \\
\hline
\end{tabular}




\section{CHAPTER 5}

\section{DISCUSSION}

\section{INTRODUCTION}

The purpose of this study was to investigate the effects of the independent variable, a teaching strategy using the TI-Nspire, on the dependent variable student achievement, measured by pre- and post-tests using the Kentucky High School Diagnostic Mathematics Assessments. This study also examined the effects of the independent variable on teacher planning, teaching, and assessments. The following questions guided the research of this study:

1) Was there a difference in student test scores on function concepts in Algebra I classrooms that used TI-Nspire graphing calculators versus those who did not use this device? The independent variable was treatment and the dependent variables were the pre-test, post-test, and post post-test.
a. Treatment Effect
b. Teacher Effect
c. Interaction of Teacher and Treatment
d. Factors: special education status and socioeconomic status

2) Did the use of TI-Nspire graphing calculators affect the way teachers taught function concepts in Algebra I classrooms with respect to representations, 
Depth of Knowledge, and TPACK? The independent variable was treatment and the dependent variables how teacher taught.

3) Did the use of TI-Nspire graphing calculators affect the way teachers planned lessons for function concepts in Algebra I classroom with respect to representations, Depth of Knowledge, and TPACK? The independent variable was treatment and the dependent variables how teacher planned.

4) Did the use of TI-Nspire graphing calculators affect the way teachers assessed students on functions concepts in Algebra I classrooms with respect to representations, Depth of Knowledge, and TPACK? The independent variable was treatment and the dependent variables how teacher assessed.

The independent variable, teaching strategy, was implemented in the first year of algebra with teachers using the TI-Nspire graphing calculator as an instructional tool to teach function concepts. The effect on student achievement was determined by measuring students' understanding of functions through comparisons of pre-test and posttest results. Student achievement was measured using a pre-test, post-test, and a post post-test and analyzed using a Repeated Measures ANOVA. The effect of how teachers teach, plan and access students while teaching function concepts was determined qualitatively by observations and document analyses.

The study occurred in the first-year Algebra classes at Eagle High School. In the summer prior to this study, teachers at Eagle High School received training on the TINspire, which was a new technology tool to them. Prior to using the TI-Nspire, first-year Algebra teachers at Eagle High School used the Casio non-graphing scientific calculator. Understanding the learning curve that existed for teachers, additional training on using 
the TI-Nspire to teach the function concept was provided for teachers two weeks prior to the study. During the study, treatment teachers taught with the TI-Nspire graphing calculator and the TI-Nspire emulator using a projector. Teachers also attended weekly meetings to discuss any concerns or issues about the TI-Nspire and to receive assistance in planning activities with the TI-Nspire for the upcoming week. During the weekly meetings, teachers completed weekly questionnaires and submitted their lesson plans and assessments. A classroom observation for each class was also completed by the researcher during the study. Vignettes were then developed around the key constructs of representations, Depth of Knowledge, and Technological Pedagogical Content Knowledge (TPACK).

\section{FINDINGS}

Some data $(21 \%)$ were missing in this study. That is, out of a possible 226 cases, 179 had complete data, and 47 had some data missing. To control for the potential bias of this missing data, a set of five imputations from these data were computed. Each imputation was analyzed separately, and the results were pooled to provide a comparison to the results of the original data. Therefore results are reported for both original data and pooled imputed data. The four components of the first research questions were analyzed quantitatively. The analysis for question 1a compared total treatment and total control with the type variable for pre-test, post-test and post post-test results. The analysis for question $1 \mathrm{~b}$ compared teachers with the teacher (tchr) variable across type. The analysis

for question $1 \mathrm{c}$ compared type by teacher. The analysis for question $1 \mathrm{~d}$ introduced socioeconomic status (ses), and special education (sped), as fixed factors. 
Statistical significance was found between treatment group and the control group (type) on the pre-test and on the post post-test. However, the differences between treatment and control groups were not significant for the post-test. The control group pre-test data were significantly higher than those of the treatment group; however the treatment group post post-test data were significantly higher than those of the control group. Post hoc tests found significant difference in the scores of the post post-test of Teacher Zeta's classes and both Teacher Epsilon's classes and Teacher Gamma's classes. The interaction between teacher and type on the post post-test were found to be statistically significant. Furthermore, pairwise comparisons among teachers revealed significance differences on the post-test and the post post-test between Teacher Zeta's classes and both Teacher Epsilon's classes and Teacher Gamma's classes.

Using the original data $(\mathrm{N}=179)$, the analysis revealed statistical significance for socioeconomic status on the post-test and on the post post-test; however, when using the pooled imputed data $(\mathrm{N}=226)$ only the post-test revealed statistical significance. The original data analysis revealed a statistically significant interaction between teacher and socioeconomic status on the post post-test, however the pooled imputed data revealed no statistical significance. The original data analysis also revealed a statistically significant interaction between type and socioeconomic status on the pre-test; however, the pooled imputed data were not statistically significant. The original data had 21 students categorized as special education while the imputed data had 27 students indicating a $30 \%$ loss in data. With such a small data set, a lack of power to complete further analysis with these factors was evident. 
The pooled imputed data analysis revealed a significant interaction between teacher and special education on the post post-test; however this interaction was not statistically significant in the original data. The original data had 124 students categorized as socioeconomic status while the imputed data revealed 155 students or about $20 \%$ missing data which was not much different from that of all students. The results from the individual imputations were also mixed. The interaction between teacher and socioeconomic status for Imputation 1 data was significant $(\mathrm{p}=.049)$; for Imputation 2 not significant $(\mathrm{p}=.051)$; and for the remaining three imputations not significant with $\mathrm{p}$ values for Imputations 3-6 of .324, .510, and .446 respectively. A possible explanation for this set of mixed results is that teachers performed quite differently in treatment and control classes. The teacher effect was quite large and may have overshadowed socioeconomic status and special education factors. A larger sample might have produced sufficient power to detect these factors even if the teacher effect was large.

Each teacher was observed twice, once in the treatment class and once in the control class. Teachers also completed a weekly questionnaire which provided insight into their teaching in each type of class. Lesson plans and assessments were gathered for document analysis to provide insight into class activities. The document analysis was designed to detect consistencies among teachers and classes with respect to three key constructs: types of representations, Depth of Knowledge, and TPACK.

During classroom observations, all teachers used a starter activity at the beginning of class. During the course of the study, some treatment teachers used this time to distribute the TI-Nspire Calculators. During the classroom observations, all teachers used the numeric, geometric, symbolic, and analytic representations within both classes. 
Teacher Alpha, Teacher Epsilon, and Teacher Gamma used more representations within the treatment class than the control class on average. Teacher Zeta used more representations within the control class than the treatment class on average. In determining the TPACK level during the classroom observations, all teachers revealed some aspects of the TPACK level within the control class. However, Teacher Epsilon was more often at the recognizing TPACK level within the control class observation and Teacher Zeta was more often at the adapting TPACK level. Within the treatment class observations, all teachers demonstrated some activity at the accepting TPACK level. On the weekly questionnaires, Teacher Alpha, Teacher Epsilon, and Teacher Gamma reported being behind in their treatment class with regard to teaching the function concept on comparison with their control class. By the beginning of the third week, all of these classes were able to catch up with the control class. All teachers noted difficulties in learning a new technology tool (TI-Nspire) and teaching with it. Teachers pointed out that the students were sometimes distracted with the new tool instead of focusing on the concepts taught. Teachers commented that they enjoyed using the Texas Instruments website and the readymade programs. Teacher Gamma noted how eager and excited the students were about the TI-Nspire. Teacher Zeta commented that it was easier to teach from the "big picture" with the TI-Nspire instead of having to piece-meal the individual concepts of functions together. Teachers specifically mentioned the topics of function notation, ordered pairs, slope, intercepts and tables as being easier to teach with the TI-Nspire. Teachers also felt that they were more effective in teaching these topics. 
Within the lesson plan, all teachers used, on average, more representations in the treatment class than the control class. Teacher Alpha, Teacher Epsilon, and Teacher Gamma used on average more representations in the treatment class than the control; however, Teacher Zeta used on average more representations in the control class than the treatment. In the lesson plan comparison, Teacher Zeta used the same starters, same state competencies, and the same goals; however the homework assignments were different. The homework assignments for both the treatment class and the control class had the same Depth of Knowledge; however, the treatment class had more representations.

During the lesson plan analysis, treatment classes on average completed activities at higher depths of knowledge than the control classes. During the analysis of the lesson plan, Teacher Alpha used, on average, higher Depth of Knowledge activities with the control class than with the treatment class. While Teacher Epsilon, Teacher Gamma, and Teacher Zeta used on average higher Depth of Knowledge activities with their treatment class than with their control class. During the analyses of average state competencies on the lesson plans, Teacher Alpha, Teacher Epsilon, and Teacher Gamma used competences that were on average at a higher Depth of Knowledge for the treatment class than for the control class. Teacher Zeta used the same state competencies for both the treatment and control class; therefore the average Depth of Knowledge was the same for both classes. While analyzing the lesson plans with objectives, goals, and listed technology, all teachers were at the accepting TPACK level for both the treatment class and the control class.

Homework assignments given by all teachers were either directly from the textbook or from textbook worksheets. The Depth of Knowledge on the homework 
included Level 1, Level 2 and Level 3, but was mainly Level 2. The types of representations used included a combination of numeric, geometric, symbolic, analytic, and written representations. The test and quizzes were taken directly from the textbook publishers and included both Level 1 and Level 2 Depth of Knowledge activities and used a combination of numeric, geometric, symbolic, analytic, and written representations. Within all assessments, teachers worked at the accepting TPACK level. All teachers allowed and encouraged students to use calculators on starters, class work, homework, quizzes, and tests.

\section{OVERALL FINDINGS}

Overall, the student scores were significantly different between treatment and control groups when controlling for teacher effect on the pre-test and the post post-test. The student scores were also significantly different when considering teacher and type on the post post-test. When controlling for the pre-test, Teacher Zeta's classes post-test and post post-test scores were significantly different from those of Teacher Epsilon's classes and Teacher Gamma's classes. Not enough data was available for the power to analyze the interaction effects of socioeconomic status and special education by teacher and type.

During the observations, all teachers used multiple representations in all classes. Teacher Alpha, Teacher Epsilon and Teacher Gamma used, on average, more representations per activity in their treatment class than their control class. Teacher Zeta was the only teacher who used, on average, more representations per activity in the control class than in the treatment class. The use of multiple representations was also supported by questionnaire responses regarding methods of representations that were used to teacher function concepts. During the lesson plan analysis, all treatment classes 
used, on average, more representations per activity in the treatment class versus the control. Multiple representations also were confirmed to be used by all teachers and all classes on the homework, quizzes, and tests.

All classes used, on average, higher Depth of Knowledge activities in their treatment class compared to their control class. Teacher Alpha, Teacher Gamma, and Teacher Zeta all used Level 1, Level 2, and Level 3 Depth of Knowledge activities within their treatment class and their control class. Teacher Epsilon only used Level 1 and Level 2 Depth of Knowledge activities within the treatment class and control class. In the lesson plan analysis, the average Depth of Knowledge used for activities was higher for Teacher Alpha's control class than for the treatment class. The opposite was true for Teacher Epsilon and Teacher Gamma in that their treatment class had, on average, higher Depth of Knowledge activities than their control class. Teacher Zeta had the same Depth of Knowledge levels for both classes because all activities for the two classes were the same.

Although some control classes reviewed function concept material, the treatment classes had begun to cover the same material, meaning that the control classes were ahead of the treatment classes in covering the function concept. However all treatment classes had caught up with the control classes by the beginning of the third week.

Teachers reported issues were reported within the questionnaire regarding teacher confidence and ability in learning to use the TI-Nspire and the emulator because it was new technology to them. Teachers noted that the treatment classes had to go slower over the material when introducing the TI-Nspire because it was new technology to the students. Teachers also expressed concern about time needed to distribute the 
calculators, but as the study progressed, the treatment teachers often used the starter time to distribute the TI-Nspire calculators.

Teachers indicated that the TI-Nspire made teaching the function concepts such as slope, tables, domain and range, functional notation, intercepts, ordered pairs, and graphing much easier and more effective. Teachers liked the capability that the calculator provided that allowed students to move from table to graph to equation all within the same exercise with the TI-Nspire. As stated in Chapter 4, Teacher Gamma explained how quickly her treatment students had learned to relate multiple concepts. Teachers also pointed out that the TI-Nspire allowed the students opportunities to see the big picture of how the function representations were all interconnected.

Teachers also benefited from having access to the Texas Instruments website with ready-made activities which served to supplement the textbook curriculum with hands-on activities. Teachers also indicated that using the emulator was effective in teaching students how to complete problems step-by-step as a class. Teachers also stated that using the emulator allowed the students to easily see the proper steps to take to complete a problem, which was especially helpful since the TI-Nspire was a new technology tool for them.

All teachers demonstrated the TPACK Accepting level during the course of this study. During the control class observation, Teacher Epsilon demonstrated a Recognizing TPACK level. Teacher Zeta demonstrated more of an Adapting TPACK level. All teachers allowed and encouraged the use of calculators on assessments, and all teachers were willing to participate in professional development on the TI-Nspire, a new technology tool. 


\section{LIMITATIONS OF THE STUDY}

This study was limited to a single southern rural school so the generalization is limited to schools of similar size and characteristics. Only the teachers, who taught Algebra I within the ninth grade, were involved in this study. The sample for this study was four teachers and eight classrooms. Analysis at the class level was limited to comparing four treatment classes to four control classes so there was inadequate power to investigate some factors and interactions between factors.

The assignment of the treatment was conducted at the class level, and although students are assigned to classes randomly moderated by their schedule and there is no ranking or tracking system used by Eagle High School to place students into certain classes still there could be some non-randomness in the scheduling. On the other hand the research design counterbalanced treatment and control classes by having one of each in the school class periods so students limited to any one school period for algebra should have an equal chance of being assigned to a treatment or control class. This assignment was conducted by the school; however, and the researcher had no control over this process. Due to both a small sample size and that students were not completely randomly assigned to the classes, the variation within the classroom and the pedagogy of each individual teacher could affect the outcome.

Students during the third period had the class interrupted daily for lunch. There was no control over other interruptions that occurred throughout the school day and school year such as fire drills, club meetings, etc.

Time was a limiting factor of this study, in that the study occurred over the course of four weeks. The topics covered by each teacher and the extent to which they covered 
such topics may or may not have been consistent. The use of TI-Nspire specific activities within the treatment classes could have impacted the study. The limitations inherent to self-reporting existed with teachers self-reporting on the questionnaire. Because all teachers taught a treatment and a control class, all control teachers received the training on the TI-Nspire. While this was necessary and added internal validity, this also limited the control teachers by having them exposed to the training for the treatment classes.

\section{IMPLICATIONS}

The control group's scores were significantly higher than the treatment group's scores on the pre-test, indicating that the control class started out at a significantly higher level of achievement than the treatment group. On the post-test, the treatment group's scores were about the same as the control group's scores. While there was not a significant difference between the group's post-test scores, the treatment group reached the same level of achievement as the control group. The treatment group's scores were significantly higher than the control group's scores on the post post-test, indicating that the treatment group had a significantly higher level of achievement than the control group. This result was supported by other research findings that showed improved test scores when using a calculator (Ellington, 2003; Hembree \& Dessart, 1996; Hollar \& Norwood, 1999; Mittag \& Taylor, 2000; O'Callaghan, 1998; and Ruthven, 1990b). This finding was also supported by classroom observations, and lesson plan analyses showed that treatment classes on average had experienced more representations and a higher Depth of Knowledge per activity between the pre-test and post post-test.

When controlling for the pre-test, students' post post-test scores were significantly higher, which implies that the teacher likely had some effect on the student 
scores. Teacher Zeta's class scores on the post-test and post-post test were significantly lower than Teacher Epsilon's class and Teacher Gamma's class. This finding implies that being placed in Teacher Zeta's class had a negative impact on student achievement when compared directly to being placed in the classes of Teacher Epsilon or Teacher Gamma. While the mean scores the classes of Teacher Zeta appeared to be lower than those of Teacher Alpha, the differences were not significant. Also interactions between socioeconomic status and teacher, and special education and teacher, may have been present, but due to the limitation of four teachers and eight classrooms, not enough power was available to analyze these interactions. Teacher Zeta's class patterns were also different from those of Teacher Alpha's class, Teacher Epsilon's class, and Teacher Gamma's class. Teacher Zeta was the only teacher during the observations covering the same material in both classes. On the lesson plans, Teacher Zeta was the only teacher to use the same state competencies in both classes. Teacher Zeta was also the only teacher who modified the worksheets for the TI-Nspire treatment class and gave them to the control class to work. These differences within the qualitative analysis seem to support the differences found with the post hoc tests which showed significant differences in the scores of the post post-test of Teacher Zeta's classes and both Teacher Epsilon's classes and Teacher Gamma's classes.

Treatment teachers adjusted for the TI-Nspire by using the time typically spent for starters to distribute calculators. All teachers used supplementary materials such as the Texas Instruments Website, TI Activities, and the emulator to teach function concepts to their treatment classes. The observations, questionnaires, and lesson plans indicated that teachers taught using more representations per activity within their treatment classes than 
their control classes. Teachers also taught using activities that were at a higher Depth of Knowledge level in their treatment classes.

No differences in TPACK levels among the treatment or control classes were found. This finding was in part to the lack of technology within the classrooms. Prior to this study, teachers had access only to the Casio non-graphing scientific calculators. During this study, teachers had the TI-Nspire graphing calculators to use with their treatment class. With such limited access to technology, the level at which the teachers would have actually demonstrated on the TPACK level with more technology was impossible to determine.

During the first two weeks of the study, teachers spent time teaching the treatment classes how to use the TI-Nspire, in addition to teaching function concepts. Teacher Alpha, Teacher Epsilon, and Teacher Gamma took longer to begin covering the function concepts during the first two weeks of this study due to the additional time needed for students to learn the new TI-Nspire teaching tool (Brenner et al., 1997; Hennessy, Fung, \& Scanlon, 2001; Privateer, 1999; Quesada \& Maxwell, 1994; and Simonsen \& Dick, 1997). Although Teacher Zeta indicated that introducing the new TI-Nspire to the treatment class slowed down the teaching process, Teacher Zeta continued to report within the lesson plans that both the treatment and the control classes were covering the same function content. By the beginning of the third week, all treatment classes were covering the same function concepts as the control classes. This information was supported by the classroom observations, questionnaires, lesson plans, and assessment analysis. 
Teachers stated that more time was needed to prepare their treatment classes because of the new TI-Nspire. This finding about implementing new technology is consistent with the reports of previous studies (Demana \& Waits, 1990; Dunham \& Dick, 1994; Hiebert, 1999; Lappan, 1997; and Simonsen \& Dick, 1997). During the Weekly Touchdown Sessions, teachers were shown programs from the Texas Instruments website that could be integrated into the treatment classroom; however, the teacher had the responsibility to plan for using them by making copies of the activity worksheets, downloading the programs to the classroom calculators, and preparing problems in the emulator. The treatment lesson plans had a higher average number of representations for the activities and a higher average Depth of Knowledge level for the activities. The Depth of Knowledge level for the state competencies listed within the lesson plan was higher for treatment classes than it was for control classes.

Within the control classes, all teachers used textbook exercises, textbook worksheets, textbook homework, textbook quizzes and textbook tests. Teacher Epsilon used an activity to map out the control classroom as a graph. Teacher Epsilon also used a USA Today activity with both the treatment class and the control class. Teacher Zeta used real-life situations as the basis for the starter questions with both the treatment class and the control class. Teacher Zeta created programs within PowerPoint for the control class to teach the function concepts interactively. Teacher Zeta also used some of the Texas Instruments website activity worksheets for the control class even though they were not using the TI-Nspire calculator. Texas Instruments programs such as "Scavenger Hunt," "What's the Point," and "Function Junction" were used in all of the treatment classes. Teachers varied in how they compensated for the Texas Instruments activities. For 
example, Teacher Epsilon would not assign homework to the control class; Teacher Gamma would not give the treatment class textbook worksheets; and Teacher Alpha and Teacher Epsilon would modified the quantity of exercises that the treatment class was assigned.

High quality, sustained professional development was key to assisting the teachers in how to teach effectively with the TI-Nspire. The TI-Nspire was new technology to all of the teachers, and they first needed to understand how it worked before they could be expected to teach and assess with it. A two-day summer professional development session, which was taught by a National Texas Instruments Instructor, helped the teachers learn how to use the TI-Nspire from scratch. Additional trained Texas Instruments Cadre Instructors were also present at the professional development session to provide one-on-one assistance at any time during the instruction. Teachers were then given a TI-Nspire, TI-Nspire emulator software, and access to online Atomic learning, and video training to continue their exploration of the TI-Nspire.

The week prior to the study, teachers attended another 6 hours of professional development taught by a Texas Instruments Trained Cadre member which reviewed the TI-Nspire, provided specific training about teaching the function concept with the TINspire, and allowed time to create lesson plans and activities for this study. During the four weeks of this study, teachers met once a week for 90 minutes after school to complete a weekly questionnaire, turn-in lesson plans, assessments, and receive further professional development on the TI-Nspire. During this time, the Texas Instruments Instructor answered questions, provided direction for the following week, and allowed time for the teachers to complete questionnaires. 
The effective integration of new technology requires sustained and supported professional development beyond the initial training of the new equipment (Burrill, 1998; Demana \& Waits, 1990; Dunham \& Dick, 1994; Hiebert, 1999; Klassen \& Vogel, 2001; Lappan, 1997; Podlesni, 1999; and Simonsen \& Dick, 1997). Having access to online training, online activities, as well as multiple professional development training sessions with Texas Instruments Instructors was key to assisting the teachers in learning how to use the TI-Nspire, learning how to implement it into their classroom, and in being able to extend the use of the TI-Nspire beyond routine calculations. While the teachers had a steep learning curve, the learning process was necessary when teaching the students how to use the TI-Nspire as well.

Based upon multiple comments by the teachers, the TI-Nspire made their teaching of the function concept both easier and more effective. Teachers liked the multiple ways to represent the same problem while having all the representations connected together within the TI-Nspire. As previously quoted, Teacher Gamma spoke about how this study brought to light the need to provide students multiple ways of looking at the same problem. The ability of the TI-Nspire to allow students to see the immediate and direct effect of data changes in a graph, an equation and a data table provided a way to web together the function concepts and show students the bigger picture instead of piece by piece. Research studies supports the findings that students using graphing technology perform better on visual and graphing tasks (Hollar \& Norwood, 1999).

With teacher training and technology within the classroom, teachers are able to teach at higher TPACK levels. The opportunity for professional development also encouraged and supported higher TPACK levels. If technology is not provided for within 
the classroom, teachers cannot teach at higher TPACK levels. School systems must set technology within the classroom as a priority in order to provide ample opportunity for classroom teachers to use the technology and increase their TPACK levels.

The emergence of calculators and computers has changed the way mathematics is both taught and used (Thorpe, 1989; \& Kieran, 1992). Thorpe (1989, p. 11) says that "it is time for algebra instruction in the schools to begin to reflect these changes." The TINspire has changed how teachers are able to teach because it allows for multiple ways to represent mathematics such as numeric, geometric, symbolic, and analytic representations that were webbed together by the teachers. Research shows that students can effectively use technology to make and understand connections between graphical and algebraic concepts (Drijvers \& Doorman, 1996; \& Choi-Koh, 2003) and using one algebraic system to extend and acquire an understanding of another (Colgan, 1993, p. 57).

The ability to foster a deeper understanding or higher Depth of Knowledge is supported by this webbing effect of the TI-Nspire. This webbing, which shows the direct effect of moving a line, changing the slope, or choosing different values within a table, not only provides multiple representations, but also allows for teachers to ask more probing questions about cause and relationships. The higher level thinking skills promoted using graphing calculators is also supported by other studies (Choi-Koh, 2003; Graham \& Thomas, 1998; Keller \& Hirsch, 1998; Dessart, DeRidder, Charleen, \& Ellington, 1999; Huntley, Rasmussen, Villarubi, Sangtong, \& Fey, 2000; \& Ronau et al., 2008).

The statistically significant results of the quantitative data analysis allow for the rejection of the null hypothesis that stated there was no statistically significant difference 
in student test scores on function concepts in Algebra I classrooms that used TI-Nspire graphing calculators versus Algebra I classrooms that did not use this device. The differences regarding the key constructs of representations, Depth of Knowledge and TPACK reject the null hypothesis that stated there was no difference in the way teachers taught function concepts in Algebra I classrooms that used TI-Nspire graphing calculators versus Algebra I classrooms that did not use this device. The differences found during the lesson plan and questionnaire analysis regarding state standards, activities, representations, and Depth of Knowledge reject the null hypothesis that no difference in the way teachers planned lessons for function concepts in Algebra I classrooms that use TI-Nspire graphing calculators versus Algebra I classrooms that did not use this device existed.

All test and quizzes were found to be the same for both classes. While some classroom tasks and homework assignments were modified for the treatment class, all assessments were essentially the same for both classes. Therefore, the null hypothesis that stated that there was no difference in the way teachers assessed students of functions concepts in Algebra I classrooms that used TI-Nspire graphing calculators versus Algebra I classrooms that did not use this device was supported.

\section{RECOMMENDATIONS}

A resounding issue expressed by the teachers was the need to have a better understanding and working knowledge of the TI-Nspire. This study provided very little time between the introduction of the new TI-Nspire technology and implementation. For future research, providing additional time and support through sustained professional development activities before teachers were expected to implement the new technology is 
recommended to allow teachers to become more proficient with the technology. While in this study students started using the new TI-Nspire in the middle of the semester, future recommendations would be to allow the students to start the school year with the TINspire calculators to eliminate issues the teachers had teaching both new concepts and new technology at the same time. This would also reduce the student's distraction of a new toy during the semester. Instead of focusing on only the function concept with the TI-Nspire, choose several key concepts throughout the Algebra course, therefore, allowing the generalization of the study to apply to an entire Algebra course.

Although this study was conducted only in ninth grade first-year Algebra classes at Eagle High School, other research opportunities could involve students in different grades or across multiple schools. Studies across multiple grades will increase the size of the study giving it more power. Including more schools in this study would not only increase the size and provide more power, but would also allow a greater generalization of the results. Future studies conducted over a longer time span would be desirable to explore the broader effect of the TI-Nspire and provide additional measures for stability. Another recommendation would be a longitudinal a study that followed algebra teachers over multiple years to see if the teachers experienced use with the TI-Nspire would make a difference and to control for student variance. This would allow for the teacher growth and understanding through the use of the TI-Nspire over multiple years. Another longitudinal approach would follow students over multiple years, that is, following student progression through sequential mathematics classes such as Algebra II and Geometry while still using the TI-Nspire calculator. This would allow for students to use the TI-Nspire at different levels of learning mathematics. To increase the power of the 
analysis for analyzing additional factors such as socioeconomic status and special education status, a larger sized study is recommended.

\section{SUMMARY}

Much research into the benefits of calculator use in the mathematics classroom has been conducted (Harvey, Waits, \& Demana, 1995; Hembree \& Dessart, 1986; and Smith, 1997). "The potential in using technology to extend the range of human mathematical learning and problem solving is only beginning to be tapped by research and development projects, much less in the day-to-day life of mathematics classrooms" (Fey, 1989, p. 266). This study sought to examine the effects of using the TI-Nspire calculator within the first year of algebra while studying the function concept. Teachers were provided sustained professional development by trained Texas Instruments Instructors on how to use the TI-Nspire and how to teach with the TI-Nspire emulator. Different quantitative analyses were completed on the pre-test, post-test and post post-test scores. Through observations, questionnaires and document analysis of lesson plans and assessments, the effect of teaching with the TI-Nspire was qualitatively analyzed.

Treatment classes, using the TI-Nspire, outperformed control classes on tests about functions. While a statistically significant effect of Teacher Zeta on the post-post test in comparisons to the other teachers was found most of the teacher effect was controlled within the design of the study.

Having sustained professional development throughout the study helped teachers expressing the need for adequate time and assistance for the new technology. Providing the Function Focus Session the week prior to the study greatly assisted the teachers in planning how to teach their treatment class. Providing a trained Texas Instruments 
Instructor on a weekly basis to answer questions, assist in providing direction for the following week, and meet weekly with the teachers to complete questionnaires were vital strategies necessary to support teachers with this new technology tool and to assure their fidelity in treatment implementation and control maintenance.

Teachers modified their teaching when using the TI-Nspire to include higher Depth of Knowledge activities as well as more representations per activity. Teachers also made adjustments within their lesson plans to incorporate the Texas Instruments website activities into their daily activities for their treatment class. Additional adjustments within the teacher lesson plans included using higher Depth of Knowledge state standards and activities as well as more representations per activity when using the TI-Nspire. Teachers did not appear to significantly modify their assessments such as test and quizzes for their treatment class.

This study supported the use of TI-Nspire graphing calculators into first-year Algebra classrooms while studying the concept of functions. This study showed that while using the TI-Nspire graphing calculator, the use of multiple representations and higher Depth of Knowledge activities can be used to increase student achievement and impact classroom teaching, and lesson planning. Although further research is needed to establish the impact of the TI-Nspire across various mathematics topics, this study demonstrated the impact of the TI-Nspire graphing calculator for the concept of functions with respect to increasing teacher's use of representations and of more complex tasks. Finally, and perhaps more importantly, the results also indicated a significant increase in student achievement for the treatment group. 


\section{REFERENCES}

Adams, T. L. (1997). Addressing students' difficulties with the concept of function: applying graphing calculators and a model of conceptual change. Focus on Learning Problems in Mathematics, 19(2), 43-57.

Alabama State Department of Education. (2006). Algebra I. Retrieved from http://www.alsde.edu/html/doc_download.asp?id=512\&section=54

Allison, P. D. (2000). Multiple imputation for missing data: A cautionary tale. Sociological Methods and Research, 28, 301-309.

American Association for the Advancement of Science. (1922). The reorganization of mathematics in secondary education. Science, 55(1416), 172-173.

The American Diploma Project. (2004). Ready or not: Creating a high school diploma that counts. Washington, DC: Achieve. Retrieved from http://www.achieve.org/achieve.nsf/AmericanDiplomaProject?openform American Mathematical Society. (1994). National policy statement. Retrieved from http://www.ams.org

Atanda, R. (1999). Do gatekeeper courses expand education options? Educational Statistics Quarterly, 1(1), 33-38.

Atomic Learning. (2011). TI-Nspire ${ }^{\mathrm{TM}}$ Handhelds and Computer Learning. Retrieved from http://www.atomiclearning.com/ti_nspire

Ball, B. (2003). Teaching and learning mathematics with an interactive whiteboard. Micromath, 19(1), 4-7. 
Ball, G. (2004). The birth of a new age. Retrieved from http://www.xnumber.com/xnumber/birth.htm

Blanton, M. L., \& Kaput, J. J. (2005). Helping elementary teachers build mathematical generality into curriculum and instruction. ZDM- The International Journal on Mathematics Education, 37(1), 34-42.

Blubaugh, W., \& Emmons, K. (1999). Activities: Algebra for all: Graphing for all students. Mathematics Teacher, 92(4), 323.

Bransford, J. D., Brown, A. L., \& Cocking, R. R. (Eds.). (2000). How people learn: Brain, mind, experience, and school (Expanded Ed.). Washington, DC: National Academy Press.

Brenner, M. E., Mayer, R. E., Moseley, B., Brar, T., Duran, R., Reed, B. S., \& Webb, D. (1997). Learning by Understanding: The Role of Multiple Representations in Learning Algebra. American Educational Research Journal, 34(4), 663-689.

Brooks, M. G., \& Brooks, J. G. (1999). The courage to be constructivist. Educational Leadership, 57(3), 18-24.

Burrill, G. (1998). Changes in your classroom: From the past to the present to the future. Journal for Research in Mathematics Education, 29(5), 583-596.

Bush, W. S. (2006). Kentucky diagnostic assessments for algebra I, geometry, and algebra II. Paper presented at the Kentucky High School Mathematics Summit, Bowling Green, KY.

Carpenter, T. P., Franke, M. L., \& Levi, L. (2003). Thinking mathematically: Integrating arithmetic and algebra in the elementary school. Portsmouth, NH: Heinemann. 
Choike, J. R. (2000). Teaching strategies for "algebra for all." Mathematics Teacher, 93(7), 556.

Choi-Koh, S. S. (2003). Effect of a graphing calculator on a $10^{\text {th }}$-grade student's study of trigonometry. The Journal of Educational Research, 96(6), 359-370.

Colgan, L. E. C. (1993). Graphing tools in the mathematics classroom: Some factors affecting successful use. (Doctoral dissertation, University of Toronto). Dissertation Abstracts International, 54, 1712A.

Connors, M. A., \& Snook, K. G. (2001). The effects of hand-held CAS on student achievement in a first-year college core calculus sequence. The International Journal of Computer Algebra in Mathematics Education, 8(2), 99-114.

Cox, P., \& Bridges L. (1999). Algebra for all: Activities: Calculating human horsepower. Mathematics Teacher, 92(3), 225.

Creswell, J. W. (2009). Research design: Qualitative, quantitative, and mixed methods approaches ( $3^{\text {rd }}$ ed.). Thousand Oaks, CA: Sage.

Davis, M. (2000). The universal computer: The road from Leibniz to Turing. New York, NY: W.W. Norton.

Demana, F. \& Waits, B. K. (1990). The Role of Technology in Teaching Mathematics. The Mathematics Teacher, 82(1).

Dessart, D. J., DeRidder, C. M., \& Ellington, A. J. (1999). The research backs calculators. Mathematics Education Dialogues, 2(3), 6.

Dimock, V., \& Sherron, T. (2005). A final report of a study of the impact of graphing calculator use on state assessment. Retrieved from 
http://education.ti.com/sites/US/downloads/pdf/graphing_use_st_assmnts_sedl_20 05.pdf

Dion, G., Harvey, A., Jackson, C., Klag, P., Liu, J., \& Wright, C. (2001). A survey of calculator usage in high schools. School Science and Mathematics, 101(8), 427438.

Doerr, H. M., \& Zangor, R. (2000). Creating meaning for and with the graphing calculator. Educational Studies in Mathematics, 41, 143-163.

Drijvers, P., \& Doorman, M. (1996). The graphics calculator in mathematics education. Journal of Mathematical Behavior, 15, 425-440.

Drijvers, P. (2000). Students encountering obstacles using a CAS. International Journal of Computers for Mathematical Learning, 5(3), 189-209.

Drijvers, P., \& Van Herwaarden, O. (2000). Instrumentation of ICT-tools: The case of algebra in a computer algebra environment. The International Journal of Computer Algebra in Mathematics Education, 7(4), 255-276.

Driscoll, M., Foster, S., \& Moyer, J. (1999). Linked Learning in Mathematics Project. The Mathematics Teacher, 92(1),72-73.

Dubinsky, E., Schoenfeld, A, \& Kaput, J. (1994). Research in collegiate mathematics education. Providence, RI: American Mathematical Society.

Dunham, P. H. \& Dick, T. P. (1994). Research on graphing calculators. The Mathematics Teacher, 87(6),440-445.

Ellington, A. J. (2003). A meta-analysis of the effects of calculators on students' achievement and attitude levels in precollege mathematics classes. Journal for Research in Mathematics Education, 34(5), 433-463. 
Ellington, A. J. (2004). The calculator's role in mathematics attitude. Academic Exchange Quarterly, 8(2), 110-114.

Ellington, A. J. (2006). The effects of non-CAS graphing calculators on student achievement and attitude levels in mathematics: A meta-analysis. School Science and Mathematics, 106(1), 16-27.

Farrell, A. (1996). Roles and behaviors in technology-integrated pre-calculus classrooms. Journal of Mathematical Behavior, 15(1), 35-53.

Fey, J. T. (Ed.). (1984). Computing and mathematics: The impact on secondary school curricula. Reston, VA: National Council of Teachers of Mathematics.

Fey, J. T. (1989). Technology and mathematics education: A survey of recent developments and important problems. Educational Studies in Mathematics, 20(3), 237-272.

Fey, J. T., \& Graeber, A. O. (2003). From the New Math to the Agenda for Action. In G. Stanic \& J. Kilpatrick (Eds.), A history of school mathematics (Vol. 1, pp. 521558). Reston, VA: National Council of Teachers of Mathematics.

Flattau, P. E., Bracken, J., Van Atta, R., Bandeh-Ahmadi, A., de la Cruz, R., \& Sullivan, K. (2006). The National Defense Education Act of 1958: Selected outcomes. Washington, DC: Institute for Defense Analyses Science \& Technology Policy Institute.

Fleener, M. (1995a). The relationship between experience and philosophical orientation: A comparison of pre-service and practicing teachers' beliefs about calculators. Journal of Computers in Mathematics and Science Teaching, 14(3), 359-376. 
Fleener, M. (1995b). A survey of mathematics teachers' attitudes about calculators: The impact of philosophical orientation. Journal of Computers in Mathematics and Science Teaching, 14(4), 481-498.

Forester, P. A. (2000). Process and object interpretations of vector magnitude mediated by use of the graphics calculator. Mathematics Education Research Journal, $12(3), 269-285$.

Froelich, G. W., Bartkovich, K. G., \& Foerester, P. A. (1991). Connecting mathematics. In C. R. Hirsch (Ed.), Curriculum and evaluation standards for school mathematics addenda series, grades 9 - 12. Reston, VA: National Council of Teachers of Mathematics.

Galbraith, P. (2002). "Life wasn't meant to be easy": Separating wheat from chaff in technology aided learning? Proceedings of the International Conference on the Teaching of Mathematics [ED 472046 SE 066 911].

Gall M. D., Gall J. P., \& Borg, W. R. (2003). Educational research: an introduction $\left(7^{\text {th }}\right.$ ed.). NY: Pearson.

Gardner, H. (1995). “Multiple intelligences” as a catalyst. The English Journal, 84(8), 16-18.

Gardner, H., \& Hatch, H. (1989). Multiple intelligences go to school: Educational implications of the theory of multiple intelligences. Educational Researcher, $18(8), 4-10$.

Garrett, A., \& Davis, O. (2003). A time of uncertainty and change: School mathematics from World War II until the new math. In G. Stanic \& J. Kilpatrick (Eds.), $A$ 
history of school mathematics (Vol. 1, pp. 493-520). Reston, VA: National Council of Teachers of Mathematics.

Gigerenzer, G. (2004). Mindless statistics. Journal of Socio-Economics, 33(5), 587-606.

Golden, W. M. (2006). USICSM in its second decade. Journal of Research in Science Teaching, 1(3), 265-269.

Goldin, C. (2003). The human capital century: U.S. schools led the world during much of the $20^{\text {th }}$ century. Will they continue to do so? Education Next, 1, 73-78. Retrieved from http://media.hoover.org/documents/ednext20031_73.pdf

Good, T. L., Brophy, J. E. (1990). Educational psychology: A realistic approach (4th ed.). White Plains, NY: Longman.

Goos, M., Galbraith, P., Renshaw, P., \& Geiger, V. (2000). Reshaping teacher and student roles in technology-enriched classrooms. Mathematics Education Research Journal, 12(3), 303-320.

Graham, A. T., \& Thomas, M. (1998). A graphic calculator approach to algebra. Mathematics Teaching, 167, 27-34.

Granello, D. H. (2000). Encouraging the cognitive development of supervisees: Using Bloom's taxonomy in supervision. Counselor Education \& Supervision, 40(1), $31-46$.

Hamley, H. R. (1934). Relational and functional thinking in mathematics: 9th yearbook of the National Council of Teachers of Mathematics. New York, NY: Teachers College Press. 
Harskamp, E. G., Suhre, C. J., \& Van Streun, A. (2000). The graphics calculator and students' solution strategies. Mathematics Education Research Journal, 12(1), 3752.

Harvey, J. G., Waits, B. K., \& Demana, F. D. (1995). The influence of technology on the teaching and learning of algebra. Journal of Mathematical Behavior, 14, 75-109.

Heid, K. M. (1997). The technological revolution and the reform of school mathematics. American Journal of Education, 106(1), 5-61.

Hembree, R., \& Dessart, D. J. (1986). Effects of hand-held calculators in precollege mathematics education: A meta-analysis. Journal for Research in Mathematics Education, 17, 83-99.

Hembree, R., \& Dessart, D. J. (1992). Research on calculators in mathematics education. In J. T. Fey (Ed.), Calculators in mathematics education: 1992 yearbook (pp. 2231). Reston, VA: National Council of Teachers of Mathematics.

Hennessy, S., Fung, P., \& Scanlon, E. (2001). The role of the graphic calculator in mediating graphing activity. International Journal of Mathematical Education in Science and Technology, 32, 267-290.

Herscovics, N. (1989). Cognitive obstacles encounter in the learning of algebra. In S. Wagner \& C. Kieran (Eds.), Research issues in the learning and teaching of algebra (pp. 60-114). Reston, VA: National Council of Teachers of Mathematics.

Hiebert, J. (1999). Relationships between Research and NCTM Standards. Journal for Research in Mathematics Education, 30(1), 3-19. 
Hill, S. A., Griffiths, P.A., Bucy, J. F. et al. (1989). Everybody counts: A report to the nation on the future of mathematics education. Washington: National Academy Press.

Hollar, J. C., \& Norwood, K. (1999). The effects of a graphing-approach intermediate algebra curriculum on students' understanding of function. Journal of Research in Mathematics Education, 30(2), 220-226.

Holliday, B., Cuevas, G. J., Moore-Harris, B, Carter, J. A., Marks, D., Casey, R. M. .., Hayek, L. M. (2005). Algebra 1. New York: McGraw-Hill/Glencoe.

Hong, Y., Toham, M., \& Kiernan, C. (2000). Super calculators and university entrance calculus examinations. Mathematics Education Research Journal, 12(3), 321-336.

Horton, N. J. \& Lipsitz, S. R. (2001). Multiple Imputation in Practice: Comparison of Software Packages for Regression Models with Missing Variables. The American Statistician, 55(3), 244-254.

Hudnutt, B. S., \& Panoff, R. M. (2002). Mathematically appropriate uses of technology. ON-Math, 1(2). Retrieved from http://www.nctm.org/eresources/view_media.asp?article_id=2264

Huntley, M., Rasmussen, C., Villarubi, R., Sangton, J., \& Fey, J. (2000). Effects of standards-based mathematics education: A study of the Core-Plus Mathematics Project Algebra and Functions Strand. Journal for Research in Mathematics Education, 31(3), 328-361.

Imig, D. R. (1981). The use of film in the measurement of student learning. Family Relations 30(2), 259-263. 
James, T., \& Tyack, D. (1983). Learning from past efforts to reform the high school. Phi Delta Kappan, 64, 400-406.

Jones, P. S., \& Coxford, A. F., Jr. (1970). Mathematics in the evolving schools. In P. S. Jones \& A. F. Coxford, Jr. (Eds.), A history of mathematics education in the United States and Canada: $32^{\text {nd }}$ yearbook. Washington, DC: National Council of Teachers of Mathematics.

Kaput, J., Carraher, D., \& Blanton M. (2007). Algebra in the early grades. Mahwah, NJ: Erlbaum.

Keller, B., \& Hirsch, C. (1998). Student preferences for representations of functions. International Journal of Mathematical Education in Science and Technology, $29(1), 1-17$

Keller, B., \& Russell, C. (1997). Effects of the TI-92 on calculus students solving symbolic problems. International Journal of Computer Algebra in Mathematics Education, 4, 77-97.

Keller, B., Russell, C., \& Thompson, H. (1999). A large-scale study clarifying the roles of the TI-92 and instructional format on student success in calculus. International Journal of Computer Algebra in Mathematics Education, 6, 191-207.

Kendal, M., \& Stacey, K. (1999). Varieties of teacher privileging for teaching calculus with computer algebra systems. International Journal of Computer Algebra in Mathematics Education, 6, 233-247.

Kentucky Department of Education. (2006). Kentucky core content for assessment [4.1]. Retrieved from 
http://www.education.ky.gov/users/OTL/CCA\%204\%201\%20FINAL/CCA_41.p df

Kieran, C. (1989). The early learning of algebra: A structural perspective. In S. Wagner \& C. Kieran (Eds.), Research issues in the learning and teaching of algebra. Reston, VA: National Council of Teachers of Mathematics.

Kieran, C. (1992). The learning and teaching of school algebra. In D. A. Grouws (Ed.), Handbook of research on mathematics teaching and learning. New York, NY: MacMillian.

Klassen, J., \& Vogel, D. (2001). Technology-supported learning: Status, issues and trends. Journal of Computer Assisted Living, 17, 104-114.

Krathwohl, D. R. (2002). A revision of Bloom's taxonomy: An overview. Theory into Practice, 41(4), 212-218.

Lankford, Jr., F. (1959). Implications of the psychology of learning for the teaching of mathematics. In P. S. Jones (Ed.), The growth of mathematical ideas: Grades $K-$ 12: 24th yearbook (pp. 405-430). Washington, DC: National Council of Teachers of Mathematics.

Lappan, G. (1997). The Challenges of Implementation: Supporting Teachers. American Journal of Education, 106(1), 207-239.

Lauten, A., Graham, K., \& Ferrini-Mundy, J. (1994). Student understanding of basic calculus: Interaction with the graphics calculator. Journal of Mathematical Behavior, 13(2), 225-237.

Lee, V. S. (1999). Creating a blueprint for the constructivist classroom. The National Teaching and Learning Forum Newsletter, 8(4). 
Leitz, A. R., \& Kitt, N. A. (2000). Algebra for all: Using homemade algebra tiles to develop algebra and pre-algebra concepts. Mathematics Teacher, 93(6), 462.

Lesser, L. M. (2000). Algebra for all: Reunion of broken parts: Experiencing diversity in algebra. Mathematics Teacher, 93(1), 62.

Lloyd, G., \& Wilson, M. (1998). Supporting innovation: The impact of a teacher's conceptions of functions on his implementation of a reform curriculum. Journal for Research in Mathematics Education, 29(3), 248-274.

Long, V., \& Barrett, L. (2007). The Moore Method and the constructivist theory of learning: Was R. L. Moore a constructivist? (Unpublished manuscript).

MacLane, S., \& Birkhoff, G. (1967). Algebra. New York, NY: MacMillian.

Mariotti, M. A. (2000). Introduction to proof: The mediation of a dynamic software environment. Education Studies in Mathematics, 44(1/2), 25-53.

Marrades, R., \& Gutierrez, A. (2000). Proofs produced by secondary school students learning geometry in a dynamic computer environment. Educational Students in Mathematics, 44(1/2), 87-125.

Maxfield, C., \& Brown, A. (1997). Bebop BYTES back: An unconventional guide to computers. Madison, AL: Doone.

May, K. O., \& Van Engen, H. (1959). Relations and functions. In P. S. Jones (Ed.), The growth of mathematical ideas: Grades K-12: 24th yearbook (pp. 65-110). Washington, D.C.: National Council of Teachers of Mathematics.

McConnell, M., \& Bhattacharya, D. N. (1999). Algebra for all: Using the elegance of arithmetic to enhance the power of algebra. Mathematics Teacher, 92(6), 492. 
McLeod, D. B. (2003). From consensus to controversy: The story of the NCTM standards. In G. Stanic \& J. Kilpatrick (Eds.), A history of school mathematics (Vol. 1, pp. 753-818). Reston, VA: National Council of Teachers of Mathematics.

Meagher, M., Ozgun-Koca, A. et al. (2008). Pre-service teachers' experiences with advanced digital technologies: The interplay between technology in a pre-service classroom and in field placements. New York, NY: Brooklyn College-CUNY.

Mergel, B. (1998). Instructional design and learning theories. University of Saskatchewan, College of Education. Retrieved from http://www.usask.ca/education/coursework/802papers/mergel/brenda.htm

Merriweather, M., \& Tharp, M. (1999). The effect of instruction with graphing calculators on how general mathematics students naturalistically solve algebra problems. Journal of Computers in Mathematics and Science Teaching, 18(1), 722.

Middleton, J. A., Dougherty, B., Heid, M. K., D’Ambrosio, B., Reys, R., de LoachJohnson, I., Gutstein, E., \& Hala, M. (2004). An agenda for research action in mathematics education: Beginning the discussion. Journal for Research in Mathematics Education, 35(2), 74-80.

Mitchelmore, M., \& Cavanagh, M. (2000). Students' difficulties in operating a graphics calculator. Mathematics Education Research Journal, 12(3), 254-268.

Mittag, K. \& Taylor, S. (2000). The evolution of a graphing calculator course for preservice mathematics teacher. Issues in the Undergraduate 
Mathematics Preparation of School Teachers: The Journal, 3. Retrieved from http://www.k-12prep.math.ttu.edu/journal/technology/mittag01/article.pdf

Museum of HP Calculators. (2004). Slide rules. Retrieved from

http://www.hpmuseum.org/sliderul.htm

National Council of Teachers of Mathematics. (1980). Agenda for Action:

Recommendations for school mathematics of the 1980s. Reston, VA: Author.

National Council of Teachers of Mathematics. (1981). Priorities in school mathematics:

Executive summary of the PRISM Project. Reston, VA: Author.

National Council of Teachers of Mathematics. (1989). Curriculum and evaluation standards for school mathematics. Reston, VA: Author.

National Council of Teachers of Mathematics. (1991). Professional standards for teaching mathematics. Reston, VA: Author.

National Council of Teachers of Mathematics. (1995). Assessment standards for school mathematics. Reston, VA: National Council of Teachers of Mathematics.

National Council of Teachers of Mathematics. (1998). Calculators and the education of youth. Position Statement. Reston, VA: Author.

National Council of Teachers of Mathematics. (2000). Principles and standards for school mathematics. Reston, VA: Author.

National Council of Teachers of Mathematics. (2008). Algebra: What, when, and for whom. Position statement. Retrieved from http://www.nctm.org/about/content.aspx?id=16229.

National Science Board. (2010). Science and Engineering Indicators 2010. Arlington, VA: National Science Foundation (NSB 10-01). 
Niess, M. L., Ronau, R. N., Shafer, K. G., Driskell, S. O., Harper S. R., Johnston, C., Browning, C., Özgün-Koca, S. A., \& Kersaint, G. (2009). Mathematics teacher TPACK standards and development model. Contemporary Issues in Technology and Teacher Education [Online serial], 9(1), 4-24. Retrieved from http:/www.citejournal.org/vo19/iss1/mathematics/article1.cfm

Norfolk Public Schools. (2006). Algebra I report. Norfolk, VA: Author.

O'Callaghan, B. R. (1998). Computer-intensive algebra and students' conceptual knowledge of functions. Journal for Research in Mathematics Education, 29, 2140.

Osborne, A. F., \& Crosswhite, F. J. (1970). Forces and issues related to curriculum and instruction, 7-12. In P. S. Jones \& A. F. Coxford, Jr. (Eds.), A history of mathematics education in the United States and Canada: $32^{\text {nd }}$ yearbook. Washington, DC: National Council of Teachers of Mathematics.

Patton, M. Q. (2002). Qualitative research and evaluation methods ( $3^{\text {rd }}$ ed.). Thousand Oaks, CA: Sage.

Philipp, R. A., \& Schappelle, B. P. (1999). Algebra for all and discuss with your colleagues: Algebra as generalized arithmetic: Starting with the known for a change. Mathematics Teacher, 92(4), 310.

Podlesni, J. (1999). A new breed of calculators: Do they change the way we teach? Mathematics Teacher, 92(2), 88-89.

Privateer, P. M. (1999). Academic technology and the future of higher education: Strategic paths taken and not taken. The Journal of Higher Education, 70(1), 6079. 
Pugalee, D. K. (2001). Algebra for all: The role of technology and constructivism in an algebra course for at-risk students. Preventing School Failure, 45(4), 171-176.

Quesada, A., \& Maxwell, M. (1994). The effects of using graphing calculators to enhance college students' performance in pre-calculus. Educational Studies in Mathematics, 27(2), 205-215.

RAND Mathematics Study Panel. (2003). Mathematical proficiency for all students: Toward a strategic research and development program in mathematics education. Santa Monica, CA: RAND.

Rech, J., \& Harrington, J. (2000). Algebra as a gatekeeper: A descriptive study at an urban university. Journal of African American Studies, 4(4), 63-71.

Redin, J. (2004a). A brief history of mechanical calculators: Part I The age of the polymaths. Retrieved from http://www.xnumber.com/xnumber/mechanical1.htm Redin, J. (2004b). A brief history of mechanical calculators: Part III getting ready for the $20^{\text {th }}$ century. Retrieved from http://www.xnumber.com/xnumber/mechanical3.htm

Redin, J. (2004c). The calculator wars. Retrieved from http://www.xnumber.com/xnumber/wars.htm

Reys, B. J., \& Arbaugh, F. (2001). Clearing up the confusion over calculator use in grades K-5. Teaching Children Mathematics, 82, 90.

Roberts, D. M. (1980). The impact of electronic calculators on educational performance. Review of Educational Research, 50(1), 71-98. 
Rochowicz, Jr., J. (1996). The impact of using computers and calculators on calculus instruction. Journal of Computers in Mathematics and Science Teaching, 15, 423435.

Ronau, R. N., Niess, M. L., Browning, C., Pugalee, D., Driskell, S. O., \& Harrington, R. (2008). Framing the research on digital technologies and student learning in mathematics. In L. Bell, L. Schrum \& A. D.Thompson (Eds.), Framing research on technology and student learning in the content areas: Implications for educators (pp. 13-31). Charlotte, NC: Information Age.

Rostky, G. (1997). Calculator: You can count on it. Electronic Engineering Times, 971, 20-25.

Russell, G. (1990). Webster's new dictionary and thesaurus for school, home, and office. New Lanark, Scotland: Geddes \& Grosset Ltd.

Ruthven, K. (1990a). The effects of using graphing calculators to enhance college students' performance in pre-calculus. Educational Studies in Mathematics, 27(2), 205-215.

Ruthven, K. (1990b). The Influence of Graphic Calculator Use on Translation from Graphic to Symbolic Forms. Educational Studies in Mathematics, 21(5), 431450.

Sackney, L., \& Mergel, B. (2007). Contemporary learning theories, instructional design and leadership. In J. M. Burger, C. F. Webber, \& P. Klinck (Eds.), Intelligent leadership: Constructs for thinking education leaders (pp. 67-98). Netherlands: Springer. 
Schwarz, B. B., \& Hershkowitz, R. (1999). Prototypes: Brakes or levers in learning the function concept? The role of computer tools. Journal for Research in Mathematics, 30(4), 362-389.

Seeley, C. (2005). Pushing algebra down. NCTM News Bulletin. Reston, VA: National Council of Teachers of Mathematics.

Shadish, W. R., Cook, T. D., \& Campbell, D. T. (2002). Quasi-experimental designs for generalized causal inference. Boston, MA: Houghton Mifflin.

Shoaf-Grubbs, M. M. (1994). The effect of the graphing calculator on female students' spatial visualization skills and level of understanding in elementary graphing and algebra concepts. In E. Dubinsky, A. Shoenfeld, \& J. Kaput (Eds.), Research in collegiate mathematics education, 1, 169-194.

Silva, C. M., Moses, R. P., Rivers, J., \& Johnson, P. (1990). The algebra project: making middle school mathematics count. Journal of Negro Education, 59(3), 375-391.

Simmt, E. (1997). Graphing calculators in high school mathematics. Journal for Computers in Mathematics and Science Teaching, 16(2-3), 269-289.

Simonsen, L. M., \& Dick, T. P. (1997). Teachers' perceptions of the impact of graphing calculators in the mathematics classroom. The Journal of Computers in Mathematics and Science, 16(2-3), 239-268.

Skemp, R. (1976). Relational understanding and instrumental understanding. Mathematics Teaching, 77, 20-26.

Slavit, D. (1996). Graphing calculators in a "hybrid" algebra II classroom. For the Learning of Mathematics, 15(1), 9-14. 
Slavit, D. (1997). An alternate route to the reification of function. Educational Studies in Mathematics, 33, 259-281.

Slavit, D. (1998). Three women's understanding of algebra in pre-calculus course integrated with the graphing calculator. Journal of Mathematical Behavior, 17(3), 303-389.

Smith, B. A. (1997). A meta-analysis of outcomes from the use of calculators in mathematics education. Dissertation Abstracts International, 58, 787A.

South Carolina State Department of Education. (2009). Algebra I. Retrieved from http://ed.sc.gov/agency/Standards-and-Learning/AcademicStandards/old/cso/standards/math/documents/course_standards/algebral.pdf.

Stanic, G. M. (1986). The growing crisis in mathematics education in the early twentieth century. Journal for Research in Mathematics Education, 17(3), 190-205.

Stein, N. W. (1983). The effective use of mass media in sociology education: confronting the competing curriculum. Teaching Sociology, 10(3), 283-317.

Stiff, L. V., Johnson, J. L., \& Johnson, M. R. (1993). Cognitive issues in mathematics education. In P. S. Wilson (Ed.), Research ideas for the classroom: High school mathematics (pp. 3-20). New York: National Council of Teachers of Mathematics Research Interpretation Project.

Stone, C. B. (1996). The gatekeepers: Rethinking the math curriculum. Principal, 76, 5253.

Tarr, J. E., Uekawa, K., Mittag, K. C., \& Lennex, L. (2000). A comparison of calculator use in eighth-grade mathematics classrooms in the United States, Japan, and 
Portugal: Results from the Third International Mathematics and Science Study. School Science and Mathematics, 100(3), 139.

Tashakkori, A. \& Teddlie, C. (1998). Mixed methodology: Combining qualitative and quantitative approaches. Thousand Oaks, CA: Sage.

Tennessee State Department of Education. (2004). Algebra I. Retrieved from http://170.143.36.85/gate/FMPro?-db=gateways.fp5\&format=record $\% 5$ fdetail.htm\&-lay=layout $\% 20 \% 231 \&$-sortfield=Subject $\&$ sortfield $=$ Standard $\% 20$ Number $\&$-op=eq \&Subject=ALGEBRA $\% 20 I \&-l o p=$ or\&$\max =20 \&$-recid $=1 \&$-find $=$.

Tennessee State Department of Education. (2009). Graduation Requirements. Retrieved from http://www.tennessee.gov/education/TDP/GradReq.shtml.

Tharp, M. L., Fitzsimmons, J. A. \& Ayers, R. L. B. (1997). Negotiating a technology shift: Teacher perception of the implementation of graphing calculators. Journal of Computers in Mathematics and Science Teaching. 16(4), 551-575.

Thompson, A. D., \& Sproule, S. L. (2000). Deciding when to use calculators. Mathematics Teaching in the Middle School, 6(2), 126.

Thompson, D. R., \& Senk, S. L. (2001). The effects of curriculum on achievement in second-year algebra: The example of the University of Chicago School Mathematics Project. Journal for Research in Mathematics Education, 32, 58-84.

Thorpe, J. (1989). Algebra: What should we teach and how should we teach it? In S. Wagner \& C. Kieran (Eds.), Research issues in the learning and teaching of algebra. Reston, VA: National Council of Teachers of Mathematics. 
Thurlow, M. L., Sinclair, M. F., \& Johnson, D. R. (2002). Students with disabilities who drop out of school: Implications for policy and practice. Issue Brief, 1(2).

Minneapolis, MN: University of Minnesota, Institute on Community Integration, National Center on Secondary Education and Transition.

United States Department of Education. (2000). Before it's too late. Retrieved from http:/www.ed.gov/inits/Math/glenn/report.doc

United States Department of Education. (2004a). Proven methods: The facts about investing in what works. Retrieved from http://www.ed.gov/nclb/methods/whatworks/whatworks.html

United States Department of Education. (2004b). Proven methods: The facts about math achievement. Retrieved from http://www.ed.gov/nclb/methods/math/math.html

United States Department of Education. (2008). NAEP - frequently asked questions.

Retrieved from http://nces.ed.gov/nationsreportcard/faq.asp\#ques1

United States Department of Education. (2009). The federal role in education. Retrieved from http://www.ed.gov/about/overview/fed/role.html

United States Department of Veteran's Affairs. (2006). History - VA history. Retrieved from http://www.va.gov/about_va/vahistory.asp and http://www.va.gov/about_va/vamilestones.asp

Usiskin, Z. (1988). Conceptions of school algebra and uses of variables. In Coxford, A.F. (Ed.), The ideas of algebra, K-12: 1988 yearbook (pp. 8-19). Reston, VA: National Council of Teachers of Mathematics.

Usiskin, Z. (1997). Reforming the third R: Changing the school mathematics curriculum: An introduction. American Journal of Education, 106, 1-61. 
Usiskin, Z. (2002). From "mathematics for some" to "mathematics for all." In R. Biehler, R. Schlz, R. Straber, and B. Winkelmann (Eds.), Didactics of mathematics as a scientific discipline. New York, NY: Kluwer Academic.

Usiskin, Z. (2004). A significant amount of algebra. Nieuw Archief voor Wiskunde, 5(5), $147-151$.

Vendlinski, T. P., Morris, J., \& Michels, C. (2008). The importance of intention and order: Teaching for conceptual understanding using handheld technology. Los Angeles, CA: University of California at Los Angeles.

Vogel, D., \& Klassen, J. (2001). Technology-supported learning: Status, issues, and trends. Journal of Computer Assisted Learning, 17, 104-114.

Wagner, S., \& Parker, S. (1993). Advancing algebra. In P. S. Wilson (Ed.), Research ideas for the classroom: High school mathematics (pp. 119-139). New York, NY: National Council of Teachers of Mathematics.

Waits, B. K., \& Demana, F. (1998). The role of graphing calculators in mathematics reform. (ERIC. ED 458 108). Retrieved from http://www.eric.ed.gov/ERICDocs/data/ericdocs2sql/content_storage_01/0000019 b/80/19/58/1f.pdf

Webb, Norm. (2006). Aligning alternate assessments. Retrieved from http://wceruw.com/news/coverStories/aligning_alternate_assessments.php Zbiek, R. M. (1998). Prospective teachers' use of computing tools to develop and validate functions as mathematical models. Journal for Research in Mathematics Education, 29(2), 184-201. 


\section{APPENDIX A}

Neme

Class Pexiod

Date

\section{Daily Data Form for Treatment Classes}

1. In what ways haveyou used rapresertations to teach functions this wedk?

\begin{tabular}{l|l|l|l|l} 
Monday & Tuesday & Wednesday & Thursday & Friday
\end{tabular}

2. In what ways haveyou linked tho serepresentations while teaching functions this week?

\begin{tabular}{l|l|l|} 
Monday & Tuesday &
\end{tabular}

3. Hava you usad the TI-Ns pire this week to taach functions?

Monday

| Tuesday

Wednesday

| Thursday $\mid$

Friday

4. How often have you usad the TI-Nspire this week?

Monday

| Tuesday

5. What is sues have you had with the TI-Nspire while teaching functions?

Monday

| Tuesday

$\mid$ Wednesday $\mid$

Thursday

Friday

Friday

Thursday

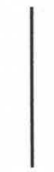

Friday



$$
\mid
$$

(n)

\section{II-Nspire wile teg ing functions?}

6. What goals do you have for students with respect to laming functions with the TI-Nspire?

\begin{tabular}{l|l|l|l|l|l|} 
Monday & Tuesday & Friday
\end{tabular}

7. What are some examples of what you have done teaching functions using the TI-Nspire this week?

\begin{tabular}{l|l|l|l|l} 
Monday & Tuesday & Wednesday & Thursday & Friday
\end{tabular}

8. What have you been able to teach (better moreasily) using the TI-Nspire than using other to ols?

\begin{tabular}{l|l|l|l|l|l|} 
Monday & Tuesday & Wednesday & Thursday & \\
& & &
\end{tabular}


Name

Class Period

Date

\section{Daily Data Form for Control Classes}

1. In what ways have you vaed representations to teach finctions todsy?

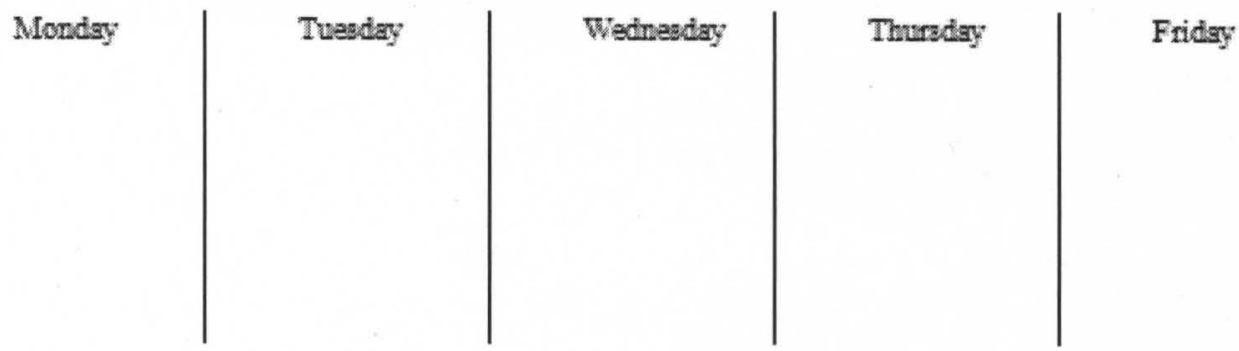

2. In what ways have you linked those rapresentations while teaching functions today?

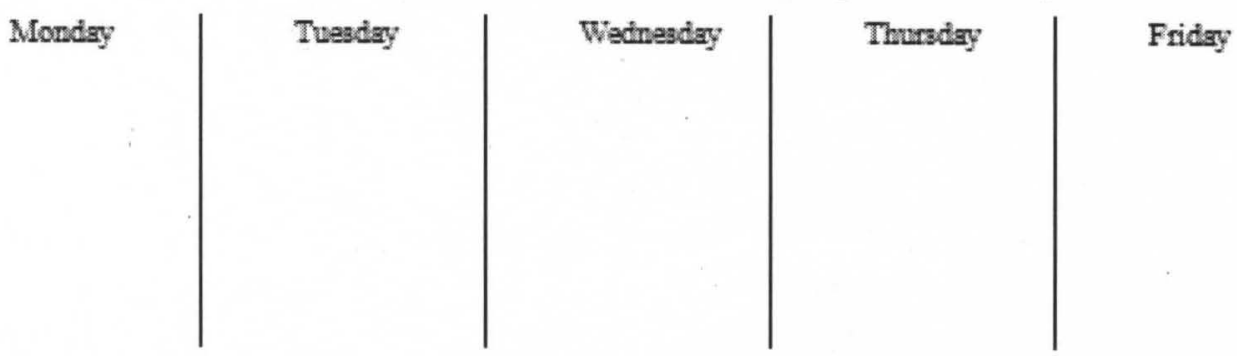

3. What teaching tools have you uaed today to teach finctions?

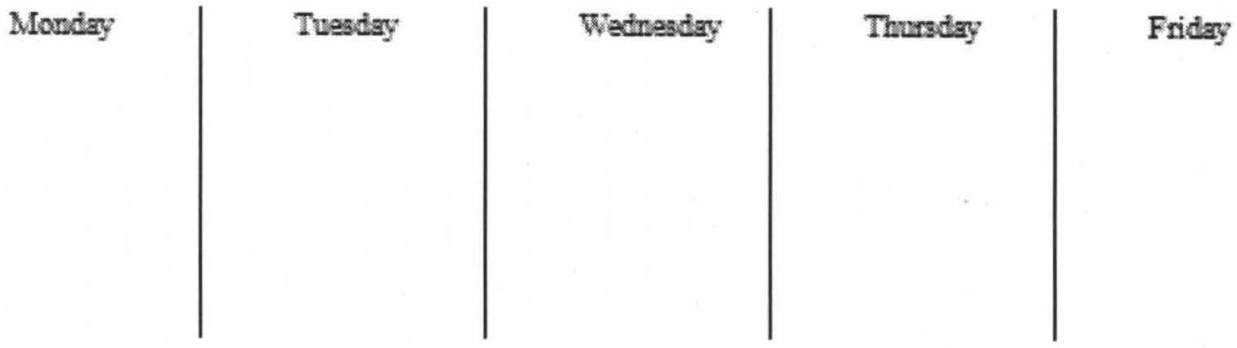

4. How cften have you used these tools to tegch functions today?




Dats

5. What isaus have you had using these taaching tools while teaching functions today? Mondsy Tuesday

Wedneadsy

Thursdsy

Fridsy
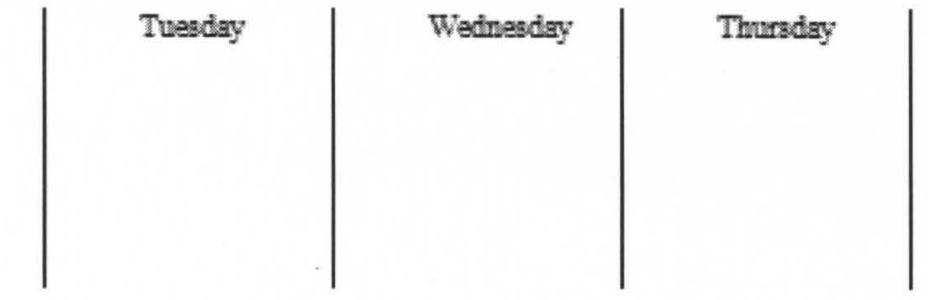

6. What goals do you have for students with respact to leaning finctions todsy?

Mondry

Tuesday

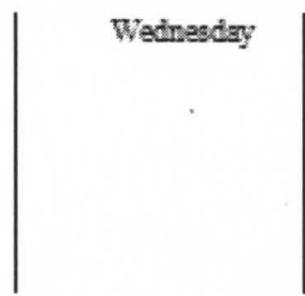

Thursdsy

Fridsy

7. What are some examples of what you have done teaching finctions using these teaching tools todizy? Mondsy Tuasday



Thursday

Friday

8. What have you been able to taach (better more asily) using the above mentionad teaching tools than using other tools?

Mondsy Tuesday

Wednesday

Thureday

Fridsy

\section{Comments:}


Classroom Observation

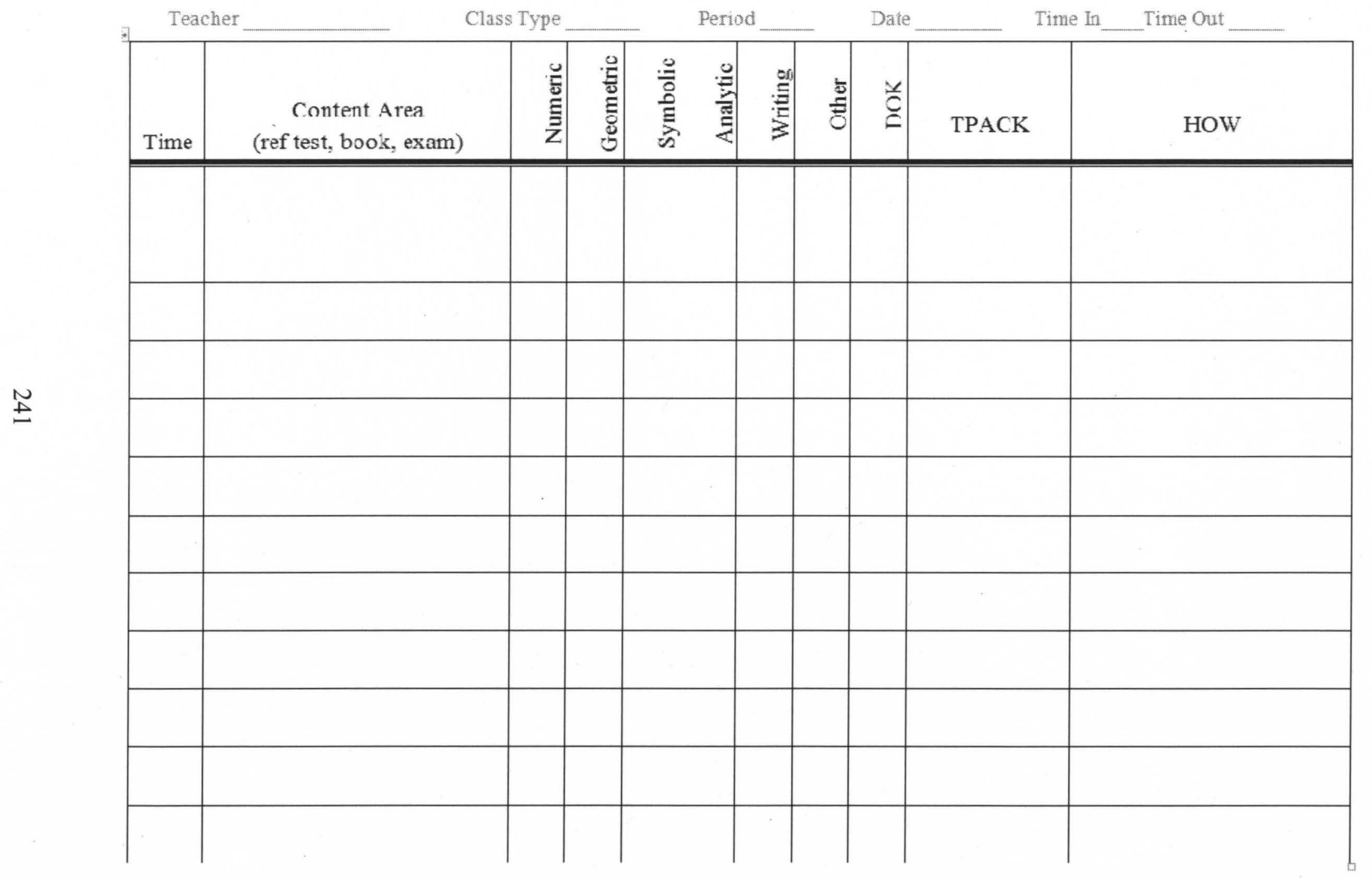




\section{APPENDIX C}

Name

Class Period

Date

Questionnaire for Treatment Classes

1. In what ways have you used representations to teach functions this week?

2. In what ways have you linked those representations while teaching functions this week?

3. Have you used the TI-Nspire this week to teach functions?

4. How often have you used the TI-Nspire this week?

5. What issues have you had with the TI-Nspire while teaching functions?

6. What goals do you have for students with respect to leaming functions with the TI-Nspire?

7. What are some examples of what you have done teaching functions using the TI-Nspire this week?

8. What have you been able to teach (better/more easily) using the TI-Nspire than using other tools?

COMMENTS: 


\section{APPENDIX D}

Name

Class Period

Date

Questionnaire for Control Classes

1. In what ways have you used representations to teach functions this week?

2. In what ways have you linked those representations while teaching functions this week?

3. What teaching tools have you used this week to teach functions?

4. How often have you used these tools to teach functions this week?

1. Name of tool How often

2. Name of tool How often

3. Name of tool How often

5. What issues have you had with using these teaching tools while teaching functions?

6. What goals do you have for students with respect to leaming functions?

7. What are some examples of what you have done teaching functions using the teaching tools described above this week?

8. What have you been able to teach (better more easily) using the above mentionedteaching tools than using other tools?

\section{COMMENTS:}




\begin{tabular}{|c|c|c|c|c|c|c|c|c|c|}
\hline $\begin{aligned} \text { CLE } & =\text { Course Level Expectatios } \\
\text { CU } & =\text { Checks for Luderstanding } \\
\text { SPI } & =\text { State Performance Indicator }\end{aligned}$ & DOK & $\begin{array}{c}\text { Aypha } \\
\text { Treatments }\end{array}$ & $\begin{array}{l}\text { Aipha } \\
\text { Control }\end{array}$ & $\mid \begin{array}{l}\text { Epsilion } \\
\text { Treatment }\end{array}$ & $\begin{array}{l}\text { Epsition } \\
\text { control }\end{array}$ & $\mid \begin{array}{c}\text { Gamina } \\
\text { Treatment }\end{array}$ & $\begin{array}{l}\text { Gamma } \\
\text { control }\end{array}$ & \begin{tabular}{|c|} 
Zeta \\
Treatment \\
\end{tabular} & $\begin{array}{c}\text { Zeta } \\
\text { Cantrol }\end{array}$ \\
\hline $\begin{array}{l}\text { CLE 3102.1.7 Use technologies appropriately to develop undestanding of abstract } \\
\text { mathematical idzas, to facliatate probitem solving, and to produce accurate and relilibete }\end{array}$ & 3 & $\mathrm{x}$ & & & & $x$ & & & \\
\hline CQL 3102.31 Use agegebraic thinking to analyze and generalize patterns. & 3 & & & $x$ & & $\mathrm{x}$ & $x$ & & \\
\hline $\begin{array}{l}\text { CLE } 3102.3 .6 \text { Understand and use relations and functions in warious representations to } \\
\text { solve contextual probiems. }\end{array}$ & 2 & & & $x$ & & $x$ & $\times$ & & \\
\hline CU 3102.1 .4 Write a nue with variables that expresses a pattern. & 3 & $x$ & $\mathrm{x}$ & $x$ & $x$ & $x$ & $x$ & $\mathrm{x}$ & $\underline{x}$ \\
\hline $\begin{array}{l}\text { CV } 3102.1 .12 \text { Crate and wotk flexibly among representations of relations (including } \\
\text { verbai, equations, tables, mappings, graphs). }\end{array}$ & 2 & $x$ & $\mathrm{x}$ & * & $x$ & * & $x$ & & \\
\hline 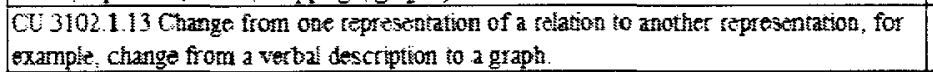 & 2 & $x$ & $x$ & $x$ & $x$ & * & $\times$ & $x$ & x \\
\hline $\begin{array}{l}\text { Cu } 3102.114 \text { Apply graphical transformations that occur when changes are made to } \\
\text { coefficints and constants in funetions. }\end{array}$ & 2 & & & $x$ & $x$ & & & & \\
\hline $\begin{array}{l}\text { Cr } 3102.1 .16 \text { Understand and axprass the meaning of the siope and } y \text {-intercept of inear } \\
\text { functions in real-world contexts. }\end{array}$ & 3 & $x$ & $x$ & $\mathrm{x}$ & & $x$ & $x$ & $x$ & $\mathrm{x}$ \\
\hline CV 3102.3.1 Racognizz and axtend arithmetic and grometric saquences. & 8 & & & $\bar{x}$ & & * & $\bar{x}$ & & \\
\hline 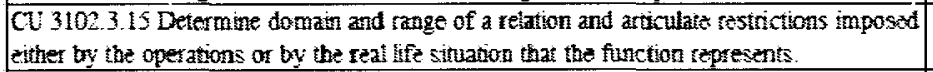 & 3 & * & $\mathrm{x}$ & $x$ & * & $x$ & $x$ & $\mathrm{x}$ & $x$ \\
\hline $\begin{array}{l}\text { Cv 3102.3.16 Determina if a relation is a function from is graph or from a sat of ordered } \\
\text { pars. }\end{array}$ & 1 & * & $x$ & $x$ & $x$ & $x$ & $x$ & $\mathrm{x}$ & $x$ \\
\hline 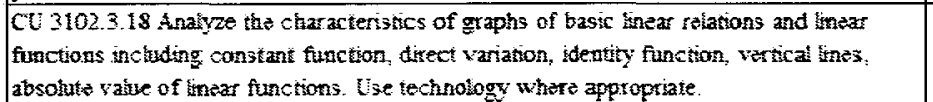 & 3 & $\mathrm{x}$ & $x$ & & & & &  & $x$ \\
\hline $\begin{array}{l}\text { Ce } 3102.3 .20 \text { Udiderstrand that a finear equation has a constant rate of change called slope } \\
\text { and represent siope in various forms. }\end{array}$ & 2 & $x$ & * & * & $\times$ & * & $\times$ & $x$ & * \\
\hline 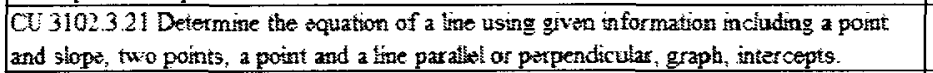 & 2 & $x$ & $x$ & $x$ & $\mathrm{x}$ & $x$ & $x$ & $\mathrm{x}$ & $x$ \\
\hline $\begin{array}{l}\text { CU } 3102.3 .22 \text { Express the equation of } a \text { ine in standard form, slope-intexcept, and point- } \\
\text { 3:iope form. }\end{array}$ & 1 & $x$ & $x$ & $x$ & $x$ & $x$ & x & $x$ & $x$ \\
\hline $\begin{array}{l}\text { Ci } 3102.3 .23 \text { Determine the graph of a finear equation including those that depict } \\
\text { contextual situations. }\end{array}$ & 2 & $x$ & $x$ & $x$ & $x$ & & & $x$ & $x$ \\
\hline CU 3102.3 .25 Find function values using $\mathrm{f}(\mathrm{x})$ notation or graphs. & 1 & $\bar{x}$ & $\bar{x}$ & $x$ & & $\mathrm{x}$ & $x$ & $x$ & $x$ \\
\hline 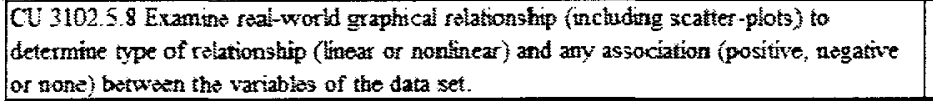 & 3 & & & $x$ & $\mathrm{x}$ & & & & \\
\hline $\begin{array}{l}\text { SPI } 3102.1 .1 \text { Interpret patterns found in sequencess, tables, and otber forms of quancitativet } \\
\text { information using variables or function notation. }\end{array}$ & 3 & & & & & $\mathrm{x}$ & $x$ & & \\
\hline $\begin{array}{l}\text { SPI } 3102.3 .1 \text { Express a generatization of a pattern in various representations including } \\
\text { ajgebraic and fuaction notation. }\end{array}$ & 3 & & & $x$ & & $x$ & $\times$ & & \\
\hline SPI 3102.36 Interpret various reiations in multipice representiations. & 2 & $x$ & $x$ & $\mathrm{x}$ & & $x$ & $x$ & & \\
\hline $\begin{array}{l}\text { SPI } 3102.3 .7 \text { Determine domain and range of a refiation, determine whether a felation is a } \\
\text { function and or evaluase a function at a specified rational value. }\end{array}$ & 1 & $\mathrm{x}$ & $x$ & & & x & & & \\
\hline
\end{tabular}




\begin{tabular}{|c|c|c|c|c|c|c|c|}
\hline \multirow{2}{*}{$\begin{array}{c}\begin{array}{c}\text { Content } \\
\text { area }\end{array} \\
\#\end{array}$} & \multirow[b]{2}{*}{ Item \# } & \multicolumn{2}{|l|}{ KY Cluster 3} & \multicolumn{2}{|l|}{ Ca 4 in book } & \multicolumn{2}{|c|}{$\begin{array}{l}\text { Ch } 4 \text { End of } \mathrm{Ch} \\
\text { Exam }\end{array}$} \\
\hline & & Content & DOK & Content & DOK & Content & DOK \\
\hline 1 & $\mathrm{Ky} \# 1$ & $\begin{array}{l}\text { Determining which is a Function with } \\
\text { mapping, table, ordered pairs, \& graph }\end{array}$ & 2 & $100 \%$ & $1,2, \& 3$ & $100 \%$ & $2 \& 3$ \\
\hline 2 & $\mathrm{Ky} \# 2$ & Evaluating a Function & 2 & $100 \%$ & $2 \& 3$ & $100 \%$ & $2 \& 3$ \\
\hline 3 & $\mathrm{Ky} \# 3$ & $\begin{array}{c}\text { Domain / Range of a Function given a } \\
\text { graph }\end{array}$ & 2 & $100 \%$ & $1,2, \& 3$ & $0 \%$ & $n / a$ \\
\hline 4 & $\mathrm{Ky} \# 4$ & Evaluating a Function using a table & 3 & $100 \%$ & 2 & $0 \%$ & $\mathrm{n} / \mathrm{a}$ \\
\hline 5 & $\mathrm{Ky} \# 5$ & Arithmetic Sequence & 2 & $100 \%$ & $1,2, \& 3$ & $100 \%$ & 2 \\
\hline 6 & $\mathrm{Ky} \# 6$ & Definition of a Function & 2 & $100 \%$ & $1,2, \& 3$ & $100 \%$ & 1 \\
\hline 7 & $\mathrm{Ky} \# 7$ & $\begin{array}{c}\text { Domain / Range of a function using an } \\
\text { equation }\end{array}$ & $2-3$ & $100 \%$ & $1,2, \& 3$ & $50 \%$ & $1 \& 2$ \\
\hline 8 & $\mathrm{Ky} \# 8$ & $\begin{array}{l}\text { Choosing function of best fit to a real life } \\
\text { problem using a table }\end{array}$ & 3 & $100 \%$ & $2 \& 3$ & $100 \%$ & $1 \& 2$ \\
\hline 9 & $\mathrm{Ky} \# 9$ & $\begin{array}{c}\text { Develop a table, write a function, \& solve } \\
\text { a real life problem using finctions }\end{array}$ & $3-4$ & $100 \%$ & $2,3, \& 4$ & $50 \%$ & $1 \& 2$ \\
\hline 10 & $\mathrm{ky} \# 10$ & $\begin{array}{c}\text { Apply concept of functions to solve real } \\
\text { life problem using a table, creating an } \\
\text { equation, and predictions }\end{array}$ & $3-4$ & $100 \%$ & $2,3 \& 4$ & $30 \%$ & $1 \& 2$ \\
\hline 11 & &  & & $\begin{array}{c}\text { Coordinate Plane, Quadrants \& } \\
\text { Ordered pair }\end{array}$ & $1,2, \& 3$ & $100 \%$ & $1,2, \& 3$ \\
\hline 12 & & & & $\begin{array}{l}\text { Geometric Transformations on the } \\
\text { coordinate plane }\end{array}$ & $1,2 \& 3$ & $100 \%$ & $1,2, \& 3$ \\
\hline 13 & & & & Graphing linear Equations & $1 \& 2$ & 0 & $\mathrm{n} / \mathrm{a}$ \\
\hline
\end{tabular}




\section{CURRICULUM VITAE}

NAME: $\quad$ Barbara Renee Buckner

ADDRESS: 247 Ayers Drive NE

Cleveland, TN 37323

DOB: $\quad$ Wyandotte, Michigan - August 25, 1973

EDUCATION

\& TRAINING: $\quad$ B.S, Mathematics

Lee University

1991-1994

M.S., Education

Tusculum College

1995-1996

Ph.D., Curriculum and Instruction in Mathematics Education

University of Louisville

2002-2011

AWARDS: Honor an Educator Award by Kappa Delta Pi

2008

Who's Who among America's Teachers

1998, 2000, 2004, 2006, 2008

State of Tennessee, Teacher of the Year Finalist

2007

East Tennessee Teacher of the Year

2007

National Chancellor's List (University of Louisville)

2004, 2006

PROFESSIONAL HISTORY:

Bradley Central High School, Cleveland, Tennessee

Math, Science, \& Leadership Teacher

1994 to Present 
Lee University, Cleveland, Tennessee

Part-time Instructor of Computer Information Systems

1999 to Present

European Bible Seminary, Rudersberg, Germany

Guest Lecturer

March 2002

Poltava Pedagogical Institute, Poltava, Ukraine Exchange Program with Lee University. Taught in Ukrainian-English classes about American traditions, history, and culture.

Summer of 1993, 1994, and 1998

\section{PROFESSIONAL SOCIETIES:}

Kappa Delta Pi (2008-present)

Appalachian Association of Mathematics Teacher Educators, (2003-present)

Executive Board Member-at-Large (2009-present)

National Council of Teachers of Mathematics (2002-present)

Association of Mathematics Teacher Educators (2002-present)

Tennessee Association of Student Councils (1996-present)

National Education Association (1994-present)

Tennessee Education Association, (1994-present)

LEA State Insurance Representative (2009-present)

Bradley County Education Association (1994-present)

Building Association Representative (2003-present)

High School Executive Board Representative (2008-2010)

\section{PUBLICATIONS:}

A correlation study between the amount of alcohol use among teenagers and the amount of dysfunction within a family.

Tusculum College, Greeneville, Tennessee 1996

Assisted with the Institute for Culturally Responsive Practice work groups to compile, produce, and publish resources.

Dr. Jo Ann Higginbotham, lead Professor

Lee University, Cleveland, Tennessee

1999

Choices a chapter within Young Women on a Journey to Excellence.

International Women's Ministries Department, Church of God Publishing.

Cleveland, Tennessee

2003 
Reflective Thoughts of the Semester in Ukraine Exchange Program

Contributing author

Poltava Pedagogical Institute, Poltava, Ukraine

Lee University, Cleveland, Tennessee

2002

\section{INVITED PRESENTATIONS}

Mentoring and Teaching Methods: Emphasis on Youth.

European Bible Seminary; Kniebis, Germany.

March 2002

Research Poster Session

National Science Foundation Centers for Learning and Teaching Conference

Washington, DC

2005

The Connection Project: Cross-Curriculum Integration between Vo-Tech Classes and Core-Academic Classes

Tennessee Vocational State Conference, Nashville, Tennessee

2004

\section{GRANTS:}

Tennessee Department of Education, Voc-Tech Grant

The ABC'S of CTE

2009

Best Buy Teach Award (Community Grants)

Infusion of Technology into the Science Classroom, \$2,000

2008

Bradley Cleveland Public Educational Foundation Teacher Mini Grant Integrating 7 Habits of Highly Effective Teens into the Science Classroom, $\$ 750$ 2007

Bradley Cleveland Public Educational Foundation Teacher Mini Grant Using Mathematics to Solve Science Problems, $\$ 500$ 2007

NCCEP and AT\&T Grant

Enhancing the Teaching and Learning Functions through the Use of Instructional Technologies in GEAR UP Classrooms: A Capacity-Building Program for Teachers, $\$ 48,275$

2006 


\section{NCCEP and AT\&T Grant}

Preparing Students for College Attendance and Supporting After-School and Summer Academic Enrichment Programs in Math, Science, Reaching and Technological Literacy, $\$ 48,507$ 2006

Tennessee Department of Education, Voc-Tech Grant The Connection Project: Cross-Curriculum Integration between Vo-Tech Classes and Core-Academic Classes, $\$ 20,000$ 2003

Tennessee Department of Education Grant Improving and updating the Bradley Central Physics lab, \$9,999 2001

Goals 2000 Technology Grant Integrating Standards into the curriculum, $\$ 250$ 1999

Tech Prep Mini-Grant

Integrating Science with Auto Mechanics, $\$ 1000$

1998

Tech Prep Mini-Grant

Integrating Algebra with Auto Mechanics, $\$ 1000$

1997 